\title{
DEVELOPMENT OF PROTECTED AREAS: AGRICULTURE, CONSERVATION, AND POLITICAL DECENTRALIZATION IN THE LA AMISTAD PACIFIC CONSERVATION AREA OF COSTA RICA
}

\author{
A Dissertation \\ presented to \\ the Faculty of the Graduate School \\ at the University of Missouri-Columbia \\ In Partial Fulfillment \\ of the Requirements for the Degree \\ Doctor of Philosophy
}

by

JUSTIN THOMAS

Dr. Sandy Rikoon, Dissertation Supervisor

MAY 2014 
The undersigned, appointed by the dean of the Graduate School, have examined the dissertation entitled

DEVELOPMENT OF PROTECTED AREAS: AGRICULTURE, CONSERVATION, AND POLITICAL DECENTRALIZATION IN THE LA AMISTAD PACIFIC CONSERVATION AREA OF COSTA RICA

presented by Justin Thomas, a candidate for the degree of Doctor of Philosophy of Rural Sociology, and hereby certify that, in their opinion, it is worthy of acceptance.

Professor Sandy Rikoon

Professor Jere Gilles

Professor Tola Pearce

Professor Carla Barbieri 


\section{Acknowledgments}

Many have provided years of support, patience, and encouragement in making it possible for me to pursue my education and the research presented here. I would like to thank James, Judy, Jeff, Carley, and Olivia for their unconditional support of a firstgeneration college student over these years. I would also like to thank the Ronald E. McNair Program for introducing me to the many opportunities available through research and higher education and for providing me the support I needed to pursue both undergraduate research at Truman State University and graduate studies and research at the University of Missouri. I would also like to thank Larry Melton and Janice Meyer, who both went above and beyond their roles as educators to provide me with support and guidance during my first years after returning to college.

During much of the analysis and writing involved in this dissertation, Jennifer, LaÉabha, and Pax provided the support, encouragement, perspective, and motivation needed to make it happen. Thank you so much for being patient and understanding and sharing your creativity and excitement throughout this process.

My committee members and several other faculty members provided me with many of the challenges as well as the support, confidence, guidance and opportunities for growth that were much-needed during my Ph. D. program. Thank you so much Dr. Rikoon, Dr. Gilles, Dr. Pearce, Dr. Barbieri, Dr. Valdivia, and Dr. Jeanetta. Many of us rely on your patience, acceptance, and support every day, and your unwavering dedication to our success is immeasurable in the way it positively influences our work, and the rest of our lives. 
This dissertation would not have been possible without the kindness, generosity, and hospitality of many people in Pittier and Biolley. I would like to give special thanks to those who were also gracious enough to tolerate my presence in their homes in Agua Caliente and Santa Maria. Thank you Cintia, Mañuel, doña Marta, Cindy, Danilo, Ronald, Marcos, and Donald. I would also like to give special thanks to the Junta Escolar of Santa Maria de Pittier for making me feel welcome in their community and providing me space to work in their school. Throughout my fieldwork, Fabricio Carbonell provided invaluable information about research in the Conservation Area and was always willing to discuss my research and introduce me to community members and others working in the region. This research would not have been possible without the willingness of MINAET, ASOMOBI, and ASOPROLA to share information about the area and coordinate housing arrangements and other aspects of data collection.

This project was also made possible by generous financial contributions towards my doctoral education. In addition to the various graduate research and teaching assistantships provided by faculty over the years, the Leopold Schepp Foundation provided support during my first years of Ph. D. coursework. The Dorris D. \& Christine M. Brown Fellowship Program of the College of Agriculture, Food and Natural Resources of the University of Missouri provided funding for dissertation fieldwork and research. And, the University of Missouri Graduate School provided a generous five-year fellowship through the Ronald E. McNair Program. 


\section{Table of Contents}

Acknowledgments ii

List of Tables $\quad$ vi

List of Figures vii

List of Acronyms viii

Chapter 1: Introduction $\quad 1$

A Brief Outline of the Study and Its Location 1

Research Statement 3

Chapter 2: Literature Review 9

Integrated Development Programs and Protected Areas 9

Culture and Institutions in Transnational Development and Conservation 14

Hybrid Landscapes: Linking Agriculture and Ecology in Systems and 20 across Scales

Chapter 3: Research Approach and Study Methods 31

Research Approach 31

Research Purpose $\quad 32$

Research Questions $\quad 32$

Working Hypothesis 33

$\begin{array}{ll}\text { Study Methods } & 37\end{array}$

Primary Data Collection $\quad 37$

Method of Analysis of Primary Documents and Description of Data 40

Secondary Data Sources $\quad 45$

Chapter 4: The National Setting 46

A Conceptual Map of Integrated, or Sustainable, Development and a 47

Framework for Political Decentralization

The Economy and Employment in Costa Rica 50

Costa Rican Agriculture: Major Exports and Domestic Production 56

Regional Agriculture $\quad 58$

$\begin{array}{ll}\text { Coffee } & 60\end{array}$

Basic Grains $\quad 61$

$\begin{array}{ll}\text { Sugar and Cattle } & 68\end{array}$

Natural Resource Protection in Costa Rica 74

Political Decentralization in Costa Rica 86 
Chapter 5: Agriculture and the Environment in the La Amistad Pacific

The History of Land Use and Community Relations in the Region 95

Deforestation, Agricultural Settlement, and Establishing PILA 97

Settlement of the Pittier District $\quad 100$

Settlement of the Biolley District 102

We all love the park, but we don't all love the park rangers 106

Tensions around land use, degradation of land and soil quality, and 112 the emergence of natural actors

The multiple scales of agricultural and economic diversification

Chapter 6: Development Associations: Establishing Inter-Personal and InterOrganizational Working Relationships

Conceptual Model

ASOPROLA: The Association of Producers of La Amistad

ASOFAC.CB: The Women's Association of Agua Caliente de Coto Brus

A Planned Intervention: Multilevel Integrated Development via a

Network Approach

Chapter 7: Discussion and Conclusion

Relationships between park rangers and communities 188

Environmental actors leading human behavior $\quad 191$

Strategies for agricultural and regional economic diversification 193

Regional leaders and planned interventions 199

Conclusion, implications for development work, and recommendations 202

for research

References

Appendix A: Guide for Semi-Structured Interviews with ASOFAC.CB Members 223

Appendix B: Guide for Semi-Structured Interviews with Farmers 226

VITA 


\section{List of Tables}

Table 1. Average frequency of occurrence of themes during interviews. 41

Table 2. Average frequency of occurrence of initial codes during interviews. 43

Table 3. Contribution of economic activities to Costa Rica gross domestic product 52

(GDP), 1991 - 2015, as a proportion of total GDP and in trillions of colones at current market prices (March 2014). (The exchange rate is approximately $\notin 545$ to \$US1.)

Table 4. Costa Rica employment, 2011 - 2015, and as a proportion of total labor

force by labor sector

Table 5. Costa Rica coffee production, 2007/08 - 2010/11, in metric tons by coffee regions and select cantones and by agricultural season.

Table 6. Costa Rica land area under rice cultivation, 2007/08 - 2010/11, in hectares by region and selected sub-regions and by agricultural period.

Table 7. Costa Rica bean cultivation, 2007/08 - 2011/12, in hectares under cultivation 65 and in humid and dirty tons by region and selected sub-regions and by agricultural period.

Table 8. Costa Rica land area under white corn cultivation by region and selected sub-regions, by agricultural period, 2007/08 - 2011/12.

Table 9. Protected area designations in Costa Rica and changes over time, 1991 - 1997. Source: INBIO (n.d.). 


\section{List of Figures}

Figure 1. Map of geopolitical designations relevant for the the study location. 2

Figure 2. Framework for analysis of integrated development in Costa Rica. 48

Figure 3. Costa Rica land area under rice production, 2010/11, as a proportion of 64 total regional area.

Figure 4. Sugar production across Central American countries, 1961 - 2007.

Source: ECLAC. 2012.

Figure 5. Processing sugar cane to make tapa dulce. 70

Figure 6. Pasture area for Central American countries, 1961 - 2008.

Source: ECLAC. 2012.

Figure 7. Costa Rican conservation areas. 76

Figure 8. Proportion of land area under protection across Central America countries. 80 Source: World Database on Protected Areas. 2013.

Figure 9. Map of PILA and surrounding territories $\quad 82$

Figure 10. Multilevel framework for analysis of the history of land use and 96 development across ACLAP.

Figure 11. Political and natural features of ACLAP. 98

Figure 12. Road block as part of protest against logging in Biolley. 104

Figure 13. Example of pasture erosion near protected area boundary. 115

Figure 14. Forest regrowth in pasture valleys. 116

Figure 15. Coffee plant infected by mycena citricolor. 122

Figure 16. Field of coffee with outbreak of mycena citricolor. 122

Figure 17. Local grocery store. 125

Figure 18. Greenhouse for vegetable production. 127

Figure 19. Example of small-scale farm diversification. 128

Figure 20. Recibidor in Pittier.

Figure 21. Household tilapia pond. 134

Figure 22. Proportion of land area under payment for environmental services 142 contract. Source: FONAFIFO. 2000.

Figure 23. Conceptual model for the study of inter-personal and inter-organizational 146 relationships.

Figure 24. ASOPROLA restaurant and visitors center.

Figure 25. Integrated development network of Biolley. 


\section{List of Acronyms}

ACLAP La Amistad Pacific Conservation Area

ADI Integrated Development Association

ASOFAC.CB Association of Women of Agua Caliente de Coto Brus

ASOMOBI Association of Women of Biolley

ASOPROLA Association of Producers of La Amistad

AyA Institute of Water and Aqueducts

CEPALSTAT Statistics Division of Economic Commission on Latin America and the Caribbean

FONAFIFO Costa Rican Fund for National Forestry Finance

GAT Territorial Action Group

GDP Gross Domestic Product

ICAFE Costa Rican Coffee Institute

ICDP Integrated Conservation and Development Program

ICE Institute for Electricity and Telecommunications

IFAM Institute of Municipal Development and Evaluation

IICA Inter-American Institute for Cooperation in Agriculture

INA Institute for National Education

INBio National Biodiversity Institute

INDER Costa Rican Institute for Rural Development

ISV International Student Volunteers

IUCN The International Union for the Conservation of Nature

LTPZ Las Tablas Protected Zone 


\begin{tabular}{|c|c|}
\hline MAB & United Nations Man and Biosphere Programme \\
\hline MAG & Costa Rican Ministry of Agriculture \\
\hline MIDEPLAN & Ministry of National Planning and Political Economy \\
\hline MINAE & Ministry of Environment and Energy \\
\hline MINAET & Ministry of Environment, Energy, and Telecommunications \\
\hline MINEREM & Ministry of Natural Resources, Energy and Mines \\
\hline PES & Payment for Environmental Services \\
\hline PILA & La Amistad International Park \\
\hline SINAC & Costa Rican National System of Conservation Areas \\
\hline $\mathrm{TNC}$ & The Nature Conservancy \\
\hline UNA & Costa Rican National Autonomous University \\
\hline UNDP & United Nations Development Programme \\
\hline UNEP & United Nations Environment Programme \\
\hline UNESCO & United Nations Educational, Scientific, and Cultural Organization \\
\hline UPACOB & Agricultural Laborers Union \\
\hline USAID & United States Agency for International Development \\
\hline WNBR & World Network of Biosphere Reserves \\
\hline
\end{tabular}




\section{Chapter 1: Introduction}

The study presented here focuses on development activity in several communities across two districts of rural Costa Rica. The remainder of this introductory chapter provides a brief description of the study location and elaborates a brief statement about the motivations of this research. A review of relevant literature is provided in Chapter 2, followed by a discussion of the research approach, questions, and study methods in Chapter 3.

\section{A Brief Outline of the Study and Its Location}

As agriculture, and coffee production in particular, is largely important for the economic development of the districts that are the focus of this study, some time is spent situating the local economies within national agricultural and broader economic systems in Chapter 4. At the same time, both the Biolley and Pittier districts are located in an areas designated as a buffer zone for the United Nations Man and Biosphere Reserve and World Heritage Site programs, and they both share part of their territories with the La Amistad International Park (PILA). The map in figure 1 on the following page shows the location of the districts within the country and with respect to PILA. Further, as shown in figure 1, both districts are also both located within the La Amistad Pacific Conservation Area (ACLAP), an area designation that comes from the Costa Rican National System of Conservation Areas (SINAC) and that is used by the national Ministry of Environment, Energy, and Telecommunications (MINAET) in guiding its natural resource management operations across the region and the country.

Although these districts are both located within ACLAP, the district designation is 


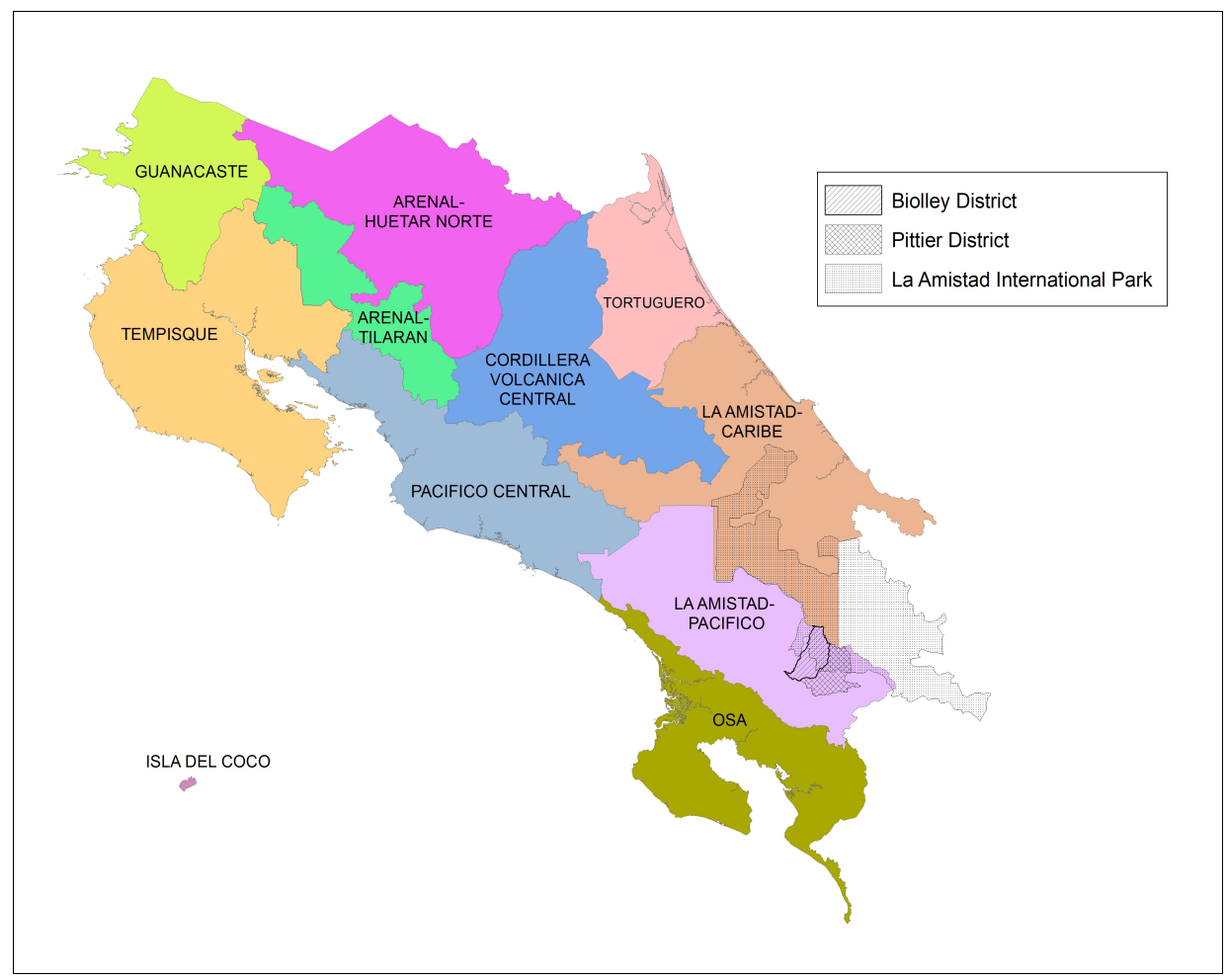

Figure 1. Map of geopolitical designations relevant for the the study location.

actually a political administrative unit designation derived from the central, or federated, national government system. The significance of this designation and the national policy on political decentralization will also be discussed in Chapter 4, along with the significance of other intermediary levels of the national hierarchy of political administration.

In Chapter 5, I draw on my own ethnographic research and secondary data to evaluate the history of land use and community relations across ACLAP, Biolley, and Pittier. This chapter provides some broad outlines of the history of regional settlement and uses ethnographic detail to explore the significance of various local actors, events, and individual experiences that have contributed to the formation of unique local histories and agricultural identities. These recent local divergences from the national and regional 
trajectories of land use and development patterns provide the basis for further discussion of the different relationships between communities members and MINAET officials, as well as the various land management and agricultural practices found in communities within the districts of Biolley and Pittier.

In Chapter 6, I draw on my ethnographic experience to describe the work of two prominent community organizations, one from each district, to evaluate their internal social dynamics and to situate them as potential influential actors within the national framework for integrated development and political decentralization.

\section{Research Statement}

According to Agüero (2006), the principle sources of environmental pressure across the La Amistad Pacific Conservation Area (ACLAP) "are the agricultural practices not compatible with conservation and a mode of development that coincides with the fragmentation of these spaces" (3). While Agüero's study focuses primarily on ecological landscape issues and habitat restoration, my research is aimed at challenging any general inferences that might be made from such claims about there being a conflictual nature in the relationship between agricultural practice and the well being of the environment. What Agüero and other researchers often show, is that particular agricultural practices are

evidently less compatible with interests in natural resource management and conservation than other, more sustainable agricultural practices. When incompatible practices are identified, however, two principled reactions readily emerge. One involves approaching farmers with an order to cease and desist from their destructive ways. Another involves inquiry into the culture and logic that underlies incompatible practices (Geertz 1963). In 
most cases, the latter approach is motivated by an ultimate intention to identify practical means through which farmers can be encouraged to transition away from the more harmful practices and towards the adoption of more sustainable ones. This approach often requires a broad and careful assessment of all human-led development activity in a region, including a critical evaluation of conservation programming and practices. Although the primary data obtained through my research does not cover the entire conservation area, as did the Agüero study, I draw on an array of secondary regional data to contextualize and later compare individuals, groups, and agricultural communities, i.e., the people and places, within the districts that provide areas of focus for my ethnographic study.

As mentioned, Biolley and Pittier are both districts located within ACLAP. They are also both districts that border the core protected area of the La Amistad International Park (PILA). These districts are neighbors, yet located within different cantones, or municipalities. Thus, their shared political boundaries and interests should be taken into account as always potentially being multi-dimensional. As will be demonstrated later, both districts also share experiences in a broad history of regional agricultural and economic development that give shape to contemporary landscapes and imaginaries that are often deemed incompatible with contemporary interests in natural resource management and conservation.

As I look at past and current development patterns and contemplate future development possibilities, I do so with an eye towards healthy relationships between different interest groups of humans and the regional environment. This means that, as part 
of my research, I consider the historical development of a regional environment as well as historical and contemporary modes of agricultural production fundamental to maintaining rural livelihoods across the region. In my attempt to provide an accurate historical account of development, however, it is not always possible to consider only modes of production in which human-environment relations are deemed potentially more sustainable or compatible. When current practices are destructive, or contrary to interests in the sustainable development of human-environment relationships, the livelihoods dependent upon related modes of production need to be called into question despite the risks associated with the negative portrayal of individual behaviors (Zimmerer 1996; Nygren 2000). Any internal tensions identified through this process need not necessarily, however, carry the greatest weight in considering possible transitions towards more sustainable modes, or pathways, towards the development of the region in the future (Wilson 2008; Long 2001).

By studying communities located in places at the interface of natural resource conservation and agricultural production, this research takes into account changes in land and resource use from a number of perspectives on development (Esteva 1992; Zimmerer 2006b). Land and resource use practices are influenced by local and global cultural preferences as well as local, national, and transnational policies on resource protection and rural development. By describing the historical connections between policy and practice related to land cover change across the region, this research seeks alternatives for supporting healthy human-environment relations as well as options for pursuing sustainable development. In other words, I seek to take into account the historical social 
forces that have contributed to landscape changes in the past, focusing in particular on changes that led to environmental degradation and that have influenced local perceptions of and relationships with the environment. Following this, I explore the reasoning behind the adoption of several current farming practices that indicate the potential of emerging alternative modes of production across the region. These appearances are evaluated as indicators of more sustainable future forms of community development and landscape restoration, as well as opportunities for future inter-personal and inter-organizational collaboration in development across the region.

This research explores the possible roles of farmers, conservation agents, and social and political organizations in the production and conservation of a desirable landscape for the region. In places where deforestation and other forms of natural resource degradation have been occurring for some time, there is a critical need to evaluate historical and contemporary modes of production and consider practical political and institutional reforms that would support individuals and organizations pursuing sustainable and alternative paths toward development. In some instances, this may even require that certain practices currently viewed unfavorably by farmers and conservation officials be provided with additional context and subsequently re-interpreted.

Despite the politically complicated task of implementing global natural resource conservation programs, the urgency of environmental protection has taken hold of many rural development efforts within Costa Rica. This is manifest in the numerous projects across the country sponsored by transnational agencies such as The Nature Conservancy and those managed by national government agencies, such as the Ministry of Agriculture 
and MINAET. The need to protect natural resources often takes precedence in contemporary development in places deemed to be integral parts of world heritage by the international community. This issue can become particularly salient and problematic in situations where there are few alternative livelihood strategies available for local populations to pursue. Land uses seen as threatening towards the environment and the people that practice them are almost automatically portrayed unfavorably by those primarily interested in the transnational conservation of natural resources. Cultural differences and a lack of historical contextualization can exacerbate confusions about the causes of apparently degrading circumstances, and it can be difficult to maintain focus on the productive social relations between humans, let alone those that might be identifiable between humans and the environment.

When funds are no longer available for the acquisition of land and the relocation of rural populations, governments and conservation agencies must rely more heavily on approaches that involve collaboration with existing community and social structures in order to protect important areas of natural resources. Thus, there are fewer opportunities and justifications for continuing the practices of exclusion and "fortress conservation," which makes it increasingly important for conservation and development agencies to think about and attempt to identify multiple interests between agricultural and conservation communities.

If farming practices and agricultural policies have contributed to land degradation in the past, and they continue to do so in the present, does that mean that agricultural production and environmental protection are inherently incompatible? When changes in 
policies are proposed as solutions to environmental problems and peasants are vilified for their involvement in resource degradation, it does seem that there is something wrong with the way humans practice agriculture in relation to each other and the environment. When practices contributing to environmental degradation are identified and change is advocated for as necessary, it is conceivable that it would be difficult to exclude those practicing agriculture responsibly from the consequences of broad reforms in policy, as those farmers are also often intimately articulated with existing social and political structures that are the targets for reform. Thus, identifying and providing support for farmers who are already working to maintain the beneficial and sustainable roles environmental actors play in their agricultural production processes should also be included as part of any agenda for sustainable development. 


\section{Chapter 2: Literature Review}

This chapter provides an overview of three areas of academic interest related to human and environmental relationships in rural development. The first section looks at the history, motivations, and controversy surrounding integrated development programs and the establishment of protected areas. This first part of the review revolves around the tension involving interests in human development and environmental protection. It is followed by a review of literature that looks at the literature that emphasizes the importance of understanding culture, scale, and social structures in evaluating the potential roles of local development associations and other institutions in integrating human and environmental interests in transnational conservation and development. The final section addresses the myriad tensions influencing decisions related the use of land and natural resources for the purposes of agricultural production and the maintenance of healthy ecosystems.

Literature on conflicts between rural communities and national and transnational development agencies is abundant. Literature that outlines the potential for traditional knowledge and community-based organizations to facilitate sustainable alternatives in development is also abundant. What this review points to is the potential value of research on how development associations work across scales to sustain integrated agricultural and ecological systems.

\section{Integrated Development Programs and Protected Areas}

According to Sachs (1992), one of the impacts of the Second Decade of development was the conflation of the concept of development: "While the First Decade 
considered the social and economic aspects of development separately, the Second Decade involved merging the two" (14). This led to the widespread support of development programs designed to work with small farmers and women, especially in rural areas (Escobar 1995). According to Escobar, "Integrated rural development was conceived as a way of bringing the green revolution to small farmers, and it was in this [ ] strategy that many of the constructs of [...peasants] originated" (158). Integrating conservation and development became important to provide popular support and legitimacy to development work during the 1960s, particularly in places where valued natural environments were being altered (Adams 2001). Later, integrated conservation and development programs (ICDP's) drew on the ideas of those earlier efforts to address rural poverty during rapid industrialization. In addition to working to establish social service programs and train and educate rural populations, ICDP's started to give special attention to social issues involving natural resource management.

Case studies of integrated conservation and development projects conducted by social scientists often conclude there is a need for increasing the technical capacities of local populations. With a limited understanding of how broader political, ecological and other systems function, local leaders and government institutions are evaluated as being in need of training and education before they can be charged with making decisions about how to manage globally important natural resources. It is also often pointed out how important working with people living in and around especially valuable natural resources is for meeting ICDP objectives like biodiversity conservation (O'Riordian 2002). In these contexts, however, research has repeatedly documented conflicts between human 
communities, usually involving agricultural peasants or indigenous people and natural resource managers (Igoe 2004).

Whereas integrated rural development programs of the industrial era focused more on introducing new technologies into traditional agricultural production systems, integrated conservation and development programs initially tended to focus on ameliorating the negative impacts of human practices on natural resources. While critical studies of conservation programs demonstrated some of the major shortcomings of approaches favoring the protection and exclusion of local human populations (Wilshusen, Brechin, Fortwangler, and West 2002), incentives available for adopting development patterns and practices that were were not modern were limited. As a result, successful management of natural resources often depended heavily on the commitment and support of local people. Further, in order for natural resources to be managed sustainably, ICDP's often need to give attention to a breadth of rural development issues (Dale, Kline, Kaffka and Langeveld 2013).

The integration of interests in community development and natural resource management becomes especially complicated when rural livelihoods are dependent upon resources that can transcend established boundaries. For example, Hartter, Goldman, and Southworth (2010) provide this description of the difficult relationships between peasant livelihoods and areas vaguely defined as being in need of protection in Uganda.

Remnants of larger forests (and wetlands) are often important lifelines to neighbouring communities, providing subsistence-based resources. These forests represent reservoirs of land, resources, and economic opportunity for people, while at the same time they are often viewed as buffers for parks by managers. (1)

In many of these situations, different positions of local and transnational actors will 
provide different assessments of the value and/or potential uses of natural resources.

Activities like human migrations, hunting and agricultural practices that are sometimes necessary to maintain rural livelihoods also appear as troublesome when they can not be controlled as part of integrated conservation and development efforts (Igoe 2004). Brown (2003) argues that in these complex situations, institutions need to have a "concern for social and environmental justice and a much more dynamic and adaptive ecological understanding [ ] to meet the dual demands for conservation and development" (91). Without careful consideration of existing livelihoods, changes in the use of land surrounding protected areas can produce unintended changes in both community social structure and the ecology of protected areas (Hansen and DeFries 2007).

West, Igoe, and Brockington (2006) refer to the complex interface between human populations and protected areas by introducing the terms 'social physics' and 'social phenomenology' in their definition of protected areas.

Protected areas provide a means of seeing and governing the world that have myriad social effects. Protected areas have increasingly become the means by which many people see, understand, experience, and use parts of the world that are often called nature and the environment [ ] As such, protected areas have become a new cosmology of the natural-a way of seeing and being in the world that is now seen as just, moral, and right. In effect, protected areas are the material and discursive means by which conservation and development discourses, practices, and institutions remake the world. (255)

Alongside these scholars, others have argued there is a need to better understand the processes from which social impacts are derived in the establishment and management of protected areas. According to Adams et al. (2004), the "specific problem of the social impacts of protected areas has been recognized by conservation planners for two decades" (1146). These concerns led trans-national actors like the United States Agency 
for International Development (USAID) to attempt to make a transition in their work "From an initial emphasis on species, protected areas, and individual interventions [ ] to include projects that integrate conservation and development, address underlying issues, and support policy development" (USAID 1994).

Similar to the way development agencies recognized the social impacts of articulating small scale agricultural production systems with world markets by changing their approach to integrated rural development, the recognition of the social impacts of establishing protected areas in integrated conservation and development programs has led to changes in approaches to rural development. Some scholars argue, however, that simply adding consideration of social dimensions in planning and programming does not go far enough towards addressing the political problems of the human-nature dichotomy underlying most contemporary social and economic development (Harvey 1996; Latour 2004; Nygren and Rikoon 2008).

One of the ways research has been framed to bring non-human actors into studies of social problems surrounding the development of protected areas more is by situating protected areas in the context of larger biological or ecological systems. According to Pujadas and Castillo (2007),

Biosphere reserves are a special category of protected areas, created to integrate ecosystem conservation with social development, through the participation of local people in conservation efforts [ ]. Biosphere reserves are expected to promote the interaction between stakeholders in order to strengthen their co-responsibility and commitment to constructing sustainable development at regional scales. (58)

In exploring the role of protected areas in sustainable development, Pujadas and Castillo describe the "Mexican model" of biosphere reserves by contrasting it to other 
conservation models, such as the "Yellowstone Model," which are often described as being derived from the "protectionist paradigm" of conservation (West, Igoe, and Brockington 2006; Wilshusen, Brechin, Fortwangler and West 2002). In making this comparison, Pujadas and Castillo (2007) emphasize how Mexican reserves were established "in relation to scientific institutions, and [how] local participation in management was given a high priority" (58).

Throughout their definition of biosphere reserves as special cases of protected areas, Pujadas and Castillo point directly to the relevance of protected area development to a number of other important social issues, such as understanding land tenancy and the relationships between institutions managing protected areas and the people living around them. In particular, they point to the importance of participatory and regulatory frameworks in providing structures for guiding interactions between local communities and development institutions. Often times, when the focus of conservation is primarily on the connection of protected areas, biological corridors, and other areas of habitat across natural landscapes, the human social dimensions of natural resource protection are overlooked (Chester and Hilty 2010). This tends to be the case in Costa Rica, where scientific institutions have also played significant roles in establishing protected areas, but local participation in management has not always been as much of a priority (Steinberg 2001; Evans 1999; Nygren 1998).

\section{Culture and Institutions in Transnational Development and Conservation}

Throughout much of the $20^{\text {th }}$ century, the management of natural resources across Latin America was heavily influenced by the processes of global industrial 
modernization. Beginning around mid-century, industrialization pushed the frontier of agricultural lands even farther and faster onto forested land across most of Central America (Weinberg 1991; Nygren 1998; Carriere 1991). As structural adjustment programs coincided with the introduction of strict environmental protection measures in some places during the 1980 s, dependency on international markets for agricultural commodities became a major problem for many small, Central American farmers. More recently, and especially in Costa Rica, institutions have been reformed or created and rural development policies have been transformed to include objectives that support sustainable rural livelihoods as part of natural resource protection (Bosselman and Lund 2013). In some instances in the past, these policies were even aimed at transforming repentant peasants into guardians of international biodiversity (Nygren 2000; Manger 1992; Zimmerer 1996). This matter became especially important in places where it was not possible, for social, political, economic or other reasons, to remove people from areas where natural resources were deemed worthy and in need of protection.

To address social problems, such as the exclusion of peasants from protected areas and the perpetuation of false narratives around development programs, that are often at the core of controversies surrounding the global management of natural resources, social scientists have made efforts to contribute to improving conservation and development practice by working to increase the awareness of the value of social research in these situations and by advocating for the consideration social and cultural impacts in the design of development interventions (Brosius 1999a). In-depth field work in particular places over time has been used to emphasize the importance of understanding cultural 
logics when attempting to articulate global and local social structures. Given an interest in learning across sites of transnational development and conservation, there have also been concerted efforts to establish frameworks to guide methods for comparison (Marcus 1995; Poteete and Ostrom 2008; Coleman and von Hllermann 2011). Similar interests in the integration of local and global institutions and the articulation of formal and informal social, cultural, and political practices have also guided studies of transnational rural development and development sociology (Long 1992, 2001). In many ways, the tensions embedded in these processes revolve around the ongoing struggle between space and place in the history of human development (Giddens 1984). Thus, the articulation of social relations in these situations is enveloped not only in a history of the global economy, but also in the history of cultural production. Although requirements for greater inclusion are included as part of many contemporary transnational development projects, there continues to be uncertainty about how these requirements will be handled by local institutions. In some cases, local leaders and community members can adopt, consciously or otherwise, subaltern strategies that undermine initiatives intended to improve development conditions (Scott 1985; McAreavey 2006; Cote and Nightingale 2012; Ribot 2009; Sundberg 2007).

In-depth case studies of community development and conservation project interventions demonstrate the myriad ways the relationships between residents of rural communities, the environment, and development agencies have been influence by changes in development patterns and conservation practices over time (Sundberg 1998, 2006; Bonta 2003; Igoe 2004). These studies also demonstrate the importance of 
understanding local cultural and social practice when introducing development initiatives that attempt to couple interests in environmental protection and economic development (Wilshusen 2009a). While the primary objective of an organization entering a community or area might be primarily the protection of natural resources or the provision of a program of services, the informal institutions and the multilevel efforts of local individuals and/or interest groups can significantly influence the possibilities for producing desired outcomes (Wilshusen 2009b; McAreavey 2006). It is not uncommon in these situations to find that informal interactions, referred to by Scott (1990) as "infrapolitics," lead local actors to align in order to acquire resources from transnational agencies and simultaneously, or soon thereafter, compete with each other over the distribution of those same resources (Sundberg 2004).

When the works of development and conservation agencies are viewed critically, taking into account the local cultural relevancy of relationships between human and ecological systems, it is possible to identify how depictions of conservation and development practices may be more or less accurate given a particular context at a give time (Nygren 2000; Brosius 1999a; Paulson and Gezon 2005). In a study of development based on conservation in the Maya Biosphere Reserve in Guatemala, Sundberg (2006) draws on the notions of "encounter" (a term adapted from colonial studies) and "transculturation" to explore how actors situated differently across scales negotiate, contest, and enact daily discourses and practices in the pursuit of particular development agendas. Through rich description, Sundberg (2006) shows how local ethnic identities are dichotomized by their relationship with the imaginaries of transnational conservationists, 
and how gender identities, among other things, are manipulated for the purposes of obtaining the means for development in a conservation area.

Research on development and conservation has also drawn on cultural critique, socio-biology, political economy and ethnography, among other fields of study, to highlight the importance of (mis)understanding patterns of local development. These studies often attempt to articulate the cultural and social meanings of local practices within a historical context of global development (West 2005; Polanyi 2001). These studies can also seriously challenge existing narratives and frameworks guiding national and transnational development projects. They show how dominant narratives may at times inappropriately portray the behavior of peasants in these situations as ignorant, or lacking agency, and as primarily responsible for the destruction of the natural environment (Zimmerer 1996; Nygren 2000). These studies also provide insight into how an uncritical dominant cultural perspective can lead to major unintended consequences for the environment as well human populations when it isthe primary point of reference for informing conservation and development policy (Sainath 1996, cited in Robbins 2004). In other words, certain portrayals of local culture and systems of production are sometimes naïve and inappropriate, if not at least incomplete or inaccurate, making them as likely to produce social problems as they are likely to solve existing development problems when put into practice. Therefore, this critical perspective in the literature supports taking a closer look at what is happening locally, and at different scales, for the purpose of pursing development alternatives that are more equitable and inclusive in their outcomes. Greater consideration of local perspective can provide equally legitimate 
descriptions of development conditions and historic events, as well as increase the likelihood of positive outcomes of transnational development interventions by pointing to opportunities for building on existing local social, political, and economic structures to establish patterns of sustainable development (Bosselman and Lund 2013). In some cases, careful analysis of local interpretations of development program agendas can also help locate better solutions by revealing some of the logic behind selective adoption of new technologies or governance structures, discrimination that might otherwise be perceived as the result of ignorance or resistance (Sundberg 2007; Bonta 2003).

Depending one's perspective, relationships between particular groups of people, their respective cultural institutions, and the environment can be viewed as problematic or as building blocks for collaboration (Agrawal 2005). In discussing the need for better integration of interests in conservation and development, Campbell (2002) argues that one of the continuing problems of traditional narratives on the development of protected areas is that when it is effective, it creates isolated patches that are more or less islands of biodiversity. Thus, conservation projects that do not integrate human and non-human concerns about development are as incapable of addressing the need for institutional reform as they are incapable of integrating protected areas with other patches or corridors. Scholars argue that the continued support for conservation practices derived from the "protectionist paradigm" in international biodiversity conservation depend on a refusal to consider the potential contributions of local cultures and institutions to broader interests in sustainable development (Wilshusen, Brechin, Fortwangler, and West 2002). Some of these and other scholars also claim that problem-oriented frameworks for 
creating better policy are more likely to lead to the successful integration of development and conservation interests (Wilshusen and Wallace 2009). Similar arguments also points strongly towards the need to challenge historical assumptions based on a real humannature dichotomy that are pervasive and implicit in a lot of research on development and conservation (Zimmerer 2010). Locating sustainable forms of future development is more likely when differences in culture and institutions are viewed as opportunities for finding new ways to integrates the various human, social and ecological dimensions of development.

\section{Hybrid Landscapes: Linking Agriculture and Ecology in Systems and across Scales}

From the perspective of an environmental historian, Worster (1990b) argues there is an increasing need to think about the agroecosystem as a domesticated system and view the production of food from an ecological perspective. He also claims that such a greater exploration of the "nature-agriculture connection" is one of the best ways to halt and possibly reverse environmental degredation caused by development (Worster 1990a). This notion resonates with Zimmerer's (2006b) call for an exploration of the "innerconnections of conservation, agriculture, and livelihoods" from a geographical perspective. When such perspectives are applied to studies of how transnational development influences social relationships in cultural and ecological systems, they also highlight the relevance of understanding horizontal movements and hierarchical structures in environmental politics (Zimmerer 2004; Zimmerer 2006a). Likewise, studies of the origins and formations of indigenous social movements have identified the importance of understanding local meanings embedded in relationships between culture 
and ecology (Escobar 2001).

Among the strengths of studies of cultural ecology is their ability to demonstrate the dynamic and integrative relationships in local agro-ecological systems (Geertz 1963). On the other hand, it can be difficult for these studies to simultaneously take into account and articulate broader development patterns with the local manifestations of their influence. In these situations, accounting for changes in the global political economy can detract from the focus required to demonstrate the significant values and adaptive capacities of local agricultural and ecological systems (Robbins 2004). Even when keeping in mind that local, small-scale, and subsistence agricultural systems are not always developmentally sustainable or environmentally benign, critical perspectives on political economy and political ecology are often most effective in demonstrating the ability of global capital to disrupt existing agro-ecological systems (Vayda and Walters 1999). Scholars critical of the industrialization and "modernization" of agriculture have also focused a great deal on how macro-level structural changes have induced local cultural change through the diffusion of technical innovations from the dominant system of cultural production. Such criticism has identified how this type of change in development tends to even further disadvantage relatively poor and small farmers (Altieri 2000; Hayami 1981).

Studies of the decision making processes of peasant households, their participation in community-based organizations and environmental programs, and their perceptions of environmental risks have provided some insight into the adoption of sustainable agricultural practices in rural areas of developing countries. Toma and Mthijs 
(2007) found that Romanian farmers with greater awareness of environmental risks were more likely to participate in an agri-environmental program sponsored by the European Union. Studies in various places have found significant relationships between membership in local organizations and the adoption of sustainable practices, in some cases independent of whether those organizations directly advocated such conservation practices (Jansen, Rodriguez, Damon, Pender, Chenier, and Schipper 2006; CavigliaHarris 2003; Shively 1997). In Honduras, Jansen et al. (2006) also found that farmers' decisions to include environmental protection as part of their agricultural practice was based in part on their perceptions of related opportunity costs in production.

Demographic and farm characteristics and the life-cycle of agricultural households have also been associated with the practice of natural resource conservation on small farms. Bosselmann (2012) found that available family labor, the age of the head of the household, and the use of shade trees among crops to be related to a lower likelihood of converting coffee fields in a biological corridor to another land use, while the participation of family members in off-farm employment significantly increased the likelihood of such a conversion. Labor availability and the ability to forgo income for a number of years after conversion are also important indicators of the likelihood of farm households to incorporate sustainable practices into their production (Shively 1997; Schelhas 1994). Wealthier farmers and those with access to credit often appear more likely to adopt alternative farming practices (Caviglia-Harris 2003; Gilles, Thomas, Valdivia, and Yucra 2013). In Shively's (1997) study of Philippine agriculture, consumption risk (measured as a percentage of production dedicated to household 
consumption, or food security) was identified as being negatively correlated with the adoption of contour hedgerows. In parts of the western Brazilian Amazon, the length of occupancy of a farm is associated with an increased likelihood that sustainable practices will be integrated into agricultural production systems (Caviglia-Harris 2003). The length of land tenure was also found to be related to adoption of conservation practices among Philippine farmers (Shively 1997). Similarly, Zbinden and Lee (2005) found that the type of land tenure was a significant predictor of participation in a payment for environmental service program in Costa Rica. Other characteristics of the farm landscape, such as the slope and soil quality, have also been identified as possible factors influencing adoption, as farmers are more likely to include conservation practices on marginal lands (Shively 1997; Zbinden and Lee 2005; Cole 2010).

While behavioral and economic studies of farm systems and household decision making can point towards relationships that are important for understanding local systems of agricultural production, culturally relative interpretations of local agricultural practices enhance the potential for cultural and ecological sustainability in transnational development. Without careful evaluation of the local interpretations of existing social, political, and environmental relations in agricultural production, development practitioners may overlook the integrative values and functions of local practices. This leads to poor estimations of how program incentives will influence the acceptance of supposed improved practices, and ultimately the condition of available natural resources and the agro-ecological landscape (Scoones 1998, 1999).

Whereas economic analyses of production are usually focused on a particular crop 
or farm and studies of cultural ecology tend to focus on providing detailed descriptions of local production systems, the field of agro-ecology emphasizes the relationships between ecological and agricultural systems. This emphasis involves identifying important local agricultural practices and re-framing them in a discussion of how maintaining these practices can contribute to increased yields for farmers (Altieri 2000). At the same time, agro-ecology offers descriptions of relationships between the adoption of industrial agricultural practices, the establishment of large, monoculture production systems, and degradation in the health of ecosystems, which can represented through the loss of spatial heterogeneity across the landscape, losses in soil fertility, and contamination of water resources. Thus, agro-ecological studies draw on a variety of perspectives to emphasize the mutual benefits that certain agricultural practices provide to humans and the environment (Altieri 1995). Such studies also attempt to demonstrate how agriculturalists and conservationists often share interests in articulating systems for the purposes of local food production and environmental protection. Making the issues identified as important in studies of agro-ecology relevant to a broader audience, however, will require the further articulation of agricultural and environmental concerns with those of public institutions that deal with political economy and land use planning across scales. González de Molina (2013) argues,

"This practical dimension of agroecology requires politics, that is, the disciplines responsible for designing and implementing institutions that make agrarian sustainability possible. In spite of this, agroecology is not yet equipped with the analytical instruments and criteria required to define strategies that could guide said change. Most agroecological experiences are still, with a few exceptions, local and uncoordinated. Agroecology is still closely bound to the scope of the farmer, the farm and the local community" (46).

Dale, Kline, Kaffka, and Langeveld (2013) claim landscape ecology provides 
fertile ground for such an endeavor aimed at integrating the adoption of sustainable agricultural practices that meet the needs of farmers with policy at local and regional scales. Part of such an effort will require researchers to draw on the strengths of different social science discplines to identify ways to communicate cross-culturally between farmers and natural resources managers and with others motivated to identify linkages between environmental protection and economic development. Although farmers may not express a particular interest in species preservation, they can increase habitat for wildlife that may help alleviate pressure on their crops from pests, ultimately leading to better financial outcomes (Ricketts and Lonsdorf 2013). Similarly, changes in agricultural land use patterns can improve conditions for crop production as well as help protect the quality of the watershed (Wishnie and Socha 2003). Hansen and DeFries (2007) studied ecological processes across protected areas and farm lands to identifiy ecological mechanisms that bring together interests in the management of protected areas and adjacent farm lands. With an interest in informing policy and action, Baudry, Burel, Aviron, Martin, Ouin, Pain, and Thenail (2003) used empirical data to create simulation models to demonstrate how rather small changes in farming systems "can lead to significant differences in landscape ecological characteristics" (311-12).

The challenges farmers often face in changing their production practices can be related to the challenges natural resource managers face in balancing the need to provide activities to support rural livelihoods with the need to protect the integrity of ecological systems as part of their work (Schelhas and Pfeffer 2008). This requires evaluating complex linkages between farming systems, other social structures and institutions, and 
natural actors in landscape ecosystems. Such a "science of connectivity" highlights the importance of exploring cultural difference and spatial heterogeneity in biodiversity conservation (Chester and Hilty 2010). One way researchers are addressing these challenges is through studies of multifunctionality in farming systems. This research address the influence of culture in relationships between humans and the environment by exploring how particular land and resource uses on farms reflect changing values related to development perspectives. These studies associate an increased consideration of the benefits of aesthetics, leisure, and the environment with changes in agricultural decision making and practice (Wilson 2008). For example, through their use of the concept of 'recreation multifunctionality,' Barbieri and Valdivia (2010) examined the relationship between recreational opportunities and agroforestry practices on family farms in Missouri. Similarly, Langholz and Lassoie (2001) found that one of the reasons people maintain private reserves in Costa Rica is for ecotourism and personal enjoyment. When considering the adoption of multifunctional practices in the context of decision making on small household farms in Costa Rica, earlier research by Schelhas (1996) found many of the factors identified by other studies of household behavior and economics to be important here as well. The likelihood of adopting multifunctional practices in this context was related to farmers' assessment of opportunity costs and the level of immediate need of income among active farmers. Reforestation and payment for environmental services programs tend to be supported more by absentee land owners, owners of larger areas of land, and older farmers interested in putting marginal lands to a better use. 
Many scholars in the fields of environmental history and political ecology have been encouraging a move away from studying human-environment relationships primarily through the lens of political economy. While cultural perspectives are necessary for understanding much of the controversies surrounding the integration of conservation and development interests, historical social and economic forces, and in particular those associated with colonialism, play key roles in these controversies as well. These fields of study, then, allow researchers of conservation and development to explore questions related to the political integration of the natural and social sciences. They also allow researchers to explore important questions about the models guiding modern development as they are based heavily on particular ideas about social and environmental equilibrium (Scoones 1999; Worster 1990a). When guided by rigid frameworks that establish preferred development patterns, researchers can "face grave difficulties in trying to incorporate natural history, social relations, technology, and culture into unified explanations of social change" (White 1990: 1114).

Depending on the scale of analysis, placing development studies in an historical perspective can lead to the establishment of nomothetic narratives of events that rely on descriptions rooted in a globally dominant cultural discourse, or they can lead to the establishment of ideographic depictions of 'militant' particularism (Harvey 1996). Similar to the ways in which science and industrialization emerged from the West, international agendas for environmental protection are often affiliated with dominant interests in global development. In response to perceived threats to resource access and individual sovereignty, alternative explanations of the importance of local practices, or modes of 
production, are devised. In terms specifically related to environmental history and political ecology, these alternative explanations often emphasize the importance of unique relationships between humans and natural resources in their local environment. As part of this transition towards recognizing the roles of previously marginalized actors in development, scholars have also emphasized the danger in the portrayal of essentialist images, ideas, and arguments (Escobar 1999; Brosius 1999a, 1999b).

In the past, one of the major differences between global and local perspectives on human-environment relationships often revolved around the belief that humans have the ability to control the environment. Increasingly though, thoughts about equilibrium and the benefits of homogenous environments are being challenged through scientific inquiry. As global development approaches have shifted to include greater acknowledgment of local variability in human behavior, culture and institutions, the ethnocentric and anthropocentric character of modern development is also being called into question by scientists and historians. According to Donald Worster (1990a) "nostalgia for that old narrow focus on the self-referential history of human ideas, society, and culture, with its tendency to dismiss nature as a mere epiphenomenon" (1142) is one of the major issues that environmental historians should be dealing with.

Following the philosophy of the Enlightenment, scientific inquiry throughout much of the twentieth century has focused largely on a perceived need of man, and above all white European man, to dominate nature (Harding 1986). In response to the social problems caused by development practice based on this reasoning, critics from a number of fields have argued there is a need for exploring the roles of human and environmental 
actors in development in new ways (Robbins 2004). Over time, in a move parallel to the transition in thought among environmental historians, the field of political ecology gradually emerged through a combination of the critical perspectives on political economy and the cultural turn in the social sciences. Increasingly, scholarship in political ecology utilized tools provided by theories of social construction and discourse analysis to challenge the policies, practices, and approaches guiding international conservation and development programming (Nygren 1998; Nygren 2000).

Studies of the negative impacts of colonial and capitalist expansion on the environment provided ample grounds on which to build critical studies in the field of political ecology (Blaike \& Brookfield 1987; Wolf 1982; Geertz 1963). Nevertheless, many now argue the field may be over-emphasizing the human dimensions of humanenvironment relationships to the point which there is insufficient attention being given to the social roles of environmental actors in studies of development (Latour 2004; Vayda \& Waters 1999; Nygren and Rikoon 2008). Collectively, the field has learned, along with other areas in science, that neither the ecological nor the human alone can be used to explain the outcomes human-environment relationships. If this is the case, the effectiveness of recent critical social theories may have led the field adrift, at least temporarily. In describing how this change in perspective has taken place among environmental historians, McNeill (2010) claims,

Over the past generation or so, a growing cohort of renegade historians has created a new subfield called environmental history. They write as if nature existed. And they recognize that the natural world is not merely the backdrop to human events but evolves in its own right, both of its own accord and in response to human actions. (346) 
While the human-centeredness of the field of political ecology is being effectively called into question and there is a similar call among some environmental historians, Carey (2009) extends this call by claiming there is an additional need for historical accounts of development and the environment that are not only relevant to but also from developing parts of the world.

Environmental histories of Latin American conservation, the export economy, and colonialism have become increasingly sophisticated and tell compelling stories of environmental transformation and human-environment relations (228).

Carey (2009) goes on to point out that most environmental historians "have not diverged much from seeing the past with overwhelming admiration for North American icons such as Aldo Leopold and Rachel Carson" (229). In order for historians to provide more accurate historical accounts, Carey suggests, "Recognizing the influence of Domingo Sarmiento's 'civilization and barbarism,' instead of Muir or Leopold, is one way to uncover a more distinctly Latin American past" (ibid). Carey also laments a bit in adding,"For historians of Latin America [ ] research generally remains in three categories: colonialism, the extraction of capitalist commodities; and conservation. [and] The theme of nation building often runs through all three categories" (224). 


\section{Chapter 3: Research Approach and Study Methods}

\section{Research Approach}

The research presented here contains elements of both conceptual and practical research (Booth, Colomb, and Williams 2007). Although the project is more exploratory in nature and was not designed to promote any particular change in practice, its conception is rooted in an interest in locating common ground for members of agricultural and conservation communities to collaborate in the future development of ACLAP. Therefore, I consider this research as belonging to the genre of applied research inasmuch as on various occasions it focuses on particular issues, or practices, as they are described by farmers and evaluates potential benefits of implementing changes in policy and practice.

Conceptually, the research looks at the the interface of agriculture and conservation and assesses opportunities for mutually beneficial relationships between humans and the environment in these fields of interest. These issues are further explored through participant observation and semi-structured interviews with residents of an area where these interests intersect and dominate the possibilities for maintaining rural livelihoods. I use similar methods, participant observation, informal conversation, and the review of archival materials in exploring the social and political landscapes of community development associations and other organizations actively working to develop and conserve natural resources across the region. In more practical terms, at various times, this survey of the past and present work of development agencies includes the study of programming and projects relevant to the immediate discussion or primary 
data. The review of archives also provides an opportunity for assessment of relative potential of different organizations for influencing the future of development across ACLAP in a sustainable way. The analysis also provides a fair amount of context for detailed discussion of the social relations of production in particular places within the study region. Likewise, in-depth description of development activity based on primary data both extends the understanding of the broader regional development context and allows for a comparative description of the actual and potential roles of agencies and actors in a program of sustainable regional development across scales.

Following sub-sections include a statement of research purpose, a list of research questions, and a discussion leading to the statement of a working hypothesis. These are used to organize my subsequent reporting of the research and to provide the reader with additional insight into the reasoning underlying the chosen study methods and design.

\section{Research Purpose}

To explore the possibilities for sustainable development at the interface of interests in natural resource management and conservation and agriculture in the La Amistad Pacific Conservation Area in Costa Rica.

\section{Research Questions}

- How do residents in agricultural communities across the study location view and relate to La Amistad International Park and natural resource managers?

- What are the views of residents of the study location on the current state of agriculture, conservation, and development in the region?

- What are the views of residents of the study location on the future of agriculture, conservation, and development in the region?

- What is the potential of development associations partnering with larger national and transnational development organizations in working towards sustainable development of the region? 


\section{Working Hypothesis}

It is possible that residents of the communities across the study location do not perceive a relationship between themselves and PILA. It is less likely, however, that people in these communities are not in some way familiar with park managers. Therefore, establishing an understanding of residents' relationships with the park, whether perceived directly or indirectly, and their relationships with natural resource managers is an important first step in this research. There is some evidence to suggest that there is a certain level of animosity that exists between those interested in the protection of the park and those in these communities who are more interested in the development of agriculture and the economy of the region (TNC 2004; Schelhas and Pfeffer 2008). However, the current condition of these relationships may be different due to changes over time or due to slightly different circumstances in the communities of this particular study location. The exploration of questions about these relationships will require the taking into account of the history of land use and settlement as well as current land use conditions and available livelihood options.

Given that agriculture is the foundation of the economy and the history of development across the region, it seems likely that residents in communities neighboring the park will have strong opinions about the current state of agriculture there. Farms in these communities are some of the farthest removed from commercial centers in the country, and in addition to their remote location, they are subject to some of the same tensions revolving around land use that many agricultural communities neighboring protected areas face around the world. The sometimes difficult and unstable economic and environmental conditions related to agricultural production in these particular 
communities also suggest that farmers will have strong opinions about the challenges of their situation and the direction in which regional development should go. In particular, given the heavy reliance on coffee production across the region, farmers will likely struggle to maintain their place in international commodity markets, where there is an emphasis on keeping the costs of production low. At the same time, it seems unlikely that farmers' visions for the future development of the region will involve moving away from the production of this commodity that has great cultural relevance and that also provides the majority of their incomes. Thus, I suspect that pathways toward agricultural diversification and more sustainable production methods that take natural resource management, conservation, and the interests of the park into account will be limited in farmers' visions for future development.

This calls into question the opportunities for collaboration between the residents of these agricultural communities and natural resource managers tasked with protecting the neighboring park. If residents to do not perceive they have an important relationship with the park, their relationships with people whose primary interest is the protection of the park is contentious, and they are dependent on commodity markets for earning income, it seems unlikely that there will be a verifiable common interest in a future agroecological or sustainable type of development trajectory across the region. This is not to suggest that people's current beliefs actions should be taken as determinants of their preferred or future behaviors. However, perceptions of possible outcomes influence contemporary decision making, and uncertainty about the role of the environment in agricultural production diminishes the likelihood that farmers will consider alternative 
modes of production. The social, cultural, economic, and natural milieu in which individuals are situated significantly influence the process of human decision making. If some activities are more integral to ecological sustainability, it appears logical that these activities will be given greater weight by natural resource managers than they will be given by commodity growers. In exploring the interface of agriculture and conservation in community members' visions of future development, however, this study does not discount the possibility that farmers also perceive the important role the environment plays in their effort to maintain the livelihood they prefer.

Issues that are of common interest can be obfuscated by varying definitions of desirable means and ends for development. The same can be said for misunderstandings and misinterpretations of beliefs and actions of others. Without taking into account the context of individual actions, it is possible to attribute that action to a mistaken belief, or a belief that is contrary to one's own. Thus, providing a clearer description of circumstances in which one takes action, whether that person be farmer or natural resource manager, could lead to the discovery of how an action initially perceived as detrimental to one's own interests is actually not threatening, or maybe even helpful. Given this new context, the action may even be attributed to a belief system, although different from one's own, that ultimately describes a desired set of conditions for future development that is more similar to our own than we would have otherwise realized. One the other hand, it is also quite possible that this process of attempting to clarify the meaning and intent behind the action of another would ultimately confirm the initial interpretation of the other and their act as threatening to one's own interests. 
Organizations, and of particular interest for this study, community organizations and development associations are metaphysical places in which interests in agriculture, conservation, and sustainable development are negotiated. Although these associations often have explicit development agendas, they also often have hidden agendas and individual members bring the weight of their own explicit and hidden agendas to bear on negotiations of interest. The communication of these interests among members and with other organizations, then, influences the political activity of the member organization. While this study explores the varying interests of local development associations and their members, it also explores the possibilities of these interests being articulated in the programming of larger national and transnational development agencies involved in the development of the region.

Similar to the misunderstanding of actions at the level of individuals, the development activities of organizations can appear to be out of alignment despite an espoused common interest in sustainable development. Therefore, organizations with potentially similar interests may not be compelled towards collaboration if communication about these interests are inhibited. Along similar lines, it may not be immediately apparent to an outside observer why organizations have decided to work together. This study looks closely at the interests of local development associations and their members to evaluate their potential contributions to the sustainable development of the region. Given the remoteness of the study location, the history of settlement and development in the region, the state of relationships between community members and outsiders like natural resource managers, and the interest of national government and 
transnational agencies in the future development of the region, it seems unlikely that local development associations will be well-positioned to make a valuable and sustainable contribution. Among the foreseeable factors limiting the potential contributions from local organizations are a lack of financial resources and a limited amount of available human capital, or a lack of technical skills, required to participate in a large-scale development initiative. Similarly, most community development associations across will lack the experience necessary to have established political network connections across scales of governance in relevant agencies.

\section{Study Methods}

This research involves multiple study methods. I used the ethnographic research methods of participant observation, semi-structured interviewing, informal conversation, and the study of development agency archives to collect primary data. As demonstrated in large part through the analysis in Chapter 4, I also collected a considerable amount of secondary data from government and development agency archives and with the assistance of research affiliates.

\section{Primary Data Collection}

I collected primary data for this project during 9 months of fieldwork carried out over the course of a year and a half, from May 2010 to the December 2011. MINAET facilitated my introduction to the communities where I spent the majority of my time during fieldwork. More specifically, staff from the ACLAP Research Program reviewed my research proposal and made recommendations for communities as research locations. Following a week of "orientation" with staff at the Altamira ranger station, I was 
transported to the community of Agua Caliente and introduced to the family with which arrangements had been made for my stay there. This initial introduction proved to be somewhat limiting during later fieldwork for a couple of reasons. First, I entered communities appearing to be an affiliate with MINAET. This was problematic because as will be discussed in later chapters, MINAET is an agency that has a history of being viewed with animosity by community residents due to its role as a government agency involved in law enforcement and the regulation of development. Second, MINAET officials made arrangements for a newly-formed local women's association to facilitate my fieldwork in Piiter. Given the significance of influence of gender norms in social interaction in the research location, this made it difficult for me to develop relationships with most men in Pittier unless they were elders or had not heard about my arrival and presence.

I spent the majority of my first three months in Agua Caliente as a participant observer of the activities of the Women's Association of Agua Caliente (ASOFAC.CB). During this time I also conducted semi-structured interviews of 16 (all but one of the then currently active) members of the Association. My second visit to the region focused primarily on observation of communities in the Pittier and Biolley districts during the 2010 coffee harvest, from October through December, and data was collected in the form of field notes. Data collection during my third visit included participant observation of development activities, including informal conversations with municipal government officials and attending government and non-government organization meetings in the communities of Biolley and Pittier. During this third visit, data was also collected through 
24 semi-structured interviews, 13 with farmers in Biolley and 11 with farmers in Pittier. ${ }^{1}$ All of the interviews, except two of the interviews with farmers in Pittier, were recorded with a digital voice recorder. Detailed notes were taken to record the responses to interview questions of the two farmers in Pittier that did not want their interviews recorded. These notes were later transcribed and included with other interview transcripts and audio recordings during coding.

All interviews were conducted in Spanish. I conducted all interviews with ASOFAC.CB members and interviews with farmers were facilitated by other community members. Separate interview guides, which will I will talk about in a little more detail in the next sub-section, were used for interviews with ASOFAC.CB members and interviews with farmers. (See Appendix A and Appendix B for translated copies of these guides.) The average length of interviews with ASOFAC.CB was 57 minutes. The range of length of these interviews was from 39 to 87 minutes. The average length of interview with farmers in Biolley was 37 minutes. The range of length of these interviews was from 22 to 53 minutes. The average length of the nine interviews with farmers in Pittier for which audio was recorded was 33 minutes. The range of length of these interviews was from 19 to 61 minutes.

I transcribed word-for-word the first seven interviews with ASOFAC.CB members before using an open coding procedure to code them (Birks and Mills 2011). I then used the same process of open coding to directly code the remaining audio files and

1 In addition to the challenges I faced in approaching men during later stages of my fieldwork, larger farmers were a population that was elusive across the study location. Many owners of large tracts of land were absentee land owners. Among those that were not, their experiences with government agency regulation of land use and labor relations led them to be suspicious of questions from outsiders. Therefore, the farmers who participated in this research tended to manage small household farms. 
other primary data that had been collected. Other documents included in the analysis were: field notes recorded during participant observation, photographs of architecture, infrastructure, the landscape, and other images characteristic of the study locations, as well as a digital copy of ASOFAC.CB meeting minutes during the year prior to my arrival. All of these materials were compiled into an Atlas.ti hermeneutic unit for analysis.

\section{Method of Analysis of Primary Documents and Description of Data}

As already mentioned, I initially used open coding to apply codes to field notes, transcripts and audio recordings of interviews, and photographs. I selected sections of files and labeled them with words, usually just one or two, that provided a succinct relevant description of what could be found there. Through this process, I derived 199 codes to describe the data. Many of these codes were used to reference no more than a few selected sections of text. Therefore, they do not play a significant role in subsequent analysis.

Next, in an effort to organize initial codes into a smaller set of super codes, or themes, I studied them for frequency, accuracy, and co-occurrence (Contreras 2011; ATLAS.ti n. d.). Through this process, I was also able to evaluate the consistency of coding by comparing the results with the themes used to structure the interview guides. ${ }^{2}$ The following are the major themes that emerged from the data and along with brief explanations of the kind of information accounted for by each.

2 It is worth pointing out here that I was the only person coding and analyzing these data. Therefore, although this step serves as a verification of the consistency of the coding structure applied to the data, it could be further validated by referencing the structure applied by an additional coder. 
- $\quad$ Agricultural Production: anything that has to do with the production of food and agricultural commodities

- Development: anything that has to do with community, regional, and local development, outside agencies promoting development programs, and participation in implementation of development programs and projects

- Environment: anything that has to do with the environment and conservation of natural resources

- Groups: anything related to the operation of formal and informal groups at any scale

- Relations: anything that has to do with interpersonal relationships, including family, and internal group dynamics

Given that two separate interview guides were used in this research and that research took place in two different districts, table 1 is organized to show the average frequency of occurrence of themes during interviews with the members of various groups. While development was discussed with similar frequency during interviews with all groups, interviews with Farmers were focused more on agricultural production and the environment, and interviews with ASOFAC.CB Members focused more on groups and relations. (Again, for a more detailed look at the differences in the structure of conversation during these interviews, see the semi-structured interview guides translated into English in Appendix A and Appendix B.)

Table 1. Average frequency of occurrence of themes during interviews.

\begin{tabular}{lcccccc}
\hline & $\begin{array}{c}\text { Agricultural } \\
\text { Production }\end{array}$ & Development & Environment & Groups & Relations & TOTALS: \\
\hline All Participants (39) & 14.1 & 17.5 & 12.6 & 14.9 & 13.5 & 72.5 \\
ASOFAC Members (16) & 11.1 & 16.8 & 10.7 & 18.0 & 15.3 & 71.8 \\
Farmers (23) & 16.2 & 18.0 & 13.9 & 12.7 & 12.2 & 72.9 \\
Farmers in Biolley (13) & 16.2 & 17.8 & 13.6 & 12.6 & 12.2 & 72.5 \\
Farmers in Pittier(10) & 16.2 & 18.1 & 14.2 & 12.8 & 12.2 & 73.5 \\
\hline
\end{tabular}


Table 2 provides a similar comparison with a select group of initial open codes. Codes such as coffee, land management, and regional development that were grouped in the Agricultural Production theme also occur with greater average frequency during the second round of interviews with Farmers than they do during interviews with ASOFAC.CB Members. Codes such as community relations, interpersonal relations, and perceptions of outsider that were included in the Relations theme occurred with greater frequency during the interviews with ASOFAC.CB Members than they did during interviews with Farmers.

Other important differences in the nature of these interviews can also be identified using table 2. For example, the guide for interviews with Farmers included direct questions about community development, while ASOFAC.CB Members were asked in a more open-ended way to describe their community. As a result, more of the discussion about the community during interviews with ASOFAC.CB Members ended up being coded with community relations as it tended to be related to people's perceptions of other community members, their inter-personal relationships, and organizations working within and outside the community. Similarly, farmers were asked directly about their perceptions of the park and ASOFAC.CB Members were not. As a result, park appears with greater average frequency during interviews with Farmers while ASOFAC.CB Members spoke more generally about the environment and their relationship with MINAET. ASOFAC.CB Members were asked directly to share their opinion about MINAET, and the higher average frequency of the environment during their interviews is likely due to the fact that much of ASOFAC.CB's activity during my fieldwork was revolving around their 


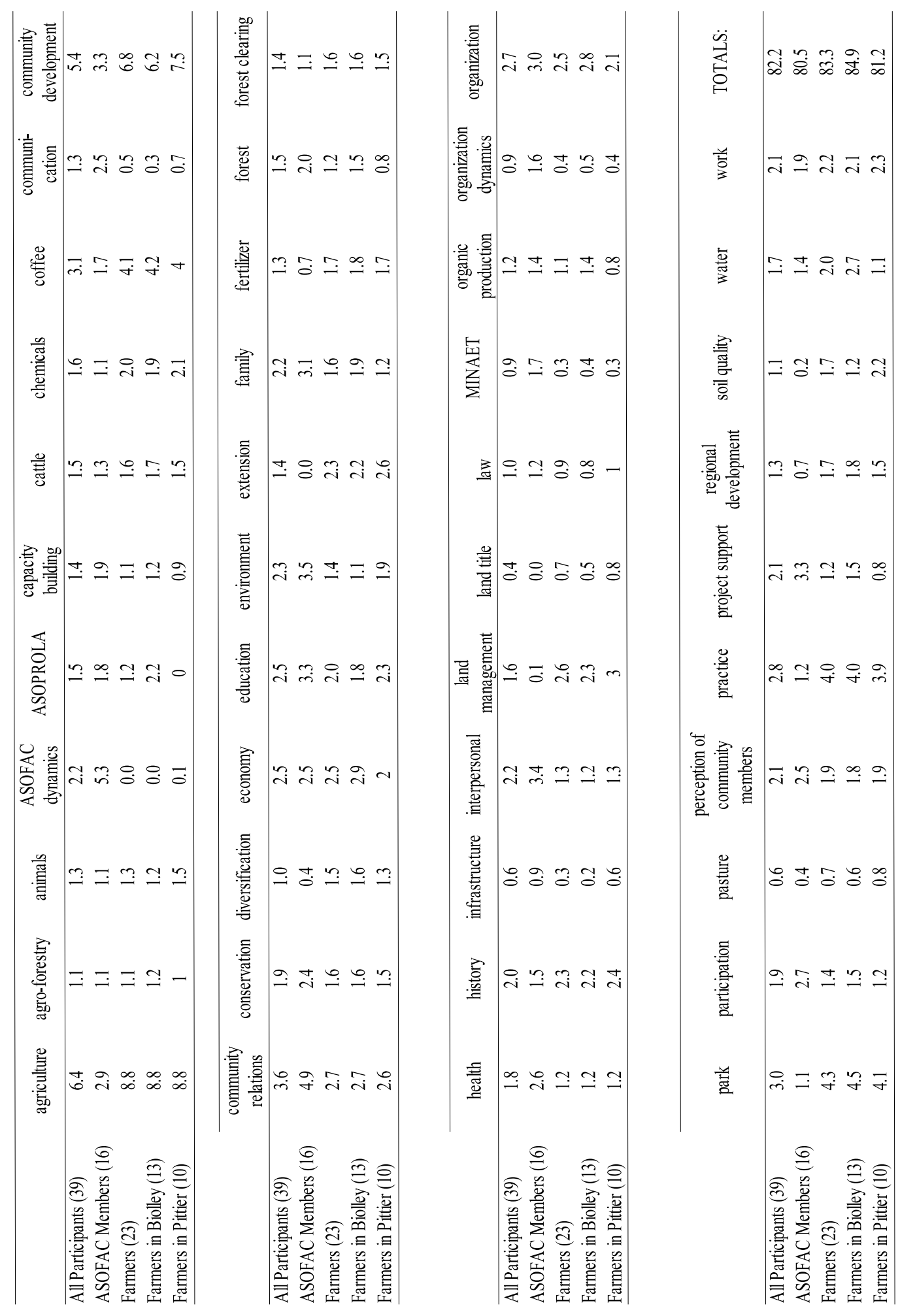

Table 2. Average frequency of occurrence of initial codes during interviews. 
relationship with MINAET and other actors promoting an agenda of environmental conservation.

My initial process of open coding did follow the procedures for developing grounded theory (Birks and Mills 2011), however the intermediate stages of data analysis involved using these codes to sort, query, and explore the detail as it related specifically to my research questions. In doing this, I developed hypotheses based on my experiences as a participant observer and themes discussed in the literature. Then, I used select codes to design queries of the data and I reviewed the queried data to test my hypotheses and design new hypotheses and queries until the queries consistently produced the same data relevant to my question.

Although there are more differences that could easily be noted here, the last thing that I want to do in this section is point to an example in table 2 to highlight this iterative process of data analysis. During interviews with ASOFAC.CB Members, discussion related to legal issues usually had to do with either familial or fund raising matters. During interviews with Farmers, discussion of legal issues tended to be related to the matter of having a clear title to land. The initial code that I used to identify these topics of conversation was law. After realizing that there was something qualitatively different about the use of this code between the different types of interviews, I added the land title code coding structure. A comparison of the average frequencies of these two codes suggests there might be an almost a perfect correlation between them within the different groups of interviews. This can be confirmed by an analysis of their co-occurrence, which shows only one instance in which a Farmer discussed a legal issue that was unrelated to 
land title.

\section{Secondary Data Sources}

A considerable amount of secondary data is included in this study. For example, the information on economic and agricultural production presented in Chapter 1 was accessed primarily through the websites and reports of the Central Bank of Costa Rica and the Costa Rican Ministry of Agriculture. Information on pasture areas of Central American countries was obtained from the online archives of the Economic Commission on Latin America and the Caribbean (CEPALSTAT). Files used to create the maps included in this study were obtained from several websites across the internet and from various Costa Rican government agencies with the assistance of ACLAP Research Program staff. The geographic coordinates of the communities that are placed on some of the maps were obtained by cross-referencing information from multiple internet sources, including general information web pages, tourism-oriented web sites, Google Maps, and Bing Maps.

Other sources of secondary data referred to throughout this study include minutes and documentation from the proceedings of local meetings that were obtained during field visits. Images and text from the web sites and other publicly accessible forms of electronic communication of local organizations were also collected during and after fieldwork and are considered as secondary data. Lastly, along with a large volume of government and other development agency reports, a number of local studies, including books, journal articles, theses and dissertations focused on development of ACLAP, are also valuable secondary data sources. 


\section{Chapter 4: The National Setting}

This chapter includes overviews of the agricultural economy of Costa Rica and the Costa Rican system of natural resource protection, as well as a brief discussion of the emphasis placed on political decentralization in Costa Rica. The overall emphasis of the chapter is on the socio-spatial organization of development activity across the country. The chapter is also intended to contextualize development activity across the La Amistad Pacific Conservation Area (ACLAP) and in the districts in this region where ethnographic fieldwork was focused.

The chapter draws on a breadth of secondary data from Costa Rican and other development agencies. It presents the variegated political boundaries and management priorities in portraying the spatial organization of select national government agencies with rural development initiatives. In exploring and describing these territories and organizations as they are relevant to the study region, the idea I have in mind is similar to notion that "writing has nothing to do with signifying. It has to do with surveying, mapping, even realms that are yet to come" (Deleuze, Guatarri, and Massumi 2008, 4 5). As areas are designated by outlines on maps, they are also often used to organize the collection of information. Organizations and individuals affiliated with these areas can attribute various rights and responsibilities to this information and influence access to and interpretation of this information. These interpretations carry very real implications both for them and for people who live and work in these areas. My goal here is to present some information about the history of these territorial and institutional designations as well as the contemporary conditions in which they exist and operate across the country. 
The data collected, selected, and presented in this chapter portrays the relative significance of these designated territories in various ways. It also points to the attributes emphasized by various political institutions in influencing the direction of national and regional development, and ultimately the identities and relationships of individuals within these territories.

\section{A Conceptual Map of Integrated, or Sustainable, Development and a Framework for Political Decentralization}

Figure 2 provides an overview of the structures of the three Costa Rican national government agencies most relevant to this study. The remainder of this chapter is organized in sections focused on empirical discussion of work related to the interests of these agencies and their respective development strategies. It also emphasizes the geopolitical dimensions of the agencies as they become apparent through their unique territorial designations. Therefore, the diagram in figure 2 provides an illustration of two things. In its entirety, it provides a conceptual map to guide the study of development activity. Also, in part, it also provides a depiction of the framework the national government has established for formally implementing a process of political decentralization. The depiction of departments, agencies and other actors, and their relationships are in some instances more speculative that definitive. However, the emphasis on integration, or sustainability, also exists in at least two different ways that are meaningful in interpreting this figure. The community-level political units that are part of the national decentralization program are referred to as Integrated Development Associations (ADI), with the intention being that the members of these local political 


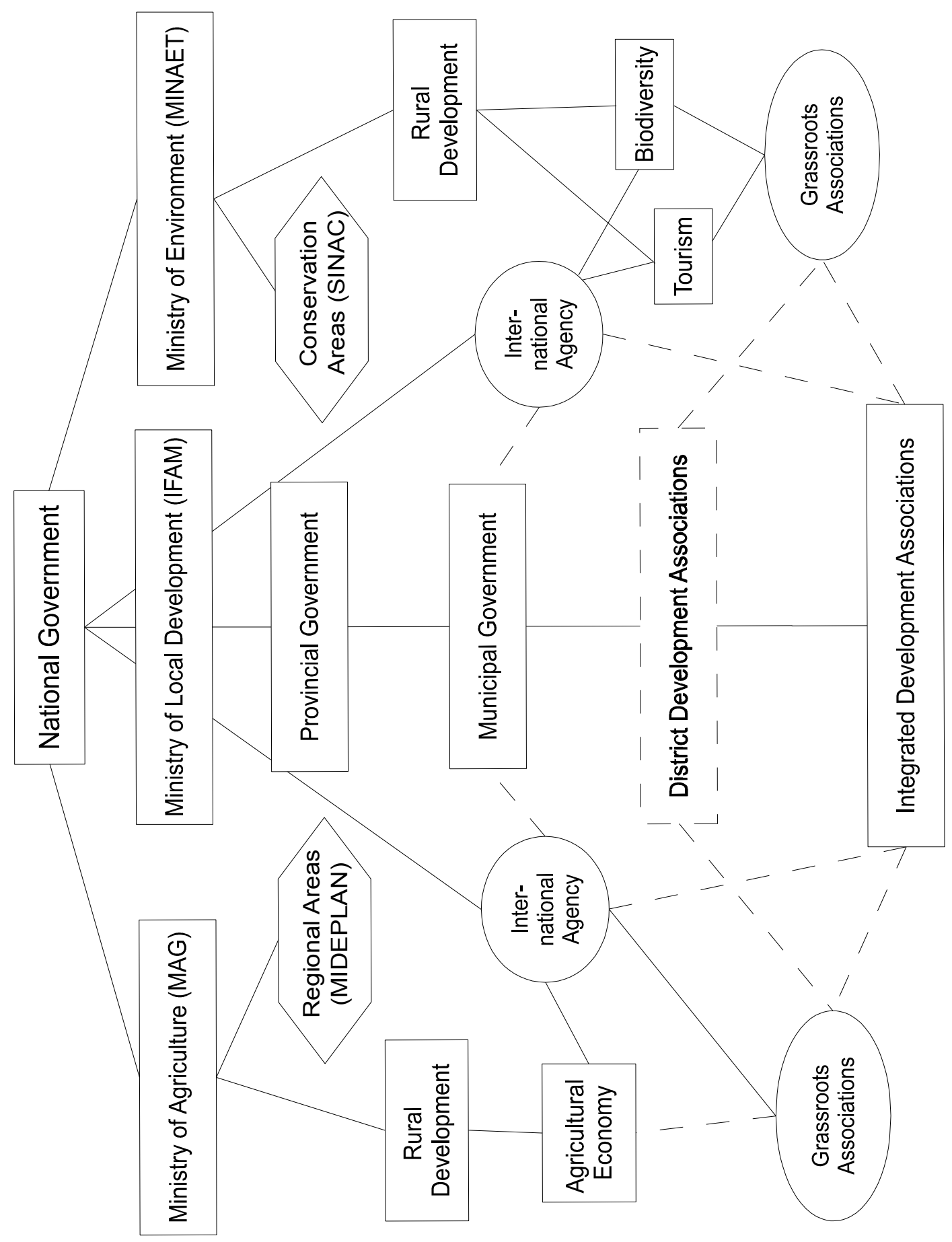

Figure 2. Framework for analysis of integrated development in Costa Rica. 
organizations become more actively involved in the political affairs of higher level units of the national government. This emphasis on hierarchical integration can be compared the focus on sustainability that is brought about by the inclusion in the broader conceptual map of agencies involved in agriculture and natural resource management.

The majority of efforts in support of political decentralization are implemented through the Institute for Municipal Development and Assessment (IFAM). IFAM focuses on providing support to municipal governments as they increasingly need to take on the roles of government associated with providing local infrastructure and public services. Thus, even through the process of decentralization, the work of IFAM follows closely the hierarchical political structure established by the central government. As illustrated in figure 1, municipal governments are nested within provincial units. Districts are the political units within municipalities, and communities are located within districts. According to the framework, only communities that have established their status as an ADI through a supervised election are officially recognized as political organizations by the central government. In some places, including the study location, as we will see in a later chapter, communities within districts and districts within municipalities are forming networks to represent their political interests at higher levels of government. Although these networks are referred to as integrated development associations, the potential for establishing a multilevel agency in this way makes it questionable as to whether the central government would ever be able to grant them official recognition.

While IFAM's work is guided by the structure and interests of a centralized government, it is also organized spatially according to the territorial designations 
associated political jurisdictions established by the same central government. On the other hand, the Ministry of Agriculture (MAG) and the Ministry of Environment, Energy, and Telecommunications (MINAET) operate to some extent according to their own sets of geophysical and geopolitical criteria. Although these territorial designations often coincide to a large extent with national political designations, especially at the level of provincial units, as we will see throughout the rest of this chapter, they also often differ based on the particular interests of the ministry.

MINAET organizes its work using the National System of Conservation Areas (SINAC), many of which are designated according to their proximity to or coincidence with the boundaries of natural landscape features, such as watersheds. MAG, indicating its historical interest in economic development, refers to the regional areas that are also used by the Ministry of National Planning and Political Economy (MIDEPLAN) in directing its work. It is interesting to note here that in some places these areas are referred to as "functional" areas, or areas designed for the purposes of planning development based on socio-economic criteria. Although there are important differences between these geopolitical organizations, the differences between the strategies for rural development of the two ministries provide a clearer contrast of their respective development interests. While MAG is dealing with the legacy of heavy investment in export-oriented agriculture, MINAET is searching for environmentally-benign sources of income for rural communities.

\section{The Economy and Employment in Costa Rica}

Overall, the economy of Costa Rica currently relies heavily on service sector 
employment. However, this has not always been the case. In the late $19^{\text {th }}$ century, the country's economy was based primarily on the production and international trade of agricultural commodities, primarily coffee. Throughout most of the twentieth century, agricultural production continued to provide the foundation for the national economy. During this period, tropical fruits and beef were increasingly competitive with coffee as the primary agricultural export. More recently, the development of secondary sectors of the agricultural industry, such as value-added processing, and other types of manufacturing also grew in importance. Towards the end of the $20^{\text {th }}$ century, Costa Rica underwent structural adjustments and free trade zones for manufacturing industries were established within the country. As this sector of the economy continued to grow, Costa Rica also became a popular destination for international tourists. For several years prior to the global financial crisis that began in 2008 , tourism was the export contributing the most to the Costa Rican gross domestic product (GDP).

Despite a slight downturn in tourism activity, the annual growth rate in the service sector was greater than $20 \%$ between 2010 and 2011. During this time, tourism contributed around $5 \%$ to the national GDP, and it employed about 150,000 people directly and 400,000 indirectly. Rough estimates are that around $65 \%$ of the employed labor force in Costa Rica works in all third, or service, sector activities. Around 20\% of Costa Ricans are employed in secondary industries, like the manufacture of textiles, pharmaceuticals and microprocessors, and around $15 \%$ of the employed labor force works in primary industries such as agriculture and mining (Portolés 2012).

Table 3 provides an overview of the contributions of major economic activities to 
Table 3. Contribution of economic activities to Costa Rica gross domestic product (GDP), 1991 2015, as a proportion of total GDP and in trillions of colones at current market prices (March 2014). (The exchange rate is approximately $₫ 545$ to $\$ U S 1$.

\begin{tabular}{|c|c|c|c|c|c|c|c|c|c|c|c|c|}
\hline \multirow[b]{2}{*}{ Gross Domestic Product at Market Prices } & \multicolumn{2}{|c|}{1991} & \multicolumn{2}{|c|}{1996} & \multicolumn{2}{|c|}{2001} & \multicolumn{2}{|c|}{2006} & \multicolumn{2}{|c|}{2011} & \multicolumn{2}{|c|}{2015} \\
\hline & $100.0 \%$ & $ф 0.88$ & $100.0 \%$ & $c 2.46$ & $100.0 \%$ & $\varnothing 5.39$ & $100.0 \%$ & ф 11.52 & $100.0 \%$ & c 20.85 & $100.0 \%$ & c 29.2 \\
\hline Less: Taxes on good and imports (net of subsidies) & $8.0 \%$ & $£ 0.07$ & $9.1 \%$ & 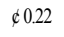 & $9.6 \%$ & $\not 0.52$ & $10.0 \%$ & $\phi 1.15$ & $9.1 \%$ & d 1.90 & $8.5 \%$ & $\dot{\phi} 2.5$ \\
\hline Gross Domestic Product at Base Prices & $92.0 \%$ & $£ 0.81$ & $90.9 \%$ & $d 2.24$ & $90.4 \%$ & c 4.88 & $90.0 \%$ & \& 10.37 & $90.9 \%$ & d 18.95 & $91.5 \%$ & $\dot{c} 26.8$ \\
\hline Agriculture, forestry, and fishing & $12.4 \%$ & $ф 0.11$ & $11.7 \%$ & 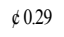 & $8.0 \%$ & $\not 0.43$ & $8.0 \%$ & $\notin 0.92$ & $5.8 \%$ & c 1.21 & $4.9 \%$ & \& 1.4 \\
\hline Extraction from mines and quarries & $0.1 \%$ & $£ 0.00$ & $0.1 \%$ & $₫ 0.00$ & $0.2 \%$ & $\not 0.01$ & $0.2 \%$ & $\phi 0.02$ & $0.1 \%$ & $c 0.03$ & $0.1 \%$ & $\notin 0.0$ \\
\hline Manufacturing Industry & $21.0 \%$ & $\pitchfork 0.18$ & $20.1 \%$ & $₫ 0.49$ & $19.8 \%$ & $\not 1.07$ & $19.5 \%$ & $c 2.25$ & $15.8 \%$ & d 3.29 & $14.1 \%$ & c 4.1 \\
\hline Construction & $3.8 \%$ & $\varnothing 0.03$ & $3.4 \%$ & $₫ 0.08$ & $4.3 \%$ & $\not 0.23$ & $4.4 \%$ & $c 0.51$ & $4.9 \%$ & c 1.03 & $5.3 \%$ & \& 1.6 \\
\hline Electricity and water & $2.8 \%$ & $£ 0.02$ & $2.8 \%$ & $₫ 0.07$ & $2.6 \%$ & $\not 0.14$ & $2.1 \%$ & 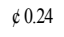 & $2.2 \%$ & $c 0.46$ & $3.1 \%$ & $\phi 0.9$ \\
\hline Retail, restaurants, and hotels & $17.9 \%$ & $\pitchfork 0.16$ & $18.1 \%$ & $£ 0.45$ & $17.9 \%$ & $\not 0.96$ & $17.6 \%$ & $\notin 2.03$ & $15.8 \%$ & d 3.29 & $15.1 \%$ & $\not 4.4$ \\
\hline Transport, warehousing, and communications & $7.5 \%$ & $£ 0.07$ & $8.1 \%$ & $₫ 0.20$ & $7.7 \%$ & $\not 0.41$ & $9.0 \%$ & $\notin 1.04$ & $9.2 \%$ & d 1.91 & $9.8 \%$ & $\dot{\phi} 2.9$ \\
\hline Financial services and insurance & $3.7 \%$ & $ф 0.03$ & $4.3 \%$ & $₫ 0.11$ & $4.7 \%$ & $\not 0.25$ & $5.6 \%$ & $\gtreqless 0.64$ & $6.2 \%$ & d 1.30 & $6.4 \%$ & $\notin 1.9$ \\
\hline Real estate activities & $6.2 \%$ & $£ 0.05$ & $4.6 \%$ & $£ 0.11$ & $4.1 \%$ & $\not 0.22$ & $3.0 \%$ & $\not 0.35$ & $2.8 \%$ & $£ 0.58$ & $2.8 \%$ & $\dot{c} 0.8$ \\
\hline Other services rendered to businesses & $2.5 \%$ & $\notin 0.02$ & $2.4 \%$ & $£ 0.06$ & $3.7 \%$ & $\not 0.20$ & $4.7 \%$ & 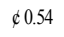 & $6.9 \%$ & c 1.43 & $8.1 \%$ & $\dot{c} 2.4$ \\
\hline Public administration services & $3.6 \%$ & $\Varangle 0.03$ & $3.6 \%$ & $₫ 0.09$ & $3.7 \%$ & $\not 0.20$ & $3.6 \%$ & $\Varangle 0.41$ & $4.6 \%$ & c 0.96 & $4.7 \%$ & d 1.4 \\
\hline Community, social, and personal services & $12.2 \%$ & $£ 0.11$ & $14.5 \%$ & $£ 0.36$ & $17.2 \%$ & $\not 0.93$ & $16.5 \%$ & $\notin 1.90$ & $21.3 \%$ & d 4.44 & $21.7 \%$ & $\notin 6.4$ \\
\hline Less: Indirect finance intermediation services & $1.7 \%$ & $\notin 0.01$ & $2.8 \%$ & 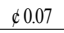 & $3.4 \%$ & $ф 0.19$ & $4.2 \%$ & $\notin 0.49$ & $4.7 \%$ & $\varnothing 0.97$ & $4.7 \%$ & $\notin 1.4$ \\
\hline
\end{tabular}

Source: Costa Rica. Central Bank. Department of Macroeconomic Statistics (2014). http://www.bccr.fi.cr/indicadores_economicos_Produccion_empleo.html

the Costa Rican gross domestic product for selected years ranging from 1991 to 2015 . In

looking at the changes in the composition of national economic activities over this period, there are at least a few things worth noting. First, the percentage of national income generated through the provision of community, social, and personal services rose from $12 \%$ in 1991 to $21 \%$ in 2011 , and is project to continue to increase through 2015 . This reflects the emphasis on social democratic principles in the national government, it also reflects the continuing of the commitment Costa Rica first made to education and the provision of social services when it eliminated its military following a civil war in 1948 . This limited need for military spending is often purported to be the reason Costa Rican stands out among Central American countries in terms of its achievements in health care and education and its relatively high standard of living.

Even though the country went through a period of structural adjustment during the 1980s, it has managed to maintain the domestic service sector of its economy as a high priority. Another reason contributing to this accomplishment is the success the country 
has had in negotiating a number of debt-for-nature agreements with creditor countries. With the help of transnational agencies, the country has been able to avoid making the dramatic cuts of budgets for social services that other countries that have been subject to during periods of structural adjustment.

While the relative contribution of other services rendered to business appear to increase significantly between 1991 and 2015, construction and financial services and insurance also appear to increase during this period. On the other hand, activities in manufacturing, agriculture, forestry and fishing, and real estate present trends in the opposite direction. This adds further emphasis to the notion that Costa Rica is a country continuing to move away from a some of the activities that have historically served as the base of its economic activity towards an economy based more on the provision of services. As table 3 indicates, the contribution to national GDP from agriculture, forestry, and fishing activities declined from 12\% in 1991 to just under $6 \%$ in 2011, and is expected to fall under $5 \%$ in 2015 . Likewise, after decades of contributing around $20 \%$ of the income of the national economy, the manufacturing sector is expected to contribute only $14 \%$ in 2015 .

Despite these recent slight declines in the contribution of the agricultural sector to national GDP, agriculture continues to be one of the defining characteristics of the country. As demonstrated in this and other research, agricultural activity is still the primary driver of local and regional economies in most rural places across Costa Rica. The influence of agricultural production also continues to play a role in shaping national identities as the country's reputation for producing high quality coffee is often coupled 
with its reputation for environmental protection in marketing tourism to international audiences.

The legacy of agricultural influence in Costa Rican political economy has its roots in the era of provincial governments. Before the ability of provincial units of government to influence the political economy waned significantly throughout the late $20^{\text {th }}$ century (Dorn 1989), large land owners used these provincial centers of political power and their relationships to the national government to determined the direction of local development (Cardoso and Faletto 1979). The current situation in which communities across large areas of the country continue to be dependent on the production of agricultural commodities for export is reminiscent of a that era. However, as discussed in the context of relative contributions national GDP, opportunities in these areas are increasingly limited. This is especially true in places across the country where the locally economy has historically been dependent on the production of agricultural commodities and where tourism or manufacturing have not been promoted and incorporated into a portfolio of regional economic development activities.

Even in places where local and regional economies have been somewhat diversified, relatively large portions of the labor force continue to be employed in agriculture. As shown in table 4, while there was variation in the numbers and percentages of the Costa Rican labor force employed in the agricultural sector during the period between 2002 and 2012, overall the proportion of the national labor force employed in this sector moved slightly around an average of $10 \%$ and the number of people employed in this sector increased by 26,797 people. This overall increase in 


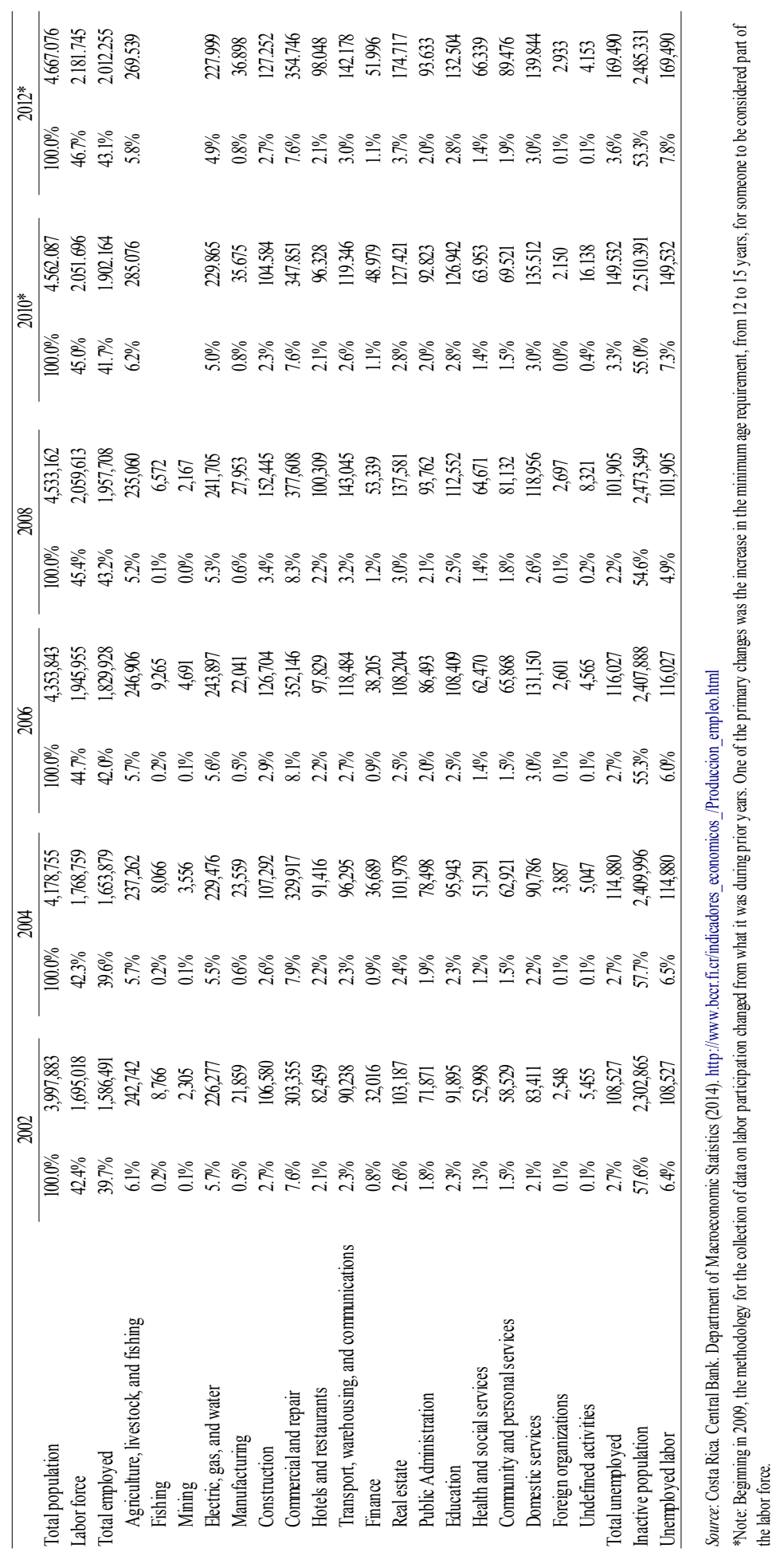

Table 4. Costa Rica employment, 2011 - 2015, and as a proportion of total labor force by labor sector 
number of people employed appears despite a change in the official method of counting people as eligible for labor (individuals from 12 to 14 years of age were no longer included in this number starting in 2009) and during a period when the proportion of national income earned in agriculture declined by $2.5 \%$.

\section{Costa Rican Agriculture: Major Exports and Domestic Production}

The United States continues to be the most important destination for Costa Rican agricultural exports, although the quantity and value of products exported to the United States has declined since 2008. Other important countries for Costa Rican exports are Holand, Belgium, and Nicaragua, the latter country providing an interesting case as it is a neighboring Central American country and one that also exports basic grains to Costa Rica.

Coffee is perhaps the most well-known Costa Rican agricultural export. Costa Rica has a global reputation for being a country that produces high quality coffee, and this crop contributes $6 \%$ of the total national agricultural product (Portolés 2012). While the history of coffee growing in Costa Rica begins some time before the twentieth century (Samper, Naranjo, and Sfez 2000), the history of other major agricultural exports, such as bananas, pineapple, and beef have more recent and varied production histories. Costa Rica has recently moved into the position of being the number one exporter of pineapple in the world, and its production of this fruit grew by $8 \%$ from 2010 to 2011 . By some estimates, this sector employs 27,500 people directly and 110,000 indirectly (Portolés 2012).

With recent reductions in the production and prices of some of the country's major 
exports, MAG Particularly in remote areas where agriculture has always been characterized by a certain level of subsistence activity, it has been common practice for farmers to produce a variety of crops, including basic grains, fruits, and vegetables. However, over time and in many places this practice has been lost, in large part due to national policies that have favored the import of lower-cost basic grains and the specialization of national production in higher-priced commodities for export. While trade agreements implemented over the course of previous decades have made conditions favorable for the import of basic grains from other countries, MAG has established a program that supports the production of basic grains across the country (Solórzano and Fallas 2008). The past over-emphasis on commodity production has had an number of negative impacts on the rural development across the country. These include the impacts on the landscape in some places, as well as the impacts on agricultural and ecological systems and the impact on the health of rural residents across the country. A lack of access to certain product markets in remote locations coupled with the reduction in the variety of foods produced in these places has been related to poorer health and nutrition. Although caloric intake based on local production or consumption of products available in local markets in these places may be in sufficient, or even excessive, amounts of when looked at strictly in terms of calories, the foods available tend to lack important vitamins and the diets in these places are moving towards the point of being nutritionally deficient (Stuchi 2009).

In addition to affecting local and regional modes of production, Costa Rican policies favoring the expansion of agriculture had a significant impact on the amount of 
land that was deforested and put into pasture across the country (Edelman 1995; Carriere 1991). Once this policy direction was changed, beef exports declined dramatically and farmers were left to search for alternative uses for their land. Under these types of circumstances, development programs directed towards maintaining stability in rural areas are critical not only in terms of economic development, but also for social and environmental sustainability.

\section{Regional Agriculture}

Unlike in the case of the overall national economy, the economy of the study region is highly dependent upon agriculture. Outside of on-farm production activities, the processing of agricultural commodities, especially coffee, is an activity that makes a significant contribution to the regional development (Fitzgerald 2013; Sick 1999). As mentioned earlier, despite the country's agricultural history and reputation as a producer of high quality coffee, bananas and pineapples have more recently held the position as the top agricultural commodities exported by Costa Rica. The relocation of banana plantations to the Pacific side of the Talamanca Highlands in the 1930s had major impacts on the agricultural economy, the environment, and social relations across the region (Vandermeer and Perfecto 2005). During the 1990s, this area, which is located primarily in the northern part of the Buenos Aires municipality, was transformed into a place that now produces the majority of pineapples exported by Costa Rica (Picado 2011; Malig 2011; Immigration and Refugee Board of Canada 2002). All of these things considered, the primary drivers of economic activity across ACLAP, and in particular in the places where I conducted ethnographic fieldwork, continues to be the production of coffee and 
cattle for export. To lesser and more variable degrees, diversified household agriculture that includes crops like tubers and vegetables contribute to the maintenance of rural livelihoods and local economic development. Other activities, like rural community based tourism also contribute to economic development in some places.

As explained in more detail throughout the remainder of this section, this research is focused primarily on communities across two districts of ACLAP. These districts are situated towards the southern part of the region near the border with Panama. They are neighboring districts, however, they are located within different municipalities and their municipalities have some distinct characteristics. By some accounts, the study districts are more comparable than their respective municipalities. According to a report from The Nature Conservancy (TNC 2004), although Biolley is legally located within the the municipality of Buenos Aires, its geographic location and history have in many ways led it to be "connected commercially, culturally and socially with San Vito [the capital city of Coto Brus]" (33). Whereas the banana plantations that have been converted to pineapple plantations have had a large historical influence on the municipal economy of Buenos Aires, "Coto Brus bases its economy in the cultivation of coffee" (32). The production of coffee and cattle and other household agricultural activities have been significant for the regional economy since it was settled during the middle of the $20^{\text {th }}$ century. These activities were particularly important at the household level and in more remote communities. Then, as coffee prices dropped and pineapple production expanded during the 1980s, the population in Coto Brus began to decline. Some people moved to the north looking for work on the plantations of Buenos Aires while others moved farther towards 
the Central Valley and larger cities. These demographic and migratory patterns continue to be emphasized today as there is a regular major inflow of indigenous people, mostly from Panama, into Coto Brus during the coffee harvest.

\section{Coffee}

Much of Costa Rica's development history is related to the spread of coffee cultivation across the country. Conditions for coffee production are particularly favorable in plateau areas such as those that exist throughout its Central Valley and in the southern part of ACLAP (Manger 1992; Millman 1987). For many years, coffee produced for export was the primary source of revenue for funding national development. Although this situation has changed over time, there is still a relatively large part of the labor force employed by the production of this crop, and the extent of land dedicated to the cultivation of this crop continues to be greater than that dedicated to any other crop, including pasture. Table 5 shows production of coffee in metric tons from 2007 to 2011 for the major regions. It also shows the production of coffee for these years in Buenos

Table 5. Costa Rica coffee production, 2007/08 - 2010/11, in metric tons by coffee regions and select cantones and by agricultural season.

\begin{tabular}{lllcccc} 
& & \multicolumn{4}{c}{ Production (metric tons) } \\
\cline { 3 - 6 } Coffee Region & Province & Canton & $2007 / 08$ & $2008 / 09$ & $2009 / 10$ & $2010 / 11$ \\
\hline Coto Brus & Puntarenas & Buenos Aires & 5304.8 & 6292.3 & 5711.8 & 4360.7 \\
Coto Brus & Puntarenas & Coto Brus & $42,996.3$ & $42,024.0$ & $38,422.1$ & $29,863.3$ \\
Coto Brus & Puntarenas & Osa & 1.0 & 1.0 & 0.8 & 2.0 \\
Coto Brus & & & 48304.1 & $48,317.3$ & $44,134.6$ & $34,226.0$ \\
Los Santos & & $182,296.5$ & $158,056.1$ & $156,200.7$ & $166,148.0$ \\
PerezZeledón & & $80,129.1$ & $63,035.1$ & $66,247.6$ & $52,952.8$ \\
Turrialba & & $47,441.4$ & $38,925.3$ & $33,234.4$ & $36,094.1$ \\
Valle Central & & $120,515.5$ & $95,912.9$ & $88,936.7$ & $108,286.9$ \\
Valle Occidental & & $131,851.8$ & $114,770.6$ & $90,387.4$ & $121,121.9$ \\
Zona Norte & & $10,314.9$ & $8,880.9$ & $5,602.2$ & $6,992.1$ \\
Total & & $620,853.3$ & $527,898.1$ & 484.743 .5 & $525,821.8$ \\
\hline
\end{tabular}

Source: MAG. 2012. Boletín Estadístico. 
Aires and Coto Brus, the municipalities or cantones, where the communities that are the primary focus of the ethnographic research reported in this study are located. In both cantones coffee production declined considerably during this time. Nationally, production declined by $15.3 \%$ over this four-year period, while it decline by $29.1 \%$ in the Coto Brus coffee region. After a slight increase in production in Buenos Aires in 2008/09, production dropped by $30.7 \%$ over the next two years. In Coto Brus, production declined consistently over the four-year period by a total of $30.5 \%$. As the quantities in table 4 also indicate, the amount of coffee produced across Coto Brus is much greater than that produced across Buenos Aires. This is in part due to the unique agricultural histories of these sub-regions, parts of which have already mentioned. In addition to the presence of banana and pineapple plantations in Buenos Aires, there are a number of other factors, such as differences in landscape and environmental conditions and local development histories that will be discussed in later chapters that also contribute to this variation in coffee production between the municipalities.

\section{Basic Grains}

To provide a general sketch of the importance of the production of basic grains to Costa Rican agriculture and development in the study region, it will be helpful to first identify the staple of the Costa Rican diet, gallo pinto. Gallo pinto is basically a dish of rice and beans. It is the foundation of most meals across the country. It is served with almost every meal and at any time of the day. It is often endearingly referred to simply as pinto. There are a number of local variations that include red or black beans and different spices. Pinto can also take on a regional character given the availability of ingredients. A 
similar rice and bean dish made with coconut milk is found in many parts of the southern Caribbean region of the country. Pinto even maintains a prominent presence in the metropolitan center of the capital city, San Jose. Much of the rice and beans used to make pinto are produced by Costa Rican farmers. However, as alluded to earlier, an increasing amount of these ingredients are also being imported from other countries, especially Nicaragua.

Table 6 shows the amount of rice produced from 2007 to 2011 in the six agricultural regions of Costa Rica, as well four of the sub-regions from the Brunca Region. (These six agricultural regions are shown in figure 3 and are the MAG/MIDEPLAN functional planing regions referred to in the discussion of figure 2. They are slightly different than the coffee regions presented in table 5.) The region that dedicates the most land area to rice production is the Chorotega Region, with $2.4 \%$ of its land area under rice production. The Brunca Region, which includes the study location,

Table 6. Costa Rica land area under rice cultivation, 2007/08 - 2010/11, in hectares by region and selected sub-regions and by agricultural period.

\begin{tabular}{lcccc}
\hline & \multicolumn{4}{c}{ Area (Hectares) } \\
\cline { 2 - 5 } Region / Subregion & $2007 / 08$ & $2008 / 09$ & $2009 / 10$ & $2010 / 11$ \\
\hline Region Central & 0.00 & 0.00 & 1.50 & 0.00 \\
Region Pacifico Central & 6685.74 & 7559.77 & 8683.06 & 7922.14 \\
Region Chorotega & 19829.32 & 19588.5 & 23009.73 & 28768.65 \\
Region Brunca & 15929.6 & 18607.32 & 15685.09 & 20576.7 \\
$\quad$ Corredores & 6269.5 & 6954.5 & 4918.9 & 5345.9 \\
$\quad$ Coto Brus & 0.00 & 0.00 & 0.00 & 0.00 \\
Buenos Aires & 0.00 & 0.00 & 0.00 & 157.00 \\
$\quad$ PerezZeledón & 0.00 & 0.00 & 0.00 & 0.00 \\
$\quad$ Golfito & 2993.7 & 3635.87 & 3473.11 & 4636.9 \\
$\quad$ Osa & 6666.4 & 8016.95 & 7293.08 & 10436.9 \\
Region Huetar Norte & 4555.1 & 8061.5 & 11445.94 & 18877.95 \\
Region Huetar Atlantica & 7042.9 & 9512.00 & 7590.1 & 4970.75 \\
Total & 54.042 .66 & 63329.09 & 66415.42 & 81116.19 \\
\hline
\end{tabular}

Source: M AG. 2012. Boletín Estadístico. 
dedicates about three quarters as much land to rice production as the Chorotega Region, making it the region with the second most land area under rice cultivation. Over time, rice production in the northern-most region of the country, Huetar Norte, has increased significantly; however, the Chorotega and Brunca regions remain first and second in terms of hectares under production. What table 6 also shows is that within the Brunca Region, most of the area dedicated to rice production is in the sub-regions, or municipalities, nearer the coast. The municipality of Coto Brus does not even register area dedicated to rice production, and Buenos Aires only reports a small area dedicated to this purpose beginning in the 2010/11 agricultural year.

The map in figure 3 provides an alternative view of this information. It compares regions by the proportion of total land area dedicated to rice production. Again, Chorotega and Huetar Norte appear among the regions emphasizing rice production the most. However, according to this proportional measure the smaller region of Huetar Norte replaces the Brunca Region as the region with the second greatest emphasis on rice production. Figure 3 also includes outlines of the cantones, or municipalities, of the Brunca Region and the outlines of the Biolley District in the cantón of Buenos Aires and the Pittier District in the cantón of Coto Brus. These are included to highlight the location of ethnographic research and to emphasize the social and spatial distances between areas within the Brunca Region. While the map presents a measure of rice production at the level of the agricultural region, table 6 also includes measures of rice production at the municipal level in the Coto Brus Region. Thus, comparing the proportional measures presented in figure 3 with the land area measures presented in table 6 highlights a major 


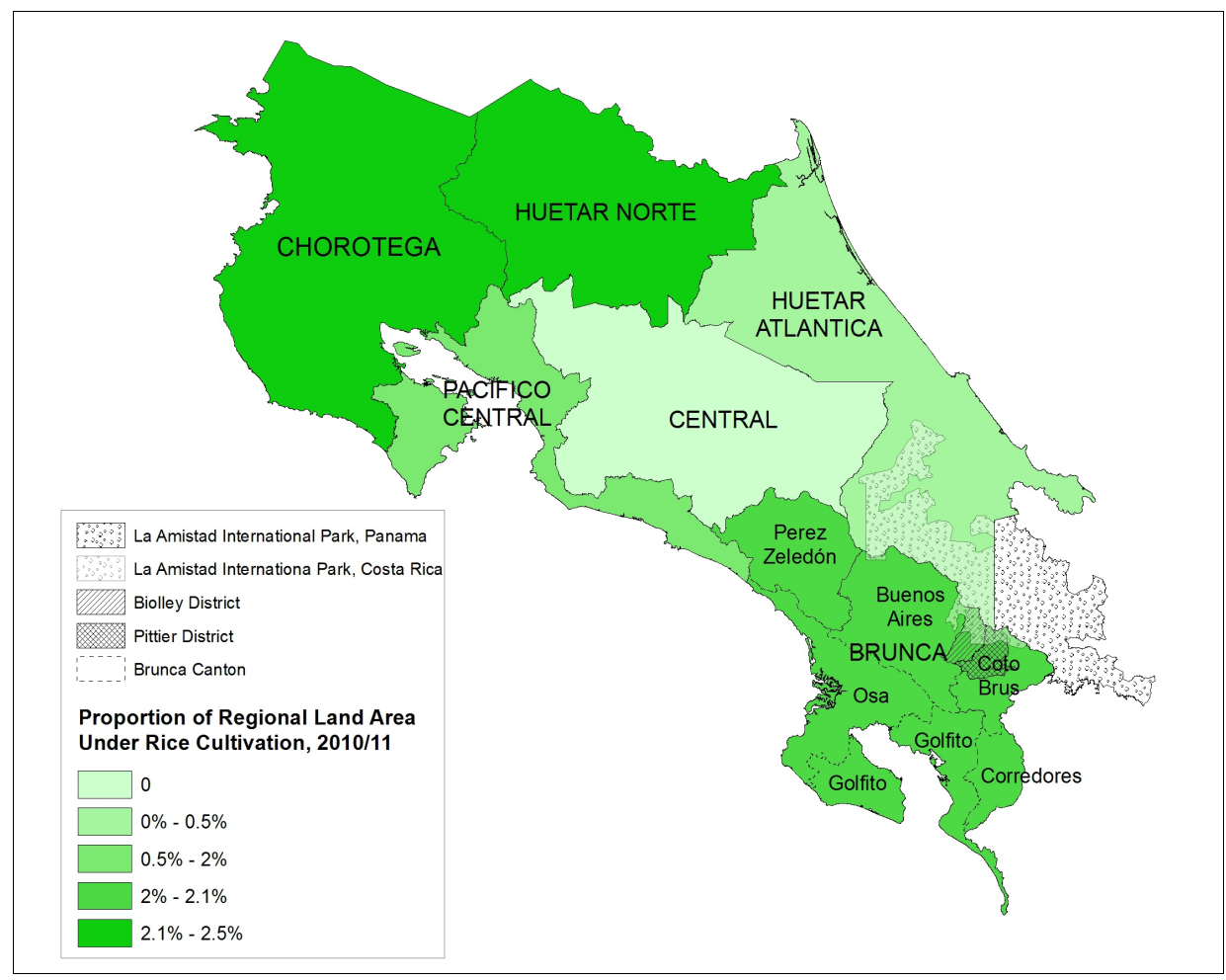

Figure 3. Costa Rica land area under rice production, 2010/11, as a proportion of total regional area.

difference in agricultural production within this region. Whereas some farmers in the Brunca Region are able to produce this nationally important basic grain, farmers in cantones and districts located in the interior, premontane parts of the region are subject to environmental conditions that make rice production a considerably less-viable alternative livelihood option.

Table 7 shows that bean production in Costa Rica has also increased steadily since 2007. The land area under bean production has nearly doubled while the amount of beans produced increased 2.21 times between 2007/08 and 2011/12. Similar trends are found in the Brunca Region, as well as for most of its sub-regions, including Coto Brus and Buenos Aires. 
Table 7. Costa Rica bean cultivation, 2007/08 - 2011/12, in hectares under cultivation and in humid and dirty tons by region and selected sub-regions and by agricultural period.

\begin{tabular}{|c|c|c|c|c|c|c|c|c|c|c|}
\hline \multirow[b]{2}{*}{ Region / Subregion } & \multicolumn{5}{|c|}{ Area (Hectares) } & \multicolumn{5}{|c|}{ Production (humid and dirty tons) } \\
\hline & $2007 / 08$ & $2008 / 09$ & $2009 / 10$ & $2010 / 11$ & $2011 / 12$ & $2007 / 08$ & $2008 / 09$ & $2009 / 10$ & $2010 / 11$ & $2011 / 12$ \\
\hline Region Central Occidental & & 120.0 & 55.0 & 90.0 & & & 62.2 & 30.3 & 41.4 & \\
\hline Region Central Oriental & & 285.0 & 335.0 & 340.0 & 186.0 & & 157.1 & 103.8 & 143.2 & 126.6 \\
\hline Region Central Sur & & 1466.0 & 900.0 & 100.0 & & 922.3 & 269.0 & 37.0 & & \\
\hline Region Pacifico Central & 1089.0 & 719.0 & 782.0 & 691.0 & 507.0 & 423.5 & 238.6 & 345.7 & 300.8 & 163.1 \\
\hline Region Chorotega & 1530.0 & 2459.0 & 3413.0 & 3130.0 & 3685.0 & 686.4 & 1100.0 & 1518.2 & 1278.5 & 1201.5 \\
\hline Region Brunca & 3280.0 & 5320.0 & 6797.0 & 5241.0 & 8008.0 & 1996.0 & 3153.2 & 4327.8 & 3052.5 & 5188.7 \\
\hline Corredores & & 220.0 & 105.0 & 119.0 & 51.0 & & 107.8 & 31.5 & 47.6 & 15.8 \\
\hline Corredores (Laurel) & & 50.0 & 130.0 & 106.0 & 45.0 & & 25.0 & 39.0 & 42.4 & 18.0 \\
\hline Coto Brus & 150.0 & 250.0 & 700.0 & 500.0 & 500.0 & 90.0 & 135.0 & 392.0 & 270.0 & 270.0 \\
\hline Buenos Aires & 800.0 & 890.0 & 1475.0 & 1025.0 & 1750.0 & 438.0 & 482.4 & 826.0 & 547.9 & 1081.9 \\
\hline PerezZeledón (San Isidro) & 1080.0 & 1980.0 & 140.0 & 75.0 & 138.0 & 648.0 & 1303.5 & 65.1 & 24.0 & 52.2 \\
\hline PerezZeledón (Pejibaye) & 1000.0 & 1500.0 & 3650.0 & 2946.0 & 5014.0 & 690.0 & 894.0 & 2649.0 & 1872.0 & 3476.3 \\
\hline Golfito (Puerto Jiménez) & 50.0 & 70.0 & 30.0 & 70.0 & 40.0 & 20.0 & 35.0 & 12.9 & 28.0 & 16.0 \\
\hline Osa (Palmar Norte) & 200.0 & 360.0 & 567.0 & 400.0 & 470.0 & 110.0 & 170.5 & 311.9 & 220.0 & 258.5 \\
\hline Region Huetar Norte & 5510.0 & 6193.0 & 8932.0 & 11105.0 & 9251.0 & 3712.2 & 3923.8 & 6679.0 & 9995.4 & 8381.7 \\
\hline Region Huetar Atlantica & & 207.0 & 40.0 & 26.0 & 34.0 & & 25.3 & 18.4 & 9.5 & 12.8 \\
\hline Total & 11409.0 & 16769.0 & 21254.0 & 20723.0 & 21671.0 & 6818.1 & 9582.4 & 13292.0 & 14858.0 & 15074.4 \\
\hline
\end{tabular}

Source: MAG. 2012. Boletín Estadístico.

A comparison of the crop production of Brunca sub-regions using tables 6 and table 7 provides further emphasis to the differences in the conditions necessary for the production of two crops considered basic grains in Costa Rica. While Perez Zeledón does not register land under rice production, it was one of the leading producers of beans in the region from 2007 to 2012, although the location of production has shifted somewhat within the cantón. From 2007 to 2012, bean production in Buenos Aires increased by more than $100 \%$. Although the conditions for production of rice in Buenos Aires are not favorable, some land was registered under rice production in the cantón for the 2010/11 growing season. Most of the rice grown in the region is produced in the cantones of Corredores, Golfito, and Osa, which are located nearer the Pacific coast and at lower elevations. Bean production in these cantones appears low when compared to most of the other cantones of the region. However, bean production in the most interior Osa district, Palmar Norte, was nearly equal the amount of beans produced by the cantón of Coto Brus 
during 2011/12. Similarly, when compared to other interior cantones, the bean yield per area planted in Coto Brus appears relatively low.

White corn is the third crop considered to be a basic grain in Costa Rica. Table 8 shows there have been some changes, but not strong trends, in national production of white corn. The production of white corn in the Brunca region appears to fluctuate in both the land area under production and the quantity produced, and the general trend appears to be a decline in production. This, however, does not appear to be uniformly the case within the Region. The production of white corn in Coto Brus and Buenos Aires has

Table 8. Costa Rica land area under white corn cultivation by region and selected sub-regions, by agricultural period, 2007/08-2011/12.

\begin{tabular}{|c|c|c|c|c|c|c|c|c|c|c|}
\hline \multirow[b]{2}{*}{ Region / Subregion } & \multicolumn{5}{|c|}{ Area (Hectares) } & \multicolumn{5}{|c|}{ Production (humid and dirty tons) } \\
\hline & $2007 / 08$ & $2008 / 09$ & $2009 / 10$ & 2010/11 & $2011 / 12$ & $2007 / 08$ & $2008 / 09$ & $2009 / 10$ & $2010 / 11$ & $2011 / 12$ \\
\hline Region Central Occidental & & 325.0 & & 200.0 & & & 321.6 & & 210.0 & \\
\hline Region Central Oriental & & 90.0 & 88.0 & 185.0 & & & 104.4 & 88.4 & 13.6 & \\
\hline Region Central Sur & 188.0 & 228.0 & 180.0 & 300.0 & & 188.0 & 396.0 & 300.6 & 315.0 & \\
\hline Region Pacifico Central & 375.0 & 447.0 & 1014.0 & 757.0 & 348.0 & 447.0 & 746.7 & 1583.3 & 2282.6 & 475.5 \\
\hline Region Chorotega & 1040.0 & 2893.0 & 3387.0 & 2510.0 & 1965.0 & 958.5 & 3455.0 & 3446.2 & 2525.8 & 3025.1 \\
\hline Region Brunca & 3491.0 & 1576.0 & 2693.0 & 2875.0 & 2865.0 & 8994.5 & 3706.4 & 7028.3 & 6906.3 & 7081.0 \\
\hline Corredores & 90.0 & 81.0 & 99.0 & 48.0 & 5.0 & 217.0 & 125.6 & 148.5 & 69.8 & 6.2 \\
\hline Palmar Norte & 150.0 & 115.0 & 130.0 & 160.0 & 130.0 & 276.0 & 211.6 & 239.2 & 271.4 & 216.2 \\
\hline Coto Brus & 75.0 & 0.0 & 160.0 & 250.0 & 200.0 & 103.5 & 0.0 & 256.0 & 345.0 & 288.3 \\
\hline Buenos Aires & 290.0 & 425.0 & 525.0 & 575.0 & 675.0 & 816.0 & 927.5 & 1057.5 & 1251.0 & 1096.6 \\
\hline San Isidro/PerezZeledón & 70.0 & 300.0 & 83.0 & 30.0 & 35.0 & 200.0 & 828.0 & 171.8 & 90.0 & 77.0 \\
\hline Puerto Jiménez & 130.0 & 130.0 & 113.0 & 130.0 & 145.0 & 336.0 & 425.0 & 309.8 & 390.0 & 385.0 \\
\hline Laurel & 86.0 & 25.0 & 81.0 & & & 202.0 & 38.8 & 121.1 & & \\
\hline Pejibaye & 2600.0 & 500.0 & 1502.0 & 1682.0 & 1675.0 & 6844.0 & 1150.0 & 4724.4 & 4489.1 & 5011.7 \\
\hline Region Huetar Norte & 4600.0 & 2925.0 & 1928.5 & 1554.5 & 3746.0 & 7590.0 & 8927.5 & 4978.4 & 3528.3 & 13303.0 \\
\hline Region Huetar Atlantica & 355.0 & 742.0 & 424.0 & 243.0 & & 470.8 & 2024.3 & 695.8 & 455.4 & \\
\hline Total & 9694.0 & 8839.0 & 10032.5 & 8805.5 & 9167.0 & 18178.7 & 18128.5 & 19449.5 & 16477.5 & 24340.0 \\
\hline
\end{tabular}

Source: MAG. 2012. Boletín Estadístico.

been fluctuating, but it has increased overall since 2007/08. This, in large part, due to the consistent increase in land dedicated to this practice in Buenos Aires. Many farmers in the region can harvest corn twice a year, and chorreadas, a regional specialty food something like a pancake made of ground fresh corn and sugar, are often endearingly shared 
between neighbors during harvests.

These statistics on the production of basic grains in Costa Rica provide important context for later discussions of local agriculture, employment, and efforts to diversify the agricultural and regional economies as they relate to farmers and communities in the study location. In particular, the recent steady increases in the production of beans and rice across the Brunca region could indicate the effectiveness of national programming in support of increasing the production of these basic grains. These trends could also indicate an increased awareness of the changing agricultural, economic, environmental, and social conditions among farmers. In some ways, it may also harken back to an era, during the 1960s and 1970s, during which Central American countries were extolling the benefits of pursuing the development strategy of import substitution for national development (Redclift 1987). However, export industries continue to play major roles in all areas of the Costa Rican economy, and this is particularly the case with coffee in Coto Brus (Fitzgerald 2013).

There are several other crops, such as the bananas and pineapples mentioned earlier, that should be taken into account in any sketch of agricultural production in Costa Rica. Depending on the context, these crops might take on a role of a commodity for export or a supplementary product for household consumption. As this study moves more towards the interior, premontane parts of the regional landscape and focuses more on the districts of Biolley and Pittier within the cantones of Buenos Aires and Coto Brus, respectively, environmental conditions become less favorable for the production of tropical fruits. Although there may be some effort by households to maintain these crops 
for sale or consumption, they are not the base on which the economies in this districts can realistically be built. Something similar could be said about the maintenance of sugar production and cattle in these districts. However, in many ways the climate is more favorable for the production of these crops, and they hold special places in local agricultural identities. Cattle, in particular, was at one point a major driver of the national agricultural economy and settlement across much of the region (Diaz 2010; Manger 1992).

\section{Sugar and Cattle}

Compared to other Central American countries, Costa Rica is not an outstanding producer of sugar. Figure 4 shows that since 1961, Guatemala has emerged as the leading producer of sugar among Central American countries. Costa Rica, along with most other Central American countries, has consistently increased sugar production, but only by marginal increments. This indicates that for the most part sugar is not a commodity utilized for the purpose of international trade and instead it is generally produced in these countries to meet the demands of local and/or domestic markets.

The photographs in figure 5 demonstrate the character of sugar production across Pittier. It is not at all uncommon to find an old mill, called a trapiche, in the communities of the study region. These trapiches were originally powered by horses, bust most that are still in operation have been converted to be run by a gasoline motor (as is the case with the one shown in figure 4. After the juice is pressed from the sugar cane using the trapiche, it is boiled in a caldron and set in molds. The cylindrical units produced by this process are referred to as tapa dulce. This raw cane sugar extract is used as a general 


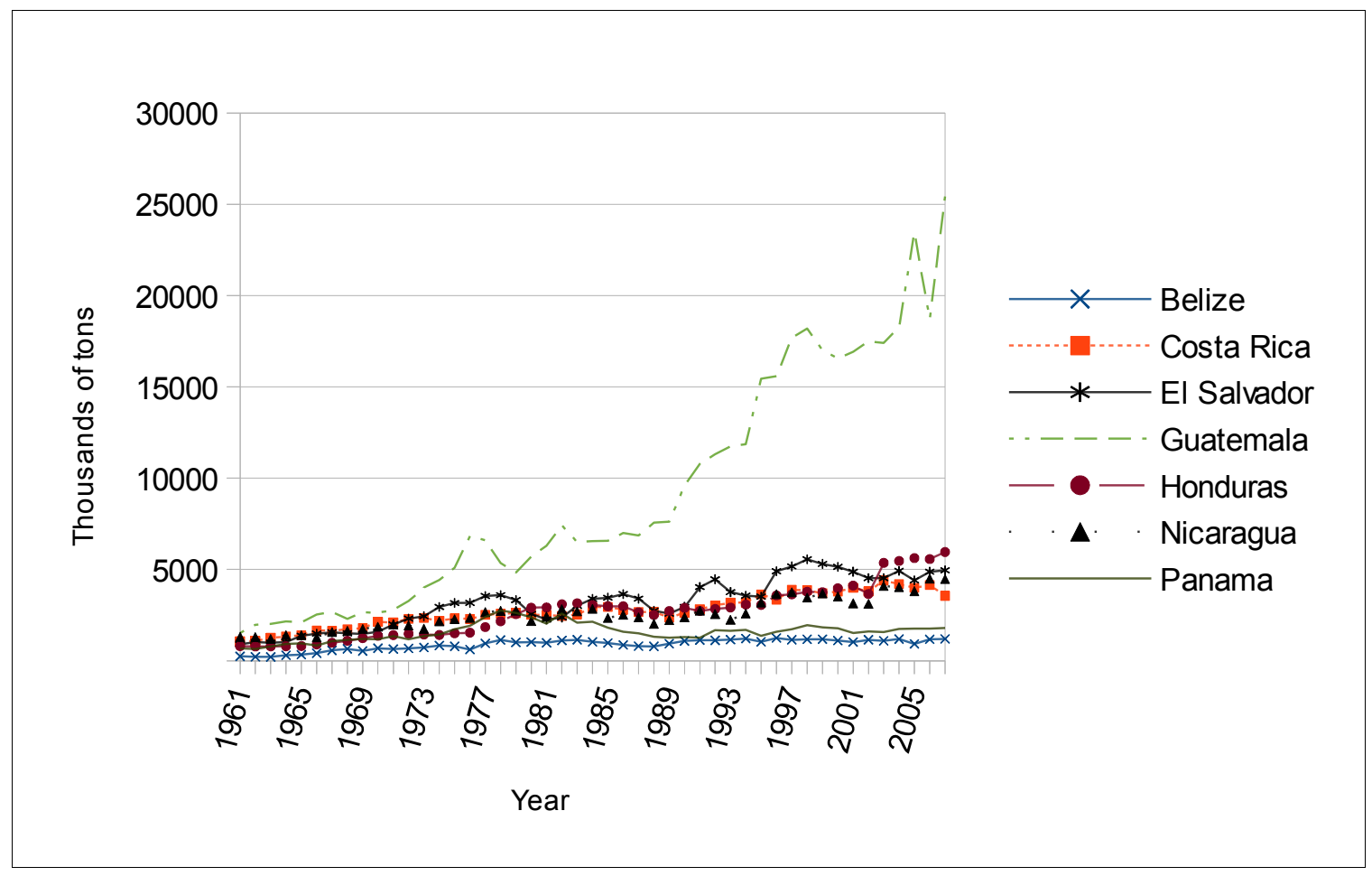

Figure 4. Sugar production across Central American countries, 1961 - 2007. Source: ECLAC. 2012.

sweetener, mostly in beverages, and it is found in most households and local grocery stores. It is also often reconstituted with hot water as served as jugo de caña, cane juice, with meals.

Like the continued production of tapa dulce, raising livestock across the region is an agricultural activity that is typically a small-scale operation. It can take on the character of a subsistence or artisan activity, and it will occasionally be an activity that generates a small amount of income. Some households maintain a few cattle for dairy production, which they might sell or share with other members of the community. There are, however, some farms across the region that include larger pasture operations. Given the conditions of the landscape, climate and infrastructure, such operations are difficult to 

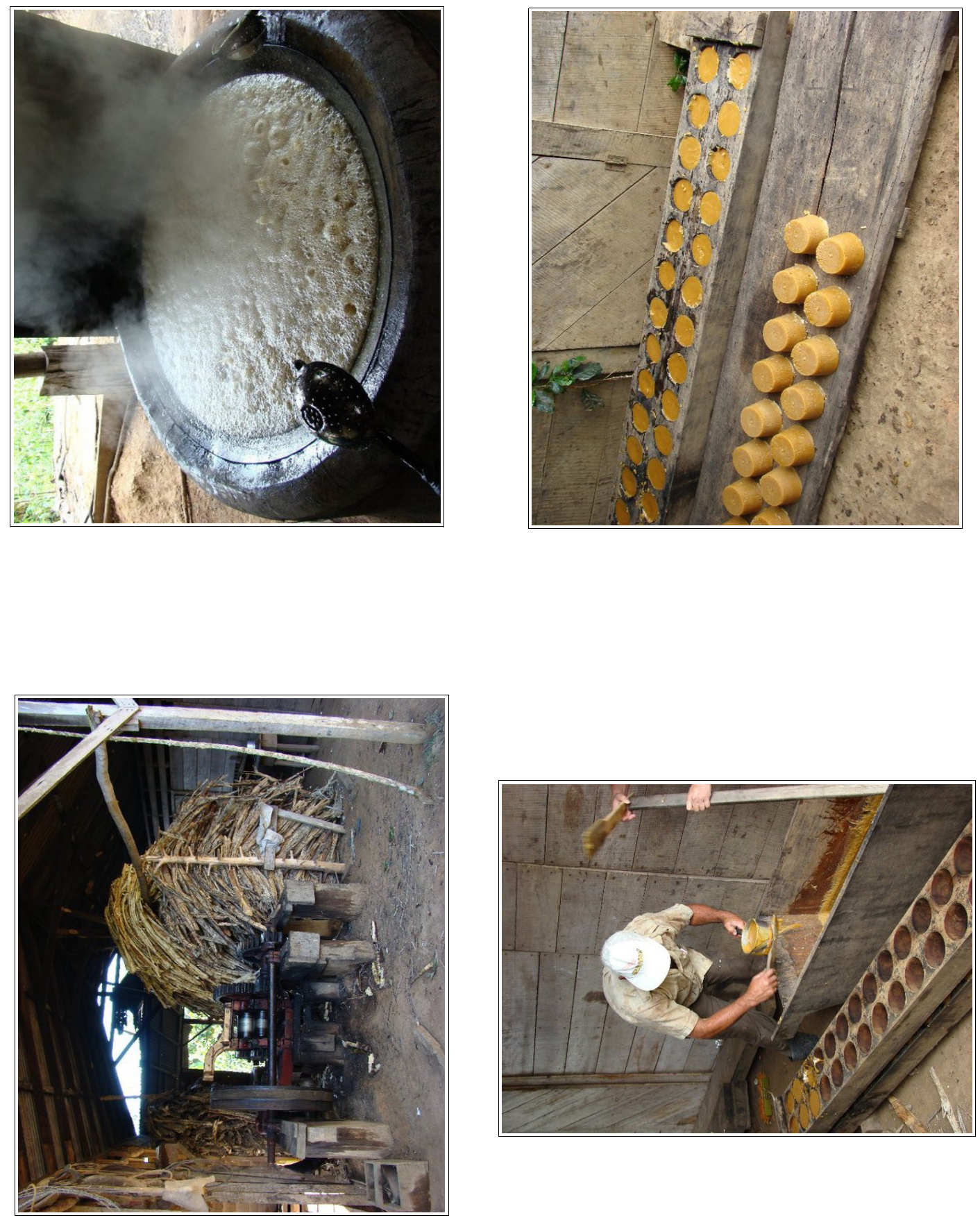

Figure 5. Processing sugar cane to make tapa dulce. 
make profitable. The system of raising livestock tends to be less intensive that is in other parts of the country. At the same time, having even a few cattle traversing a more expansive rugged terrain can have a considerable negative impact on the local, and regional, environment.

A report from The Nature Conservancy (TNC 2004) states that in comparison to Buenos Aires, where there is "a growing process of urbanization connected to the structure of land tenancy in cattle ranching and pineapple plantations...the pattern of settlement [in Coto Brus] is more disperse, responding to the structure of land tenancy in small property, common of coffee growing activity" (32). While my research does not refute this general assessment, it does provide a clearer look at differences between and within districts in these municipalities. As will be demonstrated throughout subsequent chapters, many households in communities across Biolley, Buenos Aires, are involved in a particular mode of agricultural production that emphasizes agroforestry and other sustainable practices in agriculture. In this mode, farmers prioritize and select production activities according to their ability to contribute to multiple purposes, including natural resource conservation, community development, and the diversification of local and regional economies. At the same time, I found there to be a least two distinct modes of agricultural production in agricultural communities across Pittier. While coffee is the base of most agricultural production across the district, cattle ranching largely dominates the remote agricultural landscape surrounding the nearly completely abandoned community of Santa Maria.

According the Costa Rican livestock census of 2000 (CORFOGA 2000), the 
Brunca Region, which includes Buenos Aires, Coto Brus and other municipalities across ACLAP, is,

a region of small producers dedicated to raising livestock for meat, primarily by fattening. It can be deduced that the concentration of cows is associated with a low level of dairy activity. The average size of farms is 30 hectares with 19 animal units per farm and presents the lowest animal load of the country $(0.64$ animal units per hectare). This is the result of having a mixed system of production, small farms, and a tendency of the soils of the region to be of the lowest quality. Despite the current low production index levels, this is a region that is considered to be have large potential for livestock, above all because of the dedication of its producers and for the progress of its organizations (10).

Although the census describes the livestock management in Brunca Region in this manner, MAG (2003) points out that in order for the region to meet its livestock-raising potential it would likely require major modifications of the regional landscape and ecology. As will discussed more in Chapter 3, there are multiple reasons farmers manage livestock across the region. Profit maximization through increased production is only one of the opportunities that livestock present to farmers in the region, and it is perhaps not even the most sought-after. With a limited labor force and cumbersome land use restrictions in terms of maximum allowable height of vegetative cover, many farmers rotate a few cattle over several pasture areas to keep both management costs and scrub growth low.

The decreased profitability of cattle ranching in Costa Rica corresponds with the decrease in emphasis placed on this activity by the national government. Beef production as part of Costa Rica's agricultural economy increased significantly during the era of forest colonization following WWII. As shown in figure 6, Costa Rican beef exports then peaked in the early 1980s, during the period in which the fast-food industry in the United 
States was rapidly expanding (Edelman 1995). Shortly thereafter, reflecting a shift in national policies in both agricultural and environmental ministries, pasture area in Costa Rica began a marked decline that continued through the 1990s. During this period, raising livestock in many places became an increasingly difficult proposition. Without the further establishment and maintenance of infrastructure and lacking the continued provision of financial and other means of support for production from the central government, raising livestock was especially difficult in some of the more remote places they often had to deal with rugged terrain, frequent heavy rainfalls, and other difficult conditions.

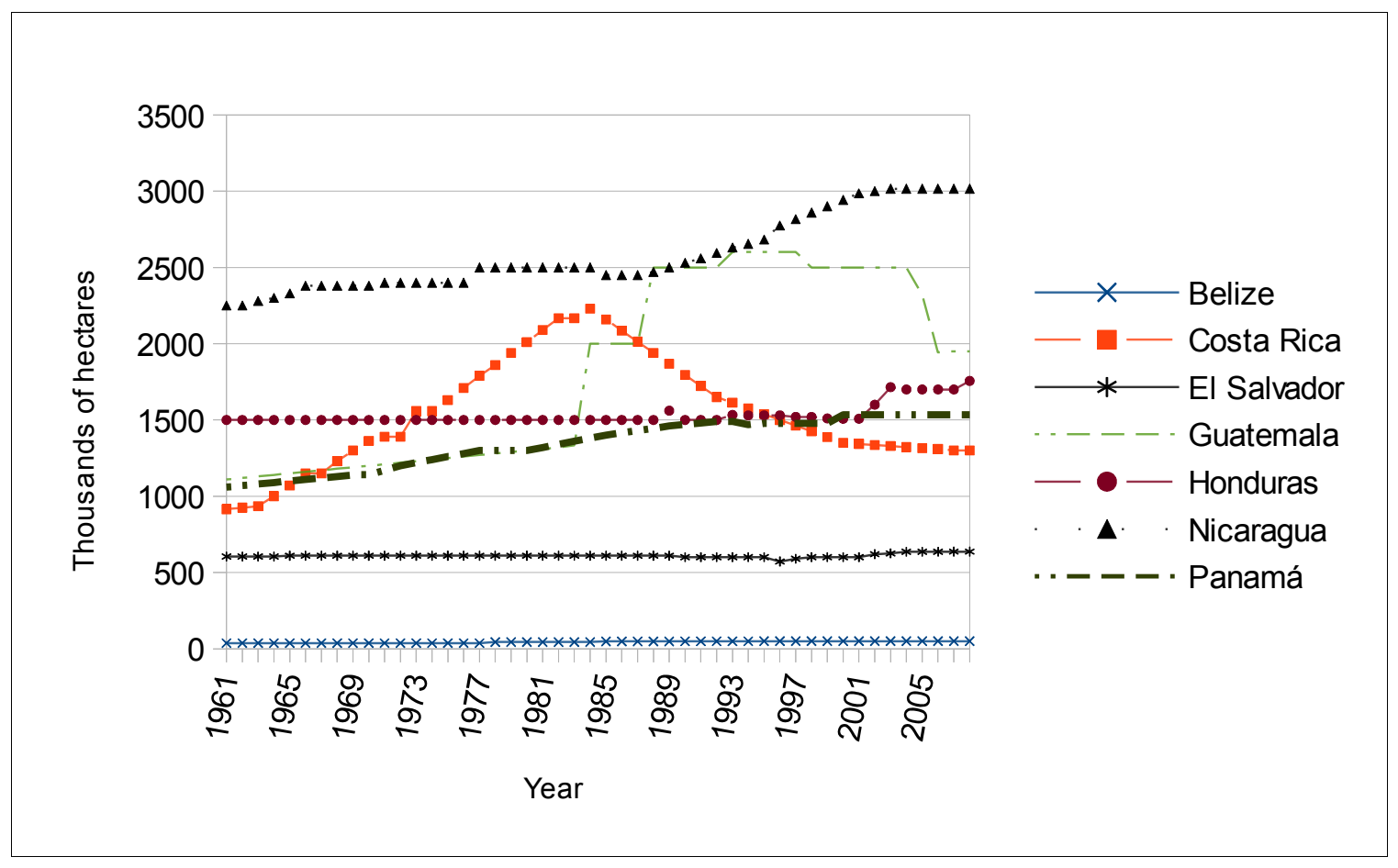

Figure 6. Pasture area for Central American countries, 1961 - 2008. Source: ECLAC. 2012.

Before I move on to discuss natural resource protection in Costa Rica, it is worth taking a brief pause rather than draw preliminary conclusions about agricultural 
communities across the study location. As has been shown, the types of agricultural activities found in different places across ACLAP can vary greatly and often do so according to local conditions and political interests across multiple levels governance. In later chapters, this initial assessment of the agricultural economy of the region will be supplemented with a focused comparative analysis of agricultural communities within the districts of Biolley and Pittier. As part of this analysis, the relative influence of grassroots actors, including individuals and community organizations, and outside interests in local development is also evaluated.

\section{Natural Resource Protection in Costa Rica}

Although Costa Rica has a reputation as a country that places high value on the protection of its natural resources, this has not always been the case. As recently as the 1980s, Costa Rica, along with many Central American countries, shared the distinction of having the highest rates of deforestation in the world (Carriere 1991). Especially between 1960 and the early 1980s, forests in Costa Rica were being removed from the land at an alarming rate. According to Evans (1999), "as late as 1950, 90 percent of the country remained in forest cover, but by 1990 the figure had dropped to only 25 percent" (39-40). Although the country's contemporary approach to development emphasizes environmental protection, the conservation of natural resources and sustainability, it important to acknowledge this is the outcome of dramatic and determined efforts by many Costa Ricans and international actors. Over time, the country established its now much-renowned parks system and solidified the formation of national agencies that support the several types of protected areas designated by the 1994 national Conventional 
on Biological Diversity (INBIO n. d.). Throughout the remainder of this section, I will briefly review how national and international relations, primarily since the 1960s, contributed to the evolution of contemporary natural resource management in Costa Rica. I will also outline how some of these relationships are materialized in the involvement of transnational agencies in resource protection in Costa Rica today.

The emergence of a system of national parks from the Ministry of Agriculture (MAG) during the 1970s and 1980s required a considerable amount of collaboration between scientists and politicians (Campbell 2002). Leading up to this event, there were many influential figures in Costa Rica history whose efforts laid the groundwork for this institutional change to take place. These figures include past presidents and members of their families and administrations (Steinberg 2001; Evans 1999), provincial leaders, and international scientists (Yacher 2004; Allen 2001). Several of these figures have also had significant impacts on the directions of local and regional development, and their efforts gave shape to many of the government and non-governmental agencies that are now responsible for managing protected areas and supporting sustainable development across the country (INBIO n. d.).

The formation of MINAET, the agency largely charged with the oversight of natural resource protection in Costa Rica, has deep roots in lobbying efforts within MAG throughout the 1970s. The long process began with the establishment of the National Forestry Directorate and continued to move forward until the National Parks Service was established in 1977. In 1986, the Parks Service was transferred out of MAG and into a newly formed Ministry of Natural Resources, Energy and Mines (MINEREM), which 
would eventually evolve into what is today the multifaceted Ministry of Environment, Energy, and Telecommunications (MINAET). The conservation programming of MINAET, as contrasted with its programming in energy and telecommunications, is organized geographically according to the areas designated by the SINAC (figure 7).

In many places, the territorial designations of the conservation area system appear to follow prominent landscape features, especially major watersheds. In this sense, the isolation of forested mountains, central valleys, and coastal regions can facilitate the careful, scientific study of distinct environments (Callon, Lascoumes, and Barthe 2009). These areas are often divided further conceptually by scientists and natural resource managers into "life zones" based on local they depend are not always even decisively clear and stable in their own right, and their variations in factors such as temperature,

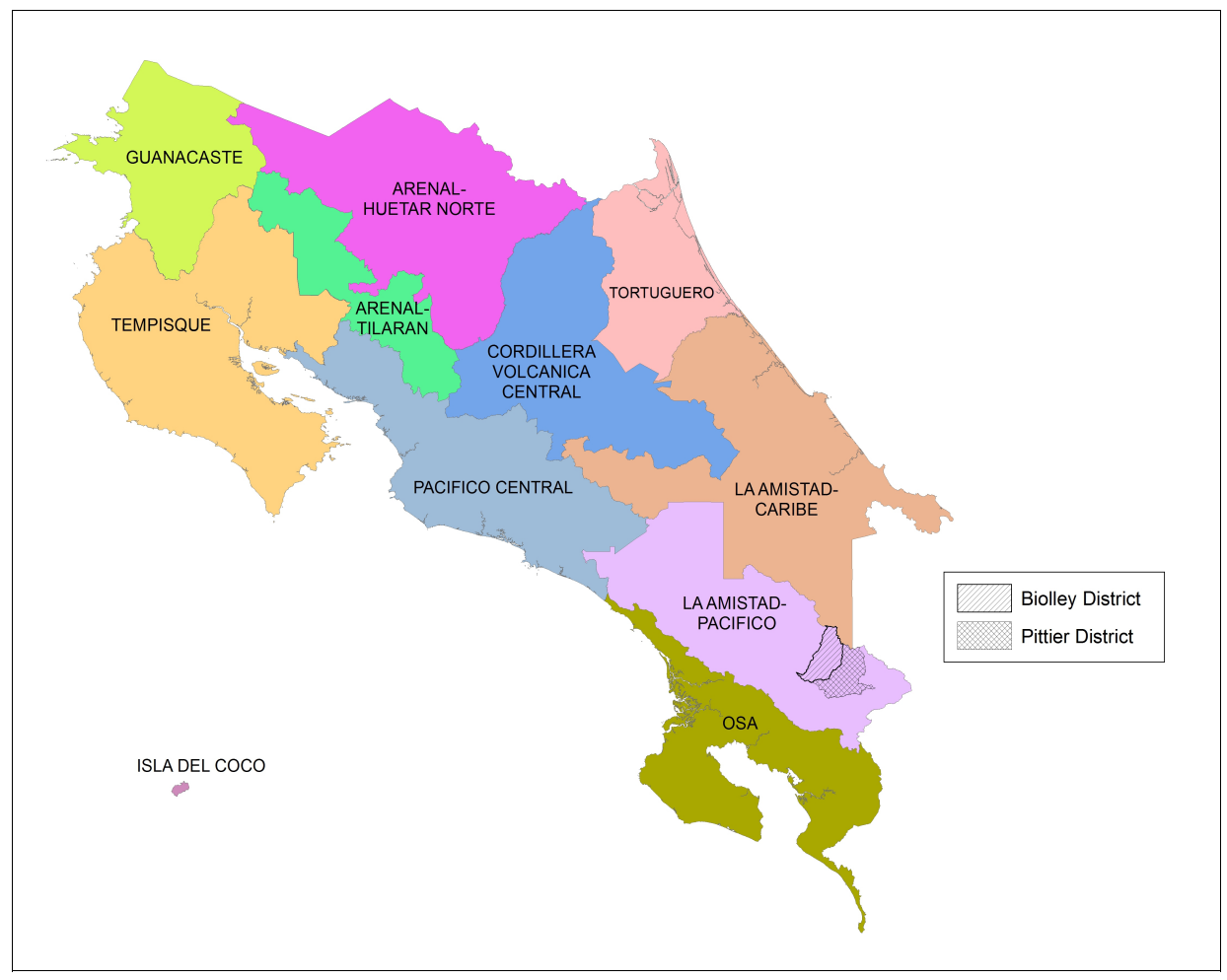

Figure 7. Costa Rican conservation areas. 
climate, and vegetation (Holdridge 1967). While these divisions may be helpful for certain purposes of research and management, the layered boundaries they produce between political and administrative units of multiple government agencies can complicate broader sustainable and integrated development efforts (Brandon 2004; Umaña and Brandon 1992).

While there are numerous central government agencies with explicit interests in the country's natural resources, their unique political interests and various initiatives and mandates lead them to approach development differently. At times, these agencies differ in how they view the trade-offs between resource protection, or conservation, and use. Given the overlapping territories of interest between government agencies, and the varied geopolitical organizations of these otherwise centralized agencies, uncoordinated development could easily produce counter-productive, if not competitive, activities. Without coordinated development efforts, the potential for problems related to natural resource management in areas where multiple government agencies claim jurisdiction will likely be high. Despite the potential for the local implementation of government programs and projects to be laden with conflict, the agencies involved in rural development in Costa Rica are parts of the same centralized government structure. In many ways, they are also bureaucratic and highly dependent on their geopolitical designations of territories for organizing, implementing, and integrating their development efforts.

The regions utilized by the Ministry of National Planning and Political Economy (MIDEPLAN) and MAG, which were presented in the previous section of this chapter 
and shown in figure 3, are based primarily on the grouping together of cantones.

Although these regions appear similar in size to the provincial-level units of the national government, in many places they often cross provincial boundaries. As mentioned before, these planning units are sometimes referred to as either "socio-economic" or "functional" areas, although the logic behind grouping cantones from different provinces in these regions is difficult to ascertain. Other agencies involved in the management of natural resources, such as the Institute of Water and Aqueducts (AyA), the Institute of Electricity and Telecommunications (ICE) and the Costa Rican Fund for National Forestry Finance (FONAFIFO), also tend to have their own unique histories and administrative areas (Dorn 1989).

Overlapping areas of interest between agencies like MINAET, MAG, ICE, and AyA can be centers of tension, especially when it comes to establishing and maintaining working relationships with community governments. As we will see later, these tensions are exacerbated when agencies have established a certain reputation in local communities and then attempt to reform policy and practice or develop an interest in establishing a physical presence in a location where they did not previously have one. For example, when the period of rapid agricultural expansion was met with the establishment and enforcement of park boundaries, in the early 1980s, the requirement for heavy monitoring of land use practices in some areas forced MINAET into the position of local law enforcement agency.

So the relation is tense, little communication and mono-thematic (hunting and deforestation). The relation between MINAE[T] and the society of these districts is structured around these themes, that are obviously not friendly means of communication. The epithets that are sometimes heard about one another are sometimes very strong and evidence of discontent and tension (TNC 2004, 40). 
Conservation agents are often given the difficult tasks of enforcing borders and imposing cultural and economic changes on households whose livelihoods have in the past involved close, albeit at times illegal according to the state, relationships with natural resources. Administrative officials and park rangers have had to assist in the relocation of some household farms, they prohibit entry into protected areas, and they constantly monitor development activity, especially in the buffer zones adjacent to core protected areas. These responsibilities can make maintaining close relationships and a good image within rural communities extremely challenging anywhere (Schelhas and Pfeffer 2008). Nevertheless, according to policy the focus of these efforts is on maintaining the biogeographical integrity of regions and protecting important ecological processes. At the same time, natural resource managers are encouraged to support the participation of local communities in the planning and implementation of protective measures (INBIO n.d.).

Compared to the amount of area protected by their Central American countries, Costa Rica has an average proportion of its land area under some form of protection (figure 8). While other countries may have larger proportions of land designated with protected area status, Costa Rica's system of protected has some distinguishing characteristics. In Costa Rica, there is a relatively large proportion of land under some form of private protection (Langholz and Lassoie 2001). This adds the requirement of understanding a complex social structure involving a large number of national and international actors to the list of other requirements necessary for any agency dedicated to the protection and management of the country's natural resources. Table 9 shows the growth in both public and private protected areas in Costa Rica for the period between 


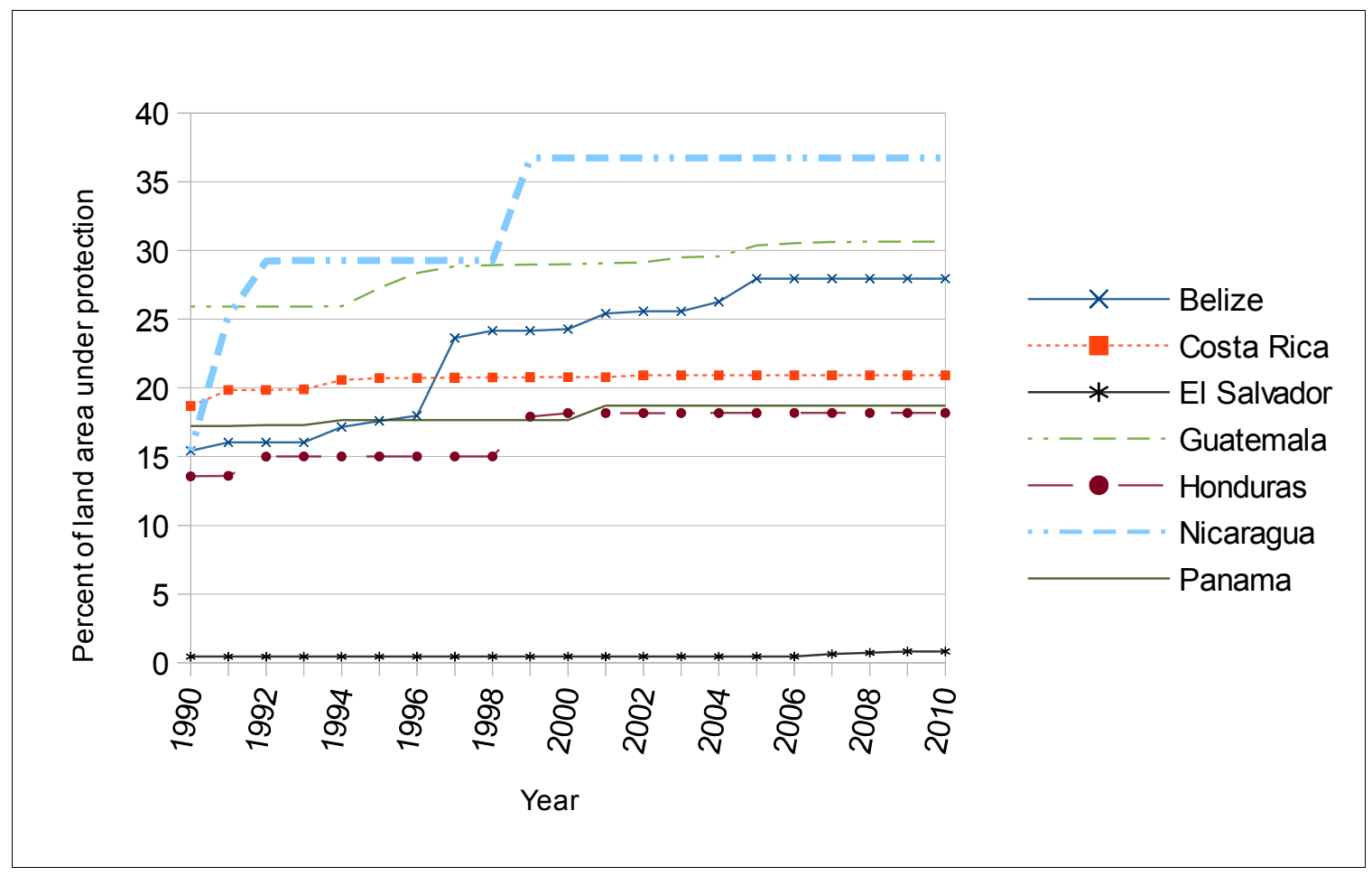

Figure 8. Proportion of land area under protection across Central America countries. Source: World Database on Protected Areas. 2013.

1991 and 1997. The increases in the numbers of National Parks and Protected Zones indicate the increased establishment of public protected areas during this time. The categories of Wildlife Refuges and Biological Reserves are those in which most of the increases in private protected area is measured. The differences underlying these designations and their implications for management at the local, regional, and national Table 9. Protected area designations in Costa Rica and changes over time, 1991 - 1997. Source: INBIO (n.d.).

\begin{tabular}{|c|c|c|c|c|c|c|c|}
\hline \multirow{2}{*}{ Management Category } & \multirow{2}{*}{ IUCN Equivalent } & \multicolumn{2}{|c|}{1991} & \multicolumn{2}{|c|}{1993} & \multicolumn{2}{|c|}{1997} \\
\hline & & \# of areas & Total Hectares & \# of areas & Total Hectares & \# of areas & Total Hectares \\
\hline National Park & $\|$ & 14 & 465,699 & 20 & 505,484 & 24 & 541,576 \\
\hline Biological Reserve & $\|$ & 7 & 17,653 & 8 & 30,482 & 9 & 39,644 \\
\hline National Monument & $\|$ & 1 & 218 & 1 & 218 & 1 & 218 \\
\hline Forest Reserve & VI & 13 & no data & 9 & 312,930 & 12 & 291,513 \\
\hline Protected Zone & VI & 21 & no data & 27 & 188,350 & 31 & 178,677 \\
\hline Wildlife Refuge & IV & 9 & no data & 9 & 117,483 & 39 & 181,018 \\
\hline Wetland & IV & 0 & no data & 0 & 0 & 14 & 50,465 \\
\hline Natural Monument & VI & 0 & no data & 0 & 0 & 0 & 0 \\
\hline Total & & 65 & $1,094,414$ & 74 & $1,154,945$ & 132 & $1,284,543$ \\
\hline
\end{tabular}


levels are all things that natural resource managers need to give careful consideration to when planning for management. As these implications of international and neighboringarea designations are taken into account, the management of any particular area will likely be a great deal more complicated than it would be if national or local authority were universal.

International interests in natural resource conservation are present in rural Costa Rican communities in a variety of other forms. Cover pages of studies and reports on conservation across the country are usually replete with the logos of agencies such as the United States Agency for International Development (USAID), the United Nations Environment Programme (UNEP), or The Nature Conservancy (TNC). Other examples indicative of international influence in natural resource protection in Costa Rica are the coordination of community-led taxonomic efforts, environmental education programs, and the promotion of community development through the adoption of practices like agroforestry and ecotoursim. In particular, since its founding in 1989 the National Biodiversity Institute (INBio) has been effective at implementing such projects with the aid of investments from international corporations and debt-for-nature agreements.

The international community also plays a role in the protection of natural resources in Costa Rica through the formal recognition of the La Amistad Park as an international park granted by the United Nations Educational, Scientific and Cultural Organization (UNESCO). For the purposes of this study, the transnational boundary of the La Amistad International Park (PILA) is shown along with the Conservation Areas in figure 9. PILA encompasses approximately 1.24 million acres and actually comprises two 


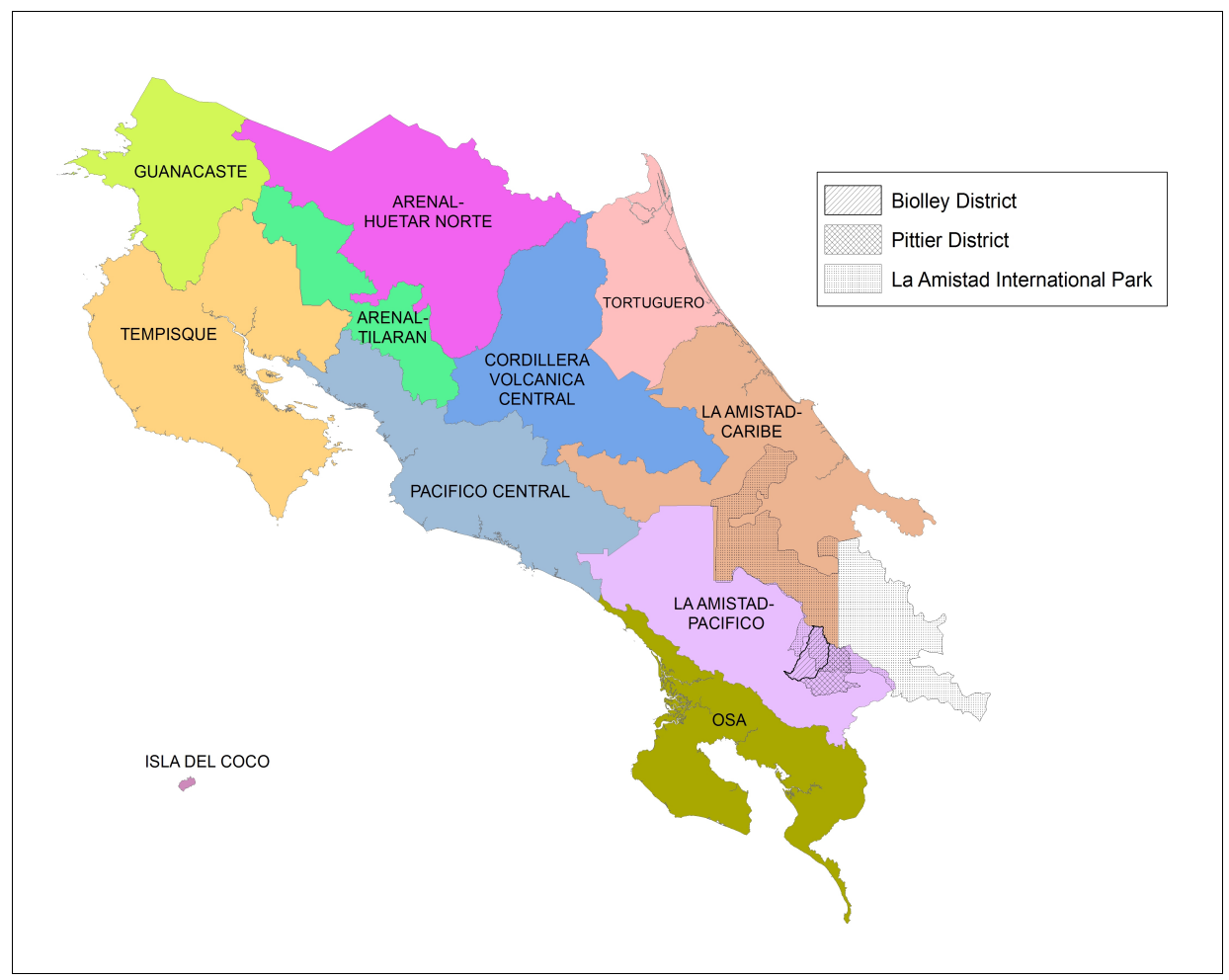

Figure 9. Map of PILA and surrounding territories

national La Amistad Park areas. There are separate La Amistad parks in Costa Rica and Panama, with about 584 thousand hectares in Costa Rica and 655 thousand hectares in Panama, and responsibility for management falls primarily on the shoulders of the respective national conservation ministries. However, La Amistad Park areas are most often referred to using the name that designates the entire as an international park.

This region is highly regarded for its unique biodiversity, and in 1982, following a great deal of effort from national and international scientists and politicians, UNESCO, a special agency within the United Nations, formally accepted the request for park designation from the Costa Rican and Panamanian governments. Just one year after declaring the region a biosphere reserve, in 1983 UNESCO also recognized PILA as a World Heritage Site (TNC 2004, 3). 
An overview of The World Heritage Convention helps show how there is considerable potential for overlap between its area designations and those of international conservation agencies. The Convention sets out the duties of States Parties in identifying potential sites and their role in protecting and preserving them. By signing the Convention, each country pledges to conserve not only the World Heritage sites situated on its territory, but also to protect its natural heritage. The States Parties are encouraged to integrate the protection of the cultural and natural heritage into regional planning programs, set up staff and services at their sites, undertake scientific and technical conservation research and adopt measures which give this heritage a function in the dayto-day life of the community.

The details of establishing boundaries around protected areas and implementing other aspects of conservation projects on the ground often need to be dealt with after formal designations are made. This is reflected in the way organizations, including governments, designate areas of relative importance for units of administration and draw on their power to mobilize resource in implementing works (Dorn 1989). Although rarely straightforward, most of this is achieved at higher levels of society. Success in implementation, however, usually depends to a much greater extent on acceptance of programming by community organizations. Therefore, what is also being pointed to in transnational narratives on resource protection is that sustainable development needs to involve careful consideration of unique political circumstances that surround particular locales (Basurto 2013a, 2013b). In order to better protect natural resource management, development programming has to do a better job of integrating multiple perspectives of 
human and environmental systems found in rural places.

Additional formal recognition of the area by the international conservation community comes from the Man and the Biosphere Reserve Programme (MAB), located within UNESCO, with the following directive.

The MAB Progamme develops the basis within the natural and social sciences for the rational and sustainable use and conservation of the resources of the biosphere and for the improvement of the overall relationship between people and their environment (UNESCO n. d. a).

Biosphere reserves are considered learning sites for sustainable development and are usually proposed as the result of an initiative taken by one or more national governments. Generally, these reserves are intended to promote sustainable development based on local community efforts and sound science. These Biosphere Reserves are,

places that seek to reconcile conservation of biological and cultural diversity and economic and social development through partnerships between people and nature, they are ideal to test and demonstrate innovative approaches to sustainable development from local to international scales (UNESCO n. d. b).

After site designation, biosphere reserves remain under national sovereign jurisdiction, yet they share their experiences and ideas internationally through the World Network of Biosphere Reserves (WNBR).

Although the purposes of biosphere reserve designation explicitly include the integration of human, social, and cultural aspects of these places, the mention of "sustainable use" is largely overlooked as it relates to development programming. The same phrase, "sustainable use," is mentioned more often in national legislation regarding the management of protected areas, and thus it represents a notion that plays a greater part in the day-to-day negotiations between officials of national government agencies. 
Transnational interests in this arena tend to be more in line with the protection of natural resources and wildlife habitat than they are with the development of human communities (Wilshusen, Brechin, Fortwangler, and West 2002). Their areas of focus range from the protection of key species of plants and animals to the general protection of watersheds or forests.

UNEP is another United Nations agency with an interest in conservation in Costa Rica (UNEP n. d. a). UNEP is one of the main offices of the United Nations and it operates outside the UNESCO framework with the following mission:

To provide leadership and encourage partnership in caring for the environment by inspiring, informing, and enabling nations and peoples to improve their quality of life without compromising that of future generations (UNEP n. d. b). Again, this agency emphasizes integration, or collaboration between partners, and the mention of "future generations" in its mission statement resonates with notions of sustainable development. Unlike international agencies with particular interests in the designation and protection of specific parks and/or resources, UNEP places more emphasis on working to increase capacity and efficiency within environmental organizations like MINAET and SINAC (UNEP n. d. c)

The International Union for the Conservation of Nature (IUCN) supports conservation efforts in Costa Rica through funding research and programming, and it provides the following definition for protected areas.

A clearly defined geographical space, recognized, dedicated and managed, through legal or other effective means, to achieve the long term conservation of nature with associated ecosystem services and cultural values (IUCN n. d.).

As other international conservation organizations do, IUCN points to the importance of balancing the relationships between humans and the environment in development. 
Although other area designations, such as World Heritage Sites, may not usually be considered as "protected areas," the agendas of all of these international agencies are brought together in their use of rhetoric expressing an interest in sustainable

development. Overall, these agencies and view their work and design programs according to their broad interests in strengthening human and environment relations and providing development opportunities for future generations.

\section{Political Decentralization in Costa Rica}

While agriculture and conservation interests motivate most of the economic development activity across the study location, in this last section I want to briefly refer back to the framework for integrated development presented in figure 2 to highlight the importance of political structures in understanding development in this national setting. Understanding the initiative and interests of the national decentralization initiative in Costa Rica will also be helpful later when considering the articulation of formal and informal community organizations with the works of centralized national government agencies.

The Institute of Municipal Development and Evaluation (IFAM) is at the top of the center column in figure 2 , which provides an outline for the formal hierarchical structure of the process of political decentralization in Costa Rica. As it is directed by national policy, this process logically flows from the top down, and it can be described as an attempt to transfer power and responsibility to "local" governments across the country. While there are implications of this policy for the operation of district and community level governments, the focus is primarily on strengthening municipal level governments, 
or cantones. Thus, the relationship between the central government and the municipal governments becomes the primary step down in the hierarchy, jumping over the provincial governments, whose roles in the government of Costa Rica have been significantly reduced over time, and especially since the 1980s (Dorn 1989).

This move towards political decentralization can be taken into account as part of a similar movement across the developing world (Lutz and Caldecott 1996), Latin America (Tulchin and Selee 2004), and Central America (Annis 1992). It can also be articulated with movements towards decentralization within particular national government agencies. For example, recognition of the potential benefits of decentralization for natural resource management was a major motivation for the creation of the National System of Conservation Areas (SINAC) (Brandon 2004). The creation of these Conservation Areas was a division of administrative labor as well as an opportunity to better evaluate the local conditions of natural resources and encourage citizen participation. Ultimately, the formation of Regional Councils within Conservation Areas was perhaps the lowest level to which the decentralization within this particular agency reached. As Larson (2003) points out, many countries are using environmental management as a basis for decentralization, linking national, regional, and local levels of environmental governance through the establishment of environmental councils or commissions.

Whether for the purpose of improving natural resource management or fiscal responsibility, decentralization is almost always framed as an effort towards improving democracy and increasing citizen participation in government (IFAM 2011). The process usually involves the designation of a geographic area to be coupled with power and/or 
responsibility for administration. As discussed in earlier sections of this chapter, almost every government agency in Costa Rica has at some time created its own area for organizing operations (Dorn 1989). With the social democratic form of government in Costa Rica, many goods and services are historically provided by the government. Although privatization of some industries has been occurring more recently, the situation is one in which many government agencies provide goods and services according to individual agency administrations, which are shaped by numerous unique area jurisdictions. In the past, few of these agencies were thinking about involving citizen participation in their work as part of this process. Their operations were structured by the characteristics of the landscape, political climate, or other factors that were most relevant to their type of business. They were focused on citizens as customers and their own roles as providers of goods and services. More so now, as many of these economic activities are being opened to private investment, agencies with activities likely to remain in the public domain are looking for ways to increase public participation and economic efficiency. One example of this is the support provided by the Institute for Electricity and Telecommunications (ICE) to local watershed councils, which can be tasked with responsibilities ranging from infrastructure maintenance and fee collections to natural resource management (Sims and Sinclair 2008; IIED n. d.; ICE n. d.). In addition to the supposed benefits that the process provides for democratic governance in general, many see decentralization as an opportunity to improve the provision of public goods and services.

Nearly $98 \%$ of all public spending in Costa Rica is being done by the central 
government. Therefore, any shift towards the local provision of public goods and services will require an adequate transfer of resources to municipal governments (IFAM 2011). While making such a transition will require a large initial effort, some people argue that it is necessary in order deal with the inefficiencies and corruption that have become regular parts of a centralized bureaucratic government. At the same time, decentralization is seen as presenting opportunities to address imbalances that exist in local power structures (Salas 2011; Salas and Alfaro 2002).

The processes of government centralization in Costa Rica began with President Braulio Carrillo in 1842 when it was deemed necessary to shift power away from the provincial governments units, and their governors. At the time, this was seen as a liberal political move and it paralleled the transition of the national economy to one based on agricultural exports. As the economy of the country developed around the production of a few key agricultural commodities, the establishment of international trade relations was facilitated by a commanding central authority (Madrigal 2011). Contemporary critics of decentralization in Costa Rica argue that a centralized administration makes sense given the small size of the country. They also argue that the centralized provision of public goods and services is in the best interest of the country and its citizens. They view the centralized system as being potentially more efficient and consistent, and they believe it makes more sense than having so many local governments take on these responsibilities independently. Not only do they see decentralization as ineffective and inefficient, they are also concerned that it will sacrifice the quality goods and services, such as education, that are provided by the government (Jiménez 2012). 
Decentralization is considered by others as a process that involves more than the transfer of the regular business of the central government to local governments. They attempt to differentiate between types of decentralization depending on the degree to which they remain reliant on the bureaucracy and hierarchy of a centralized government. For example, some juxtapose description of "deconcentration," a process through which government activities are shifted to lower-level departments of a centralized organization without any significant shift in power or structural change, with a more democratic form of "decentralization," which requires the transfer of decision making power and fiscal authority along with the responsibilities for program design and project implementation (Salas and Alfaro 2002; Dorn 1989). From a perspective critical of formulaic deconcentration, the 2001 government budget reform that resolved to eventually transfer $10 \%$ of the national government budget to spending by local governments needs to be accompanied with the placement of municipal governments in charge of programming for education, health care, transportation, etc.

While decentralization takes on a different character in Costa Rican national government and its various departmental agencies, there are also a number of transnational agencies taking a decentralized approach in their development strategies. As shown in part in figure 2, international agencies can enter this framework in a variety of ways. They can partner with official government agencies and programs, or they operate more freely at the municipal, district, or community levels as non-governmental organizations. This is important to keep in mind when studying development in this research context because at different points development activity in the region is being 
guided by transnational interests that may more readily acknowledge the territorial jurisdictions of the central government or any of its various agencies. These interests may be specifically linked to a cause, such as natural resource conservation, or they may have a more general interest in research or education. Whatever the case may be, they potentially bring various types of influence and resources to bear on development within the region. The strategy of establishing a Territorial Action Group (GAT) is one example in particular of how international interests can collaborate with and challenge the national process of political decentralization in the context of regional and/or local rural development (IICA n. d.).

The GAT approach is heavily integrated into the work of the Inter-American Institute for Cooperation in Agriculture (IICA) and can be an effective way to mobilize resources in rural development outside of the confines of government bureaucracies. Again, the idea is to identify a territory and group of interested parties and organize a plan for regional development, usually based on agricultural production, but also could include tourism or other rural livelihood opportunities. It is also important to point out that these types of decentralized efforts have the potential to introduce a destabilizing, or debilitating, affect on existing arrangements within and between existing national and local institutions if they are motivated by predominately by a special development interest. They can be situated in unique positions at the regional level to support the efforts of grassroots associations or other local agencies, and they possess the potential bring an outside presence into the local development arena that could potentially be as dominating as interests that move through the channels of a centralized national 
government. While many of these types of networked relationships will involve representatives from government agencies to some degree, they are not usually explicitly referred to in the policies of the national political administration. Problems of interagency collaborations have been identified as problematic by researchers across the study region (Wishnie and Socha 2003); however, the national political decentralization campaign is largely aimed at addressing the technical issues related to the transfer of finance and administrative responsibilities to the government of cantones across the country. GATs tends to be focused on the strengthening of the municipal political institutions themselves. In the study location, GAT-SUR has GAT-BAJO and GAT-ALTO divisions focused on promoting sustainable development and building the technical capacities of municipal governments in areas such as management, logistics, and finance. 


\section{Chapter 5: Agriculture and the Environment in the La Amistad Pacific Conservation Area}

General accounts of deforestation as part of a process of agricultural expansion in developing countries are common in academic literature and familiar to natural resource managers. The intensification of industrial agriculture, implementation of structural adjustment programs, and the articulation of international commodity markets all played timely roles in facilitating this process. Whereas research often portrays political economic systems and flawed development policy as major culprits of environmental degradation, peasants also tend to be portrayed as complicit and unaware of their own involvement in this process (Zimmerer 1996; Sundberg 1998; Nygren 2000; Agrawal 2005). There are real agro-ecological and social tensions embedded in historical accounts such as these, and these tensions remain despite attempts to more accurately depict local development histories.

For the most part, descriptions of the history of agriculture and land use across the La Amistad Pacific Conservation Area (ACLAP) fit with traditional narratives on the expansion of the agricultural frontier across Latin America. Large areas of land were deforested for the purposes of agricultural settlement, or colonization, and to increase national revenues through increasing the production of agricultural commodities for export (Carriere 1991). National government policies provided favorable conditions for this expansion of agriculture, and many settlers involved in the process were motivated by a desire to work on and own their own piece of land (Evans 1999). Unfortunately, as has often been the case in these types of situations, there were few long-term plans to 
maintain investments in infrastructure or care for the quality of the land upon which the people of the region were soon to become dependent for their livelihood. This can be particularly problematic in regions such as ACLAP, where soils only maintain fertility for a period shorter than a lifetime of a farmer without intensive management once their forest cover is removed (Carpenter, Mayorga, Quintero, and Schroeder 2001).

With the establishment of the La Amistad International Park (PILA) in 1982, expansion of agricultural activities into the protected area were halted almost immediately. In the past, some communities needed to be relocated and there was a period of years during which park rangers felt the need to carry firearms for personal protection (personal communications). Today, many farmers across the districts of Pittier and Biolley regard PILA with great favor. Some farmers describe the park as a "source of life." It is widely appreciated for the provision of pure air and water. The park is also a great source of pride among neighboring community members because it is viewed an asset for regional development. It serves as an example of a strong system of national park system, and it is believed to be a valuable part of world heritage.

In the remainder of this chapter, I evaluate the working hypothesis that historical relationships between farmers, local organizations, and conservation and development agencies are related to differences in the patterns of development encountered in Biolley and Pittier. To do this, I first explore the context of regional development by drawing on historical accounts of development and my experiences as a participant observer during fieldwork. I begin by looking at the history of settlement, focusing specifically on land use patterns and events of local relevance. With the help of words from farmers, I make 
an important distinction about the sometimes ambiguous use of the term "park." I present descriptions of the park and the relationships between park management and people living in communities near the park as they are provided by community residents. Throughout this presentation, I group data at the district level and identify differences to facilitate description and comparison.

\section{The History of Land Use and Community Relations in the Region}

Figure 10 provides a chronological outline that provides additional support and organization to this chapter. At the top is the General Trend Towards Agricultural Expansion \& Deforestation that took place across the region from the 1960s through the early 1980s. Unlike in many places in Costa Rica and across Central America, this aspect of international industrial development did not have a significant impact on ACLAP until several years after World War II. However, as mentioned in the Introduction, once it started, deforestation happened quickly and extensively across the region (Steinberg 2001; Evans 1999; Carierre 1991).

Figure 10 shows two major subsequent events that had an impact on land use in ACLAP at the regional level. The establishment of PILA in 1982 and the global coffee crisis that began shortly thereafter (Babin 2012; Bacon, Méndez, Gliessman, Goodman, and Fox 2008). As the settlement of agricultural communities in the region slowed due to the enforcement of park boundaries, global coffee prices and demand for beef exports were also declining. As will be discussed in more detail later, many farm families, such as those settling in Santa Maria, Pittier, were still in the process of establishing themselves in the region when park boundaries were put in place. At the same time, there were 


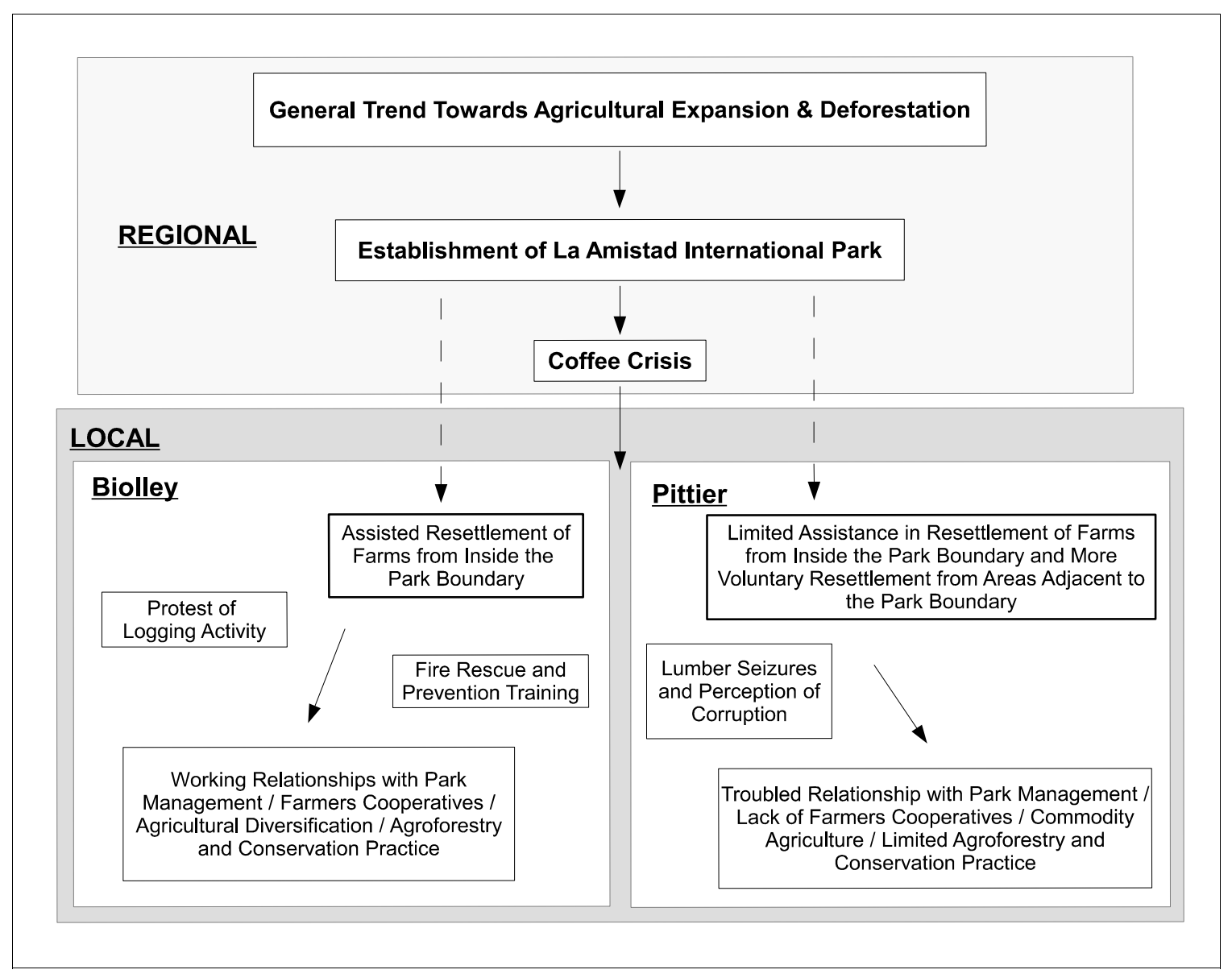

Figure 10. Multilevel framework for analysis of the history of land use and development across ACLAP.

families that had established farm operations in the region and were expanding their production to cover cover even more land. Therefore, the enforcement of PILA boundaries caused some families to withdraw from the region entirely and others to retreat to their farms in nearby communities. As global coffee prices continued to fall over the course of the next several years, it became even more difficult for farmers to earn a livable income working the land of the region. For these and other reasons, farmers near the protected area in Pittier removed coffee plants from their land to convert it into pasture (Gómez 1992 cited in Carbonell 2009). This trend of conversion of land use 
brought with it not only the potential of a negative impact on the local ecology but also the potential to negatively impact the environment across ACLAP (Agüero 2006; Rickert 2005).

Figure 10 also lists, at the local level, a number of practices in community development, agriculture and conservation practices, along with references to significant local events. The Protest of Logging Activity in Biolley during the early 1980s is a particularly unique local event that arguably played a major role in the subsequent development of this district. This event will be explored in more detail when describing the process of settlement in the Biolley district as it serves as a key point of departure for the emergence of a pattern of development in Biolley that is distinct from those found in other districts across the region. Other events, such as Fire Rescue Training and Lumber Seizures are recurring types of events that started occurring more recently and are ongoing with the establishment of PILA, at least up through the time of this research.

The map in figure 11 provides additional geopolitical and natural detail to this analysis by portraying some important characteristics of the region. Along with presenting several important natural and political features, the map in this figure also shows green dots where communities visited during ethnographic fieldwork are located. The red diamond marks Cerro Pittier, the highest point in Pittier, located just inside the core protected area of PILA.

\section{Deforestation, Agricultural Settlement, and Establishing PILA}

Particularly in Pittier, residents talk with great pride about the hard work that it took to colonize the land there. Getting access to the area was very difficult. Some of the 


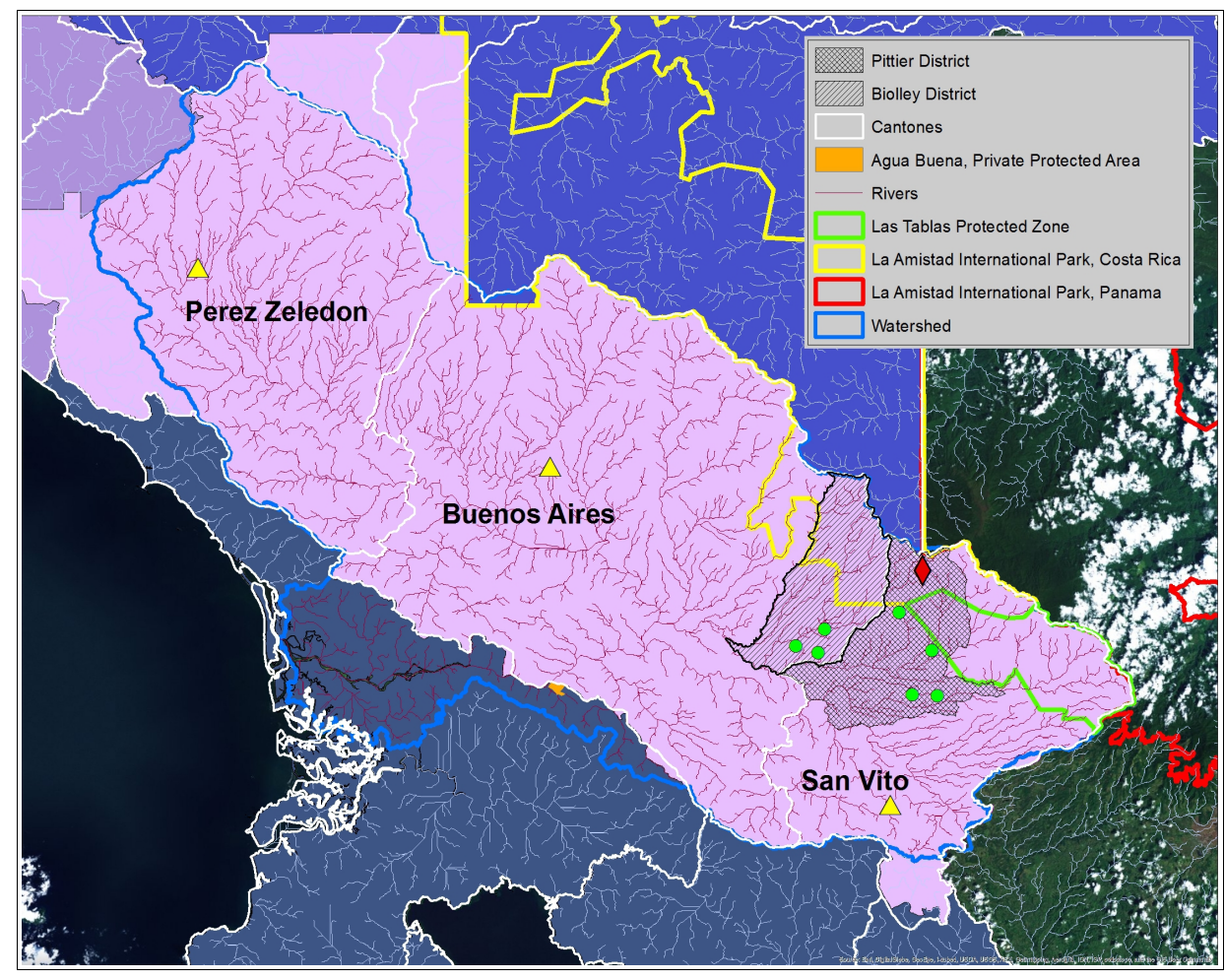

Figure 11. Political and natural features of ACLAP.

first expeditions into the region took place around 1970, and fuller expansion took effect during the middle and late 1970s (Gómez 1992 cited in Carbonell 2009). At that time, there were no roads or bridges, no indigenous presence (Anchukaitis and Horn 2005; Clement and Horn 2001), and people had to trek with the rations they could afford to bring. It took time for pulperias, or small grocery stores, that are now common fixtures of the rural landscape to start appearing across the region. Settlers had to travel by narrow trails over rugged, forested terrain, and they had to cross rivers with all they were carrying on foot or horseback.

Participant (23): We we arrived there weren't any people. Or, there was only this Señor that lived here by himself, Walter Jiménez. There weren't basic services for anything ... This community has improved a lot. Agua Caliente has overcome a lot. And the changes that happened at that time, if the mountains had not been cleared there wouldn't have been a community either. If it wasn't 
cleared, it wouldn't have been possible to have a community. So, it was cleared and burned so that it could be cultivated ... It was difficult for Pedro because he had to leave here at night when this was all forest until Miguel de Sabalito carrying gallons of guaro that he would exchange for the dulce and day-to-day supplies that he would bring back. The supplies were only half of what we needed, the rest we got from hunting. Fifty percent of the people in the community were surviving off of the meat they got from the forest and the corn and beans from their fields.

As more people were able to settle in the region, the pace of land clearing accelerated.

Participant (26): The use of the land before was a lot different than it is now because the soils were so good, more than anything because people cleared the mountains. They took down these huge piles of trees and later set everything on fire. Well, this made a big cloud of smoke all the time, for a long time the air was contaminated with this. Everything looked dark. It looked horrible. There was a lot of smoke in the air. Now, thank God, everyone is aware. Everyone is aware that to burn this is very bad and does a lot of damage to the ozone layer. So now, almost no one makes these burns because we know about the big mistake that we made during that time.

Today, activities related to the clearing of forest from land near PILA are far less common. Awareness of the problems caused by clearing land has increased to the point that people are paying attention to the ways in which the forest is returning. Particular species, like the quercus, are part of the biological history of the region, but despite the elimination of a massive human threat in a relatively short period of time, these trees are slow to reappear across the landscape (Kappelle, Geuze, Leal, and Cleef 1996). Other species that emerge can dominate secondary stands of forest and they present potential benefits as well as problems for people who are concerned about the development in the forest.

Participant (42): We don't see the regeneration of oaks, we see the regeneration of other species, and less oak.

What I see is that in the Valle de Silencio is that the jaúl rojo [alnus acuminata] is coming back a lot. It is important. It's not known where this seed came from, 
but there a lot of seedlings of jaúl. To me, it seems like the best way to deal with something like this, which I see as a threat to the park, is allowing nature itself to make the change.

\section{Settlement of the Pittier District}

During the period of intense forest removal, some people made it as far east as Santa Maria de Pittier. Santa Maria is a small community adjacent to the PILA border indicated by the northern-most green dot in figure 9. Today, most people refer to Santa Maria of Pittier as simply "Pittier." Whether or not this is a conscious effort to ignore the history of Santa Maria, it indicates that people now generally consider this place more as a part of the forest than they consider it to be another community of the district.

A few families continued to work the land in Santa Maria following the establishment of PILA. Most eventually decided the challenges of pursuing a livelihood in such a remote place were too great. During the period of agricultural expansion, Santa Maria was a growing community. A school was built, roads were put in place, and by some accounts there were around 100 families that had settled there (Gómez 1992 cited in Carbonell 2009). During the time of my fieldwork, it was a place where there was only a few small farm houses scattered among pastures. Of the dozen or so dwellings that remained, several had long since been abandoned and a couple were maintained as outposts for ranching operations. Only 3 or 4 dwellings were occupied. One family that maintained residences in a couple of different places had recently purchased a small piece of land right next to the park and built a rustic lodge hoping that tourism would soon develop as a viable avenue for development of the area.

During my time there, Santa Maria was a very quiet place. The school was well- 
maintained for the 3 or 4 students it served. Infrastructure for electricity was not installed there until the late 1980s, after most people had already left the community. Most of the buildings that remained that were used regularly were connected to this service during the time of my stay there. There was no need to treat the water as it came directly from the park just a few hundred meters away; however, the plumbing infrastructure was makeshift. Water lines were mostly laid on the surface of the ground, or very near the surface, along roadways and through pastures and they were frequently in need of repair.

Of the small population living in Santa Maria when I was there, the majority were older couples with children that were adults. There was a younger family with a toddler, and a few school-aged children. Most day-to-day activity in the community was related to managing land, pastures and cattle, and this activity seemed irregular and infrequent. Most land and livestock owners were absentee owners living in nearby communities and they would visit only occasionally to supervise repairs of property, vaccinations, or calving. For day-to-day operations, they would rely on the aid of the few people living locally or send a family member or laborer for a period of several days at a time.

The following is a description given by one long-time resident of a neighboring community in the Pittier district of how the community of Santa Maria declined after PILA was established.

Interviewer: Do you know what happened there?

Participant (6): More or less, more or less. Well, there are various factors, right. A lot of people left because the park bought their land. Yes, they bought the neighboring farms, those that were right next to the park. After the park bought these properties, the people left, various families left, various. Then, this, I don't know, I think if I live in a community, and you too, and you sell your property to the park and leave, the next person sells, and the next person sells, and I start, I start to feel kind of alone, and I don't...I sell too and I leave. This was the main 
reason. Yes, later, there were others that didn't have anything to do with the park, but they didn't like that the park entered. I argued with some from there who were clients of mine. I asked them, "What is the damage that the park causes you? What is the damage that is makes for you?" The damage that is does is this. Before the park was here, we were free to go to the mountain a montear (to hunt). Mmhm. Now it's prohibited. Well, now you can't do that. They were upset because of this. If you had the idea to cut a tree for firewood, you cut it. Now, you can't even do that because the park will be on top of you and give you a ticket. They couldn't live next to the park like that, they couldn't do it. So they left. Just like that, people went and people went and people went, almost everyone went. Some because the park bought their land, and others alleged that the park made their lives inconvenient, that the park came to make their lives inconvenient. I told them, "No, no, no. The park didn't come to inconvenience anybody. It came to bring order."

Many people left to look for work on the coffee plantations around San Vito,

where they could find a place to stay and may have still had family. They sold their land cheaply, sometimes making informal arrangements to receive small payments over a period of time without interest in exchange for property rights. Given the situation, many were happy to get at least something for their land and to get rid of it quickly. The alternative would have been the difficult responsibility of maintaining their land in the condition required to demonstrate continued ownership while at the same time maintaining gainful employment in a place that was by most means of the time still a half-a-day's journey away. Thus, a few people accumulated relatively large holdings of land in Santa Maria on which they continue to rotationally graze cattle. With not all of the landlords present, and others at times coming and going from this remote location, people tend to keep a close eye on their neighbor's business and they communicate with each other when they perceive their might be a problem.

\section{Settlement of the Biolley District}

Throughout the 1970s and 1980s, a different process was unfolding in Biolley. 
Although people in Biolley also talk about how difficult life was when they first arrived in the region, I found fewer prideful portrayals of a continuing struggle between humans and the environment in Biolley than I did across Pittier. Whereas in Pittier individuals and families were pooling resources to clear large patches of forested land and make their claims, the process of deforestation in Biolley was facilitated by GROMACO, an international logging operation (Diaz 2010; Monge, Cortés, Delgado, Delgado, and Carbonell n.d.). Then in 1982, peasants organized a Protest of Logging Activity to make claims for the environment and take control of the local economy.

During the years prior to the protest, people initially moved into the area seeking employment in the logging industry, and later as laborers on a few large coffee farms. Small agricultural communities developed around the logging activity and the coffee plantations that were later established by GROMACO. Increasingly, individuals and families acquired and work their own land in the area because it was in their own interest and opportunities with GROMACO were limited. Over time, people began to notice environmental damage caused by the way the area was being developed and they assessed what they felt was an unfair economic situation. They felt that too much of the revenue generated locally was leaving their communities and that this, along with the degradation of the environment, was having a negative impact on the possibilities for agricultural production on their farms.

Figure 12 shows a road block that was organized as part of this protest. In addition to serving as a transitional event that propelled an alternative development trajectory within the region, this protest contributed significantly to the emergence of an 


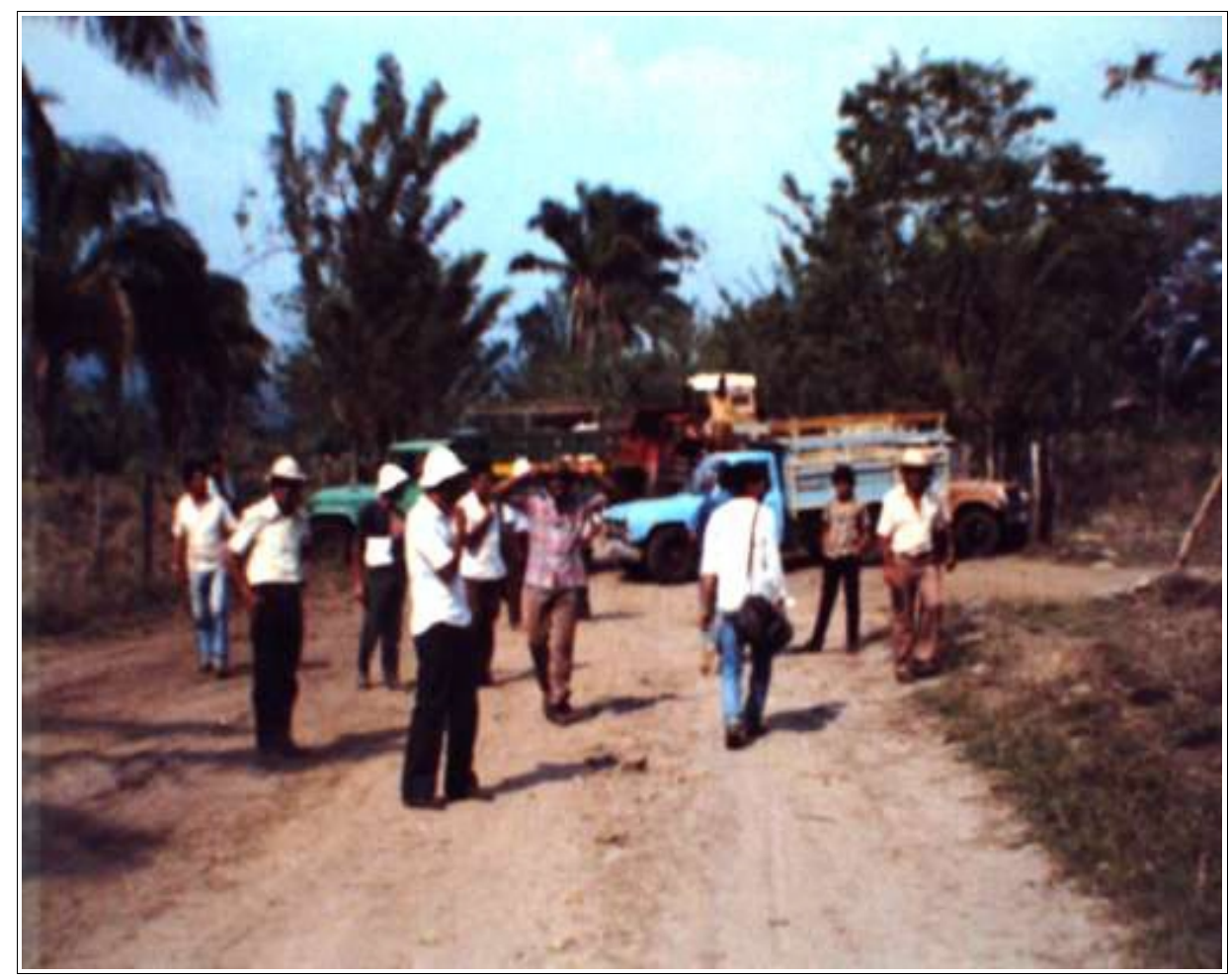

Figure 12. Road block as part of protest against logging in Biolley.

environmentally-oriented consciousness within the Biolley district. Although it is debatable which factors, economic or environmental, carried more weight in organizing this local action, there are at least two important local environmental issues related to this event.

First, many of the same people who were involved in organizing this protest were also responsible for later establishing the Association of Producers of La Amistad (ASOPROLA), an association of community members in Altamira, Biolley. Although the relationship of a farmers cooperative to this protest implies greater economic motivation, the current character of ASOPROLA as an agricultural organization with high regard for the environment speaks to the motivating influence of an interest in protecting natural resources as well. More detailed discussion of ASOPROLA's environmental agenda and 
its influence in development across the region is provided in the following chapter. In sum, though, ASOPROLA has a history of collaborative work in research, international development, and environmental education programs, and much of its contemporary work revolves around community development, the promotion of organic agricultural, sustainable tourism, and the diversification of local economic development opportunities (Rainforest Alliance n. d.; ASOPROLA 2012).

The second thing that relates the protest in Biolley to the environmental history of the region is the coincidence in the timing of the event with the establishment of PILA. Figure 9 (page 75) shows that a significant part, nearly half, of Biolley is located inside park boundary. When the park was established, the property on which many farms were situated was purchased by the government and farming operations needed to be relocated. Through the process of relocating farms down the hillside and into nearby communities, working relationships were established between MINAET and many people in the communities across Biolley. Many people affiliated with ASOPROLA were involved in this process, and the organization continues to provide an institutional basis for maintaining this relationship between MINAET and the communities that neighbor the park, in particular in Altamira.

Thus, despite the districts of Biolley and Pittier being so geographically close and physically similar, and despite both of these districts undergoing a process of rapid deforestation and agricultural expansion, their respective settlement and resettlement histories are quite different. In addition to a lack of infrastructure that directly connects communities of the districts, geophysical features of the landscape, such as the steep 
ridge and deep river valleys that separates them, continue to make transportation and communication between Biolley and Pittier difficult. Not only are these conditions challenging for farmers, but they also complicate matters for conservation agencies such as MINAET. After working hard to establish PILA in Biolley, establishing comparable working relationships across Pittier has not been easy. As alluded to before, MINAET was far less involved in the relocation of settlements in Pittier. There was a contraction of agricultural activity in Pittier due to the interruption of land clearing activities and the agency's primary roles have been the monitoring of resource use and law enforcement (TNC 2004).

We all love the park, but we don't all love the park rangers When asked to share their thoughts about PILA, people in both Biolley and Pittier tended to talk about the park as a source of valuable natural resources. Similar to what Wishnie and Socha (2003) and Schelhas and Pfeffer (2008) in other parts of ACLAP, participants in this research often mentioned the importance of the forest in maintaining a good water supply. They also often attributed the roles of providing clean air aesthetic benefits to surrounding communities to the park. Research participant comments also indicate the park is a source of local pride. Not only are people proud of PILA because of the prestige it brings to their communities in the form of recognition from outsiders (national and international), but they also acknowledge it as an excellent example for the national park system and as a valuable part of world heritage.

In exploring participants' perceptions of the park and their understanding of the relationships between their communities and natural resources in the area in general, they 
make clear connections between the condition of natural resources, and in particular forests, air and water, and the perceived well being of communities near the park. Several people mentioned the importance of PILA in bringing order to the area. In particular, residents who had witnessed the initial settlement of the region and transitions in settlement following the establishment of the park noted the changes in local microclimates over time, citing changes in the range of temperatures and the relationships between forest cover and the quantity and quality of water.

Participant in Biolley (54): I think, about the La Amistad Park, as if it were a person that arrived to the area about 40 years ago. With my own eyes, I saw these forests fall until this Cerro de Biolley was bare, completely. And, I had to go to the Sábalo River, here, a kilometer from here, and in a summer see that what came down was una pajita [a straw] of water that was maybe five inches of water. It even smelled like dead fish. It was a river at the point of failure as being a river. And when the La Amistad International Park arrived, we have seen how this river has come up again. The level of water has risen, and the scenic beauty has come up, like those green hills and everything, they are pretty. It has been a great savior. For me, declaring this international park was a salvation for this area.

Although many people in Pittier do not perceive PILA as playing an active role in the physical and mental activities of their everyday lives, the connection between forest cover and water quality is still in the forefront of some people's minds there. Figure 9 shows Santa Maria as it is located almost on the PILA boundary. The same figure shows how other communities in Pittier are considerably farther from PILA, and how they are actually much closer to an area that is protected under a different, national designation, Las Tablas Protected Zone (LTPZ). A few of the waterways that pass through Pittier do originate in PILA; however, a larger portion of the waterways that pass through the communities of Pittier originate in and/or pass through LTPZ, which is subject to a slightly different set of land use regulations than PILA. 
In discussing their interest in reforesting pasture to protect the community water source, a husband and wife draw strong connections between land use and water quality. They do not take issue with park rangers in describing their situation, but they do mention having difficult interactions with another government agency, the Institute of Water and Aqueducts (AyA).

Husband, Participant in Pittier (7): ... we lack reforestation of the springs of the...

Wife, Participant in Pittier (7): Mmhm, another project that is much needed is the reforestation of the springs that provide water to our community. They are abandoned and uncovered in some pastures, and they spray herbicides in some of those pastures there, and, and this herbicide runs towards the, the. .

Husband: It penetrates.

Wife: It penetrates

Husband: Mmhm.

Wife: And we don't know that we are not drinking it. Yes, it is something that is important for the health of the community, the water. Potable water, but from the springs. I don't know how it is there, how we are in this, that those farms have those aqueducts that we depend on. I don't know why it is that there we aren't given a chance to reforest. Oscar, why is it?

Husband: Well, perhaps I won't be too much of a bother, and I adore you. It's that the aqueduct committee cannot reforest land that does not have insurance of the aqueduct. It's like this. The owners of the land where the springs are, doesn't let them reforest the springs above because the land is not in the name of the aqueduct. So, they tell us that if we reforest a hectare, if we are reforesting it for the land owner...

Wife: But yes, the owner...

Husband: ...we are using community money to reforest the farm of the land owner. That's it. They won't let them reforest...

Wife: We want to reforest.

Husband: ...there is nothing along the banks of the spring...

Wife: We want to reforest.

Like this couple, other people across the region often shared their frustrations 
related to dealing with government officials and agencies. Although there appear to be challenges in communicating with various government agencies, including public works, health, and education, given the focus of this research, many participant complaints were related specifically to MINAET. Further, unlike the case just presented in which the Institute of Water and Aqueducts appeared to be prohibiting reforestation efforts, many people tend to conflate problems with government officials and agencies and not particular policies. One participant summarized this issue very well by pointing out how the word "park" is often used interchangeably to refer to both PILA and park rangers.

Interviewer: What do you think about the relationship between the park and the community?

Participant in Biolley (54): It's that, there there is an issue. When people talk about the park, I understand it as being about the way of thinking that was developed to protect it. But there is a relation that people do not see. The relation with the park, and the relation with the...the park rangers...which have been two different things. We all love the park, but not everyone loves the park rangers. This is because of the policies that we have seen them implement. Despite them not having jurisdiction, because this was made known in a meeting by [a MINAET official], they do not have jurisdiction to operate outside the park. Their function is to take care of the park, but they affect, they have affected the cutting of lumber outside of the park. So, this has made many people look at the park as if it is something negative. Which is a pity. It's a shame.

Inadequate communication and misunderstandings about proper jurisdiction can make relationships between park management and communities in the conservation area problematic. The limited departmental resources available to natural resource managers for maintaining an ongoing presence in communities amplifies in people's minds the significance of those instances when managers appear suddenly to enforce rules and regulations.

Interviewer: How is the relationship between MINAET and the community? Is it difficult, or are they welcome here? 
Participant 1 in Pittier (12): Yes. Well, I think they are welcome, but in reality MINAET has a lot of, of ... well, in part it is unjust. Because if someone wants to cut a tree for, what do I know, to build a house, a little house, one has to, it depends if they allow it. And people have needs and they can't, how to say, sometimes you need to cut a tree to make a house, but it all depends on whether they let you or not. So, in part this is unjust because if someone needs it, right? But, yes, in part it is good to have MINAET because if it wasn't for this it [the forest] would no longer exist, there would be no protected areas, right. Everything would be...

Participant 2 in Pittier (12): In part, here, what is the community doesn't get along well with MINAET because, it's to say, MINAET is run by money. Because here if a poor person is trying to get permission for one tree, they won't give it to them. On the other hand, like I was telling you before about the destruction of mountains that they have done inside, they are millionaires. Millionaires have been able to get permission to deforest an entire mountain. So, in part, people don't get along with MINAET because of this. It's like...it's like they are bought.

Interviewer: So, they deal with the situation differently depending on who...

Participant 2 in Pittier: Yes. It's like...

Participant 1 in Pittier : Yes.

Participant 2 in Pittier: ...they are bought more than anything. Because, yes. Because any poor person that needs permission to cut a tree, it's difficult that they are able to get permission to fell one tree, right. On the other hand, well, not too long ago, not even, in December, what do I know, when it was, over there they took out lumber, they deforested the whole mountain inside, taking out lumber. Aye, but the owner of this lumber is from, how they say, is from [snaps fingers to indicate wealth]. They got permission so they would let them take it out.

Interviewer: And this has happened here, in this community.

Participant 2 in Pittier: Yes, this has happened here. ... Here, there is a young man, to give you an example, a young man, bit by bit, in front of many obstacles and everything, right, a lot of work, a few years ago, he was able to get the lumber to make himself a small house, small, he had it there on a small parcel. And there came MINAET and took it away from him, the lumber. They took it. Aye, when this happened, almost the entire community was saying to grab these men from MINAET and make an appeal against them, right. Because it seemed very unjust to everyone.

Interviewer: Everyone was upset?

Participant 2 in Pittier: Yes, a big part of the community was upset, but no one, 
it's like no one shouted. No one said anything. But yes, very upsetting because it was a poor person who made a lot effort to take out this lumber to build a house. And immediately...it's believed that it was because someone accused him. But they came and left him without the lumber for the house. And there are things, and one gets upset because of this, because a poor, honest person that has taken out lumber with a lot of effort, and you can see that people, because they have money because they are millionaires they can clear mountains, they have cleared mountains to make pastures, they have deforested mountains to do business taking out lumber, and MINAET...

Participant 1 in Pittier: Doesn't appear.

Participant 2 in Pittier: ...doesn't appear. We say, on the poor, yes they are on top of us.

There are, however, some differences in the ways people from Pittier and Biolley perceive their relationship with the park and park managers. While confrontations with park officials are fresher in the minds of many people in Pittier, farmers in Biolley have had more frequent positive interaction with park managers since PILA was established and they tend to view rangers more favorably. Even those who have had negative experiences with MINAET in the past admit that the relationships between MINAET and the communities of the district have improved considerably over the years.

Participant in Biolley (52): I have seen that MINAET has made a lot of harmony with the communities through projects. It is not like before when we came. Well, at least for me, they were at the point of arresting me for trafficking firewood. Now, I see that they don't get involved in that. I see a lot of people cutting trees, chopping trees, and nothing. They don't get involved in this anymore. I see how they are working now, and we can continue like this. Everyone has trust in them and they respect them legally. If they say you have to leave it [a tree], you have to leave it. That's different than before when they were very bothersome, too demanding.

Increasingly, MINAET has focused less on monitoring of land use and enforcement restrictions and more on regional development through its involvement in research and environmental education (EDUCA/PILA n.d.) and through supporting land owners in pursing alternative income-generating activities. MINAET has demonstrated 
more of an interest in community development through its efforts to train communities to prevent and fight forest fires across ACLAP (INBio 2012). The agency also supports the training of local residents as nature guides (OTS n.d.), and it works with farmers in the development of land management plans that include measures for environmental protection (Forestry Law 7575; Biodiversity Law 7788). In these ways, MINAET has managed to significantly improve the public's perception of it in many places across ACLAP. However, the agency's primary role continues to be that of a protector of natural resources, and there are several common agricultural and development practices that perpetuate antagonisms between communities, farmers, and park managers across the region.

\section{Tensions around land use, degradation of land and} soil quality, and the emergence of natural actors

When left to its own devices, the deforested landscape of ACLAP will produce secondary forest relatively quickly. To the casual observer, it is often difficult to distinguish between areas of primary forest and many of the patches of secondary forest that have emerged from farmland and pastures abandoned over the last 20 to 25 years. One of the consequences of this potential for rapid regrowth of vegetation can only be fully understood by taking into account the practices that farmers adopt to make sure that secondary forest species remain latent.

According to the rules for management of land in the protected area buffer zone, when certain species of vegetation appear on a person's land and those species are allowed to grow to a certain width and height (more the $5 \mathrm{~cm}$ in diameter at chest height), 
the rights of the land owner to use the land are restricted without a permit (MINAET 2007). In order to prevent the loss of property rights in this way, or risk entering into a conflict with park management, farmers have adopted practices to prevent the growth of this type of vegetation, which is referred to by many as monte or tacotal (Diaz 2010;

Schelhas and Pfeffer 2008).

Participant in Pittier (16): I think that conservation is something very beautiful. I am fascinated by it. I am fascinated because I am fascinated by nature, and how pretty the hills are here. Well, right now they are difficult to see because it is cloudy. In the morning when I wake up, the first thing I do is go outside to see how pretty the whole hillside is. I am fascinated by everything that is conservation. It is because of this that there is monte everywhere here. But, how to say, the conservation is nice as long as one can do what they want. Because there is, this has a consequence. Let's say someone has a small parcel and they have it in, let's say monte alto. And if this monte grows to a certain height, even though it is not a forest but is a monte charal, it can't be cut. It can't be worked. And this is one of the problems that come with...let's say, the institutions that work for nature. The do not allow a person to work in order to plant the products that they are going to use. And they do not allow that people work this monte, and if someone works it they will fine them, they take them to jail, and up to taking them to jail and making a judgment they will put someone in jail for this. And to me, this doesn't seem right. I agree with conservation, but not taking things to extremes. If a person needs a tree, here is a tree of the size needed to make a house, a lot of the houses here are made of wood. And, you have to go and pay, I don't know how much, to pay for permission to be able to cut three trees, no more. That is what they allow to cut. It's a very strict law, because if I am going to cut a tree I can plant another. Why am I not going to plant. If the law was like that, if someone cuts a tree, plant another, not that they place so many obstacles to cutting a tree. It's that to me it seems, if someone is, or yes there are those that deforest and others pay for those that cut and cut and cut without paying attention that they are deforesting. But I think if someone is a little, it's because of this that they are putting in place these laws that are so cruel.

Given the current situation, instead of allowing any trees to grow in coffee fields or pastures, farmers monitor the growth of emerging vegetation closely. If they want trees on their farms, they plant species that they know can be harvested for lumber and are not subject to protection by the law. In this way, they are able to harvest lumber and at the 
same time avoid conflict with park management. This type of practice can offer significant improvements in both agricultural production and natural resource management, especially in places where access to roads is easier (Caviglia-Harris 2003). While these practices do reduce the potential for conflict over land use, the resulting land uses are generally not those that would be ultimately preferred by protected area managers and those more interested in maintaining ecological functions and diversity across the site (Zahawi 2009; Janzen 2004). Even where trees are maintained for shade in coffee fields and farmers practice more ecologically diverse forms of agriculture, conservationists may see a greater potential for restoring or creating landscape-scale ecosystems that exclude the immediate purposes of agriculture and include select species of protected trees, plants, and animals.

In places like Santa Maria where the labor and infrastructure needed to manage coffee fields or stands of harvestable timber is not available, raising livestock is perceived as one of the few options, if not the only one, available to land owners interested more in agriculture.

Interviewer: What are the advantages of cattle?

Participant (25): Well, the advantage of cattle is that you don't have to be there with them every day, right. Coffee you have to take care of a lot. And while you are taking care of it in one place, you have to continue working in another because of the lack of money. We don't have money to pay laborers, so, we have to work there by ourselves to be able to get ahead.

In addition to the financial costs and benefits associated with cattle by farmers, during several informal conversations land owners shared with me the importance of cattle for maintaining full land use rights. While it is difficult to claim this is the primary motivation for grazing cattle in pastures in remote areas, it does allow land owners to use 
livestock to keep scrub growth under control on their land with very little investment in labor, therefore minimizing potential conflict with protected area managers. Although this form of land management is less-intensive (Wishnie and Socha 2003), many of the pastures managed in this way are on some of the most marginal lands and the soil has not been cared for for many years. Once the fertility of these pasture soils is depleted and as the continue to be trodden by cattle, they become even more susceptible to channelization and erosion (Carpenter, Mayorga, Quintero, and Schroeder 2001; Wishnie and Socha 2003). The center of the image in figure 13 shows the collapse of a small water channel in a pasture near the protected area boundary in Pittier.

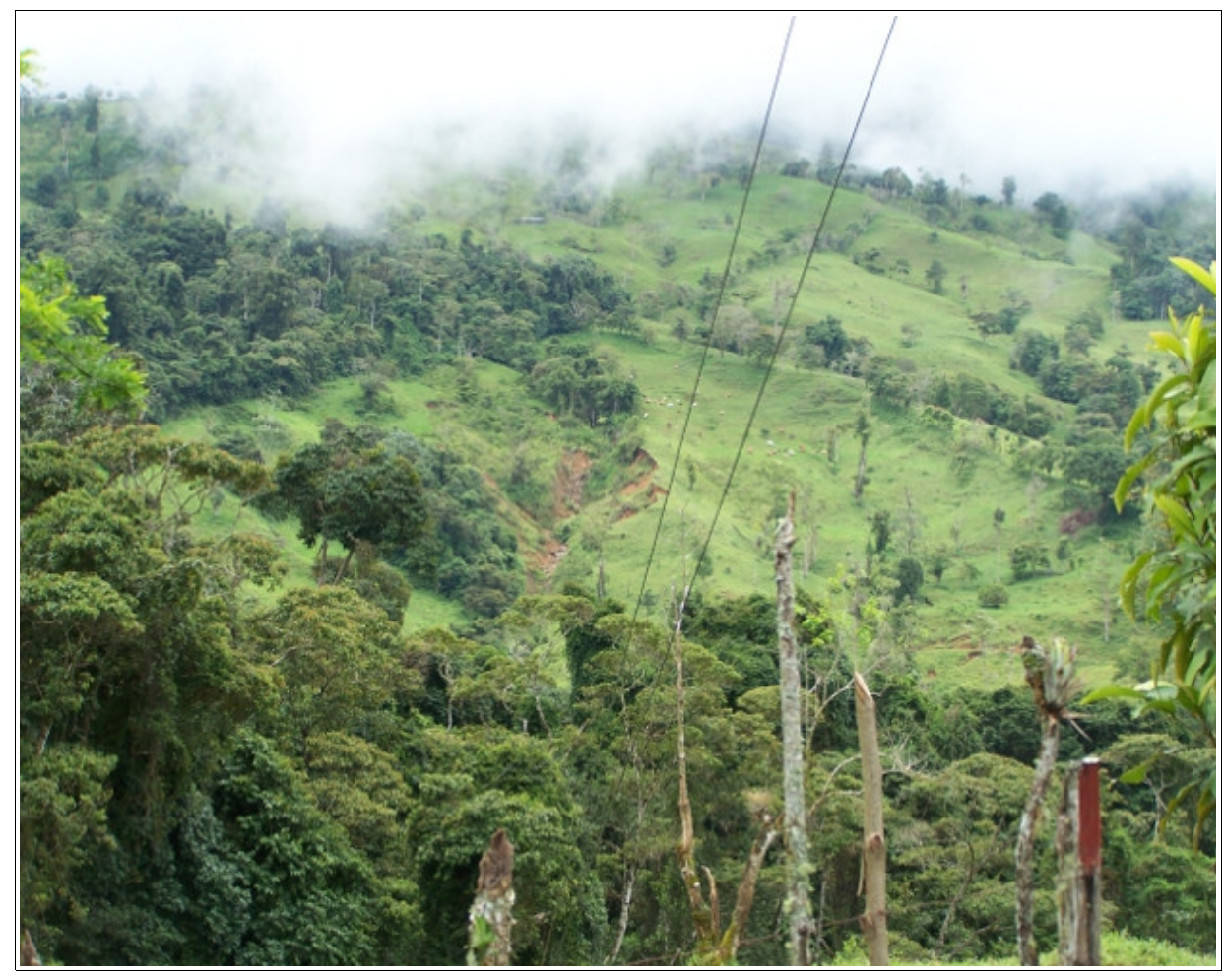

Figure 13. Example of pasture erosion near protected area boundary.

Many people in Biolley express clear concern about the detrimental effects that raising livestock, in particular cattle, can have on land in the region. Therefore, it makes 
sense that I observed fewer extensive cattle grazing operations across Biolley during fieldwork. The pastures that I did observe there were primarily on the north-facing slope of the ridge between Pittier and Biolley, on land distant from community centers and better-maintained roads. The land closest to communities in Biolley tended to be under some type of tree cover, either secondary forest or a managed agroforestry system.

Figure 14 provides an image of the natural process that unfolds in pastures across the region when they are abandoned. The forest regrowth first appears in pasture valleys and slowly moves up the hillsides. This reforestation process can also be seen taking place on land where cattle grazing continues but activity has been reduced. The flatter land at the top of the hillsides is kept open as it is more easily accessible by the remaining cattle that are rotated between these periodically. While it is not uncommon to see such

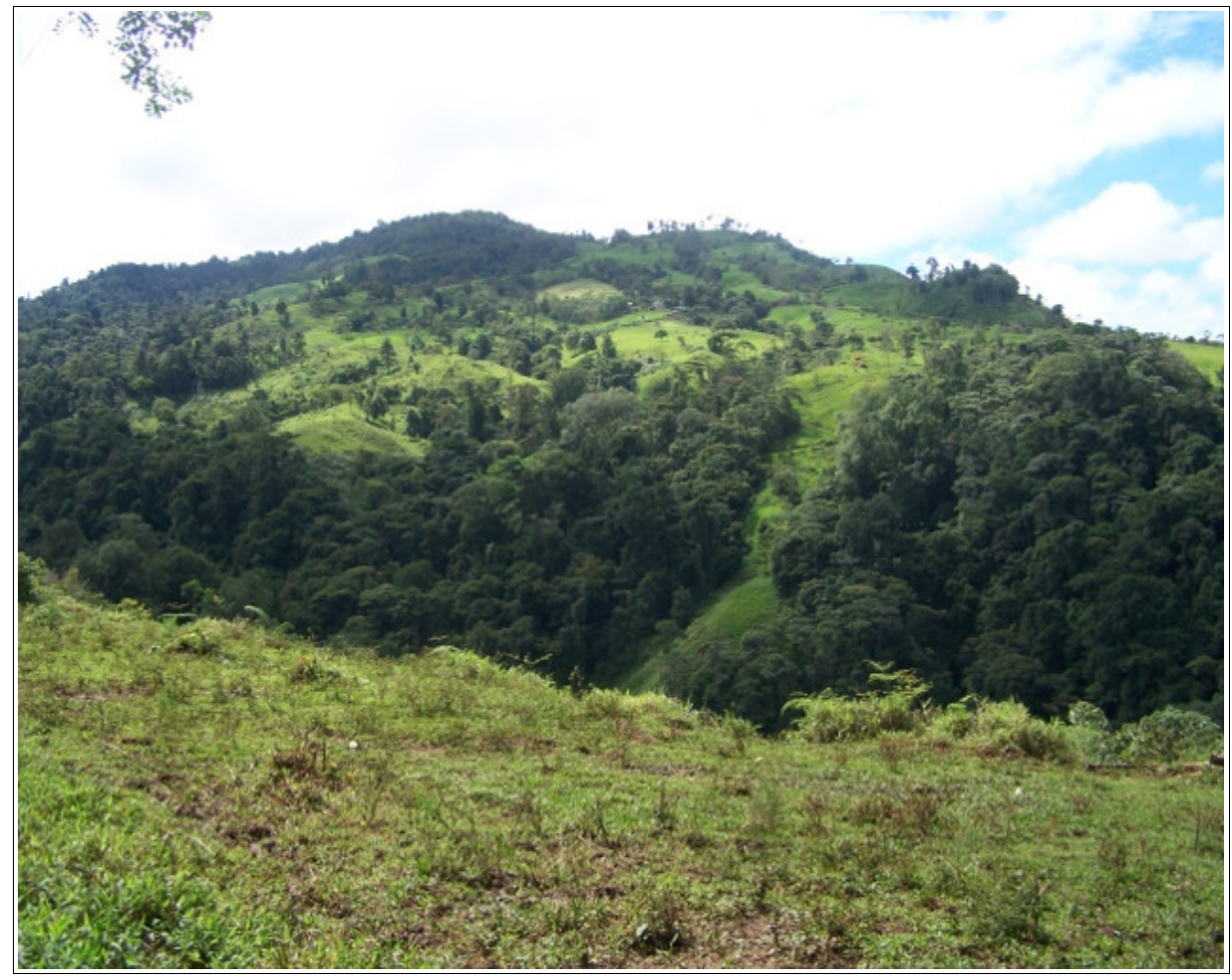

Figure 14. Forest regrowth in pasture valleys. 
an image almost anywhere across the region, given the advanced stages of much of the successional forest across Biolley and the broader implementation of agroforestry practices there, it actually a scene somewhat more commonly encountered across Pittier.

In talking about the various uses of land by farmers across the region and the significance of those different uses for the park, one farmer from Biolley pointed to the threat cattle grazing poses in the region while also indicating that, from the perspective of a farmer, not all uses of the land threaten the well-being of the park. According to this farmer, the way one practices agriculture makes a big difference in terms of how the use of surrounding land affects the protected area. This farmer also expresses the belief that using the land in the right way can be better for the park than not using the land at all. In this context, when community members become complacent they lose their connection to the land and the environment and bad practices are more likely to take hold.

Interviewer: So, how is it that this bad use, like you say, has affected the park?

Participant in Biolley (54): The bad use of the land? In some ways, the bad use of the land has affected the park. I think that the way it has an affect is that...that...it's that it is difficult for me to come up with the answer, because the bad use that I am telling you about is a lack of good use of the land. The bad use that affects the park is not really this. The bad use that affects the park is really, it's livestock activity that degrades more and deforests more. Many more trees are cut, many more areas are opened up for livestock activity. Industrial agriculture right, with mechanized areas comes to destroy. It's bad for the protected area of the park, because all of this is protected area. So...but this is at another scale. I was listing more than all of this, the majority of people have their little piece of land, but they don't use it well.

Nevertheless, some farmers in Biolley maintain large livestock (pigs and cattle) for savings and for the purposes of household and/or community consumption. A few people also continue with intensive practices of raising livestock despite knowing, or perhaps they only can because they know, about related deficiencies in the soil. Although the 
following discussion of this matter from a farmer in Biolley does demonstrate a certain level of appreciation of local soil conditions, it contrasts sharply with discussions I had with other farmers across Biolley, especially those affiliated with ASOPROLA, who are searching for ways to reduce the environmental impact of maintaining livestock by exploring practices such as the stabling of animals and increasing the local production of fodder.

Interviewer: Tell me a little bit about your farm. What activities are most important for you farm?

Participant in Biolley (43): At this moment, the most important is cattle. Because I live from that. I live in this. Well, my work is in this. The activity of cattle.

Interviewer: This is the principle?

Participant: This is the principle. Or, in other words, this is everything. That's how the saying goes, "This is what I do."

Interviewer: What are the benefits of this activity?

Participant: No, no. The benefits are that this is a...well, you understand well, it's like a plant, right. We live from the harvest of this plant, right. Let's talk about if you plant a bean field, the harvest sticks. That's how I am. I have cattle there, and I wait for something from this cattle, right. This is what the cattle generate. That you go, well to explain it quickly, there you are going to get ahead. You sell animals and you eat and you live, and there you go.

Interviewer: You sell a little bit?

Participant: Yes, yes, yes. You go along living.

Interviewer: What do you do to improve your chances of success?

Participant: Ah, how is it done?

Interviewer: Yes?

Participant: What is done is, here, you have to take very good care of the cattle because where we are is not good for cattle. So, you have to be giving them salt daily, and giving them vitamins so that they give a harvest, let's say.

Interviewer: This is what usually has to be done? 
Participant: This is what is done here. Make sure they have vitamins and the salt that they want to eat.

Interviewer: This is done all the time?

Participant: All the time. From today forward, I give vitamins every month, when it is very late, right. Equal.

Interviewer: Where do you get information about how to do this?

Participant: Well, the information that I have gotten for this is the same disease that produces, let's say, let's talk about the land here. Right. Because here we are in a part where...where this thing has stayed. I'll just leave it like that. Naturally, this land is acidic, right, and this problem can't be cured. This can't be cured. It's already this way. That is the way its going to stay. And the only way that you can go leveling things out a little bit with the cattle is by giving vitamins monthly, because the pasture does not have the vitamins that the cattle need, you see.

Interviewer: Yes, this a complicated subject, cattle.

Participant: Ah yes, how complicated. You have to wrestle with and not feel sorry about the money that you have to spend for vitamins so that you can give vitamins to the cattle. I give vitamins monthly. But, between these cattle, perhaps there are three or four that I have to give vitamins to every fifteen days because they are very thin, they are feeding calves. So, I have to help them. You have to do it.

With the major emphasis of production across the region still in smallholder agriculture, farmers are continually weighing the costs and benefits of taking different approaches to agriculture. Although, most people believe further degradation of biological health happens as a consequence of certain practices, they continue those practices because they feel that there are no, or very few, alternative solutions to their problems. Many farmers are quick to point out that the increasing costs of chemical inputs is making it even more difficult to maintain their operations. Thus, when farmers recognize poor soil quality as a problem, or when their animals and/or crops are infected with a pest or disease, they are forced to make difficult choices. Depending on the point of view of the farmer, they may look for a solution to be provided from an outside source, 
such as a supplement or chemical company. On the other hand, farmers might choose to diversify their farming operation and explore the possibility of producing inputs locally, whether it relates to livestock, crop, or artisan production.

During interviews with farmers in Biolley, people talked a lot about the poor condition of the soil, much of it being attributed to the "burning" of the soil in the fields around their community and in neighboring communities around the region. Along these lines, people often reflected on their own and other people's use of fire and heavy applications of chemicals in agricultural production while also reminiscing about the years of extraordinarily high soil fertility immediately following deforestation. Given their assessment of the situation, several people interviewed had, in recent years, converted to using organic methods in their production of coffee and vegetables. This trend was particularly evident in discussions with farmers in Biolley.

Interviewer: What type of management does your coffee have right now? Participant in Biolley (32): Right now, it is in, like, organic. For a while it was conventional. Now it is organic.

Interviewer: What was the reason you changed from conventional to organic?

Participant: Well, more than anything, it's that one starts getting afraid of the chemicals, and one starts feeling that they are doing harm to the soil by applying venom and things. One wishes that it was like during earlier times when no one had to use these things. Sometimes there is a curiosity if one can achieve something without contaminating so much.

Although farmers are aware of the damage conventional methods can do to the environment and they are interested in pursing more sustainable methods of production, they still have to deal with some of the same problems that they had before.

Mycena citricolor, or "ojo de gallo," cochinilla, and Hemileia vastatrix, or "roya," are natural actors related to coffee production that have become persistent 
problems for farmers across the region. Recently, during the 2012/2013 coffee season, there was a major outbreak of roya, a fungus that attacks the leaves of coffee plants. The outbreak was significant enough that it was perceived as a threat to the national harvest and a state of emergency was declared by the Costa Rican Coffee Institute (ICAFE). As a result, over the course of February and March, 2013, ICAFE and the Costa Rican Ministry of Agriculture (MAG) held instructional workshops on integrated management in communities of coffee-producing regions across the country (elguardi@n.cr n.d.; ICAFE n. d. a).

Ojo de gallo is another fungus that attacks the leaves of coffee plants and can spread quickly. The fungus can produce an impact that devastates production immediately and for years to come. Figure 15 shows a defoliated plant and figure 16 shows a hillside view of a coffee field with an infected area. People have differing opinions about how much of a threat the disease presents to production and how to manage coffee fields when it is present. For example, the following interview excerpt relates a disagreement between a widow and her son-in-law about how to manage coffee in the presence of mycena citricolor in Pittier.

Participant in Pittier (3): Right now, I have some coffee planted over there. I know reforestation is very important for people from the United States, reforestation for the environment. There, in the coffee that I have there are also cedro trees planted. And, my son-in-law, that young man working over there, he tells me, "I am going to cut some of that cedro because it is very twisted and it causes the coffee to be infected with ojo de gallo." I tell him, "no." I have to educate him not to cut the cedro for me because cedro is a tree that grows up above, tall, it grows tall, and it doesn't make as much shade. And, it is protecting the environment there through reforestation. And, in a few years it will provide lumber, too, that can be sold. 


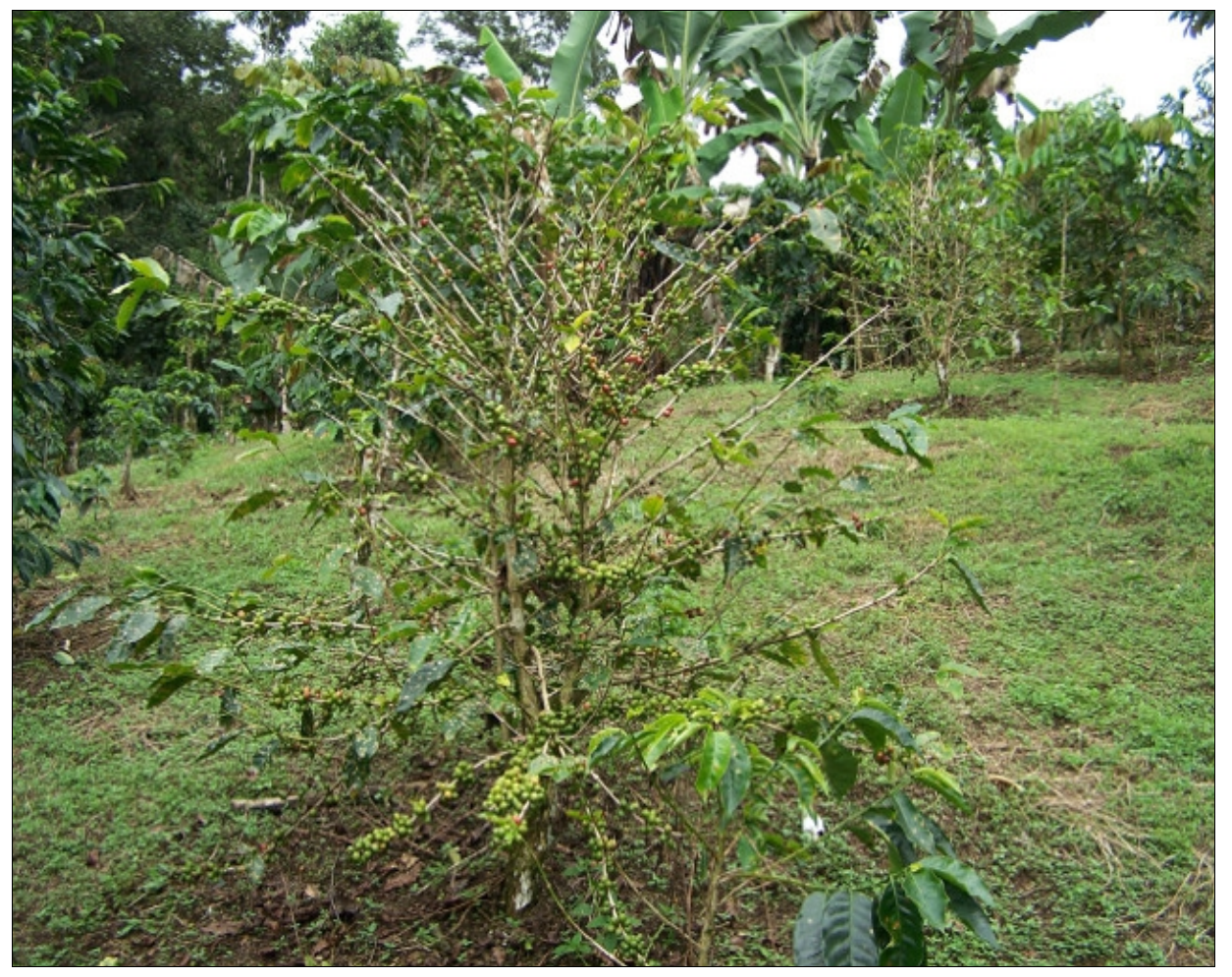

Figure 15. Coffee plant infected by mycena citricolor.

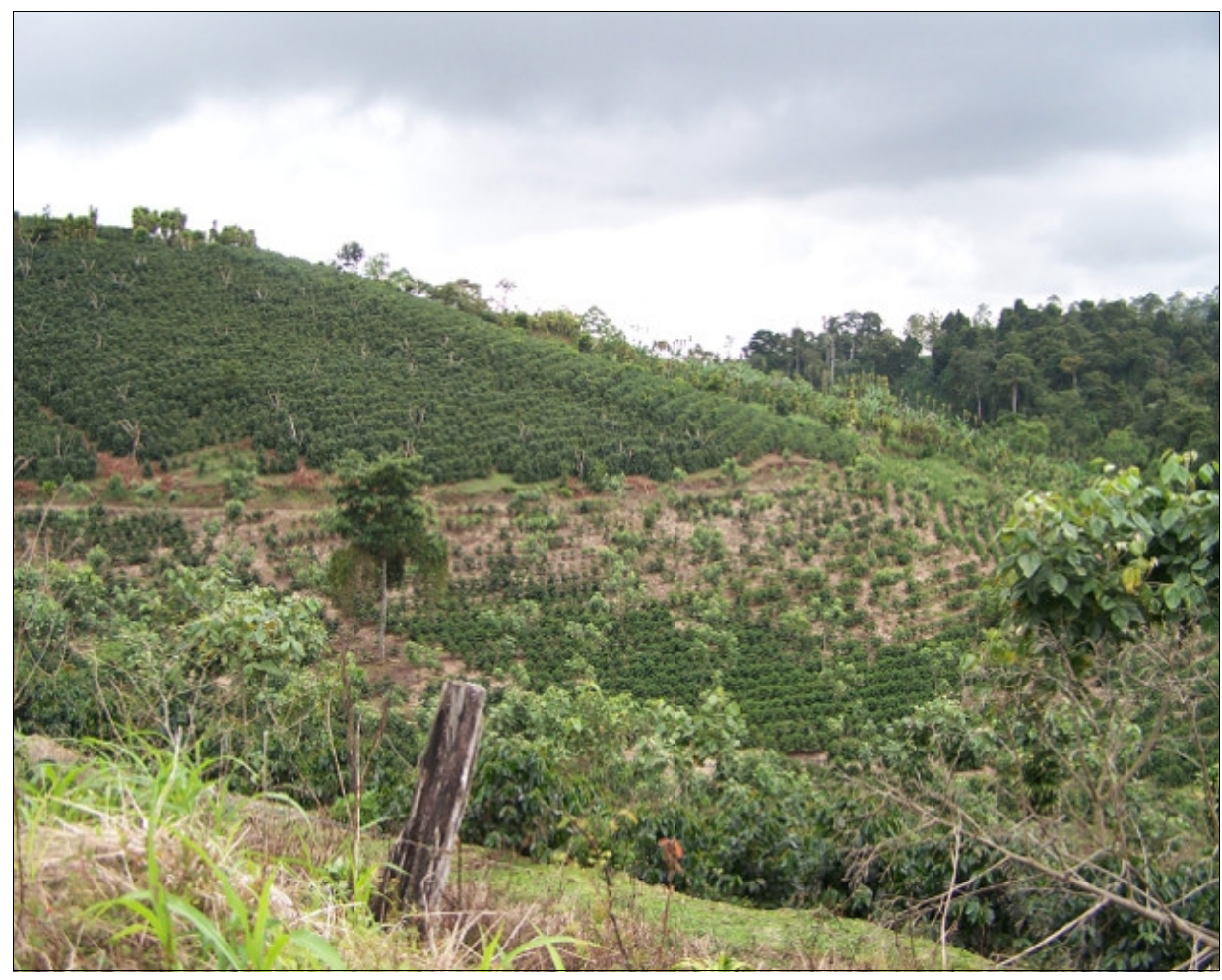

Figure 16. Field of coffee with outbreak of mycena citricolor. 
Interviewer: I think within 30 years, more or less.

Participant: Yes. Aside from the earnings that we will have, the reforestation is there and there is a beautiful planting there. This whole part from these houses there to over there. Look how there is a very beautiful planting of, of cedro.

While the effects of an ojo de gallo outbreak are almost immediately visible, pests and diseases such as cochinilla operate below the surface of the soil attacking the roots of coffee plants. Whatever the case, the potential damages from crop pests can be significant, and despite there being an almost universal lack of interest in treating the situation by applying chemicals to plants and fields, many farmers feel that there are no other real options.

Participant (28): The plants have a lot of infestation, whether they are diseases or in the roots. One has to treat them with chemicals because...I don't know. If there is another solution, I don't know it.

This desperation with pest and disease management in coffee plantings resonates with ideas shared by many farmers about how, over the years, the condition of the environment has generally moved in a direction that is less favorable for production.

Interviewer: Have you noticed changes in vegetation? For example, have you noticed that before certain plants produced more than now? Or that certain plants were around more before and now they are not.

Participant (25): Well, what I remember first is coffee. The coffee was something very special. You planted a few bushes and it was beautiful, without any fertilizer or anything. Without any fertilizer, the coffee, the banana plants, this was beautiful, all the even bunches that there were, that were cultivated. Everything was organic. Squashes, oh there were so many squash that were brought for the pigs. And, and they gave corn to the pigs, too. There were some ears, but big and thick that tasted good. With a little corn you could do a lot. A lot of things, say, in those times we made tortillas, we made grilled tamales to have here in the house. We made a lot of empanadas with cheese that was made here on the farm. We made the cheese.

Interviewer: So, you think that before you produced more?

Participant: Well, yes. Of course, yes, because the squash plants were unbelievable, unbelievable how much squash they produced. The plants of 
everything. When someone planted a passion fruit plant...

Interviewer: Are there any other changes that you have noticed?

Participant: That I have noticed now?

Interviewer: $\mathrm{Mmhm}$.

Participant: Too much change. Now, the coffee only has plagues, too many plagues. Now, the coffee, if you don't fertilize it, well, any minute it will be without leaves. All the leaves fall off. Now there are a lot of ants. Ants, there are so many that damage the crops. There is a lot of fungus, a lot of cochinilla. The ants carry away the cochinilla and feed off of it. And well, now you have spray chemicals to kill some of the plagues. Things that weren't done before. There was no spraying or fertilizing, and the production was a lot better than it is now.

Not only is production of commodity crops more difficult, and expensive, than it was before, but as many farmers have specialized in these crops their attention is directed more towards concerns about soil fertility and the management of pests and diseases. The days of obtaining abundant harvests of corn and beans and ample produce from home gardens without significant inputs have waned quickly during the first years following deforestation. At the same time soil fertility is diminished, markets for coffee and cattle are distant from this remote region and they can be volatile and are often in decline. Although people have fond memories of those years of plentiful harvests and are prideful when they occasionally have good produce to share, trees increasingly cover the landscape and pests and diseases are lingering threats to sustainable livelihoods. Therefore, maintaining cultural values related to agricultural production in the region is also increasingly dependent upon an integrated effort across individual, social, and institutional lines.

The multiple scales of agricultural and economic diversification As agriculture continues to be the primary income generating activity across the 
region, many of the dilemmas faced by farmers on a daily basis are related to the legacy of economic development. Many of the dominant local social and economic structures descended directly from practices of resource extraction and the production of agricultural commodities (Yacher 2004: Cardoso and Faletto 1979). Through these practices, farms and households were articulated with global capitalist markets that, along with national development policy, heavily influenced both the availability of the means of production, i.e., chemical inputs, and the means of consumption, i.e., imported food items in local grocery stores (figure 17). This integration with global markets can serve as both a blessing and a curse in the sense that it both limits the ability of local actors to shift development patterns while at the same time it opens the door to new development opportunities that involve investments from external interests.

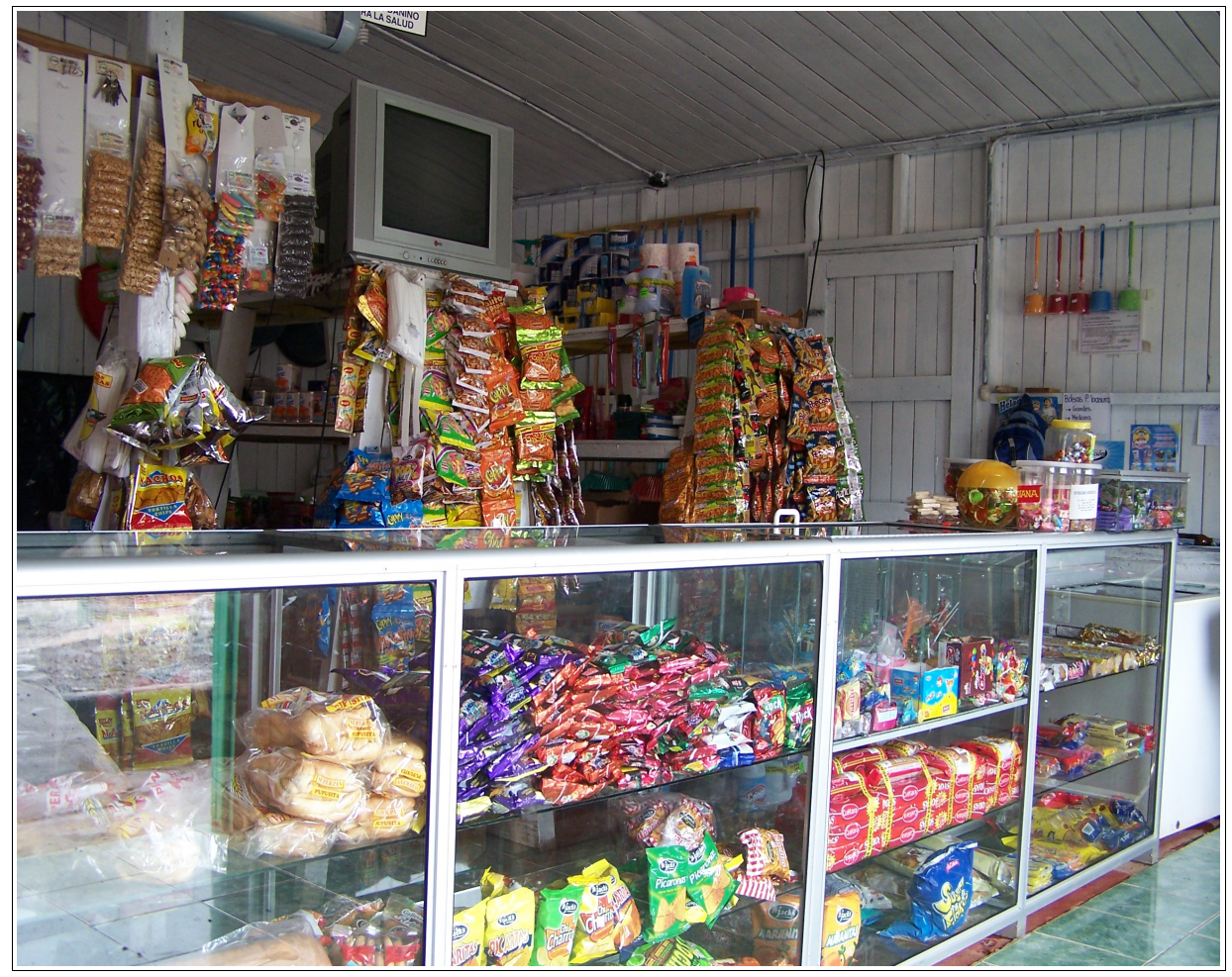

Figure 17. Local grocery store. 
Economic activities like organic production and tourism are widely viewed by people across Pittier and Biolley as desirable modes of production for the region. Redirecting resources to support these activities, however, can require farmers to accept increased risk, at least temporarily. The adoption of new activities can also involve increased production costs and they may require a certain amount of time, energy, and money to be invested in capacity building.

Farmers are aware that conversion of coffee fields to organic production methods will likely cause immediate reductions in yield that may not be met with a compensatory increase in market prices. Similarly, the diversification of agricultural production to include more variety in crops may be accompanied by difficulties in locating products in markets, especially without significant investments in infrastructure. For example, figure 18 shows the greenhouse-type structures that are being built across the region by those with some financial means. Even those working towards the diversification of the regional and agricultural economies are quick to admit, however, that they are aware that their efforts are ultimately limited by the conditions of infrastructure for transportation and access to markets.

In addition to these requirements of capital and ability to assume risk, the scale of operations plays a critical role in considering the pursuit of more sustainable patterns of development. During interviews in both districts, farmers mentioned how important it is to find ways to produce more in smaller areas.

Interviewer: What do you think the plans should be for the future development of this community?

Participant in Biolley (54): I have always thought that there needs to be, eh, the 


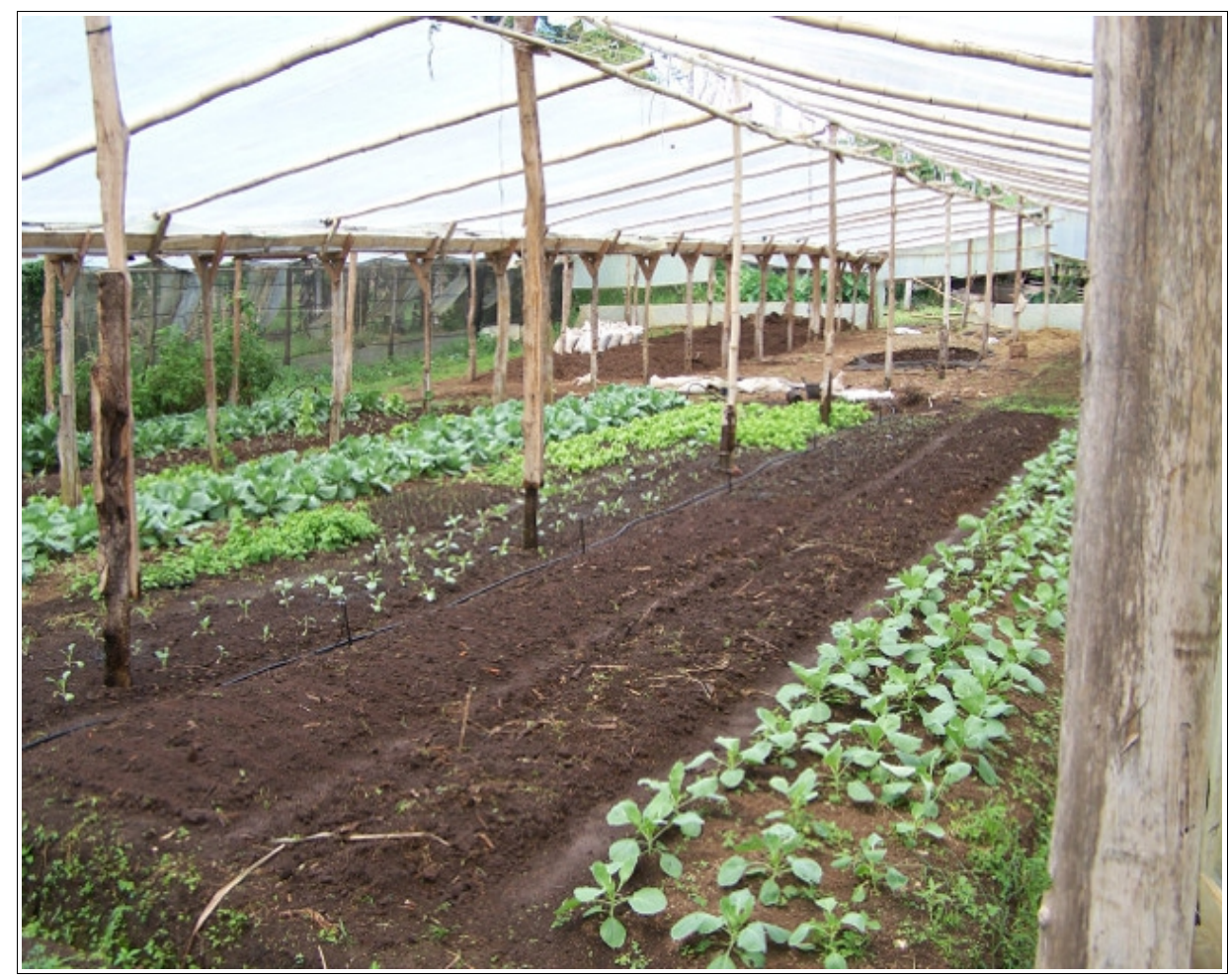

Figure 18. Greenhouse for vegetable production.

implementation of models of production, models of production in which microbusinesses can be made, or family businesses that can produce anything from vegetables to small animals. And there needs to be a market. Markets need to be stimulated, and micro-businesses so that families can resolve their problems, because it is not giving a fish so that they can eat, but teaching how to fish. There are other models. We are watching transnational companies that want to invade our territory, like the pineapple plantations and others. But, we know that these are not the models that we need, that bring a very drastic environmental impact and a social impact that is tremendous, too. So, these are not the models that we need for our communities. One has always thought that it should be a model of production at the scale of the family, in which the the wife and the kids and everybody cultivates and everybody grows and they are all together.

Figure 19 provides an image of what the diversification of agricultural production at the farm level looks like in Biolley. This household has a field cleared in the background, presumably for planting beans. On the hillside, there is sugar cane and coffee planted. There are ornamental and fruit trees around the house, and there is a small 


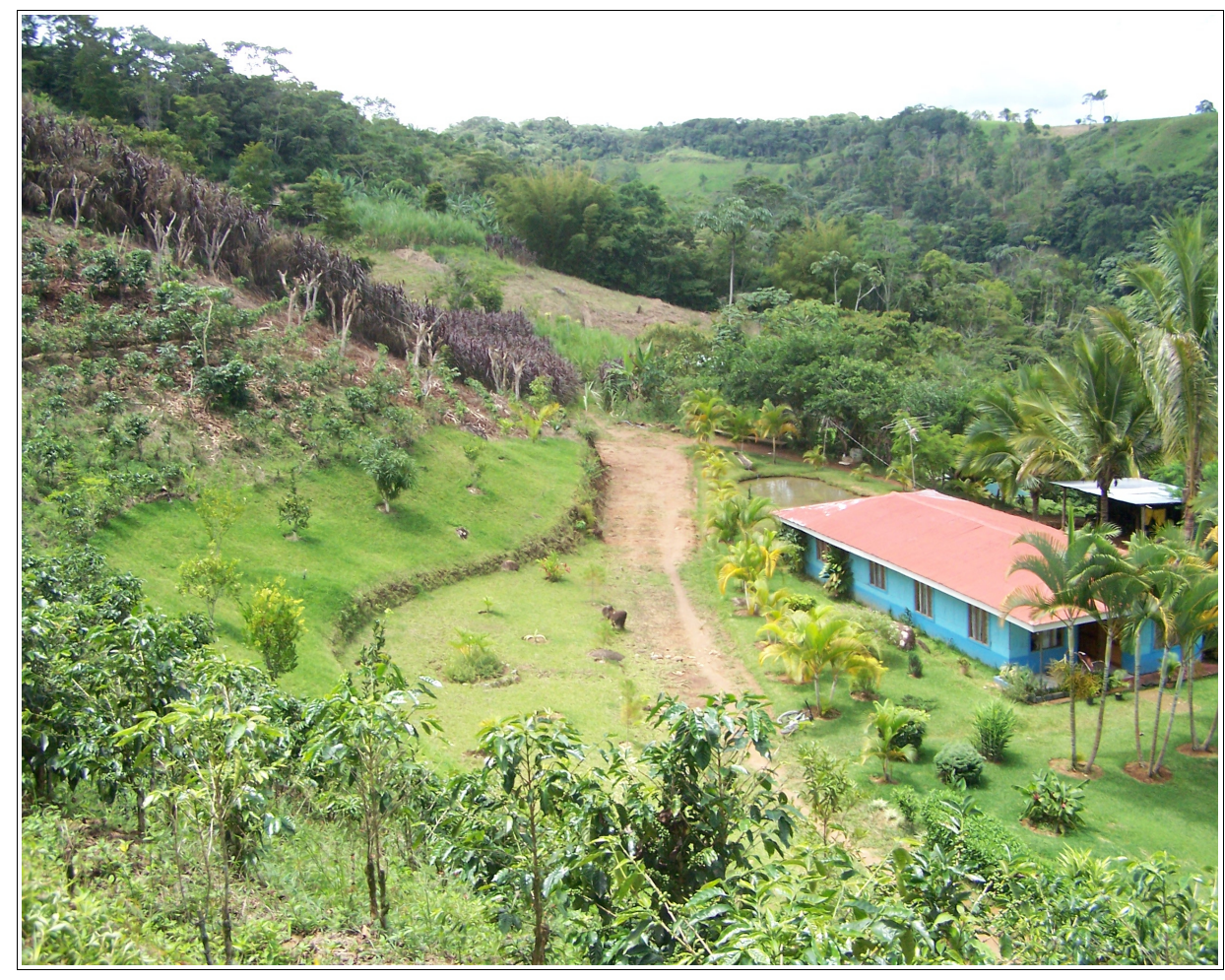

Figure 19. Example of small-scale farm diversification.

pond next to the house as well. Practicing this type of agriculture is labor-intensive and it requires that a farmer have both a broad base of knowledge and have simultaneous access to multiple product markets. Even when farmers do have sufficient land and other forms of capital to transition their mode of production, there are cultural barriers that prevent them from doing so.

On several occasions during fieldwork, and in particular across Pittier, I had people talk to me or I overheard people talking about "the lazy tico." This phrase was used to express the idea that many people prefer to continue certain behaviors, for example producing commodities instead of diversifying production on their farms, because they perceive it will be too much trouble to change. Often, the use of this expression also indicates that people choose not to change despite thinking that 
maintaining conditions as they currently are is not in their best interest. For example in terms of sustainable agriculture, even though people may know how and have the ability to raise chickens and vegetables, produce other household items, use organic fertilizer, and integrate conservation practices into their production systems, they prefer to earn cash and buy inputs and other household items they might need from local stores and other suppliers. An elder in Pittier who had served on the local health committee for 16 years expressed this sentiment when asked about the relationship between agricultural practice and the environment.

Interviewer: Are there production methods that are better for the conservation of the planet?

Participant in Pittier (27): Now, there is better access to fertilizer. There are groups that come to make sure fertilizer is used appropriately, but it costs a lot. Various groups have come here encouraging people to do this, and it is very good, but it takes too long.

Interviewer: Do you think this can improve the soil?

Participant: It's doubtful. By now the soil...it is going to take a lot for it to take up the same rhythm like it was because it had been burned, it has been totally lost.

Interviewer: But if it was worked...it's that people don't do it. If people were to work more like, the broza of the coffee or the manure to fertilize. It they were to utilize, to make the trenches for drainage so that the property didn't wash away so much. If they would even put a living fence to attach to the soil so that it didn't wash away as much.

Participant: Yes, there are opportunities to do those things. For example, there are coffee plantations that tanquean. They have tanks so that when the water washes above it falls into a tank below and stays there. From there below it will wash into another one. So, it is collecting the fertilizer and the soil.

Interviewer: And, what is your opinion as to why people don't do these things?

Participant: Sometimes because we are lazy. Sometimes because we don't want to be involved in doing so many things. But it is very good.

(The participant continued with a discussion of the time and attention involved 
in the process of composting food scraps and other organic material that are common around the household / farm and concluded with the following.)

... But this costs, or say we don't like to do those things. We want to do everything at once. Overnight. And the only thing that works that quickly is the fertilizer, the chemicals. It's easier even though its costs money.

Interviewer: How lazy, right? It's that the tico is very lazy.

Participant: That's the carcajada (joke).

While the diversification of household production is an option for some households, given the limited scale at which many operate, usually on just a few hectares of land (Schuit 2011), diversification can limit the ability of others to participate in the cash economy. Thus, the need for income and the inclination towards less labor-intensive production methods leads to a concern shared by some across Biolley that many people are not using their land at all. In the context of our discussion about how the use of land in areas surrounding PILA affects the park, one farmer expressed particular concern about cattle and industrial agriculture while labeling other methods of agricultural production "good" and suggesting their implementation to be in the interests of the park. This person went on to further explain how he perceived there to be a lack of good use of agricultural land in general and to include the lack of use in the category of bad uses mentioned earlier.

Interviewer: What do you think about the current use of land across the region? Participant in Biolley (54): I think that the use of the land, there are many ways to look at it because it depends on the different production activities. Or, how is the land being used in terms of ownership. So, there are two questions that are a little different.

Interviewer: $\mathrm{Mmhm}$.

Participant: Well, I think it's that the use, or better said the bad use of the land, 
because one of the things that I have commented about a lot in meetings that have to do with this topic, is that the people don't want to produce anymore. People don't like to plant anymore. They plant very little. The majority of people have land and they have it empty. They have it contaminated and everything because they hardly every plant. So, in other words it is use that is lacking of our land, because everyone should have their little parcel of yucca, their little parcel of produce for the family. And this is something hardly seen around the houses. So, it's more like I have noticed a lack of use of the land, or a good use of the land that has affected the community. You have to buy everything.

Although this person does not attribute the problems he sees in this situation directly to the shortcomings of individual farmers, his assessment of the current state of local agriculture and land use across Biolley points more towards the importance of understanding the "the lazy tico" and the rationale of farmers when contemplating possible development alternatives, like diversification.

Connectivity to markets, for both inputs and sales, is an important factor for farmers when considering investment in new production methods, and in this case there are differences in the patterns of connectivity across the region that depend on product as well as location. While farmers in Biolley who are diversifying their farm operation by producing vegetables are currently doing so with local markets in mind, people in Pittier are taking their produce, mostly tomatoes and peppers, to across the border into northern Panama (personal communications). On the other hand, while large cooperatives manage most of the business of exporting beef and coffee from Pittier, many farmers in Biolley have been working for years to establish relationships to help them export their coffee directly to international buyers. The conversion of coffee production across Biolley from conventional to organic has been justified in part by an awareness of how the international community associates certain production methods with environmental degradation and the quality of coffee. 
The farmer cooperative operations of ASOPROLA and ASOMOBI are the clearest manifestations of local independent efforts towards the vertical integration of their coffee production. Whereas ASOPROLA has been successful at promoting agroforestry and organic practices in farming, ASOMOBI has been successful in establishing a long-term relationship with a major Italian buyer. The significance of these two operations for local development is apparent not only in their activities, membership and reputations, but also in the lack of recibidores, or collection centers, affiliated with large commercial cooperatives with large-scale processing facilities situated in the urban, industrial centers of San Vito and Perez Zeledón (Fitzgerald 2013; ICAFE n. d. b). In Pittier, these recibidores, like the on shown in figure 20 , are commonly found along roadsides and scattered across the landscape. Farmers bring the fruit of their coffee harvest to these locations with 24 hours of being removed from plants, and it is combined with the harvest of other farmers and transported by large trucks to commercial centers for processing, drying, roasting, and preparation for shipping.

Therefore, the need for physical infrastructure for product processing and distribution is one of the factors limiting agricultural and economic diversification across the region. The history of local development and social relations within, across, and outside the region also carry significant weight in determining the portfolio of development alternatives. Given the history of commodity production in Pittier and the orientation towards external markets, vegetables production could follow the pattern of coffee production in which external interests facilitate economic efficiency and the achievement of economies of scale through investments in collection, processing, and 


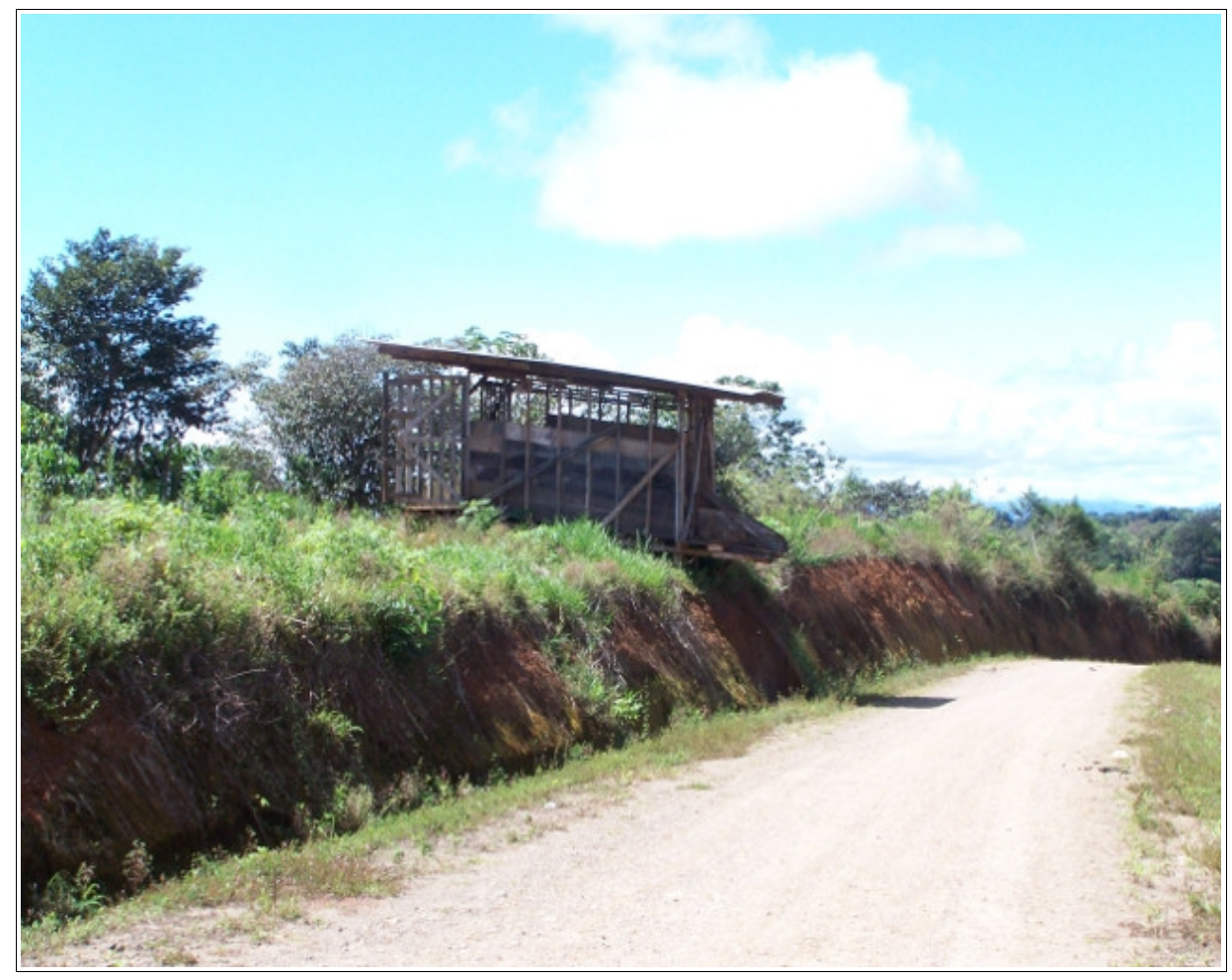

Figure 20. Recibidor in Pittier.

distribution centers. Among the potential consequences of that scenario for farmers are the receipt of lower prices for their products and dependence on the demands of external markets and national government policy. Although the history of social relations between farmers across Biolley suggest a more collaborative approach in investing in alternative production methods, this has not always been the case there either, as it appears the success of development projects may depend just as much on the support of key individual farmers as well as organizations and their leaders.

Recently, development agencies have attempted to introduce the production of new commodities in the region as part of broader national and international development programming (Maroto 2010). Figure 21 shows the results of one particular campaign to promote tilapia production in Biolley and other districts across the southern Pacific 


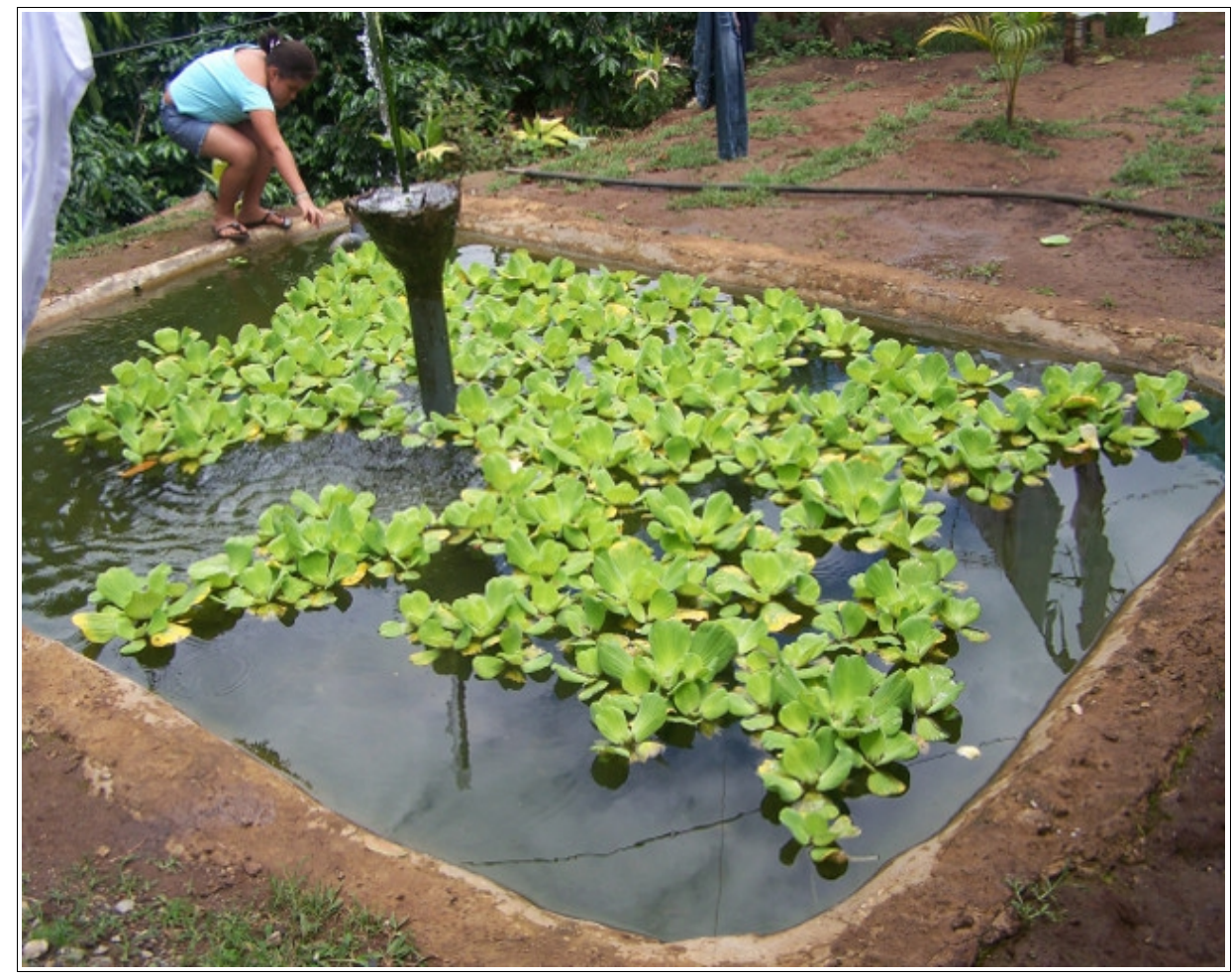

Figure 21. Household tilapia pond.

region. This small tilapia pond was installed on the property of one small landowner next the family's house. This individual, Hector, was a local entrepreneur in the sense that he was involved several income-generating endeavors simultaneously. Hector owns and operates a small pulperia, he has a small piece of land on which he had inter-planted coffee, banana, and hardwood trees, and he occasionally works as a day laborer on other farms. He became interested in tilapia production when he attended a meeting held in the community about the project. He subsequently took it upon himself to install the pond on his property and turned into a local advocate for the project. For a short period of time, funding was available for capacity building and investments in local infrastructure. However, after about a year of promotion there appeared to be little buy-in from the communities in the district. Funding for the project was no longer available and 
representatives from the agency stopped visiting communities in Biolley. In telling me about this project, Hector took me on a walk around the community to show me a few ponds that he helped install on other people's property that he now takes care of. He also introduced me to another person who he described as his "partner" in his effort. The man was older, with adult children, and his property (home, vehicles, etc.) indicated that he, in comparison to Hector whose most valuable asset appeared to be his health and ability to labor, had some accumulated material wealth. As we visited with him, he mentioned the economic opportunity he saw in project, he showed us the improvements he was making to his pond, and talked most about his day-to-day experiences in caring for the fish.

Somewhat like the experience of vegetable growers in Pittier, one of the challenges people interested in producing tilapia in Biolley face is the isolation of their effort. Without the participation of a critical mass of local producers, it may be too costly for individuals to pursue what might otherwise be more sustainable alternative methods of agricultural production. A major difference, though, is the presence of established local associations of farmers in Biolley. During my last field visit, ASOPROLA was utilizing some of its international student volunteers in the installation of a pond behind the lodge on its property.

There are at least two other activities somewhat outside of food and agricultural production that present themselves as viable options for the diversification of local and regional development: tourism and payments for environmental services. During the time of research, tourism as a development strategy was more widely practiced in Biolley than in Pittier. Tourism activities included training guides for tourists interested in entering 
PILA, and rural community-based tourism for tourist groups interested in experiential learning and community development. As alluded to earlier and discussed in more detail in the next chapter, many people across Pittier are interested in increasing tourism activity in their area. However, the actual physical and human capacity to host visitors and the number of tourists visiting Biolley are far greater.

Nevertheless, when talking with people from both districts about the benefits associated with PILA, one of the most common responses is the opportunity for development through tourism that the park presents in the area. [BIO] A housewife and member of a local women's association in Pittier had this to say about the park:

Participant in Pittier (29): I think that the park is a very important means that we have, like an ally that we have here for our tourism, too. An ally for our nature, an ally to breather pure air, to have a healthier community. There is hope that one day the community can take advantage of the opportunity for ecotourism.

Interviewer: What do you think about the relationship between the park and the development of the community?

Participant in Pittier (30): Well, right now, there is not really community development through the park. But I think there could be something in the future, something that could bring us benefit with tourism.

$\cdots$

Interviewer: What do you think about the relationship between the park and this area?

Participant in Biolley (32): It is coming along good, but here, it still hasn't been a lot of tourism. Well, it is happening, but it still isn't at the scale that we would like.

Interviewer: What do you think about the park?

Participant in Biolley (55): I see it as being very important because of conservation, not only of forests, plants and animals, the conservation of the 
springs and rivers, and also as a tourist attraction. It is really an important part of the district, so, the expectation is that we have is the place becomes touristic to improve the area.

In theory, tourism as an economic development activity has the potential to be beneficial for both the environment and the communities in the buffer zone. Tourism is the park is highly regulated, with admission into the core protected area only allowable when accompanied by a guide who is formally trained and recognized by park management as being in good standing. During my fieldwork, there were no trained guides available in Pittier. Access to the park through Pittier was granted on a person-by-person basis and a the decision was made based on the judgment of the ranger working the station. On the other hand, there were already a few guides in Biolley who had been trained. Access to the park was granted by staff and the Altamira ranger station where there was a trail that was regularly maintained and a valley, known as Valle de Silencio, that is a rather popular destination. Although some people in Biolley may feel that the level of tourism activity has not reached its full potential, institutional arrangements and market demand may limit the number of people who will have the opportunity to be involved in this development activity.

Another activity that might provide an alternative source of income for some households in the region is participation in Costa Rica's payment for environmental services (PES) program. Research participants were not asked about PES directly, and no one contemplated this explicitly as an alternative source of income during interviews or informal conversations. However, data on PES contracts is available from the Costa Rican Fund for National Forestry Finance (FONAFIFO), and an overview of this secondary data can be coupled with thoughts interview participants did share about the 
management of secondary forest growth to speculate a bit on how the promotion of such a program might be received in communities across the study location.

During interviews, people pointed to the need to train farmers how to manage the secondary forests and other resources adjacent the protected area.

Interviewer: Are there opportunities to improve land use around the park?

Participant (36): Yes, there are clearly opportunities.

Interviewer: What might these be?

Participant: These could be training people how to work along the edge of the park, how to work secondary forest and all of that. This would be a good opportunity for protection. Who knows what the government would think about that, if they might pay those people to have their land like that. Give them an opportunity like that or if it would be up to them to take it on themselves, to conserve those secondary forests there in the area of support.

$\cdots$

Interviewer: What do you think the plans for development here should be?

Participant (42): In these plans, well, I think that my vision, at least, that I have been able to share with a lot of people, is towards this, the education of the people, adults as much as young people, women and children. This should be the base. Capacity building in administration, above all, of natural resources, whether it be land, water, forest, and all of this.

The recognition of a need for this type of capacity building points to an awareness among farmers of the importance of social and ecological relationships between surrounding lands, core forest area, and neighboring communities for future development and land and resource use and conservation in the region. It also suggests the possibility of a future collaboration between members of agricultural communities and park management in a PES program.

Among the problems of proposing such a collaboration is that in order to obtain financial and institutional support, conservation programs are usually required to 
demonstrate an ability to make an impact on a large scale in order to get funding and other types of institutional support. While giving the necessary attention to large-scale impacts, it can be difficult to operationalize measures at a scale that would enable farmers in many places to implement approved conservation practices on their farms. When asked about farming practices that might be better or worse for the environment, the following farmer in Pittier readily acknowledges that he is limited in his ability to implement alternative production methods, like forestry, on his farm because he does not have enough land available to take out of other forms of production.

Participant (31): Well, there are methods that are good for conservation. In fact, if one can, as a farmer, reforest a certain part of our land, well, in my case I can't because the area is too small. I'm not going to be able to say that I would do that. But there are projects that are advantageous.

In addition to the importance of understanding economies of scale as it relates to the implementation of conservation programs on farms, Zbinden and Lee (2005) points out that understanding the dynamics of land titling in a particular location can be critical to understanding participation in PES programs.

In comparing farmer's ideas about the importance of obtaining clear title to land across the study location, farmers in Biolley tended to talk about the value of having a secure sense of ownership as well as the opportunities a land title creates for working with banks and attracting attention from outside investors.

Interviewer: Is it important to have a title for your property?

Participant in Biolley (52): Ah yes. Of course it is. It is one of the things that I worried about most here, because we are almost without title. And how they laws are now, if the government feels like it they leave someone in the street. So, this worries me a lot because a bill of sale doesn't mean anything here. I asked how much they would charge me for this, they were going to measure this lot for me. They told me they were going to charge 350,000 [\$US 700]. The only way 
to pay for the measurement is to sell something.

Interviewer: What would be the benefits if you had a title?

Participant: The first thing is that one would be able to live calmer, knowing that legally here I have a piece of land. We would feel more confident. And the second thing is that for me, the title has a lot of value because it shows that there will be a time when the land will not be sold. With the situation they way that it is in the whole country now, if you offer to sell a piece of land with title... a person who wants to buy won't be able to negotiate much, but with just a bill of sale, everybody wants to sell because it seems like a lie.

Interviewer: Do you think it is important have title to your land?

Participant in Biolley (53): This is like having it registered, it's very important because with something registered you can work with a bank. You can work anywhere. If you don't have paperwork, you can't work.

Interviewer: Does your farm have title?

Participant: No, a plan.

Interviewer: What are the benefits of having title?

Participant: The benefit is that one has security. More security, and it opens more opportunities for one to work, with credit, because then you don't have to worry about what to fertilize with. And this provides a lot of support.

Interviewer: Do you think it is important to have a title for your property?

Participant in Biolley (55): Yes, I think it is because people with title can apply for a loan or something like that to improve production. Legal documentation can speed up these kinds of things.

On the other hand, while farmers in Pittier also mentioned the importance of having a clear land title presents for their sense of security and obtaining access to credit and government services, they were also inclined to talk about the various obligations it represents. For most of them, a clear title gave them a sense of security in the ownership of their property for themselves and their family, and they also valued a clear title because it was part of fulfilling one's obligations to family and to contribute to the 
national and municipal tax base.

Interviewer: Is it important for people to have title for their land?

Participant in Pittier (23): Yes. Yes, it is very important.

Interviewer: What are the benefits?

Participant: If you don't have title, you don't have anything. If you need a loan or something, they aren't going give it. If you don't have title, you don't have anything. That's just the way it is.

Interviewer: Maybe it's better not to have title, that way you also don't have debt.

Participant: No. No, no, it's that you have to know...it's that this is the problem. I remember when the coffee here was worth something. Many people took out loans, but they used these loans for other things, not only for what they took them out for. That's all good, they spent the money. But when the payments came, no, but I think, well, I have never worked with loans, but I think it is very important. If someone needs a bit a help, I think it is very important. And if one doesn't have title...this is why I am getting title for this part where the business is. I already have the house on a plan. I am going to title the land my uncle's house is on, too. I you don't have anything legally in your name, you can't make any transactions. That's just the way it is. I see it as an advantage.

Interviewer: So, what might be some reasons people have for not wanting to get a title? Do you think there might be people who do not want to title their property?

Participant: I think so, but I am giving my personal opinion. I have a daughter, and if I pass away my daughter would be completely with out anything. That's how I see it. It's for the kids. In my case it is. So, I don't know. I don't see any reason...Many say that we should have it so that we pay taxes. I think that paying taxes is an obligation of everyone, to pay what's fair. If you don't have anything, although the majority of millionaires don't pay them...well, you don't have to base it on this. I'm basing it on my own situation. If I have something and all my paperwork is current, I am ready in case something happens, at the municipality, if not everything is current, first you have to pay and then make another trip later.

Interviewer: Is it important for you to have title to your land?

Participant in Pittier (26): Ah yes, clearly, it is very important for someone to know that the land that you have is all in order. 
Interviewer: What are the benefits?

Participant: I would say that the benefits are that everything...well, I would like that all the properties have their titles so that we all pay taxes in the country. For everyone to pay the taxes that correspond to them in the country, in the municipality.

Given the clearer emphasis on a connection between land title and economic opportunities by farmers in Biolley, and based on some of the other differences between approaches to agriculture and conservation across Biolley and Pittier as presented throughout this chapter, one might conclude this section by speculating that there would be a greater rate of participation in the PES program in Biolley than in Pittier. As shown in figure 22, however, this was not the case in 2000. According data available for that time, the districts had similar proportions of their land under under some from of PES contract. When considering this issue, it is also important to keep in mind the larger relative proportion of territory in Biolley already subsumed by PILA should and the level of integration of forests and farmlands across the landscape.

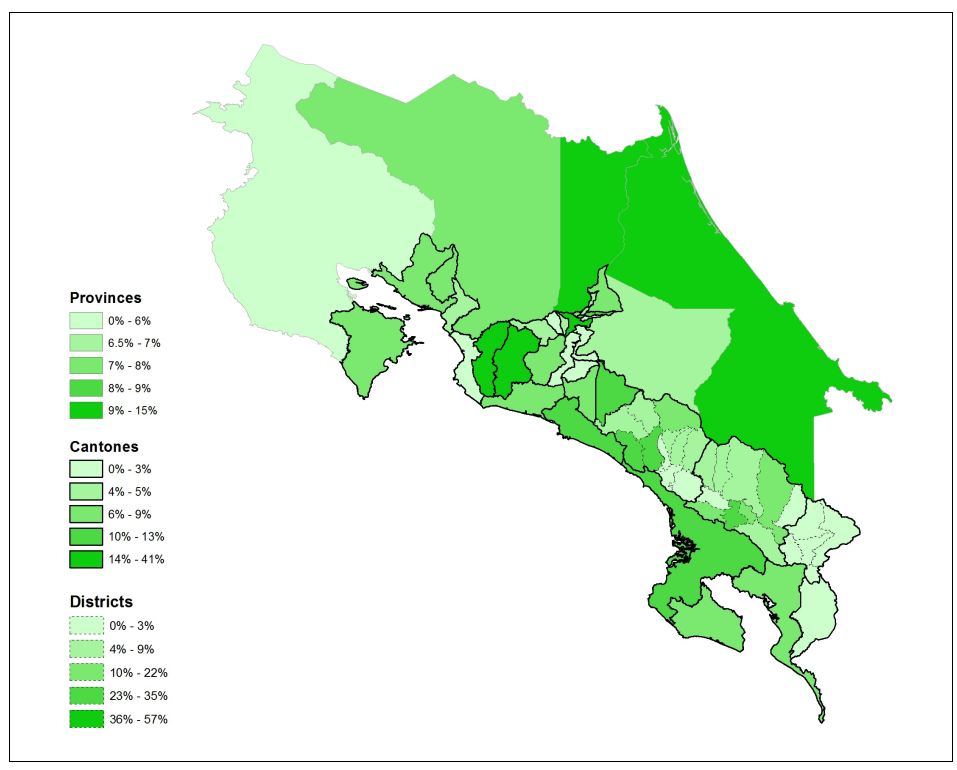

Figure 22. Proportion of land area under payment for environmental services contract. Source: FONAFIFO. 2000. 


\section{Chapter 6: Development Associations: Establishing Inter-Personal and Inter- Organizational Working Relationships}

In this chapter, I provide a detailed analysis of some of the social structures and organizational processes influencing development across the study region. The chapter looks at two organizations in particular, the Association of Producers of La Amistad (ASOPROLA) and the Women's Association of Agua Caliente of Coto Brus

(ASOFAC.CB), and it introduces a network development processes intended to increase collaboration between municipal districts across Pittier. First, I identify and describe ASOPROLA as a local actor with influence in development across the municipalities of Buenos Aires and Coto Brus. In doing so, I also briefly explore the organization's history, its structure, and some of its activities related to agricultural production and social organization. Next, I identify and describe ASOFAC.CB as having the potential to become an influential actor in local and regional development and I explore some of the achievements and struggles of this organization during its first years of existence. Lastly, I present the "planned intervention" of the municipal government of Coto Brus that is part of a national development strategy to join the efforts of district-level governments and grassroots organizations in a multilevel integrated network of development associations.

In the context of this chapter, it is important to keep in mind that I employ two distinct uses of the phrase "development association." Both of the local organizations being discussed are associations in name and function. However, there is a national policy framework for integrated development that provides formal recognition of community 
governments as development associations by the national government, and these local governments are referred to specifically as Integrated Development Associations (ADIs). Local governments gain recognition through a supervised electoral process, and it follows that each community-level government that fulfills the requirements set forth by the policy of the central government is also legitimately recognized by its respective, higherlevel district and municipal level governments. Whereas ASOPROLA is an association of producers, or farmers, and ASOFAC.CB is an association of women, I also consider these organizations local development associations; however, neither is an ADI.

The formal (re)structuring of government through the national program for political decentralization in Costa Rica actually focuses more on transferring power to the municipal level of government, which operates at the level of the cantón, a territory somewhat comparable to a county in the United States. The Institute of Municipal Development and Evaluation (IFAM) provides further incentives and support to municipal governments for encouraging increased citizen participation in government through the continued establishment and recognition of ADIs. In situations such as the one in which this study is located, however, landscape conditions and local histories may sometimes have a greater influence on local political organization than national policy. As mentioned earlier, many communities across Biolley identify more closely with the commercial and political center of Coto Brus than they do with the center of their own municipality, Buenos Aires (TNC 2004). Nevertheless, according to research participants, there is no history, at least not until very recently, of a direct relationship between some of the more remote communities of Coto Brus and Biolley. Even though some of these 
communities are physically located within 10 miles of one another, the rugged terrain and transnational investments in infrastructure have oriented them in different directions. Now, the presence of PILA and the relative strengths of grassroots organizations across the region present possible tensions in the formation of regional networks of development associations as well as in the establishment of formal community governments.

The study of development associations presented here is more so one that focuses on group formation and inter-personal and inter-group relations than it is a study of formal government (Margerum 2011, 88-110). When people in the area were asked about the role of the formal, or central, government in their lives during interviews and conversation, their responses were limited to complaints about government intervention in agricultural commodity markets and their experiences with the Ministry of Environment (MINAET). One might assume that the Rural Development Program of the Ministry of Agriculture (MAG) would have an established presence in the communities across the study region, however, very few family farm members reported having interacted at all with government agencies other than MINAET. Instead, in discussing their work in agriculture and/or community development, most participants who were farmers in Biolley and members of the womens association in Pittier talked about their relationships and experiences in dealing with ASOPROLA.

Interviewer: Where do you get information about how you grow your coffee? Are there people that you have worked with in the past?

Participant in Biolley (54): When I took the initiative to convert my farm to organic, I found myself working with an ally named ASOPROLA. They are the ones who have helped me by providing information, training, and everything for this activity, to be able to implement my plan in the best way. ASOPROLA has directed capacity building and I always participate in that. This has helped me a lot. 
Indeed, ASOPROLA has played a key role in the formation of other organizations, including ASOFAC.CB, in various places across the region. Its presence is also related to an array of research, education, and community development activities that have given shape to the social and natural landscape of the region.

\section{Conceptual Model}

I developed a sketch of the diagram in figure 23 during fieldwork to aid in my attempt to understand the inter-personal and inter-organizational dynamics of community organizations in the study region. When the focus is placed on the individual actor, the model also proves to be a useful tool for demonstrating the complexity of individual identity formation. It shows how association members can be simultaneously involved in

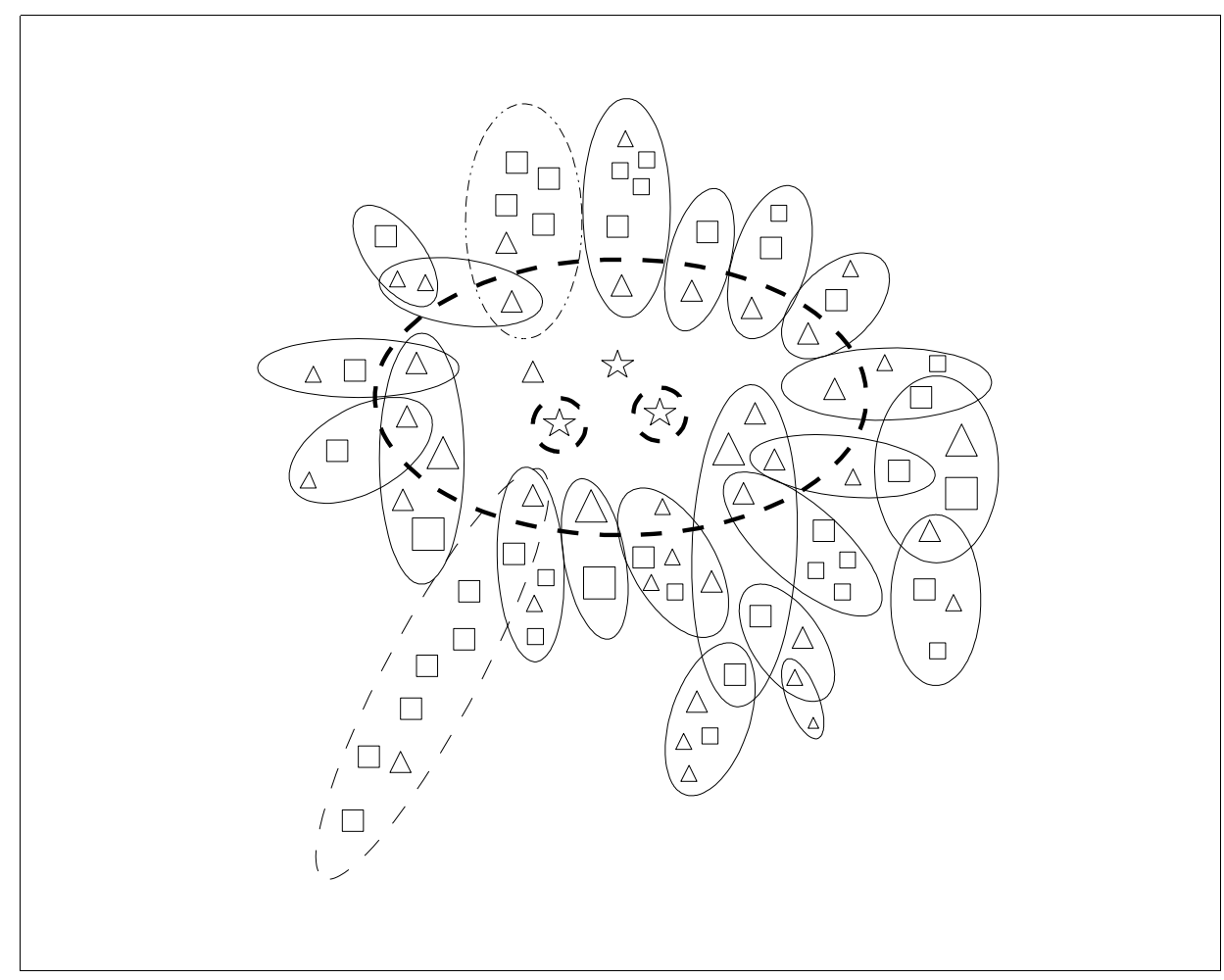

Figure 23. Conceptual model for the study of inter-personal and interorganizational relationships. 
association activity while negotiating their roles and responsibilities as a family member, a community member, and a member of any number of other organizations. Along with having to negotiate organizational political agendas, members of development associations have to consistently deal with personal matters that may or may not seem relevant to the organizational context. Further, membership in multiple organizations can create tensions within individuals and subsequently across the membership of the organization. When applied in a study of social relations, such a model can help evaluate how key individuals, from within or outside an organization, can play significant roles in influencing organizational initiatives and membership. For example, in a later discussion of the historical trajectory of the work of ASOFAC.CB, we will see how the interests and influence of organizations and individuals outside the Association end up changing the direction of the work of the Association, and in the process cause some members to question their commitment to it.

According to a report by The Nature Conservancy, families that have relocated to Biolley and Pittier tend to "incorporate" when there is a need to work collectively (TNC 2004, 36-7). While in the past this process of incorporation was demonstrated in the collective work of land clearing, for the most part the contemporary process revolves around the planning of annual festivals, and to a lesser extent the provision of public services. The annual festivals are very important sources of pride and identity in communities across the region. Generally, there is a lot of prestige associated with the committees and their members that organize these events. Many of the festivals emphasize a certain aspect of agriculture or the environment. For example, the Festival of 
San Juan in March includes a parade of harvest fruits and vegetables, and there is an annual anniversary celebration of the founding of PILA. It is not uncommon for people to spend weeks or months preparing for these celebrations, and some communities have invested in infrastructure used for related events. The redondel, or rodeo center, in Agua Caliente is one particular example. The prevalence of soccer fields across the districts could be considered another. These events bring people together in planning and celebration, and they allow people to set aside differences, at least temporarily, to acknowledge their identities and the accomplishment of forging ahead in a place where it is often very difficult to maintain a livelihood.

The regular business of community development, such as that conducted by formal community government or other organizations, is less apparent in Pittier and Biolley than the public celebrations. Communities in these districts tend to have committees that coordinate efforts for establishing and improving schools, churches, health care, and infrastructure for utilities, among other things. Most of these efforts, however, are not widely discussed and obtaining information about committee activity depends on identifying an individual who is a member of a relevant committee or someone with a particular interest in the topic. Most often, however, the extent to which people are willing to discuss these topics is to mention the name of someone who they know as being a member of one of the committees. This being the case, I was, however, able to accumulate some information about various activities related to community development in my research. In terms of studying "formal" development associations, however, my research focused on the two organizations that had the closest working 
relationships with MINAET, and perhaps therefore the two most important in terms of understanding the relationships between agricultural production and natural resource management in their respective districts. Perhaps also due to their relationships with MINAET, these two organizations seem to also be the most available to me and accessible by the public during the time of my fieldwork.

\section{ASOPROLA: The Association of Producers of La Amistad}

There are two rather well-known and well-established development associations in Biolley. The Association of Women of Biolley (ASOMOBI) is located in the community of San Luis (which is commonly referred to as Biolley), in the district of Biolley; and, the Association of Producers of La Amistad (ASOPROLA) is located in Altamira, Biolley. There is also a continuing effort to establish a network of community organizations across the districts of Biolley, Potrero Grande (to the north), and Pittier (to the south). This network is referred to as La Red Quercus, and it is organized by community leaders, primarily from Biolley, Biolley, to promote tourism, environmental education, and sustainable development across the region. Community leaders from Altamira have also been involved in the development of La Red Quercus, however, during my most recent fieldwork I was told that they had decided to step away, at least temporarily, from this network organizational effort and focus more on solidifying ongoing development activities within ASOPROLA.

ASOPROLA is by far the most prominent grassroots organization in the region. This position is established by it being the organization referred to most often by research participants, its history of working with farmers, researchers and educators, and its 
continuing involvement in community development activities within and beyond the district (ASOFAC.CB meeting minutes). During several interviews, ASOPROLA was the only organization that people could think of when asked to identify organizations working towards the development of the region. In addition to its role as a cooperative for local coffee growers, this organization is a member of a national rural tourism network (ACTUAR 2013) and it frequently hosts groups of student tourists from around the world as part of its ecotourism and community development programming. ASOPROLA maintains a broad array of close working relationships that include outside professionals, such as those from MINAET, International Student Volunteers (ISV), and other government and non-governmental agencies involved in research, education, environmental protection, and community development. ASOPROLA works with agencies involved mostly in transnational development as well as local groups and individuals. For example, the organization coordinates visits from ISV groups along with the training of local guides, environmental educators, and researchers (Stuchi 2009). These relationships are present at both personal and organizational levels. In fact, much of the time I spent in Biolley during fieldwork was facilitated in some way by ASOPROLA.

Figure 24 provides a window into several important aspects of ASOPROLA's operations. This is the restaurant and visitor center that is run primarily by the Women's Association of Altamira. This type of small, casual restaurant is referred to as a soda across most of Costa Rica. In this context, it provides a place for groups of visitors to have their meals. It also serves as an informal meeting place for community members and 


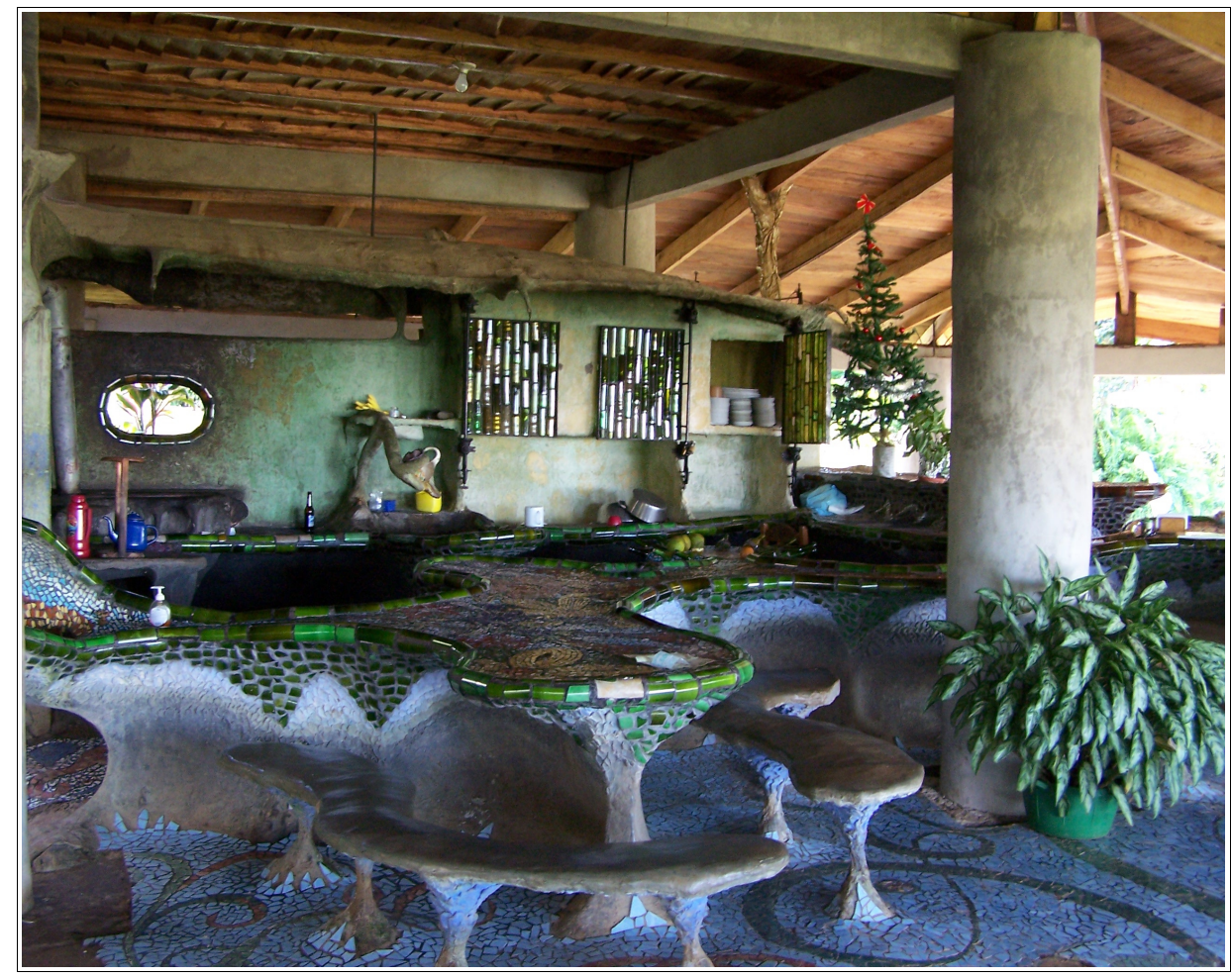

Figure 24. ASOPROLA restaurant and visitors center.

a place for people passing through the area to relax and have a meal or coffee and snack. The appearance of this particular soda, however, is not typical of sodas across Costa Rica. The design, construction, and decoration of this and many other ASOPROLA structures has involved a local resident, who is a nationally celebrated artist. He has been commissioned for various projects, usually in protected or environmentally sensitive areas, across Costa Rica, and likes to use as many natural and recycled materials in his work as possible (Pancho's Projects 2014). One particularly well-known example of his work is the pedestrian suspension bridge made with marine debris on the Costa Rican Isla de Coco.

In addition to the image and opportunity ASOPROLA's soda represents for international visitors (many volunteer groups have been involved in setting the tile 
mosaic and in other projects around the property during their visits), this particular soda provides some insight into the culture of the region. This is one of the few places, it not the only place, within an-hour drive that is regularly open to serve hot meals to the public. Otherwise, the only refreshments available to visitors to the region who do not have other arrangements for meals and lodging are the snacks and drinks sold in the pulperias that scatter the landscape (figure 17 in Chapter 3).

All of ASOPROLA's facilities are centrally located in Altamira. In addition to its open-air restaurant, these facilities include a small lodge that can accommodate around 15 guests at one time. There is a small office building with three offices and a reception area. There is also a separate building that can serve as a classroom or meeting room for about 30 people. All of these buildings are located within 50 meters of the main road where there is a covered bus stop that matches the mosaic design of the soda. Although part of the road between ASOPROLA and the MINAET Altamira ranger station is a steep climb, it is relatively well-maintained and easy for people to access. This is important because it is the primary legal point of entry into the core of PILA from this area. With these facilities and the capacity of its members, ASOPROLA is in a good position to facilitate increased tourism activity in the region, which is what people across the region think is one of the major potential benefits that PILA has to offer their communities (page $103-4$ in Chapter 3).

As discussed in Chapter 3, ASOPROLA's origins can be located in large part in the protest of logging activity that took place in Altamira during the early 1980s. Many of the people responsible for the organization of the community at that time were, or are still 
today, active and influential in the formation of ASOPROLA (personal communication; Monge, Cortés, Delgado, Delgado, and Carbonell n.d.). That protest led to the consolidation of community concerns about environmental protection and local economic development in the Reforestation and Natural Resource Protection Committee, which was established in Altamira in 1986. Although this Committee no longer exists, many of the interests that were expressed in it are still present in the current work of ASOPROLA. The following brief excerpt from an interview with a farmer in Biolley, who is also an active member of ASOPROLA, demonstrates how the organization continues to support a broad array of community development interests by emphasizing improvements in communication and social relations between farmers as a general practice in its work.

Interviewer: What do you see as the benefits of your collaboration with ASOPORLA?

Participant in Biolley (54): It's that when somebody talks with the farmer and people involved, one goes along building a belief. In the dialogues, sometimes, with different farm owners, one can tell them that in reality it is important to look beyond money when looking at organic products. It is not only the economic benefit that it provides, but also the health it generates, as much for human health as for the health of the planet. So, one goes building a circle of environmental education, too, for the families that are participating in the program.

Before continuing as if this is indicative of the general public perception of ASOPROLA in different places across the study location, it is important to point out that there was no mention of ASOPROLA during interviews with farmers in Pittier (table 1 in Chapter 1). The presence of ASOPROLA in Pittier appears to be limited to its involvement in activities with ASOFAC.CB and for the most part through its role as a facilitator of an indirect working relationship between MINAET and ASOFAC.CB. There are at least two major reasons ASOPROLA is not in the fore of the minds and practices of 
farmers in Pittier. During informal conversations with members of the ASOPROLA board, they mentioned to me that they have continually struggled with efforts to market their agricultural services to a regional audience. And, as mentioned in the previous chapter, farmers across Pittier tend to be focused more on markets outside the region for the sale of their agricultural products. Further, the production of organic coffee is a major focus of ASOPROLA, while the current major export of farmers across Pittier is coffee produced conventionally, in other words, relying heavily on the use of chemical inputs. In a similar way, production across Pittier is still heavily influenced by larger, commercial cooperatives located in the urban, industrial, and commercial centers of San Vito and Perez Zeledón (Fitzgerald 2013). In this sense, the distinct roles ASOPROLA plays in collaborating with other local and transnational organizations as part of broader regional agricultural and community development efforts can be highlighted by comparing the various ways farmers evaluate opportunities for implementing organic production methods on their farms.

Farmers across both districts generally recognize that organic production methods are better for the environment and they associate the use of these methods with many of the aesthetic and natural characteristics of the environment that they also list as the things they like most about the place they live. Similarly, farmers across both districts claim there is a need for additional support for those interested in transitioning from conventional to organic production methods. They refer to a need for financial support, especially during the first three years after deciding to adopt organic production methods. They also generally agree there is a need for information about best practices and 
strategies for dealing with pests and diseases that are usually dealt with through the application of chemical.

One of the major differences between conversations about organic production with farmers in Biolley and conversations about organic production with farmers in Pittier is that farmers in Pittier tend to ascribe the responsibility for providing related information to the government. On the other hand, farmers in Biolley, even those who for financial reasons have recently converted their farms back to conventional methods of production, tend to refer to ASOPROLA as their best source of information about agricultural production. The influence of ASOPROLA on agriculture across the Biolley district is also noticeable in the way that farmers use financial terms in talking about production costs and price premiums associated with organic coffee. It is also apparent that they are drawing on their personal experiences during these discussions, and at times they do so conflicted ways as they may have recently decided to reintroduce conventional methods for financial reasons despite their concerns about the health of their family and the environment. When these discussions of organic production are compared with discussions with farmers in Pittier, no mention of finance appears in Pittier other than when it is discussed in the context of a need for government support and access to credit. In other words, it appears ASOPROLA has been somewhat successful in filling gaps in markets and meeting the financial and informational needs of farmers so they are able to gain experience in organic production. Farmers in Pittier, where ASOPROLA has a very limited presence, lack experience in organic production and therefore have not been involved in organic produce in formal commercial markets. As a result, their discussion 
of reasons for producing organically did not include mention of price premiums or the availability of inputs, and they did not discuss their rationale for deciding between production methods. Instead, their comments were focused primarily on the environmental and health benefits that they associated with organic production.

The following excerpts of interviews highlight some of the key differences and similarities in conversations about organic production that were found through comparing discussions of organic production involving farmers in Biolley with discussions of organic production involving farmers Pittier.

Interviewer: Are there opportunities to improve land use and other natural resources with good agricultural practices?

Participant in Pittier (31): Yes...trying as much as possible to not use chemicals, but doing everything naturally. Many places in this area are generating organic fertilizers that are used to generate good production, because it is something natural and it is not damaging the environment.

Interviewer: What might prevent someone from adopting these practices?

Participant: In reality, I don't see any consequence that would prevent anything that would generate a benefit for the environment. Because doing something organically is not affecting with anything chemical, neither the oxygen nor the soils. So I don't see any concern in this respect.

Interviewer: What are some of the biggest obstacles faced by families in this area? For example in community development.

Participant in Pittier (25): In community development, well, perhaps a lack of good roads. Perhaps a lack of more information. Just a little while ago the community development association was formed here. These associations help a lot, and they provide a lot of training for the people, right. Because here, the truth is that we are all people without education, right, the majority, all of the old people we are people without education. So, through the Integrated Development Association they can provide capacity building for farmers, and women, too. Because through the development association one can also look for help so that they send people to collaborate and give courses, courses from INA [Institute for National Education] to learn more about how to improve...well, my son Juan, he is taking classes to learn how to have the farm in good condition, in 
pasture. I don't remember the name of the course exactly, pasture management or something like that, to learn how to plant good pastures on the farm. Through the association, they can be asking for courses for people to learn about a lot of things, like sewing and making furniture.

Interviewer: How do you manage your farm now?

Participant in Biolley (36): Manage. How? To talk about conservation?

Interviewer: Yes, if it is organic or conventional?

Participant: It was just converted to conventional.

Interviewer: Mmhm.

Participant: Yes, it was organic for about three years, but we saw that it didn't generate enough for us to make it. So, we returned to conventional methods...We have always been very much in favor of environment, right. We converted to conventional methods with a lot of attention to the use of chemicals.

Interviewer: What was the reason for changing?

Participant: Because it wasn't profitable. The main reason was because it wasn't profitable. The problem is that we don't have a difference in price. The price is almost the same for conventional as it is for organic, with the disadvantage that the organic comes with a lot of requirements for maintenance. But the price difference in this, the price difference did not make up for the loss in production, you see.

Interviewer: What do you think about the difference in the yield between the two?

Participant: I am in $100 \%$ in agreement with the conventional.

Currently, as the primary driver of the regional economy, coffee production appears to be the greatest avenue for diffusion of practices related to organic, or sustainable, agriculture across the study location. While ASOPROLA has been effective in working with farmers to introduce organic production in some places, the emphasis on finance has relied heavily on price premiums for increased quality to compensate for reductions in harvest quantities. Absent a local mechanism for stabilizing prices or a direct relationship with a buyer willing to commit to a certain pricing method, 
ASOPROLA and its membership remain vulnerable to the fluctuations of the commodity market. Although ASOPROLA is aware of farmers' interest in price premiums and has focused on this issue in presenting organic production as viable option for farmers in the past, the organization is aware of the challenge market instability as it relates to this approach and it uses other strategies to promote sustainable agriculture in its district.

Some members of ASOPROLA are emphasizing the local production of inputs for organic production. One of the things mentioned often by farmers in Biolley during their discussions of organic production is the difficulty they have in acquiring inputs for production. The following comment from an organic coffee grower with a diverse production system in Biolley attests to the significance of this challenge.

Interviewer: What are the difficulties in coffee production?

Participant in Biolley (37): The difficulties of coffee have always been the same. The total collapse of the price of coffee around '97. Prices are so terrible, it doesn't even pay to maintain the fields. So, the low price is the most terrible thing. After that, the diseases. In the case of conventional agriculture, expensive inputs and things like that. And in the organic, maintaining labor in the fields is very difficult because it rains so much here. Weeds grow so quickly that it costs a lot to maintain a coffee field. And, to bring basic materials, even to produce organic fertilizer, is difficult because we can't believe what some people say about cutting some handfuls of weeds and throwing in them in a sack and throw it on the plants. No, this is a lie. For an organic coffee field to truly be good, you have to apply sufficient organic material that has been converted into organic fertilizer. Let's hope with MM [mountain microorganisms] and already well prepared. Adding compost, what you like to add. But this has a cost and it requires basic materials like gallinaza (chicken manure) or broza de café (leftover pulp and skins from processing coffee beans) or cow manure. All of this that I am mentioning, almost all of the farms should have a model with one, two, or three cows, with a few goats, a few horses, that will produce this manure for fertilizer. Then, it is easier. The animal gives a little milk, it gives a little start for the farm, for the family, and also this added production of fertilizer because four or five stabled animals in one year will produce huge amounts that can be mixed with leaves and other organic materials, with MM, this that can be picked up from the mountain that reproduces with other things. Then you have something to fertilize the farm a little easier. 
Along with its efforts focused on organic production, ASOPROLA also promotes some of the agricultural diversification strategies highlighted in Chapter 3 (93-107). Although the organization, its members, and other local farmers may have experienced setbacks in their pursuit to implement organic production methods, a turn towards emphasizing the complexity of local agricultural and ecological systems in agricultural production may ultimately better serve the broader interests in the environment and health that are present among farmers in both Biolley and Pittier. The option to produce inputs locally may be another strong point to make with farmers as problems associated with the cost and availability of inputs were often discussed by farmers across the study location.

Under certain circumstances, whether they are related to agriculture or community organizing in general, ASOPROLA has also demonstrated the ability to take on the role of a training and capacity building agent in agriculture and community development across the region (Stuchi 2009; EDUCA/PILA n. d.). Several farmers in Biolley mentioned the importance of having an organization in which people could collaborate for the purposes of community development. Not only do people believe that more can be accomplished working together than when they work alone, but the ability to present a coherent group effort is believed to be important for gaining access to outside resources, whether they be in the form of increased access to agricultural credit or come from international agencies interested in supporting development projects.

Interviewer: Have you worked with other farms or cooperatives?

Participant in Biolley (34): Yes, we have worked with the Association, with ASOPROLA.

Interviewer: What are the advantages and disadvantages of this collaboration? 
Participant: The advantage is, that working together can bring projects or money. And, working alone nothing happens. One alone can't do much.

Interviewer: Are there any disadvantages?

Participant: Disadvantages? No. It's that working alone one is worse, or in other words, the substance of the farm is a lot less.

Farmers often mentioned ASOPROLA as a valuable resource for supporting agricultural decision making. This is especially the case among association members and/or farmers who had converted their land from conventional to organic production methods. In particular, ASOPROLA is viewed as a valuable source of information for growing organic coffee.

Interviewer: Where do you get information about growing practices.

Participant in Biolley (54): When I took the initiative to begin working, I encountered an ally called ASOPROLA. They have provided information and training, and everything for this activity [coffee growing], to be able to implement it in the best way. ASOPROLA provides training in which I always participate. This has helped me a lot.

Although farmers frequently mentioned ASOPROLA as a valuable resource for capacity building and information, many also continue to rely heavily on personal experience and informal communication to inform decision making about agricultural production. In other words, farmers also rely on observations of the behavior of crops and changing environmental conditions, their communication with family members and neighbors, and their own spatio-temporal knowledge in managing production on their farms.

Interviewer: Where do you get information about good practices for coffee production.

Participant in Biolley (36): Well, in ASOPROLA I have received some good ideas about how to work coffee. But, more than anything the campesino is converted into an engineer through practice, because one goes along working and noticing what the soil needs and what needs to be done to the crops and 
when things needs to done.

ASOPROLA may not be the primary source of information about agricultural practice for all farmers across the region, or even in Biolley, but it is a potentially valuable resource for many, particularly those involved in growing organic coffee. Its emphasis on coffee, in particular shade-grown and organic, is the primary point of reference for many when describing the organization. Several farmers mentioned having worked with larger cooperatives from San Vito before working with ASOPROLA. However, it is important to keep in mind, as one farmer stated, that ASOPROLA is more an "association of growers" than a traditional sort of coffee cooperative. In a similar way, despite the emphasis on coffee, many community members view the organization as an agricultural economic vehicle that serves the general purpose of community development.

Interviewer: Have you collaborated in projects with other farms or cooperatives?

Participant in Biolley (36): Well, I have been a client of the cooperatives. For example, of COOPEROSANVITO, a while ago we turned in our coffee to COOPEROSANVITO. But work on farms, I haven't gone. All of the time has been on my property.

Interviewer: In the case of cooperatives, just COOPEROSANVITO?

Participant: COOPEROSANVITO, yes, because the other beneficios are not cooperatives. What are these beneficios called? They are private beneficios. It's the same with ASOPROLA. This can't be called a cooperative, right, because it is an association of producers, that in large part I have worked with them.

Interviewer: What are the advantages and disadvantages of working with these organizations?

Participant: What are the advantages? The advantage is that directly or indirectly the whole community or district benefits from these organizations, through the projects that come to the district and the community. And, they receive better prices for the crops. And, there is more of a market for what one produces. On top of that, one receives training and one's kids receive training. 
These are a lot of advantages.

Interviewer: Have you had the opportunity to work with organizations in the community? For example, with ASOPROLA?

Participant in Biolley (45): Yes. In the case of ASOPROLA, the experience that we have had is that in one way or another, the majority of this community has benefited. With only the fact that we take our coffee to ASOPROLA and the organization grows, I believe that we are collaborating, because we are not sending this coffee to San Vito and that this money is circulating in San Vito and other places. What we want is that the major part of the money that is made in these communities circulates in the same place, for the well being of everyone.

On the other hand, as much as people see the value that ASOPROLA brings to the community, they can be frustrated at times by the difficulties encountered in their relationships with development organizations working in such a rural and remote place. Many talk about the potential and promises often being greater than what is delivered by ASOPROLA and other development organizations. These experiences are then translated into criticisms of development organizations in general and skepticism about the real interests of actors.

Interviewer: How has the experience of working with this organization been? Did you like it?

Participant in Biolley (45): No. I have liked it. Clearly. What happens is..perhaps...there has been a lack of a little thought so that everything goes better.

My experience during fieldwork also suggests that there are misunderstandings in the community about the work of the ASOPROLA and other organizations. ASOPROLA has a relatively complex structure given that its membership is often involved in different ways in numerous development activities related to agriculture, tourism, and community development simultaneously. Therefore, it can be difficult for leadership to communicate clearly to farmers how the regular business of coffee production, the primary interest of 
most potential members, is kept separate from other aspects of its operations. The organization is multifunctional inasmuch as it emphasizes organic and alternative production methods in its work, it occasionally serves as a collection center for tubers, vegetables and other products, it coordinates research and education activities, and it hosts groups of international tourists, among other things. Its own production includes crafts and artisan products, such as honey, soaps and jewelry, and it generally promotes the diversification of the agricultural and the regional economies. It is involved in a variety of economic development activities, ranging from providing local farmers with organic fertilizer to arranging 2-week-long home stays in Altamira and nearby communities as part of its tourism and community development operations. Having the organization and its various members simultaneously involved in many of these activities makes it likely that there will be confusion about the intentions of the organization and some of its more active members and leaders. Such confusion can amplify the tensions within a production system, like the one typical for coffee, in which credit is given for agricultural inputs and payments for harvests are delayed until the product is sold to a producer or in a distant market.

Interviewer: What are the advantages and disadvantages of being a member of this organization?

Participant (35): Of the advantages...well, there are advantages and disadvantages. For example, if you want to go and join the cooperative, you become a member and you have the right to things like fertilizer and fumigation, and as I understand it up to marketing. They have their administration and everything there. Like that. And, if you become a member they take a percentage of the profits. So, in that way, it has its advantages and disadvantages.

What is perhaps unique in the case of ASOPROLA, is that it continues with its other operations during times of the year when farmers are without money and waiting for their 
return from their harvest. During informal conversations, several community members shared with me their suspicions about the intentions of some of the organization's leaders and its ability to appropriately manage its finances. By conflating areas of finance, it becomes relatively easy for community members to imagine ways the Board of ASOPROLA, or a group of family members that is dominant in the Board, may be using the profits of others to serve their own interests. Although this was not a major area of concern among most farmers in Biolley, it does point to an area in possible need of attention. Many across Biolley continue to be skeptics of alternative practices in development and agriculture. If ASOPROLA continues to grow as a membership organization and is interested in generating a broad base of public support from the local community in doing so, it may be well-served by giving some attention to the public perception and the management of its image as a local organization.

Understanding ASOPROLA's role as an actor in regional development can be complicated even further by taking into account other activities of the organization. As mentioned earlier, ASOPROLA is a local organization with a history of influential involvement in local and transnational development projects, and in the past its leadership has taken on the responsibility of assisting other local organizations across the region during their formative stages. At times, ASOPROLA leaders may feel more or less able to provide support to other organizations depending on the resources they have available at the time. Their support may also depend on their perceptions of the potential for future collaboration with another organization.

During recent fieldwork, ASOPROLA made the decision to reduce its level of 
involvement not only in the development of La Red Quercus, but also in its work with the Women's Association of Agua Caliente de Coto Brus (ASOFAC.CB). ASOFAC.CB, a local organization that is the focus of discussion in the next section, already had a tenuous, albeit short, history and had come to expect support from ASOPROLA in capacity building and integration into regional development activities. In deciding to reduce its level of involvement with ASOFAC.CB, ASOPROLA's decision may have depended as much on the perceived potential, or dependency, of ASOFAC.CB as a partner as it did on ASOPROLA's perception of its ability to meet its own immediate needs. In informal conversations with some of the younger and more active leaders of ASOPROLA, one member in particular, Sara, who is referred to in the following excerpt from ASOFAC.CB meeting minutes, told me that future support for regional collaborations seemed uncertain and that it was in the immediate best interest of ASOPROLA, as well as in the best interests of its potential partners, that it work on strengthening its own portfolio of productive activities. As the following documentation of meeting proceedings of ASOFAC,.CB an organization that perceives itself as a potential partner of ASOPROLA and member of La Red Quercus, shows, such a decision by ASOPROLA could have a significant impact on the development of other local associations across the region.

Excerpts from ASOFAC.CB meeting minutes: It is likely that within a few days we will get a visit from don Pedro and Sara.

... [9 days later]

Point one. Sara apologized for having been away for so long due to a lack of time.

Point two. Sara asked if we are continuing with our focus en the same 
objectives; and Isabel explained that we are still dealing with the same issues, and we are trying to build a small greenhouse. Sara and Javier advised us that it is important that the lodge and the restaurant are in the same building. They also advised us to be thinking about things to offer visitors, like trails and entertainment activities, hopefully cultural. They also advised that we try to get training for everyone, because these are very important and it would help us when presenting our project to the Program of Small Donations. Javier told us that ACTUAR provides courses that would be useful for us, and it is would be important if some of us could go. They left us some pamphlets of information

Point three. Sara informed us that Melinda [one of the members of the ASOFAC] had called her requesting help with a work plan. Sara will help us with this and she can pass this plan on to Javier by Internet.

Point four. They informed us about a camp with places open for two young people.

Point five. They advised us to enroll again in ASDI.

Point six. On behalf of PILA, Educapila will be visiting us very two months at 11:00am.

Point seven. There is a possibility that they will teach us how to design projects. We should wait for more information about this.

Point eight. They suggested that we negotiate with Juan and Phillip about the issue of getting permission to access PILA.

ASOPROLA has a significant reputation to uphold across the region, and its

executive members felt that they were stretching their resources too thinly. They decided that it was time to focus on some of their core activities, local agriculture and tourism, and take a step back from their involvement in building the capacity of other local and regional organizations. Although they acknowledged the immediate impact this might have on their reputation with potential future partners, they also recognized that without a strong local base the association would not be able to face some its own internal challenges. While taking such measures may allow ASOPROLA to reduce the immediate strain on the internal functioning of the association caused by some outside interests, a lack of clarity, or transparency, about this decision could also be cause for future concern. 
There are no definitive answers to questions about the future of development in Biolley or across the La Amistad Pacific buffer zone. There is also no way to clearly identify what role ASOPROLA might play in that future development. What my analysis has helped clarify, though, is that the social complexity of this organization is cause for some concern and confusion among people across the region. The conceptual model introduced at the beginning of this chapter can be used to highlight this difficult situation. In this case, considering ASOPROLA to be at the center of a large amount of development activity across the region, certain members may become so heavily involved in working with groups or projects outside the organization that this activity comes to dominate their participation within the organization as well. Even the perception of this occurring can cause leaders to reevaluate their positions. When this happens, community and association members may also perceive a contradiction between the words and actions of an organization and/or its leaders, leaving them feel as if they are being cheated or even betrayed. For example, community members expressing skepticism about ASOPROLA's ability to manage its finances highlights the difficulty of communicating the multifunctional character of the organization to its members and the broader community. This exacerbates any real deficiencies that it has in financial management and accounting (personal communication with ASOPROLA manager). If community development and tourism activity continue while payments to farmers for their coffee harvest are delayed, it seems reasonable to expect a disgruntled membership, especially if they are not fully informed about how other activities in which organizational leadership is involved are funded. At the same time, it seems unlikely that cooperative members 
would justify using revenues from tourism to pay them for their coffee production if the situation were presented this way.

ASOFAC.CB: The Women's Association of Agua Caliente de Coto Brus In general, my experience observing the activity of community organizations across the study region resonates with observations made during The Nature Conervancy's rapid rural appraisal mentioned earlier (TNC 2004). The extent to which communities across Pittier are formally organized and integrared appears to be considerably less than the extent to which communities are formally organized across Biolley. Similarly, when compared to the multifunctional structure of ASOPROLA, organizations across Pittier appear to focus more on specific local interests, or projects, and they work more independently within in the community. For example, while ASOPROLA was the organization that dominated conversation throughout interviews with people in Biolley, interview participants in Pittier tend to mention various local committees and groups working on specific issues, whether they be related to the organization of the school, the church, athletic events, or annual festivals.

Agua Caliente is one of the most interior communities settled in the Pittier district (figure 9). This is the community where I spent the majority of my time while in the field. During my first three-month stay in the region, I spent almost all of my time there as a participant observer. I focused my attention primarily on the Women's Association of Agua Caliente de Coto Brus (ASOFAC.CB), and I conducted semi-structured interviews with 16 of the 18 currently active members of this Association. Thus, I had the opportunity to discuss the history and development of Agua Caliente, as well as the 
history and work of ASOFAC.CB, with nearly all of the members of this organization.

My introduction to ASOFAC.CB was almost immediate upon my arrival in Agua Caliente. In preparing for fieldwork, I had been communicating with the Research Director for La Amistad Pacific Conservation Area and he suggested a few communities as potential sites for my research (Carbonell 2009). During my first trip to the field, and following 10 days of visiting in between the MINAET Altamira Ranger Station and town center of Altamira, Biolley, I was transported to Agua Caliente and introduced to the household where I would reside during much of my fieldwork. The following day, I met with most of the ASOFAC.CB membership during what I thought was a regular business meeting. After some time, I realized the Association was rather adept at calling ad hoc meetings for which they would often get near full attendance from membership and during which they were also able take care of regular business. During this meeting, the members talked about several projects they were involved or interested in, including trash collection, recycling and greenhouse construction, and I was formally introduced to the group towards the end of the meeting. During the following weeks, I observed daily routines and spoke informally with many community members in preparing to conduct semi-structured interviews with ASOFAC.CB members. During these interviews, we discussed the association, their involvement, their views on the history of regional and community development, and their general perceptions of issues that are important in the community.

Of the membership that remained during the time of my first visit, very few had a clear recollection of the "official" or "formal" history of the Association. They shared 
various reasons as to why they thought the group was initially formed and they shared pieces of stories about how it happened. Several did clearly recall the presence and influence of the Agricultural Laborers Union (UPACOB) in the early stages of group formation. There is disagreement, however, in their descriptions of UPACOB's role in the process. Once the seed of the idea of forming a women's association was planted, UPACOB relatively quickly disappeared from the scene as it maintains no active presence in the Pittier district otherwise. One ASOFAC.CB member even thought the interest of UPACOB was somehow specifically related to organizing women and strengthening women's associations in the communities across Pittier. As it turns out, the temporary presence of this outside interest was actually part of a regional initiative to build the capacity of local organizations to support organic agriculture (SGP 2012b).

Current ASOFAC.CB membership was divided on their assessment about how the departure of this outside agency should be viewed. Most members felt that they had been left prematurely on their own to figure out how to move forward.

Participant (3): UPACOB was united with the Costa Rican Social Security program, and they go around making sure that insurance doesn't go up and they supposedly live helping campesinos. Mr. Juan Prendas is the president. So, one of the community members heard something and went and talked to him and the set a date for him to come and meet with the community. So, they invited us. So, I went, to the meeting. That same day we formed the committee, with Juan Prendas. He came. He promised to follow us as we went through the process and accompany us is meetings and assess our progress. But he didn't come back. He didn't come back. There we formed the committee. Since then...we have the committee, the committee that we formed, but we haven't been able to get things together. I arrived there. I accepted the position that I was given...not with the intention of getting some personal benefit, but to help the community. Well, then that's where we ended up. He didn't come back. Everything stopped there. It's because of this, more than anything, that we haven't done much. We sat waiting and waiting. He never came back to evaluate us, nothing, he didn't tell us anything. From there we went organizing ourselves, without his assessment. 
Or, we left him to the side. We went and requested a business license. We have a business license, we have all of our book in order, everything to work. But we are there, the group that we started, we're still there but we haven't done much, because...Then, we started to communicate with partners and such, we started communicate with them here, with ASOPROLA. So, that was when they started, yes them. They have been helping us a lot.

Other members felt that they, as a group, had formed more according to their own initiative and that UPACOB had departed because the group decided to move in a different direction than the one that was being promoted by this agency from San Vito.

Participant (5): Well, in reality, like we told you the other day how long we've been together, almost two years, almost. We have almost arrived at two years. It started by, how we had the initiative to form a group that would help the women of the community because here there aren't, there aren't, you see that here there aren't jobs, there isn't anything that generates, let's say that the women get involved, participate, and all of this. Here, the majority of work is for the men. So, with this thought, all the time, we wanted to make a group of women or something, a job for the women or something like this. Then, news arrived that we could form an association. So, we, from there, we simply called a meeting, all of the women of the community. And, from there we started meeting, between those of us who arrived. There were about 40 that day. About 25 continued. The rest didn't want to. Or in other words, they didn't want to be part of the group because they saw it so, like, "What are us women going to do?". So, those of us that stayed started to look for information. Some one way, other another way, until we were able to form the board of directors. Well, obviously with the help of other organizations. Organizations that in that moment were coming from the side of San Vito. But, working with them wasn't working for us. It didn't work because they, what they had was like...or, they were looking for associations that would later work for them. So, that was working for us and we separated from the, the help we were getting from San Vito. We separated from and started looking for help in Altamira, in this region. From there was where, where we started to take hold and where we have almost always been better.

This difference in opinion about who was primarily responsible for the direction of ASOFAC.CB in the early stages of its history is just one area in which the influence of an outside interest may have intervened in the formation of this potentially grassroots organization. Over time, the support offered by other regional actors, such as MINAET and ASOPROLA, started to distract ASOFAC.CB member attention away from their 
interests in employment and community development and direct it more towards the purpose of environmental protection. The tension revolving around this transition became clear through participant observation and after evaluating member responses to my questions about the organization's history, goals, and objectives.

Interviewer: If you don't mind telling me about the history of the Association. Participant (16): This is something that started, let's say, a woman called us to a meeting because a man was coming to make, to make an association. But, this man started telling us about how we had to have a cédula jurídica and pay for a bunch of different things. So, we ended feeling a little more on edge and we decided to renounce this man. Actually, he wasn't doing anything, legally. So, we went on our own to apply for the cédula jurídica, but on our own, not through this man. He was from an institution, UPACOB. He was from an institution, but he wasn't doing anything, so we decided to do it on our own. We started to apply and make the trip, or the Board did, because I am only a member. I can't . . . there are a lot of things that I don't know because they are the one's who take charge. I don't know, it's like I have a question. In an association, the Board sometimes does things, let's say, they have the obligation to meet and do things, but inform the rest of the members ...

Interviewer: $\mathrm{Mmhm}$.

Participant: ... of what they do. Yes. That's how it is, right. That is how an association works. It's that, if one has never worked in an association, one doesn't know what to do. One is like indecisive, and they inform us what they have done, of what they have already done, right. And sometimes we meet to see what we are going to do. Well, applying for the cédula jurídica helped us, other institutions here in the community helped us because, because the truth is that other institutions helped us in the community, other groups in the community. And, we were able to get the cédula jurídica. From there, we have been looking for assistance, but, at least we got some help for the trash cans and they arrived to place the trash cans. But, what other help came? Ah, a man donated a parcel there so that we could ... The way I understand it, this is like a goal. They are telling us that we are going to make a soda, we are going to build a lodge, we are going to sell things, and that we plant vegetables because we can take them and sell them, but now everything has completely changed. They are telling us, "No. It doesn't work that way." At least those that went to the meetings with ASOPROLA, they say that it is not this way. That first we have to take care of the environment, or for nature and all of that, and that the soda is extra. In other words, it is for the future, for sure. That's the way I understand it. So now we are going to build a greenhouse. 
Participant (4): My mom told me that there was an association, that there was an association forming to implement projects in the community, or to make the community more prosperous, with a soda and a lodge. But, in the beginning, well, in the beginning, I don't know what the perspective was exactly. When I joined, let's say, when I had already entered, this was already the plan. They had already communicated with ... it wasn't with the Red Quercus, but with MINAET. I think it got started with them. Well, I really don't know who it started with. But, they were already with these people. Then, their idea was to have, or say try to figure out how to get tourism here, but also protect the environment. Because it seemed like, our job should also be to protect the environment, right. So, this was the idea. To begin working, more than anything, in what we were working on those days, in cleaning the community. Or, how do I say, the ordering of the recycling and the trash. What do I know? In everything that was taking care of the environment. This is why we are working with the people from MINAET and the Red Quercus and all of that, right. Because the idea is to get started, but protect the environment more than anything, $\mathrm{mmhm}$.

Interviewer: What are the objectives of the Association?

Participant (9): Of the Women's Association, supposedly, well, supposedly, they always told us that we were going to get together work towards a better economic future for everyone. But more than anything, now we are working together to help learn, learn everything about helping the environment.

Interviewer: So, the objective of the Association has changed?

Participant: Oh yes. In fact, look, in fact in the first meeting there was this man who came and just talked to us about supposed money and that we were all going to benefit. Of course, we had to work in vegetables and change everything about the way we do things. In other words, everything had to be helping the environment. But yes, he talked to us to get us interested. But, after going to meetings and workshops and everything, they have shown me that it is not about money, but it is about conserving the environment and making a better life conserving the environment. This is something that has been left by the wayside a lot, right.

Interviewer: And where was he from?

Participant: What?

Interviewer: The man.

Participant: Oh, he was from San Vito. He makes a living...from, I don't know. He makes a living from, let's say, in San Vito there is an office called UPACOB. He helps people in various ways. I don't really know how to explain their system. But, they also help with insurance. I don't know. The way they distribute 
receipts for insurance, plans, and all of those things, and people's savings. But we completely moved away from him. If we wanted to continue working with him, he was going to be in control of our plan of work. But, the first thing that happened was he was going to help us with the cédula juridica and we had to pay more money. So, in other words, it wasn't the best way, and we changed. So we are no longer with him. He was only at the first meeting.

Interviewer: And after arriving to where you are now, do you think there might be benefits of working with him?

Participant: Perhaps, but in a different way. Perhaps, because like we say, there are a lot of sources of help now and different ways. Sometimes one goes, they invite you to meetings, and it just so happens that he is at one of those meetings. He has been at several. What do I know? Perhaps everything is over. We don't know. I don't know.

As participants continued to share their motivations for becoming active members of ASOFAC.CB, much of the conversation revolved around an interest in increasing opportunities for female household members to participate in the formal economy and contribute to community development. In particular, most members were interested in helping establish opportunities in the community for women to participate in the formal economy, which is primarily oriented towards male labor.

Participant (9): For the women, I feel like the [economic] situation is problematic because the men are the ones who work. The women, we don't have, we don't have salaries. Yes, we can say that we work in the home, but there is no salary here. So...I feel that, that we are a little stuck as far as that goes. And it's always a little difficult because of the machismo of the men. Right. That they do not want us to work.

Several members were looking for opportunities that allowed them to both contribute to the general economic development of the community and at the same time redefine their roles in the community and in their households. In some instances, women expressed the desire to establish independence and freedom from a situation in which they were dependent on their spouse in financial matters. In other instances, women framed this concern over household finance in terms of them wanting to alleviate some of the 
pressure of income generation that tended to be placed primarily on the shoulders of their husbands.

Interviewer: What motivated you to become a member of the Association?

Participant 1 (12): Like she was saying, to try to do better, to be able to maintain in the future, and capital too, to help my spouse, because like she said there isn't anything for us to do here except stay at home at take care of the baby. And, I feel like I would like to be an independent person, too, to be able at some point to work in something even if the earnings are minimal. But, at least to have some income to help a little more. (emphasis added)

While the opportunity to, at some point in the near future, gain employment was one of the primary issues that motivated members to join ASOFAC.CB, my observations of association activities and other information shared during interviews indicate several inconsistencies in individual and group goals. Membership had waned considerably since the initial formation of the group almost two years before my fieldwork. Considering the size of the community, however, a relatively large number of women still remained active members in the Association. When the group was first formed, nearly every female head of household in the community was in attendance at regular meetings. One participant commented that there were probably around 40 women in attendance at the initial meeting. Gradually, attendance tapered off and membership size was reduced by about half. Among the reasons people gave for why this happened were pressure from family members, a lot of which was related to gender norms, as well as individual realizations of the time involved and the likelihood that not every member would have the same future opportunities.

Despite membership initially being most interested in establishing a restaurant and lodge for the purposes of economic and community development, the influence of outside 
interests related to environmental protection came to dominate ASOFAC.CB's current visions of where the association is heading. Initially, many members viewed their involvement as something that might eventually lead to them gaining greater control over their household financial circumstances. This was clearly one of the ideas that brought these women together during the early stages of establishing the association. The possibility of working in a restaurant or lodge would provide women with an opportunity to participate in wage labor in a position more desirable than the opportunity presented of seasonal employment in the coffee harvest. Native American migrant labor is largely responsible for harvesting coffee beans from plants. They are sometimes joined by women (and children) from the families of lower socio-economic status in the community. In addition to people, migrant and local, having to bring children in the fields due to lack of available child care, much of the harvest takes place during the rainy period from mid-September to early November.

At the time of my fieldwork, there were only a few other wage labor opportunities available to women in the community. Female members of families that owned a pulperia could attend customers there. There was one position in the school cafeteria. This opportunity was only open to one person at a time. It was a highly sought after position for which there was an annual competition that involved submitting an application and being selected by a Board of community members. A few wealthier families would occasionally employ local women for a few hours in their homes to do domestic work.

Thus, by establishing a soda and a lodge, ASOFAC.CB would be contributing to 
the future growth of the local economy and creating opportunities for its female membership to play an increased role in generating household income. During interviews, all but one participant mentioned the idea of the Association opening a soda in the community. When probed, however, only a couple were able to articulate their initial development interests with the environmental goals and objectives currently guiding the activity of the organization.

At the organizational level, natural resource management and sustainable or organic agricultural production were becoming more predominant themes in ASOFAC.CB activities. Obstacles in the acquisition of quality real estate and funding for the soda and lodge projects slowed organization momentum along these lines. Conversations about the soda shifted toward incorporating organic and local ingredients in the dishes they would serve their customers. Individual members also began to put together tourist packages that included guided tours of La Amistad park and visits to other natural resource amenities to offer to future tourists in the region. While members did not generally consider these ideas in and of themselves as bad, several members began to feel frustrated with the changing direction of the Association. They perceived a lot of activities as diversions, or overly-detailed and abstract planning exercises. There was a general perception of there being a lack of actual progress, in particular as it related to the initial project ideas. Shifts in power within the organization also made members feel that organization was favoring those more willing and able to align with the special interests introduced by outside actors such as those from UPACOB, MINAET, or international development programs. 
Again, I find the conceptual model in figure 23 helpful in highlighting the empirical sources of some of these frustrations. As a new interest is introduced into the organization by an outside organization, emphasis can be shifted away from shared areas of perception and interest that are based on the common experiences of local history and family relationships. Certain members within the organization may be in more favorable positions for working with the "new star" and they may alienate other organization members in the process of pursuing this new connection, or linkage.

It appears that since its inception, ASOFAC.CB was part of a broader effort to promote regional territorial development. Although the initial motivation may have come from an external agency, this need not necessarily preclude collaboration within the organization. If the process is not transparent and clearly understood, however, certain actions by association members and/or leaders can easily be portrayed as misleading or as acts of betrayal. If opportunities are presented in a clear and coherent way, and in a way in which membership understands the implications of new partnerships on existing relationships, it becomes less likely that the general membership, and the broader community, will view these new relationships with outsiders with skepticism.

It was not until a much later stage in the research process when I was able to reflect more deeply on what these women shared with me during fieldwork. The almost immediate withdrawal of UPACOB during the group formation process and the subsequent delays in project implementation left many ASOFAC.CB members feeling stressed, confused, and defeated. Some members, however, were aware of similar projects that had been implemented in other places across ACLAP and they drew on this 
perception of other successes to justify their continued involvement in ASOFAC.CB. They were reassured in this belief by the continuing presence of outside development agencies in their community and their continued offerings of support. The persistence and sense of urgency of some individual members also kept hope alive in the organization despite challenges in acquiring the resources needed to implement their projects.

Some of the tensions within ASOFAC.CB were also be fueled by this outside presence. The shifting focus of the organization, which was felt by many members, and the perceived lack of progress of the organization were closely related. The suggestions of available resources for project created expectations among members that were often met by the realities of funding guidelines and competition with other organizations. Unfortunately for its members, ASOFAC.CB was forming during a time when there was a significant reduction in the amount of funding available for small development projects across the region (SGP 2012a; SGP n. d. a; SGP n. d. b.). The need to seek alternative sources of funding was primarily the reason why ASOFAC.CB was being advised to modify their project proposals. This was necessary in order for their ideas to fit the criteria for eligibility of other potential donor agencies (GAT-ALTO 2013; JUDESUR 2009).

As confused as these efforts appear, they do indicate a serious interest in integrated development across the region. While community organization has happened informally across the region in the past, there is an increasing amount of energy being put into formalizing these structures, or at least articulating formal and informal organizations in some places. While some transnational agencies and government 
departments are better-positioned to work with grassroots organizations, the Costa Rican policy on political decentralization is also compelling municipal governments to search for ways to extend the decentralized model into their work with district- and communitylevel governments.

\section{A Planned Intervention: Multilevel Integrated Development via a Network Approach}

During my fieldwork, I had the opportunity to talk with several government officials working in the region. In particular, I found the experience of attending municipal development planning meetings helpful for understanding how regional development is being approached across Coto Brus. The primary purpose of discussing this experience here is to demonstrate how the integrated development framework is being extended empirically through a "formalizing" process of political decentralization. Among other intentions behind relating these experiences is to highlight the legal structures involved in the national political decentralization process that was introduced in Chapter 2, and to point to potential challenges in articulating the work of grassroots organizations, such as ASOPROLA and ASOFAC.CB, with this structure.

I was able to attend two of these municipal-led planning meetings in Santa Elena, the seat of the Pittier district. Both meetings were led by faculty and assistants from the National Autonomous University (UNA). The first was especially well-attended and informative. As we learned during the meeting, this experience was indicative of what was taking place in other districts across the municipality. I later learned that this process is part of the municipal development strategy being implemented across the country

(PRODELSAN n. d. a). All members of the communities located within a specific 
district, in this case Pittier, were invited to attend. The invitations were extended through communications with community integrated development associations and by word of mouth, which is perhaps still the most effective form of communication in these rural communities.

Both the first and second meetings followed a similar format. University faculty members opened the meetings by giving presentations to the full group. After these presentations, the group was divided into focus groups for discussion of predetermined themes. There were considerably fewer people in attendance at the second meeting, and the focus group sessions in this meeting were mainly for the purpose of following up on and verifying what was discussed during the first meeting. Given that I was not able to stay for the entire second meeting and that there were considerably fewer people in attendance at that meeting, I will focus my discussion here primarily on my observations of and participation in the first meeting and information that can be gleaned from the final draft of the planning document (PRODELSAN n. d. b).

The meeting began with introductions of municipal staff and officials, university facilitators, and local leaders. Following an opening prayer, meeting facilitators gave brief presentations on the reasoning behind the planning process and the integrated, or network, development strategy. The first presentation of meeting outlined a Proposal of a Model for the Integrated Development for the County of Coto Brus, which was followed by a presentation on The Importance of Working as a Network for our District. From the perspective of an academic, I found these presentations interesting and informative. However, in retrospect it is not clear how relevant the information provided in these 
"lectures" during this first half-hour of the meeting was to the majority of those in attendance. On the other hand, there may have be details about the meeting that were more readily apparent to others than they were to me at that time. It was not completely clear to me until having a conversation with one of the facilitators during a breaks in the meeting that the facilitators were faculty and graduate student assistants from the national autonomous university. Up to that point, I thought they could have been municipal government officials or from an international development agency. As the conceptual framework for the strategy was being presented to the group, I was under the impression that this was information coming from directly from the municipal staff. Come to find out, people from UNA were acting as extension agents sub-contracted by the municipality to facilitate this process and later assist in the analysis of information and elaboration of the final planning document.

Following the opening presentations, there was a brief question-and-answer period before the large group was divided into smaller groups for round-table, or focus group, discussions. For this part of the meeting, people from the municipality and university joined efforts in leading the discussions of their respective groups. The discussions were focused on themes such as agricultural production, health, sports and culture, integrated development associations, natural resources, education and gender, respectively, and lasted approximately 45 minutes.

Before breaking into small groups, the lead facilitator reminded participants, as he did throughout the meeting, that they should set aside their own agendas, personal, religious, political, etc., and for the day think of themselves as a group of people with a 
common cause.

Facilitator: Before we start, I want to say something that I think is very valuable. We are going to put a rule in place so that he [referring to another facilitator] doesn't behave badly and so that I don't behave badly. Here, what there is, is an interest in the common good. The flags stay outside, political parties stay outside, what also stay outside are religious creeds because it is important that we are together in one mission like Christians. Here everything is worth something. It doesn't matter what religion you are or what political party you are with, because at this moment what is more important is that we have come together for the common good. Why is it that we are coming together?

Participants: [softly in unison] For the common good.

Facilitator: I didn't hear anything. Why is it that we are coming together?

Participants: For the common good.

Facilitator: Clearly. For the common good of Pittier.

Once participants were in their discussion groups, my perspective was limited by my ability to act as a participant observer in just one of the focus groups. For this, I chose to sit at the table where agricultural production was being discussed. There were about 25 people representing different communities and organizations at the table. After we introduced ourselves, the discussion turned to the challenges faced by farmers in the district. The first few minutes of our discussion was led by a graduate student assistant that I had met during the first break. After groups had started settling in to their own discussions in different area of the auditorium, the meeting facilitator ended up taking the lead in our discussion.

The conversation was dominated by a few topics: the costs of inputs, access to markets, and the lack of interest in labor-intensive farming practices. For example, when the facilitator asked participants about people in their communities raising their own chickens instead of spending their money buying chickens, participants responded by 
saying, "Yes, this is possible. There is plenty of land available. But, people don't want to do it. Ticos are lazy that way." Participants expressed concerns about their ability to grow products that would be competitive in international agricultural markets. They complained about the central government making trade agreements that make the price of beans that they find in their local grocery stores, which are imported from Nicaragua, less than what it would cost them to grow beans on their own farms. Overall, participants felt the costs of agricultural inputs, like the fertilizers and pesticides necessary for obtaining worthwhile yields, were increasingly rising beyond their means. Although they felt their returns on coffee were historically consistent and reasonable, they felt their ability to get good prices for other products, such as beans, vegetables and cattle, were limited. In response, the facilitator pointed to the new trade agreement negotiated between Panama and Costa Rica, and he urged participants to organize locally to take advantage of this opportunity. Farmers in this region are physically closer to this international market; however, farmers in other parts of the country have more well-established linkages to regional and international production systems. As the facilitator pointed out, if people across Coto Brus are not able to get their act together soon, "I have no doubt the farmers in the Central Valley will take advantage of that opportunity."

Although the majority of development across the region is based in the agricultural economy, the concerns expressed in the focus group on agricultural production were just some of those expressed during the meeting that day. Other groups identified needs for improvements in health care and education, among other things. In combination with the distance between many communities of the district and major 
market distribution centers, the lack of interest in producing a variety of foods on the farm or around the household contributes the stagnation of local or regional markets and diets that are nutritionally deficient. Although there is not a lack of quality calories consumed by household across the region, my experience and the findings of the planning process resonate with Stuchi's (2009) household study, which indicates an insufficient amount of fruits and vegetables being consumed by families across the region. Similar findings are also reported in the overview of the health of the population in the Municipal Development Plan for Coto Brus (PRODELSAN n. d. a). This study shows that over $15 \%$ of children under the age of six in the region were suffering from some level of malnourishment in 2002; and, of the chronic and infectious diseases reported in the region in 2001, 63\% were presented as cases of arterial hypertension. The thoughts shared by participants in the focus group on agricultural production do not indicate a tendency towards improving this situation. Despite having an ability to diversify local food production and a belief that current environmental conditions in the region are amenable to growing almost anything there, farmers are reluctant to do so. Further, almost all the people I asked in Pittier felt that people there were very healthy. Nevertheless, they also almost always wanted improvements in health care, including a better clinic and increased access to a doctor and related services. Given this situation, one of the things that an integrated development strategy could consider is the relationship between local and regional agricultural production, nutrition, and health. If opportunities to pursue alternative modes of agricultural production are being limited, it is possible that such limitations are contributing to environmental and human health 
problems encountered across the region.

While identifying issues that need to be addressed in future development activities is an important part of this planning process, identifying the structures guiding political action is also very important. Local committees that deal with the regular business of community health care and education are not usually formally recognized by municipal governments across Costa Rica. In order for these committees, or other grassroots organizations, to gain power or access to resources, they often have to depend on personal relationships or repeated petitioning. At the end of the meeting that day, however, the facilitator presented a newly appointed multilevel network of leaders to the group as a solution to the problems of access and accountability in the political bureaucracy. Although there was no discussion of this network included in the proceedings of the meeting and there was not apparent democratic process behind the selection of representatives in the network, about a dozen leaders, many of whom were members of their community ADI, were identified as people who would have direct access to the Mayor of Coto Brus for the purpose of filing grievances about municipal administration. Along with fulfilling certain responsibilities, such as holding regular meetings and maintaining communications with their respective communities, these individuals were encouraged to communicate directly with the municipal government about the quality of services, such as education and health care. If they had a complaint about a local school, instead of having to deal with the bureaucracy of the department of education, they are encouraged to express their concern directly to the administration. It was said that this system will increase accountability and improve the quality of services provided by the 
government. What was not made clear, at least not immediately, was how this new district-level integrated development network was supposed to support the work of existing community-level ADIs.

Figure 25 provides a glimpse into how the district-level integrated framework resulting from this municipal planning process may eventually undermine the potential for working through community-level ADIs. It is interesting to note that of the community organizations identified in the figure as key participants in the Integrated Development Association of Biolley, Buenos Aires, none are community-level ADIs. Although the executive board of the district-level ADI was appointed that day of the first planning meeting in Pittier, I am currently unaware of any effort there to implement this network similar to what appears to be underway in Biolley.

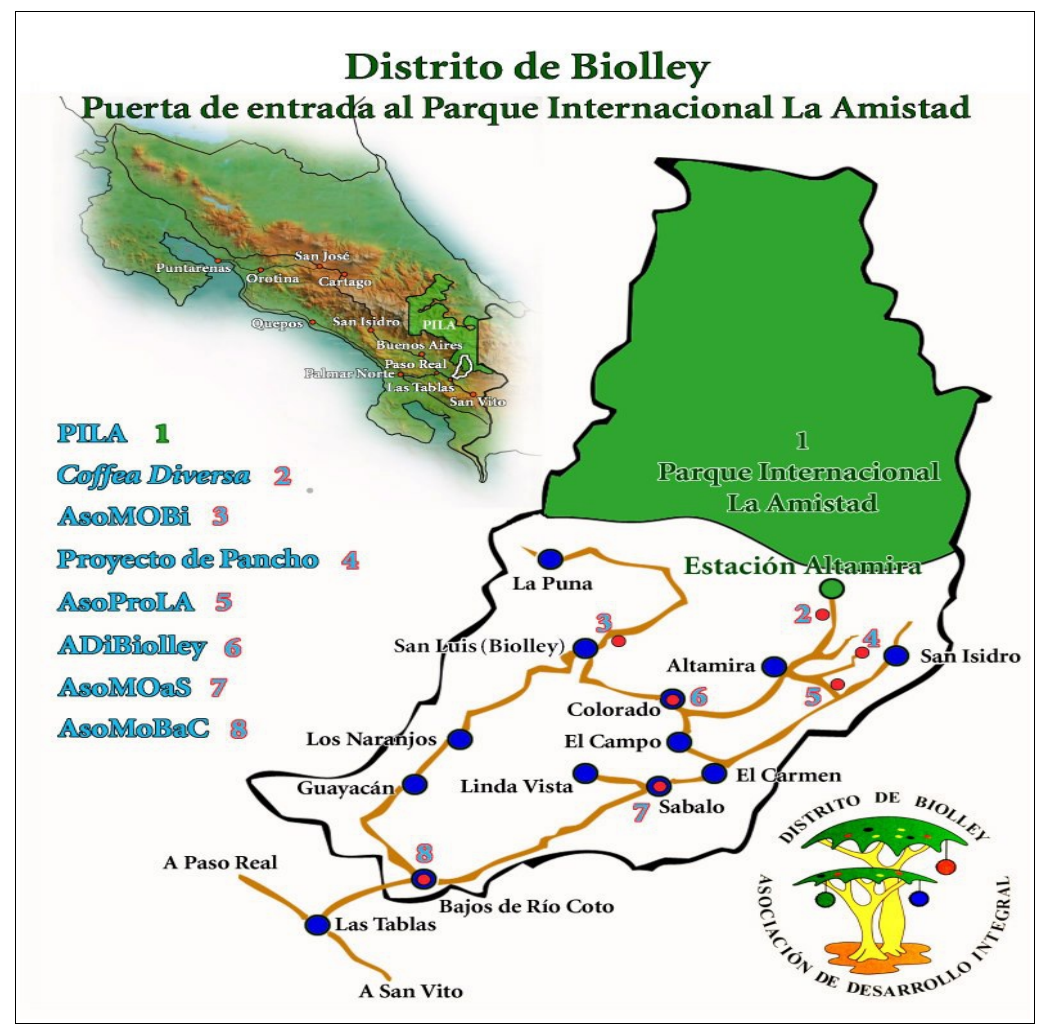

Figure 25. Integrated development network of Biolley. 


\section{Chapter 7: Discussion and Conclusion}

This study has drawn on a number of primary and secondary data sources and utilized ethnographic research methods to evaluate various aspects of development in a small, interior part of the La Amistad Pacific Conservation Area. Overall, there appear to be movements towards restoration of a forested landscape and the transformation of a traditional commodity-based system of agricultural production to a system that integrates agricultural and ecological process across the region. However, this study has also highlighted how key historical and contemporary differences influence these transitions, which appear to be dependent in many ways on relationships between human interest groups as well as relations between humans and the environment.

In this chapter, I draw on major themes that emerged from the literature and research to discuss human interest group and human-environment relationships in the context of the possibilities for future research and development across the La Amistad Pacific Conservation Area in Costa Rica.

\section{Relationships between park rangers and communities}

When comparing farmers' attitudes towards PILA and park rangers in Biolley and Pittier, a key difference appears to be based on the way residents of communities in these districts experienced the establishment of La Amistad International Park and the quality of their everyday interactions with park rangers in their respective communities. Park officials were engaged with communities in Biolley from the outset of park establishment during the early 1980s. In some ways they were welcomed by farmers and laborers who were also interested in arresting control of their communities, local natural resources, and 
opportunities for future economic development from international interests in commercial logging. This is not to say that there was never conflict between farmers and park rangers in Biolley. However, as MINAET was involved in the relocation of several farms in the area, the groundwork was established for working relationships in communities across Biolley that was not established in communities across Pittier. Although some farmers in Biolley can clearly recall being pursued by MINAET officials for infractions they might have considered minor or illegitimate at the time, they have also observed changes in priorities among themselves and natural resource managers that have improved the nature of their relationship.

On the other hand, MINAET was not involved in the removal, or relocation, of farmers from the newly established park area in Pittier. In Pittier, MINAET's image as a looming presence prepared and perhaps eager to act on its authority as a law enforcement agency is perpetuated by its regular physical absence and its lack of awareness of and involvement in community development activities in the communities of this district. This image continues to be in the forefront of people's minds across Pittier as community members more readily recall than people across Biolley how lumber is seized from hardworking families and seemingly insurmountable restrictions are placed on people who want to use and manage natural resources to develop their property in ways they feel are sustainable.

As far as conservation interests are concerned, the abandonment of communities like Santa Maria de Pittier could produce benefits for the environment and neighboring communities. Although some families may have no choice but to relocate and start new 
farms or go back to working as laborers on plantations, these areas will soon undergo a process of reforestation even without effort from natural resource managers and conservation agencies. One of the major risks in adopting such a laissez faire approach to integrated conservation and development, however, is allowing the production of an outcome similar to what this research found in Santa Maria de Pittier. As people were eager to leave the area quickly, their farm land located just outside the park boundary was purchased by individuals who now maintain that land as extensive pastures. Without the the history of working relationships between park managers and land owners in this area, it will be particularly difficult for MINAET and other agencies to promote the preservation and restoration of a forested landscape and ecology. Farmers have historical grounds to be suspicious of MINAET's intentions when they do appear in their communities, and conservation officials have relatively few economic incentives to offer farmers to convince them to incorporate conservation practices into their production systems. In the absence of a clear community development agenda, park rangers and other natural resource managers will continue to be viewed as operating outside of their jurisdiction when trying to interject themselves in conversations about development and conservation in communities.

Farmers across the study location are almost uniformly aware, if not concerned, about the impact of agriculture on the environment. They are keenly aware of some of the consequences of the aggressive and destructive colonization of forested land in the past, and several research participants described the establishment of PILA as a much-needed measure to bring order to the area. They described it as providing life in the form of clean 
air and water. Participants across the study location also saw the potential for the park to contribute to economic development because of its ability to attract the attention of international development and conservation agencies and tourists. However, MINAET, the agency tasked with park management, has very limited resources and they do not have a history of collaborating with other government agencies in projects that would address the livelihood concerns of farmers. When the agency is involved in rural development, is it usually through an effort to promote eco- or nature-based tourism or other conservation activities like taxonomy or species observations. While these activities do provide some people with income and they can draw international attention to a community or an area, they are typically limited in both the economic impact that they can have on a community and their ability to address broader concerns related to community development (Brown 2003; Stem, Lassoie, Lee, Deshler and Schelhas 2003).

\section{Environmental actors leading human behavior}

Residents across the study location experienced a number of challenges in continuing regular practices related to community development, health, and agricultural production. Research participants expressed concern over the quality of their drinking water, one of the natural resources they considered as contributing greatly to the high quality of living in their communities. While some participants related the establishment of PILA to the improved condition of particular streams and surrounding areas, other participants voiced their frustrations about the continued presence of pastures and the continued application of chemicals in areas that they thought were strategic for maintenance of the quality of their water supply. 
Among the environmental actors most participants expressed some concern about were the diseases and pests that plague their soils and in particular their coffee plants. Coffee growers are continually struggling to find ways to deal with the threats that Mycena citricolor, Hemileia vastatrix, and other fungi and soil microbes present to their crops. In the context of producing commodities for markets with fluctuating prices, farmers are weighing the costs of purchasing and accessing chemical inputs in attempting to maintain yields and control threats to their crops against using alternative agricultural production methods for the same purposes. At the same time, they are taking into account their knowledge and experiences of the harmful effects of using chemical controls on human and environmental health.

Another important environmental actor that many participants discussed, although in many cases indirectly, were the trees sprouting in their farm fields. If land owners allow these trees to grow, their ability to use their property as they see fit is at risk. The continued emergence of the forest from abandoned pasture lands and in areas on farms that are maintained under crop production is a pressing concern for many land owners. It has become common practice to monitor fields for this growth and eliminate it, and in some situations livestock are utilized and rotated regularly to keep it under control. In certain places, such as on marginal lands and in low-lying areas surrounding stream beds, this growth may be allowed take over. However, these buffers or patches of forest are at the same time perceived as encroaching on valuable agricultural land and therefore considered as a constant threat to rights of property and land use. In terms of evaluating the dynamics of human relationships in the study location, this natural activity of forest 
succession introduces and maintains a certain amount of tension between park rangers and land owners.

\section{Strategies for agricultural and regional economic diversification}

Most farmers across the study location are heavily dependent on the coffee export market for income. Although people perceive coffee growing to be one of the most reliable agricultural activities available across the region, prices do fluctuate and environmental conditions can have a significant impact on production at any given time. Additionally, diminishing soil fertility across the region is a concern for many farmers, primarily due to the requirement of spending more time and money acquiring and applying the inputs needed to maintain yields. Farmers across Pittier, in particular, are dependent on coffee production as the market for Costa Rican beef has declined during recent decades and their relationships with large coffee cooperatives in San Vito and Perez Zeledón have intensified.

In Biolley, farmers are pursuing different strategies for diversifying agricultural production systems and expanding their portfolios of income-generating activities at the household and community levels. Farmers in Biolley have expressed an interest in expanding local economies through the pursuit of activities like vegetable production, apiculture, and the production of organic inputs. These interests and attempts to diversify agricultural production systems in Biolley are accompanied by an interest in increasing the role of tourism in local economic development. At present, ASOPROLA in Altamira, Biolley, appears to be the leader in attracting international tourists to the region. With several other communities and organizations in the area interested in participating in the 
tourism industry, it will be important for ASOPROLA to continue to evaluate the potential of its role as a leader of a regional tourism network. Obversely, as other organizations consider initiating their own tourism projects in the region, they will have to consider the actual size of the market as well as determine if their relationship with ASOPROLA is one with a partner or competitor.

There are clear differences when comparing the experiences of people with alternative agricultural production methods and the presence of established organizations in communities between Pittier and Biolley. The cooperative endeavors in Biolley reflect people's experience in community organization, and this experience has provided people with opportunities for interacting with national and international tourists and development professionals. These connections to people and outside organizations interested in issues such as conservation and organic production are assets that help them deal with the challenges related to the remoteness of the region. Without these experiences and connections, farmers in Pittier appear more likely to continue to be dependent on commodity markets in agriculture for livelihood opportunities. Even when farmers in Pittier pursue diversification strategies, like when they invest in the production of alternative crops or adopt organic production methods, the emphasis appears to remain primarily on generating income through the sale of produce in markets outside their communities. For example, several farmers in Pittier have demonstrated an interest in producing vegetables for sale in markets just across the border in Panama. The efforts of these farmers, however, remain for the most part in isolation of each other and at the level of the individual farm. As the facilitator of the planning session in Pittier told the people 
participating in the discussion at the agricultural production table, people across the district will need to work together if they want to compete in this market with larger experienced and well-established growers from the Central Valley. In other words, they will need to organize production in their communities and across the district to achieve the economy of scale that will be required to get contracts with larger commercial buyers in Panama under the conditions of the relatively new free trade agreement established between Costa Rica and Panama.

Despite farmers across the study location generally viewing organic production methods as more desirable than production using chemical inputs, the potential to implement organic practices is severely limited by available inputs, including labor. Without as many people in Pittier focused on expanding local agricultural markets and producing inputs locally, diversification of production by introducing new crops is just as likely to involve an increase in the use of chemical inputs as it will be promoted through commodity markets. Thus, when considering the possibility of diversifying agricultural production and decreasing farmer dependency of coffee production across the region, it can not be assumed that this strategy is always intended to improve the health of the community or the agro-ecosystem. Superimposing such a false dichotomy on diversification would be comparable to opposing "intensive" and "extensive" in a comparison of practices in agriculture. Agricultural intensification can be linked to resource degradation, especially when it involves the heavy use of chemical applications. Intensification can also be linked to increased soil fertility and ground cover and improved conditions of a watershed when farmers try to reduce their dependence on 
external sources of chemical inputs for agriculture. On the other hand, a forested landscape can be interpreted as a rather extensive monoculture. An ecologically diverse forest, however, can not be reasonably compared on ecological grounds to a landscape dominated by fields of genetically modified corn or soybeans unless the political relationships between humans and natural actors across scales are fully taken into account.

In order ensure a strategy of agricultural diversification contributes to a transition towards sustainable development of the region, communities need to have access to external product markets and as well as receive support for an effort to expand and protect local markets. This would require not only an active engagement with regional and national policy makers, but it also suggests the need to consider local cultural change, including improving nutritional quality of diets and promoting local food security for the purpose of environmental sustainability, economic development, and human health.

Interestingly, despite concluding that the soils across much of the Brunca Region (the region in which Biolley and Pittier are located) are in poor condition, a report on the agricultural census (MAG 2003) suggests a large potential for raising livestock there. In doing so, it appears MAG is not weighing heavily the broader potential impact this practice could have on the land cover and the ecology of the region, nor does it appear to be taking into account how this activity, requiring the use of extended areas of land, would reduce opportunities for agricultural diversification and regional sustainability. The addition of livestock across the landscape implies a strategy for further introducing pasture vegetation or a system of local production of feed crops that will thrive in the 
premontane climate predominant there (2). Such initiatives would likely lead to reductions in local biodiversity and they could also prove contrary to the work of natural resource conservation agencies interested in taking a landscape ecology approach to the design and restoration of protected areas (Guevara and Laborde 2008). Although the Pittier district was not considered by MAG as part of the area of influence in their census report a decade ago (MAG 2003), this perception may be changing. During a field visit in 2011, there was a week-long, intensive course on improving methods for raising livestock in Pittier that was sponsored by the Institute for Rural Development (INDER).

Overall, my fieldwork demonstrates that many farmers and community organizations across the study location are interested in incorporating natural resource conservation practices into their agricultural production systems. However, the Ministry of Agriculture (MAG) does not have the expertise or the established presence in the study location that it would need to facilitate this process; and, no local or regional organization has yet to emerge as being capable of supporting this transition across ACLAP. ASOPROLA has established itself as a potential leader of sustainable development through its work in agriculture, environmental education, and community development activities. However, the recent withdrawal of some of its members from leadership roles in the Red Quercus and their reduction in outreach efforts have reduced the potential of ASOPROLA to play a leadership role in regional development in the immediate future. While local organizations are quickly stretched thin when they try to extend their more integrative development efforts across the region, large-scale government agencies such as MAG and MINAET are constrained by their budgets and their positions within an 
historically centralized government bureaucracy. By purpose and definition these agencies are committed to their key interests and their strength in focus often precludes them from developing and participating in collaborative programming for sustainable regional development.

Given limited opportunities for tourism-based development and the overwhelming emphasis placed on commodity and food production in regional agriculture, there is a need to consider additional activities that could potentially integrate agricultural and conservation practices in farmer livelihoods across the region. There was only limited discussion among research participants of any livelihood opportunities in the pursuit of agroforestry or the production environmental services. The participants that did discuss incorporating trees in their agricultural fields were primarily interested in either the future harvest of lumber or receiving premiums for shade-grown coffee. In some instances, these trees were even described as a nuisance or mentioned as a source of disagreement between people over land use and pest management practices. Only two participants mentioned the need and potential benefits of educating farmers on the management of secondary forests surrounding PILA. Given Costa Rica's well-established program for payments for environmental services and its policy initiatives favoring the establishment of biological corridors across the country, it appears even more important that these forest patches be considered as part of a strategy for regional agricultural and economic diversification in the study location.

In considering forestry as part of a diversification strategy in this area, farmers could be involved in evaluating the trade-offs between natural regeneration and planting 
species for profit. This could prove to be an effective development strategy in a place where labor is in relatively short supply and there is a need to establish trust and the grounds for a working relationship between government agencies and land owners in rural communities. Other potential strengths of this approach include the way it addresses a concern expressed by some participants over the tendency of young people to leave the region to pursue educational and/or economic opportunities. In fact, despite a growing population in Costa Rica, the population of the Brunca Region has not increased for decades, and those that choose to stay will be looking for ways to manage more land with less labor. Likewise, coupling forest restoration with environmental services could prove to be an effective approach in a place like Santa Maria de Pittier where abandoned farm land has been put into permanent pasture. Research in other areas has shown that older households are more likely to adopt conservation practices, and previous research in ACLAP has also found the management of secondary forests and maintenance of pasture areas to both be farm management strategies associated with lower levels of available labor (Schelhas 1996).

\section{Regional leaders and planned interventions}

As previously mentioned, there are a number of individuals and organizations across the study location that could prove to be leaders of future regional development. This study has identified some potential leaders with more experience than others, and it has demonstrated the complex, multilevel social structures involved in integrated development across the region. In addition to the needs of farmers to locate pathways towards establishing agro-ecological production systems, the region is in need of a better 
coordinated effort to politically integrate community, national, and transnational development interests.

To the extent that there has been some collaboration between community organizations, such as ASOROLA and ASOFAC.CB, and government ministries like MINAET, these efforts have also been limited by a lack of resources and the political motivations of individual actors. The history of community organizing in Biolley has lent itself somewhat to maintaining working relationships with national government agency partners and to the establishment and maintenance of similar relationships with transnational development partners like ISV and those collaborating with INBio. While the national initiative for political decentralization has motivated the formation of additional integrated development associations (ADIs) in communities across the study location over recent years, farmers associations like ASOPROLA and ASOMOBI appear to be more involved in integrated development efforts than these ADIs. Although the ADIs are agencies formally articulated with the national political administration, and therefore in theory able to directly draw on support from other government agencies, the leaders of established farmers associations have also often taken leadership roles in local ADIs. In such a situation, it is important for outside development interests to understand which of these associations actually take primary leadership roles, which associations work towards the general best interest of the community, and which associations are more influential in determining the agendas for local and integrated development.

The emergence of community organizations in Pittier is more recent, and therefore ADIs could potentially play more influential roles in development in this 
district. This potential is seemingly increased upon considering the lack of a presence of farmers associations across Pittier. Farmers across Pittier are articulated with the large commercial cooperative centers, and previously existing community organizations across the district tend to be focused on the issues of health and education. Although these groups could provide the future political leaders of integrated development efforts, the organizations themselves are usually directed by more specific interests rather than general interests in community development or interests in integrated conservation and development.

Something this study has pointed to on multiple occasions is that there is a significant difference between establishing and maintaining a development association for local integrated development and establishing associations to support integrated development across a district, municipality, or region. For the most part, extra-local organizations have looked to partner with grassroots organizations in the communities across the study location to organize integrated development efforts. This is evidenced in Biolley through the relationships ASOMOBI and ASOPROLA have established with national and international partners. This was also evidenced by the efforts of government and semi-autonomous government agencies (i.e., the Municipality of Coto Brus, MINAET and UPACOB) to support the establishment and/or development of associations in communities across Pittier. While the Red Quercus project has struggled for years to get off the ground, the leadership of ASOPROLA concluded, at least temporarily, that the coordination of regional development efforts was beyond it current means. In Pittier, the Municipality of Coto Brus' effort to scale up the integrated association framework by 
promoting district-level networks of ADIs through its planning process appears somewhat arbitrarily contrived. As many of the elected or appointed members of this network were also the elected members of community-level ADIs, this process may compel local leaders to become more involved in district-level and municipal-level politics. It could also undermine the potential for newly-formed ADIs to increase the participation of residents of their respective communities. We also saw evidence of a similar process being promoted in Biolley by the Municipality of Buenos Aires. There, too, the process appeared to rely more on leadership outside the ADIs.

\section{Conclusion, implications for development work, and recommendations for research}

Although the emphasis in this research was placed on exploring farmers' views of the park and their perceptions of park rangers, the results of the analysis of farmers' views imply measures that can be taken by natural resource managers to improve this relationship, and possibly the condition of the park. Residents of Pittier and Biolley do tend to have a favorable view of the park, and in some places their relationship with park rangers has improved considerably over recent decades. Despite the generally positive image of PILA across the study location, there appear to be significant variations in people's opinions about individual actions taken by natural resource managers, which indicates a need for MINAET to evaluate its purpose and presence in different places across the ACLAP. Given limited resources and a mandate to strictly protect access to the park, the ministry's has not been able to get involved in community development projects across the region. As a result, the varied presence and seemingly arbitrary enforcement of land use regulations in some places has contributed to confusion about the roles of natural 
resource managers in communities adjacent to the park. Further, MINAET has a very limited presence in communities besides those that are adjacent to PILA, which makes it even more difficult for the ministry and its officials to be involved in work that articulates agro-ecosystems across communities and landscape features such as watersheds.

In meta-analyses of the impacts and effectiveness of protected areas, researchers have found connectivity to population centers and community-based natural resource management organizations to be related to positive outcomes in terms of decreased rates of deforestation and poverty (Porter-Bolland, Ellis, Guariguata, Ruiz-Mallén, NegreteYankelevich, and Reyes-García 2012; Ferraro, Hanauer, and Sims 2010). All of this suggests natural resource managers in ACLAP could benefit from taking pause, looking away from the core area of the park, and reflecting on their potential role in the sustainable development of the region. In this way, the image and presence of rangers in agricultural communities across the conservation area could be improved by identifying ways they can contribute to development outside the park that also benefit the core protected. Some of this effort should be directed towards clarifying the connections between the agricultural and ecological systems across the landscape, which will improve communication between everyone involved in development of the ACLAP.

Farmers in Pittier and Biolley expressed an intimate awareness of some of the major environmental problems across the area. They are not always in situations, however, in which they can act in ways that reflect what they think and feel are in the best interests of themselves and the environment. Natural resource managers could establish and/or maintain better working relationships with farmers across these districts by 
addressing a number of farmer concerns. Farmers are concerned about issues such as soil quality and pest management, issues which are directly related to broader concerns of natural resource managers about land use, climate change, and the environment. A key initiative to improve opportunities for sustainable development across the region could be to articulate these production-related concerns with the concerns about the conditions of natural resources. Although current administrative efforts in integrating development and conservation do employ a few community residents as park guides, taxonomists and environmental educators, these efforts do not address the concerns of agricultural production and therefore are likely to have limited impact on livelihoods and land use patterns across the region. They are also unlikely to produce much of an improvement in the relationship between park rangers and farmers.

It is not an uncomplicated thing to recommend that natural resource managers get involved in community development outside the park. The presence of international nongovernment organizations has been diminishing across the region during recent years, and it is well-known that MINAET has very limited resources. Nevertheless, the region could benefit from the extension of current participatory monitoring programs, which are currently very limited in scope. As suggested by Kremen, Merenlender, and Murphy (1994) these programs should include an emphasis on indicator species, or natural actors, and assemblages that provide explicit links between conservation interests to the current drivers of agricultural economic development. Over time, such an effort in a place like Agua Caliente could go a long way towards alleviating the perception of park rangers as actors who eagerly and arbitrarily enforce land use regulations. MINAET's reputation 
across the region could also be improved with their involvement in education focused on clarifying the reasoning behind land use restrictions and with their taking on a role of intermediary or facilitator in the process of requesting logging permits. Currently, the majority of environmental education happening across the region is focused on biology, ecology, and species protection, and there is a lack of information and resources available for small land owners interested in improving their land management practices.

Again, taking into account the limited availability of resources, partnerships between government agencies like MINAET, MAG, and AyA could prove to be an effective strategy for sustainable development of the region. For example, in situations where communities are interested in reforestation projects to project the quality of their water resources, if there were working relationships between agencies like MINAET and AyA in the region, some of the problems related to disagreements about appropriate uses of available funds and land might be easier to address (Sims and Sinclair 2008). As it currently stands, community representatives have to spend significant amount of time and money traveling to negotiate with agency officials separately. Although local ADIs are well-positioned to fill the role of a facilitating agency in these situations, these associations currently tend to have limited capacity and resources and they do not appear to be generally recognized or the first point of contact in the communities, even for the major agencies of the central government. In some ways, this may reflect Costa Rica's political history of depending on individual transnational actors and local grassroots organizations to play lead roles in integrating conservation and development (Steinberg 2001). Other researchers have also pointed to the general lack of inter-agency 
collaboration in the region and the impacts that this has on environmental and human health and development (Wishnie and Socha 2003).

In order to increase the possibilities for inter-agency collaboration across scales, there needs to be further investigation into the cultures of individual national government ministries. Having a better understanding of these institutional environments would improve the chance that sustainable development initiatives could involve multiple agencies on programs with common areas of interest. Without this inter-cultural perspective, agencies often tend towards adopting a narrow focus (de Vos 2007), which can be very effective in pursuing specific outcomes and at the same time very limiting of attempts to transition towards sustainable development by implementing regional environmental policy (Bruger 1982; Brandon 2004).

Likewise, organizations in remote regions would benefit from an increased awareness of their own internal cultures and an understanding of cultural differences between potential agency partners that operation out of the centers of population and government. As Ferraro, Hanauer, and Sims (2010) suggest, these relationships are important for efforts to reduce poverty and natural resource degradation in remote areas, and an awareness of culture and cultural difference among government ministries, development associations, and community organizations would likely prove beneficial in establishing and maintaining work relationships and partnerships in sustainable development across ACLAP. Research into this area will be important for maintaining an awareness of the impact of transnational development on local culture as well as for evaluating the implementation and effectiveness of the national political decentralization 
process in Costa Rica. As Basurto (2013a) points out, the potential for these types of strategies in Costa Rica is highly dependent upon existing social and economic divisions within communities. And, without an understanding of the existing, social, political and economic divisions, there is little basis for action and evaluation. 


\section{References}

ACTUAR. 2013. Alianza Comunitaria Conservacionista de Turismo Alternativo Rural. [accessed October 30, 2013]. http://www.actuarcostarica.com/

Adams, W. M. 2001. Green Development: Environment and Sustainability in the Third World. New York: Routledge.

Adams, William M., Ros Aveling, Dan Brockington, Barney Dickson, Jo Elliot, Jon Hutton, Dilys Roe, Bhaskar Vira, and William Wolmer. 2004. Biodiversity Conservation and the Eradication of Poverty. Science 306:1146-9.

Agrawal, Arun. 2005. Environmentality: Technologies of Government and the Making of Subjects. Durham: Duke University Press.

Agüero, Margarita Victoria Céspedes. 2006. Diseño de una red ecológica de conservación entre la Reserva de Biosfera La Amistad y las áreas protegidas del Área de Conservación Osa, Costa Rica. Thesis. Tropical Agricultural Research and Higher Education Center.

Allen, William. 2001. Green Phoenix: Restoring the Tropical Forests of Guanacaste, Costa Rica. New York: Oxford University Press.

Altieri, Miguel A. 1995. Agroecology: The Science of Sustainable Agriculture. London: Westview Press, Inc.

-. 2000. Enhancing the productivity and multifunctionality of traditional farming in Latin America. International Journal of Sustainable Development and World Ecology 7:50-61.

Anchukaitis, Kevin J. and Sally P. Horn. 2005. A 2000-year reconstruction of forest disturbance from southern Pacific Costa Rica. Palaeogeography,

Palaeoclimatology, Palaeoecology 221:35-54.

Annis, Sheldon. 1992. Poverty, Natural Resources, and Public Policy in Central America. New Brunswick: Transaction Publishers.

ASOPROLA, (Asociación de Productores la Amistad). 2012. Bienvenidos a Asoprola! [accessed November 1, 2013]. http://www.asoprola.org/

ATLAS.ti. n. d. Some Cooc Table Explorer (CTE) Mysteries Unveilled. [accessed October 30, 2013]. http://www.atlasti.com/395.html

Babin, Nicholas L. 2012. Agrarian Change, Agroecological Transformation and the Coffee Crisis in Costa Rica. Ph. D. diss., University of California, Santa Cruz. 
Bacon, Christopher M, V. Ernesto Méndez, Stephen R. Gliessman, David Goodman, and Jonathan A. Fox. 2008. Confronting the Coffee Crisis: Fair Trade, Sustainable Livelihoods and Ecosystems in Mexico and Central America. Cambridge, Massachusetts: The MIT Press.

Barbieri, Carla and Corinne Valdivia. 2010. Recreation and agroforestry: Examining new dimensions of multifunctionality in family farms. Journal of Rural Studies 26:465-73.

Basurto, Xavier. 2013a. Bureaucratic Barriers Limit Local Participatory Governance in Protected Areas in Costa Rica. Conservation and Society 11:16-28.

—. 2013b. Linking Multi-Level Governance to Local Common-Pool Resource Theory Using Fuzzy-Set Qualitative Comparative Analysis: Insights from Twenty Years of Biodiversity Conservation in Costa Rica. Global Environmental Change 23:573-87.

Baudry, Jacques, Françoise Burel, Stéphanie Aviron, Manuel Martin, Annie Ouin, Guillaume Pain, and Claudine Thenail. 2003. Temporal variability of connectivity in agricultural landscapes: do farming activities help? Landscape Ecology 18:303-14.

Birks, Melanie and Jane Mills. 2011. Grounded Theory: A Practical Guide. Thousand Oaks, CA: Sage Publications, Ltd.

Blaikie, Piers and Harold Brookfield. 1987. Land Degredation and Society. New York: Methuen.

Bonta, Mark. 2003. Becoming-forest, becoming-local: transformations of a protected area in Honduras. Geoforum 36:95-112.

Booth, Wayne C., Gregory G. Colomb, and Joseph M. Williams. 2007. A Manual for Writers of Research Papers, Theses, and Dissertations, 7th edition. Chicago: The University of Chicago Press.

Bosselmann, Aske Skovmand. 2012. Mediating factors of land use change among coffee farmers in a biological corridor. Ecological Economics 80:79-88.

Bosselmann, Aske Skovmand and Jens Friis Lund. 2013. Do intermediary institutions promote inclusiveness in PES programs? The case of Costa Rica. Geoforum 49:50-60.

Brandon, Katrina. 2004. The Policy Context for Conservation in Costa Rica. Pp. 299-310 in Biodiversity Conservation in Costa Rica: Learning the Lessons in a Seasonal Dry Forest, edited by G. W. Frankie, A. Mata, and S. B. Vinson. Berkeley: University of California Press.

Brosius, Peter J. 1999a. Analyses and Interventions: Anthropological Engagements with Environmentalism. Current Anthropology 40:277-309. 
Brosius, Peter J. 1999b. Green Dots, Pink Hearts: Displacing Politics from the Malaysian Rain Forest. American Anthropologist 101:36-57.

Brown, Katrina. 2003. Three challenges for a real people-centred conservation. Global Ecology \& Biogeography 12:89-92.

Bruger, Ernst A. 1982. Regional Policy in Costa Rica: The Problems of Implementation. Geoforum 13:177-92.

Callon, Michel, Pierre Lascoumes, and Yannick Barthe. 2001. Acting in an Uncertain World: An Essay on Technical Democracy. Cambridge: The MIT Press.

Campbell, Lisa M. 2002. Conservation Narratives in Costa Rica: Conflict and Coexistence. Development and Change 33:29-56.

Carbonell, Fabricio. 2009. "Recomendaciones y Comentarios al Proyecto de Justin." Programa Investigaciones MINAET-SINAC-ACLAP-PILA.

Cardoso, Fernando Henrique and Enzo Faletto. 1979. Dependency and Development in Latin America. Berkeley: University of California Press.

Carey, Mark. 2009. Latin American Environmental Hisory: Current Trends, Interdisciplinary Insights, and Future Directions. Environmental History 14:22152.

Carpenter, F. Lynn, Sergio Palacios Mayorga, Eduardo Gonzalez Quintero, and Michelle Schroeder. 2001. Land-Use and Erosion of a Costa Rican Ultisol Affect Soil Chemistry, Mycorrhizal Fungi and Early Regeneration. Forest Ecology and Management 144:1-17.

Carriere, Jean. 1991. The crisis in Costa Rica: an ecological perspective. Pp. 184-204 in Environment and development in Latin America: The politics of sustainability, edited by D. Goodman and M. Redclift. New York: Manchester University Press.

Caviglia-Harris, Jill L. 2003. Sustainable Agricultural Practices in Rondônia, Brazil: Do Local Farmer Organizations Affect Adoption Rates? Economic Development and Cultural Change:23-49.

Chester, Charles C. and Jodi A. Hilty. 2010. Connectivity Science. Pp. 22-33 in Connectivity Conservation Management: A Global Guide, edited by G. L. Worboys, W. L. Francis, and M. Lockwood. Washington, DC: Earthscan.

Clement, Rachel M. and Sally P. Horn. 2001. Pre-Columbian land-use history in Costa Rica: a 3000-year record of forest clearance, agriculture and forest from Laguna Zoncho. The Holocene 11:419-26.

Cole, Rebecca J. 2010. Social and environmental impacts of payments for environmental services for agroforestry on small-scale farms in southern Costa Rica.

International Journal of Sustainable Development \& World Ecology 17:208-16. 
Coleman, Simon and Pauline von Hellermann. 2011. Multi-Sited Ethnography: Problems and Possibilities in the Translocation of Research Methods. New York:

Routledge.

Contreras, Ricardo B. 2011. Examining the Context in Qualitative Analysis: The Role of the Co-Occurrence Tool in ATLAS.ti. [accessed October 30, 2013]. http://downloads.atlasti.com/library/contreras_nl201108.pdf

CORFOGA, (Corporación Ganadera). 2000. Análisis de Censo Ganadero 2000. [accessed October 30, 2013]. http://www.corfoga.org/censo.php

Cote, Muriel and Andrea J. Nightingale. 2012. Resilience thinking meets social theory: Situating social change in socio-ecological systems (SES) research. Progress in Human Geography 36:475-89.

Dale, Virginia H., Keith L. Kline, Stephen R. Kaffka, and J. W. A. (Hans) Langeveld. 2013. A landscape perspective on sustainability of agricultural systems.

Landscape Ecology 28:1111-23.

Deleuze, Gilles, Félix Guattari, and Brian Massumi. 2008. "A Thousand Plateaus: Capitalism and Schizophrenia." London: Continuum. [accessed October 30, 2013]. http://laurel.lso.missouri.edu/search S1?/adeleuze/adeleuze/1\%2C6\%2C66\%2CB /frameset\&FF $=$ adeleuze + gilles $+1925+1995 \& 35 \% 2 \mathrm{C} \% 2 \mathrm{C} 59$

de Vos, Hugo Jeroen. 2007. Organisational culture: Institionalisation of GIS for forest monitoring in Costa Rica. Environment and Planning B: Planning and Design $34: 355-68$.

Diaz, I. S. Candanedo. 2010. Nature - Culture Interactions Among Peasant Communities Near La Amistad Trans-boundary Park, Panama and Costa Rica. PhD diss., University of Essex.

Dorn, Marilyn April. 1989. The Administrative Partitioning of Costa Rica: Politics and Planners in the 1970s. Chicago: The University of Chicago.

ECLAC, (Economic Commission for Latin America and the Caribbean). 2012. Statistical Yearbook for Latin America and the Caribbean. [accessed October 30, 2013]. http://interwp.cepal.org/anuario_estadistico/anuario_2012/default.asp

Edelman, Marc. 1995. Rethinking the Hamburger Thesis: Deforestation and the Crisis of Central America's Beef Exports. Pp. 25-62 in The Social Causes of Environmental Destruction in Latin America, edited by M. Painter and W. H. Durham. Ann Arbor: The University of Michigan Press. 
EDUCA/PILA. n. d. Programa de Educación Ambiental Comunitaria en al Zona de Amortiguamiento del Parque Internacional La Amistad, Sector Pacifico, Costa Rica. [accessed January 10, 2014]. http://www.inbio.ac.cr/pila/pdf/EDUCA \%20PILA\%20Documento\%20del\%20programa.pdf

elguardi@n.cr. n. d. ICAFE desrrolla amplio programa de capacitación contra Roya. [accessed April 11, 2014]. http://www.elguardian.cr/es/Nacionales/ICAFE_desarrolla_amplio_programa_de capacitaci $\% \mathrm{C} 3 \% \mathrm{~B} 3 \mathrm{n}$ contra_Royal

Escobar, Arturo. 1995. Encountering Development: The Making and Unmaking of the Third World. New Jersey: Princeton University Press.

-. 1999. After Nature: Steps to an Antiessentialist Political Ecology. Current Anthropology 40:1-30.

-. 2001. Culture sits in places: reflections on globalism and subaltern strategies of localization. Political Geography 20:139-74.

Esteva, Gustavo. 1992. Development. Pp. 6-25 in The Development Dictionary, edited by W. Sachs. New York: Zed Books Ltd.

Evans, Sterling. 1999. The Green Republic: A Conservation History of Costa Rica. Austin: University of Austin Press.

Ferraro, Paul J., Marlin M. Hanauer, and Katharine R. E. Sims. 2010. Conditions associated with protected area success in conservation and poverty reduction. Proceedings of the National Academy of Sciences 108:13913-8.

Fitzgerald, Charity Samantha. 2013. Not for Members Only: Cooperatives and Community Development in Costa Rica. PhD diss., University of California, Berkeley.

GAT-ALTO. 2013. GAT-ALTO: Buenos Aires - Coto Brus. [accessed November 1, 2013]. http://gatsur.com/index.php

Geertz, Clifford. 1963. Agricultural Involution: The Process of Ecological Change. Berkeley: University of California Press.

Giddens, Anthony. 1984. The Consitution of Society: Outline of a Theory of Structuration. Berkeley: University of California Press.

Gilles, Jere L., Justin L. Thomas, Corinne Valdivia, and Edwin S. Yucra. 2013. Laggards or Leaders: Conservers of Traditional Agricultural Knowledge in Bolivia. Rural Sociology 78:51-74.

González de Molina, Manuel. 2013. Agroecology and Politics: How to Get Sustainability? About the Necesity for a Political Agroecology. Agroecology and Sustainable Food Systems 37:45-59. 
Guevara, Sergio and Javier Laborde. 2008. The Landscape Approach: Desinging New Reserves for Protection of Biological and Cultural Diversity in Latin America. Environmental Ethics 30:251-62.

Hansen, Andrew J. and Ruth DeFries. 2007. Ecological Mechanisms Linking Protected Areas to Surrounding Lands. Ecological Applications 17:974-88.

Harding, Sandra G. 1986. The Science Question in Feminism. Ithaca: Cornell University Press.

Hartter, Joel, Abraham Goldman, and Jane Southworth. 2010. Responses by household to resource scarcity and human-wildlife conflict: Issues of fortress conservation and the surrounding agricultural landscape. Journal for Nature Conservation.

Harvey, David. 1996. Justice, Nature \& the Geography of Difference. Malden, MA: Blackwell Publishers Inc.

Hayami, Yujiro. 1981. Induced Innovation, Green Revolution, and Income Distribution: Comment. Economic Development and Cultural Change 30:169-76.

Holdridge, L.R. 1967. Life Zone Ecology. San Jose, Costa Rica: Tropical Science Center.

ICAFE. n. d. a. La Roya del Café. [accessed April 11, 2014]. http://www.icafe.go.cr/icafe/anuncios/roya_del cafe/roya.html

—. n. d. b. Sistema de Información Geográfica. [accessed April 11, 2014]. http://www.icafe.go.cr/sector_cafetalero/SIG/sistema_informacion_geografica.ht $\underline{\mathrm{ml}}$

ICE, (Instituto Costarricense de Electricidad). n. d. "Responsabilidad Social y Ambiental." [accessed November 1, 2013]. http://www.grupoice.com/wps/portal/gice/acerca_ice/acerca_ice_resp_amb/acerca ice resp amb refos/acerca ice resp amb fauna/! ut/p/c5/04 SB8K8xLLM9MSSzPy8xBz9CP)0os gQL0N D2cLEwN Vy8XA08z Y09TUzNTi9BAA6B8JJK8QYCIK1De1dcyyMzVwMDAhBjdBjiAowEB3X4ebmp-gW5oRHljoqKALcvcLY!/d13/d3/L2dBISEvZ0FBIS9nQSEh/

IFAM, (Instituto de Formacón y Capacitación Municipal y Desarollo Local). 2011. "Ideario sobre la descentralización en Costa Rica." [accessed October 30, 2013]. http://www.ifam.go.cr/docs/Ideario\%20final.pdf

Igoe, Jim. 2004. Conservation and Globalization: A Study of National Parks and Indigenous Communities from East Africa to South Dakota. Belmont, CA: Wadsworth/Thompson Learning.

IICA, (Instituto Interamericano de Cooperación para la Agricultura). n. d. Portal de la Estrategia Centroamericana de Desarrollo Rural Territorial 2010-2030 (ECADERT). [accessed October 30, 2013]. http://www.territorioscentroamericanos.org/Paginas/Default.aspx 
IIED, (International Institute for Environment and Development). n. d. Costa Rica - Costa Rican Electricity Institute (ICE). [accessed November 1, 2013]. http://www.watershedmarkets.org/casestudies/Costa_Rica_ICE_eng.html

Immigration, and Refugee Board of Canada. 2002. Costa Rica: The Pineapple Development Coroporation (PINDECO): The Treatment of Union Activists and Union Attempts to Organize a Union by PINDECO and Authorities in Buenos Aires Province (1999 to 2002). Immigration and Refugee Board of Canada. [accessed October 30, 2013]. http://www.refworld.org/cgi-bin/texis/vtx/rwmain? page $=$ category \& category $=\&$ publisher $=\&$ type $=$ QUERYRESPONSE\&coi $=$ CRI\&d $\underline{\text { ocid }=3 \mathrm{f} 7 \mathrm{~d} 4 \mathrm{~d} 8231 \& \text { skip }=0}$

INBio, (Insituto Nacional de Biodiversidad). 2012. Campaña de Incendios Forestales para el PILA. [accessed November 1, 2013].

http://www.inbio.ac.cr/pila/campanas introduccion.htm

—. n. d. Areas Protegidas en Costa Rica. [accessed October 30, 2013]. http://www.inbio.ac.cr/estrategia/Informe1/labor art8 a1.htm

IUCN, (International Union for Conservation of Nature). n. d. . What Is a Protected Area? [accessed October 30, 2013]. http:/www.iucn.org/about/work/programmes/gpap_home/pas_gpap/

Jansen, Hans G. P., Angel Rodriquez, Amy Damon, John Pender, Jacqueline Chenier, and Rob Schipper. 2006. Determinants of income-earning strategies and adoption of conervation practices in hillside communities in rural Honduras. Agricultural Systems 88:92-110.

Janzen, Daniel H. 2004. Setting up tropical biodiversity for conservation through nondamaging use: participation by parataxonomists. Journal of Applied Ecology 41:181-7.

Jiménez, Francisco Delgado. 2012. La Inviabilidad de la Descentralización en Costa Rica. La Nación. [accessed http://www.nacion.com/foros/inviabilidaddescentralizacion-Costa-Rica 0 1309869142.html

JUDESUR, (Junta de Desarrollo Regional de la Zona Sur. 2009). Proyectos. [accessed November 1, 2013]. http://www.judesur.go.cr/index.php? option $=$ com portfolio\&view $=$ categories $\&$ Itemid $=7 \&$ lang $=$ es

Kappelle, Maarten, Thorwald Geuze, Miguel E. Leal, and Antoine M. Cleef. 1996. Successional Age adn Forest Structure in a Costa Rican Upper Montane Quercus Forest. Journal of Tropical Ecology 12:681-98.

Kremen, Claire, Adina M. Merenlender, and Dennis D. Murphy. 1994. Ecological Monitoring: A Vital Need for Integrated Conservation and Development Programs in the Tropics. Conservation Biology 8:388-97. 
Langholz, Jeff and James Lassoie. 2001. Combining Conservatin and Development on Private Lands: Lessons from Costa Rica. Environment, Development and Sustainability 3:309-22.

Larson, Anne M. 2003. Decentralisation and Forest Management in Latin America: Towards a Working Model. Public Administration and Development 23:211-26.

Latour, Bruno. 2004. Politics of Nature: How to Bring the Sciences into Democracy. Cambridge, MA: Harvard University Press.

Long, Norman. 1992. From Paradigm Lost to Paradigm Regained? Pp. 16-43 in Battlefields of Knowledge: The Interlocking of Theory and Practice in Social Research and Development, edited by N. Long and A. Long. New York: Routledge.

—. 2001. Development Sociology: Actor Perspectives. New York: Routledge.

Lutz, Ernst and Julian Caldecott. 1996. Decentralization and Biodiversity Conservation. The World Bank. [accessed October 30, 2013]. http://documents.worldbank.org/curated/en/1996/12/695073/decentralizationbiodiversity-conservation

Madrigal, Errol Vladimir Cunningham. 2011. "Atisbos del Processo de Descentralización en Costa Rica: Los Albores de su Evolución Histórica 1821-1871." Pp. 23-44 in Ideario sobre la descentralización en Costa Rica, edited by IFAM.

MAG, (Ministerio de Agricultura y Ganadería). 2003. Programa de Agencia de Servicios Agropecuarios 2003 - 2006. [accessed October 30, 2013]. http://www.mag.go.cr/regionales/p br_gutierrez 03-06.pdf

—. 2012. Boletín Estadístico Agropecuario, Número 22. [accessed October 30, 2013]. http://www.mag.go.cr/bibliotecavirtual/a00305.pdf

Malig, Anahi. 2011. The Environmental and Social Cost of Pineapples in Costa Rica. Labor is Not a Commodity. [accessed October 30, 2013]. http://laborrightsblog.typepad.com/international_labor_right/2011/01/theenvironmental-and-social-cost-of-pineapples-in-costa-rica.html

Manger, William F. 1992. Colonization on the Southern Frontier of Costa Rica: A Historical-Cultural Landscape. Masters, Memphis State University, Memphis State University.

Marcus, George E. 1995. Ethnography in/of the World System: The Emergence of MultiSited Ethnography. Annual Review of Anthropology 24:95-117.

Margerum, Richard D. 2011. Beyond Consensus: Improving Collaborative Planning and Management. Cambridge, Massachusetts: The MIT Press. 
Maroto, David. 2010. Diagnóstico y tendencias de la situación económica en la Región Brunca. [accessed October 30, 2013]. http://www.ifam.go.cr/PaginaIFAM/docs/PRODUCTOS\%20FOMUDE\%2020062011/R4-Productos/P3\%20Estudios\%20sobre\%20tendencias\%20de \%20desarrollo\%20local/Tendencias\%20del $\% 20$ desarrollo\%20en\%20el $\% 20$ sur $\% 20-\% 20$ sur $/ 03 \% 20$ Informaci $\% \mathrm{C} 3 \% \mathrm{~B} 3 \mathrm{n} \% 20 \mathrm{econ} \% \mathrm{C} 3 \% \mathrm{~B} 3$ mica $\% 20 \mathrm{General} . p d f$

McAreavey, Ruth. 2006. Getting Close to the Action: The Micro-Politics of Rural Development. Sociologia Ruralis 46:85-103.

McNeill, J.R. 2010. The State of the Field of Environmental History. Annual Review of Environment and Resources 35:345-74.

Millman, Joel. 1987. Coffee, Cops and Chorizo. Why Coto Brus said, 'No.'. Institute of Current World Affairs, San José, Costa Rica.

MINAE (Ministry of Environment and Energy). 2007. Plan de Protección y Control: Parque Internacional La Amistad. [accessed October 30, 2013]. http://www.inbio.ac.cr/pila/pdf/Plan-control-Parque-Internacional-Amistad08 05 07.pdf

Monge, Silvano, Randall Cortés, Leydi Delgado, Scott Delgado, and Fabricio Carbonell. n.d. "La historia de Colorado, Altamira y El Campo (Biolley, Buenos Aires, Puntarenas): Una metodolgía para la historia de nuestros pueblos." Pp. 11. Altamira.

Nygren, Anja. 1998. Environment as Discourse: Searching for Sustainable Development in Costa Rica. Environmental Values 7:201-22.

-. 2000. Development Discourses and Peasant-Forest Relations: Natural Resource Utilization as Social Process. Development and Change 31:11-34.

Nygren, Anja and Sandy Rikoon. 2008. Political Ecology Revisited: Integration of Politics and Ecology Does Matter. Society \& Natural Resources 21:767-82.

O'Riordan, Tim. 2002. Protecting Beyond the Protected. Pp. 3-29 in Biodiversity, Sustainability and Human Communities: Protecting Beyond the Protected, edited by T. O'Riordan and S. Stoll-Kleeman. New York: Cambridge University Press.

OTS, (Organization for Tropical Studies. n. d. The Las Cruces - Guaymí Biological Corridor in Southern Costa Rica. [accessed November 1, 2013]. http://www.ots.ac.cr/index.php? option $=$ com_content\&task $=$ view $\&$ id $=227 \& I t e m i d=431$

Projects, Pancho's. 2014. A glimpse of Pancho's world \& his plans for the future. [accessed May 9, 2014]. http://panchosprojects.com/ 
Paulson, Susan and Lisa L. Gezon. 2005. Political Ecology across Spaces, Scales, and Social Groups. New Brunswick, NJ: Rutgers University Press.

Picado, Patricia Blanco. 2000. The Price of Pineapples. Pesticide Action Network, UK. [accessed October 30, 2013]. http://www.panuk.org/pestnews/Issue/pn48/pn48p8.htm

Polanyi, Karl. 2001. The Great Transformation: The Political and Economic Origins of Our Time. Boston: Beacon Press.

Porter-Bolland, Luciana, Edward A. Ellis, Manuel R. Guariguata, Isabel Ruiz-Mallén, Simoneta Negrete-Yankelevich, and Victoria Reyes-García. 2012. Community Managed Forests and Forest Protected Areas: An Assessment of Their Conservation Effectiveness across the Tropics. Forest Ecology and Management 268:6-17.

Portolés, Edmundo. 2012. Costa Rica: Estructura Económica. Institúto Español de Comercio Exterior. [accessed October 31, 2013]. http://www.oficinascomerciales.es/icex/cda/controller/pageOfecomes/0,5310,528 04495296126 5296234_0 CR,00.html

Poteete, Amy R. and Elinor Ostrom. 2008. Fifteen Years of Empirical Research on Collective Action in Natural Resource Management: Struggling to Build Large-N Databases on Qualitative Research. World Development 36:176-95.

PRODELSAN, (Proyectos de Desarrollo Local y Seguridad Alimentaria. n. d. a. Plan de Desarrollo Integral, Coto Brus, 2011 - 2016. [accessed November 1, 2013]. http://www.prodelsan.org/images/Descargas/pdic_coto brus.pdf

—. n. d. b. Plan de Desarrollo Integral, Distrito de Pittier, Coto Brus, 2011- 2016. [accessed November 1, 2013]. http://www.prodelsan.org/images/Descargas/pdid_pittier.pdf

Pujadas, Anna and Alicia Castillo. 2007. Social Participation in Conservation Efforts: A Case Study of a Biosphere Reserve on Private Lands in Mexico. Society \& Natural Resources 20:57-72.

Rainforest Alliance. n. d. La Amistad Association of Producers (ASOPROLA). [accessed November 1, 2013]. http://www.eco-index.org/ong/asoprola-cr-eng.html

Redclift, Michael. 1987. Sustainable Development: Exploring the Contradictions. New York, NY: Methuen.

Ribot, Jesse C. 2009. Authority over Forests: Empowerment and Subordination in Senegal's Democratic Decentralization. Development and Change 40:105-29.

Rickert, Eve. 2005. Environmental Effects of the Coffee Crisis: A Case Study of Land Use and Avian Communities in Agua Buena, Costa Rica. Thesis. The Evergreen State College. 
Riketts, Taylor H. and Eric Lonsdorf. 2013. Mapping the margin: comparing marginal values of tropical forest remnants for pollination services. Ecological Applications 23:1113-23.

Robbins, Paul. 2004. Political Ecology: A Critical Introduction. Malden, MA: Blackwell Publishing.

Sachs, Wolfgang, ed. 1992. The Development Dictionary: A Guide to Knowledge as Power. New York: Zed Books Ltd.

Sainath, Palagummi. 1996. Everybody Loves a Good Drought. New York: Penguin Books.

Salas, Ronulfo Alvarado. 2011. "Descentralización, contexto y tendencias." Pp. 13-22 in Ideario sobre la descentralización en Costa Rica, edited by IFAM.

Salas, Ronulfo Alvarado and Jorge E. Esquivel Alfaro. 2002. El Processo de Descentralización en Costa Rica. Instituto de Formacón y Capacitación Municipal y Desarollo Local. [accessed October 30, 2013]. http://www.ifam.go.cr/docs/Descentral.pdf

Samper, Mario, Carlos Naranjo, and Paul Sfez. 2000. Entre la Tradición y el Cambio: Evolución Tecnológica de la Caficultura Costarricense. Universidad Nacional: Escuela de Historia.

Schelhas, John. 1994. Building Sustainable Land Uses on Existing Practices: Smallholder Land Use Mosaics in Tropical Lowland Costa Rica. Society \& Natural Resources 7:67-84.

Schelhas, John. 1996. Land Use Choice and Change: Intensification and Diversification in the Lowland Tropics of Costa Rica. Human Organization 55:298-306.

Schelhas, John and Max J. Pfeffer. 2008. Saving Forest, Protecting People? Environmental Conservation in Central America. New York: Altamira Press.

Schuit, Pascale. 2011. Livelihood Strategies in the Buffer Zone of La Amistad Biosphere Reserve, Costa Rica. Thesis. Wageningen University, The Netherlands.

Scoones, Ian. 1998. Sustainable Rural Livelihoods: A Framework for Analysis. Institute of Devlopment Studies. [accessed April 11, 2014]. http://www.ids.ac.uk/files/dmfile/Wp72.pdf

Scoones, I. 1999. New Ecology and the Social Sciences: What Prospects for a Fruitful Engagement? Annual Review of Anthropology 28:479-507.

Scott, James C. 1985. Weapons of the Weak: Everyday Forms of Peasant Resistance. New Haven, CT: Yale University Press.

- 1990. Domination and the arts of resistance: Hidden transcripts. New Have, CT: Yale University Press. 
SGP, (Programa Pequeñas Donaciones del FMAM Costa Rica). n. d. a. Estrategia Nacional: Costa Rica. [accessed November 1, 2013]. http://www.pequenasdonacionescr.org/dmdocuments/Estrategia_Nacional_OP3 C ON\%20FOTOS.pdf

—. n. d. b. "Estrategia Nacional: Fase Operativa IV (2008-2010), Costa Rica."

SGP, (The GEF Small Grants Programme). 2012a. Costa Rica. [accessed November 1, 2013]. https://sgp.undp.org/index.php? option $=$ com countrypages \&view $=$ countrypage $\&$ country $=39 \&$ Itemid $=204$

-. 2012b. COS/05/48. UPACOB. Fortalecimiento de Procesos de Comercialización de Productos Orgánicos a Través de Ferias Locales y Otros Espacios en la Región. [accessed November 1, 2013]. https://sgp.undp.org/index.php? option $=$ com sgpprojects \&view $=$ projectdetail $\&$ id $=9524 \&$ Itemid $=205$

Shively, Gerald E. 1997. Consumption Risk, Farm Characteristics, and Soil Conservation Adoption Among Low-Income Farmers in the Philippines. Agricultural Economics 17:165-77.

Sick, Deborah. 1999. Farmers of the Golden Bean. Dekalb: Northern Illinois University Press.

Sims, Laura and A. John Sinclair. 2008. Learning Through Participatory Resource Management Programs: Case Studies from Costa Rica. Adult Education Quarterly 58:151-68.

Solórzano, Nils and Max Ureña Fallas. 2008. Programa de Extension para la Incentivación de la Producción de Granos Básicos (Maiz, Frijol y Arroz). Ministerio de Agricultura y Ganaderia. [accessed October 30, 2013]. http://www.mag.go.cr/biblioteca virtual/bd.html

Steinberg, Pual F. 2001. Environmental Leadership in Developing Countries: Transnational Relations and Biodiversity Policy in Costa Rica and Bolivia. Cambridge, Massachussetts: The MIT Press.

Stem, Caroline J., James P. Lassoie, David R. Lee, David J. Deshler, and John W. Schelhas. 2003. Community Participation in Ecotourism Benefits: The Link to Conservation Practices and Perspectives. Society \& Natural Resources 16:387413.

Stuchi, Julia Franco. 2009. Calidad de Vida, Sistemas Agroforestales y Servicios Ambientales en la ámbito de la gestión territorial participativa de la Zona de Amortiguamiento del Parque Internacional La Amistad, Costa Rica. Masters Thesis, Centro Agronómico Tropical de Investigación y Enseñanza, Turrialba.

Sundberg, Juanita. 1998. NGO Landscapes in the Maya biosphere reserve, Guatemala. The Geographical Review 88:388-412. 
-. 2004. Identities in the Making: conservation, gender and race in the Maya Biosphere Reserve, Guatemala. Gender, Place and Culture 11:43-66.

-. 2006. Conservation encounters: transculturation in the 'contact zones' of empire. Cultural Geographies 13:239-65.

—. 2007. Reconfiguring North-South Solidarity: Critical Reflections on Experiences of Transnational Resistance. Antipode:144-66.

TNC, (The Nature Conservancy). 2004. II. Contexto Regional del PILA. [accessed November 1, 2013]. http://www.inbio.ac.cr/pila/pdf/contexto_regional_pila.pdf

Toma, Luiza and Erik Mathjis. 2007. Environmental risk perception, environmental concern and propensity to participate in organic farming programmes. Journal of Environmental Management 83:145-57.

Tulchin, Joseph S. and Andrew Selee. 2004. Decentralization and Democratic Governance in Latin America. Woodrow Wilson Center Report on the Americas \#12. [accessed October 30, 2013]. http://www.wilsoncenter.org/sites/default/files/ACF18E5.pdf

Umaña, Alvaro and Katrina Brandon. 1992. Inventing institutions for conservation: lessons from Costa Rica. Pp. 85-107 in Poverty, Natural Resources, and Public Policy in Central America, edited by S. Annis. New Brunswick: Transaction Publishers.

UNEP, (United Nations Environment Programme). n. d. a. Global Partnership on Waste Management. [accessed October 30, 2013]. http://www.unep.org/gpwm/InformationPlatform/CountryNeedsAssessmentAnaly sis/CostaRica/tabid/106562/Default.aspx

—. n. d. b. The Voice of the Environment. [accessed October 30, 2013]. http://www.unep.org/About/

UNESCO, (United Nations Educational, Scientific and Cultural Organization). n. d. a. About the Man and the Biosphere Programme (MAB). [accessed October 30, 2013]. http://www.unesco.org/new/en/natural-sciences/environment/ecologicalsciences/man-and-biosphere-programme/about-mab/

- n. d. b. Biosphere Reserves - Learning Sites for Sustainable Development. [accessed October 30, 2013]. http://www.unesco.org/new/en/naturalsciences/environment/ecological-sciences/biosphere-reserves/

USAID, (United States Agency for International Development). 1994. Biodiversity Conservation and Sustainable Development: USAID Program Overview. [accessed November 1, 2013]. http://pdf.usaid.gov/pdf_docs/PDABJ684.pdf 
Vandermeer, John and Ivette Perfecto. 2005. Breakfast of Biodiversity: The Political Ecology of Rain Forest Destruction. Oakland, CA: Food First Books.

Vayda, Andrew P. and Bradley B. Walters. 1999. Against Political Ecology. Human Ecology 27:167-79.

Weinberg, Bill. 1991. War on the Land: Ecology and Politics in Central America. New Jersey: Zed Books Ltd.

West, Paige. 2005. Translation, Value, and Space: Theorizing an Ethnographic and Engaged Environmental Anthropology. American Anthropologist 107:632-42.

West, Paige, James Igoe, and Dan Brockington. 2006. Parks and Peoples: The Social Impact of Protected Areas. Annual Review of Anthropology 35:251-77.

White, Richard. 1990. Environmental History, Ecology, and Meaning. The Journal of American History 76:1111-6.

Wilshusen, Peter R. 2009a. Shades of social capital: elite persistence and the everyday politics of community forestry in southeastern Mexico. Environment and Planning A 41:389-406.

- 2009b. Social process as everyday practice: the micro politics of community-based conservation and development in southeastern Mexico. Policy Science 42:137-62.

Wilshusen, Peter R., Steven R. Brechin, Crystal L. Fortwangler, and Patrick C. West. 2002. Reinventing a Square Wheel: Critique of a Resurgent "Protection Paradigm" in International Biodiversity Conservation. Society \& Natural Resources 15:17-40.

Wilshusen, Peter R. and Richard L. Wallace. 2009. Integrative problem solving; the policy sciences as a framework for conservation policy and planning. Policy Sciences 42:91-3.

Wilson, Geoff A. 2008. From 'weak' to 'strong' multifunctionality: Conceptualising farmlevel multifunctional transitional pathways. Journal of Rural Studies 24:367-83.

Wishnie, Mark H. and Gregory Socha. 2003. Watershed Management in the Pacific Slope Buffer Zone of the La Amistad Biosphere Reserve, Costa Rica. Journal of Sustainable Forestry 16:65-102.

Wolf, Eric R. 1982. Europe and the People Without History. Berkeley: University of California Press.

Worster, Donald. 1990a. Seeing beyond Culture. The Journal of American History $76: 1142-7$.

—. 1990b. Transformation of the Earth: Toward an Agroecological Perspective in History. The Journal of American History 76:1087-106. 
Yacher, Leon I. 2004. The Role of Geographer and Natural Scientist Henri Francois Pittier (1857-1950) in the Evolution of Geography as a Science in Costa Rica. Lewiston, New York: The Edwin Mellen Press.

Zahawi, Zak. 2009. The Las Cruces - Guaymí Biological Corridor in Southern Costa Rica. [accessed April 11, 2014]. http://ots.ac.cr/index.php? option $=$ com content $\&$ task $=$ view\&id $=227 \&$ Itemid $=431$

Zbinden, Simon and David R. Lee. 2005. Paying for Environmental Services: An Analysis of Participation in Costa Rica's PSA Program. World Development $33: 255-72$.

Zimmerer, Karl S. 1996. Discourses on Soil Loss in Bolivia. Pp. 110-24 in Liberation Ecologies: Environment, Development, Social Movements, edited by R. Peet and M. Watts. New York: Routledge.

-. 2004. Cultural ecology: placing households in human-environment studies - the cases of tropical forest transitions and agrobiodiversity change. Progress in Human Geography 28:795-806.

-. 2006a. Cultural ecology: at the interface with political ecology - the new geographies of environmental conservation and globalization. Progress in Human Geography 30:63-78.

-. 2006b. Geographical Perspectives on Globalization and Environmental Issues: The Inner-Connections of Conservation, Agriculture, and Livelihoods. Pp. 1-43 in Globalization \& New Geographies of Conservation, edited by K. S. Zimmerer. Chicago, IL: The University of Chicago Press.

-. 2010. Biological Diversity in Agriculture and Global Change. The Annual Review of Environment and Resources 35:137-66. 


\section{Appendix A: Guide for Semi-Structured Interviews with ASOFAC.CB Members}

"Thank you for deciding to participate in this interview. With your collaboration in this part of the process, I hope that by the end of the evaluation we can begin to look at some of the things that are most important for the development of the Association and the community. Although this is an interview and I have a few things in particular that I would like us to talk about, I also want you to feel comfortable during in the process. Feel free to ask any questions or make any comments that occur to you during during our conversation."

\section{SPECIFIC QUESTIONS FOR CONVERSATIONS WITH ASOFAC.CB MEMBERS}

"I would like for us to begin talking about the history of ASOFAC.CB. How was it the Association formed? How did you become a member of the Association? Why did you decide to join?"

"What does the Association do? What are its objectives?"

"Why do you participate in the Association?"

"Who are the other participants in the Association?"

"What do you think about the personal dynamics within the Association?"

"How does ASOFAC.CB relate with other organizations? (Here, I am looking for information about collaborations both with other organizations from the same community and with organizations from outside the community. After listening to the explanation from the participant, I will ask that they make two sketches: one will have to do with how they see the positions and relationships within the ASOFAC.CB, and the other will have to do with the other organizations that are important for the work of ASOFAC.CB and how they relate to them.)

"How do you see the Association in the future? For example, what will the Association be like five years from now? Will it be the same or different? If it will be different, how will it be different?"

"What are the next steps the Association should take?" 


\section{GENERAL QUESTIONS ABOUT COMMUNITY DEVELOPMENT}

"Now, I'd like for us to change the topic a little bit and talk about the community of Agua Caliente in general. I'd like for us to talk about the community's strengths and weaknesses, and I'd like to start with the strengths. So, what do you think are the strengths of the community?"

"What are the things about the community that are most important to you?'

"Do you think that these are the things that are most important for other people in the community?"

"In talking about the strengths that you mentioned, I'd like to know how they impact your everyday life." (Here, the construction of the following questions will be important. For example, they might be used to follow up on each of the strengths mentioned.)

"How are (e.g., water, trees, etc.) useful in your everyday life?"

"How do you take care of (e.g., water, trees, etc.) as part of your everyday life?"

(I also want to know if participants think these practices are common within the community, or if they think that other people do things differently, even if it is only a little different. If it is possible, I would like to elicit information about decision making as it relates to the use and conservation of natural resources.)

"Now, I would like to hear whatever concerns you might have about your community. In your opinion, what are the problems, or the needs, that exist in the community?"

"How do you know these problems exist? Do you or members of your family experience these problems? If so, how do you deal with them?

"What are the most urgent needs of the community? And, how can the community deal with these urgent needs?

"In general, how is the health of the community? Do you see that there are health problems here? If so, what are they and why do you think they exist?"

"What do you think about the education system in the community? Are there problems with education here? If so, what are they and why do you think they exist?"

"How important is infrastructure for your personal life and community development in general? What aspects of infrastructure are most important?" (I am looking for at least two things here. Although I don't want to be directly leading participants to complain, I 
would like to know their opinions about services related to water, electricity, and roads. At the same time, I would like to know how they think any problems related to infrastructure should be resolved. Do they think these are responsibilities of the community? Or, do they think these are responsibilities of the state? This has to do with the decentralization process that is being promoted by the state and several development organizations.)

\section{QUESTIONS ABOUT NATURAL RESOURCES AND CONSERVATION}

"How does community development affect the quality of natural resources?" ("For example, how would you explain the importance of water for your life and the life of your family, and the development of the community?") (Here, I would like to know about participant perceptions of resources like water, trees, soil, and other forest resources. If they have talked a lot about these in the first part of the interview, it will not be necessary to ask for the same information again. However, this would be the time to probe these areas a little more, or talk about other resources that were not mentioned earlier.)

"Now, I'd like for us to talk about a few terms that can sometimes be as important as they are confusing. So, it is important to keep in mind that I am not looking for any particular, or correct, answer here. I am just interested in what you think when you hear these words, and if you have had any experience talking about them."

"What do you think of when you hear conservation?"

"What do you think of when you hear protection?"

"What do you think of when you hear restoration?"

"What do you think of when you hear rural community tourism?"

"What do you think of when you hear biosphere reserve?"

"What do you think of when you hear organic production?"

"What do you think of when you hear biological corridor?"

(If participants do not have an idea or if they have never heard of any of these terms, it may be appropriate to probe them with some follow up question or with a little explanation of the context; however, too much information provided by the interviewer is not recommended. If the participant does not appear comfortable talking about any of the concepts, leave it and move on to the next one.) 


\section{Appendix B: Guide for Semi-Structured Interviews with Farmers}

\section{INTRODUCTION}

Tell me a little bit about yourself. Have you always lived here? Do you remember what the community was like when you were young or when you came here to live? How have things changed since then?...Have there been changes in infrastructure, roads, schools, electricity and telecommunications, for example?

Have there been changes in the climate? Changes in the vegetation? Other important changes?

\section{AGRICULTURAL PRODUCTION}

What do you produce on your farm? How do you manage your farm? Have you ever changed the way you manage your farm? If so, what was the reason you made the change?

How would you compare your farm with your neighbors' farms or the farms of other farmers in the region?

Do you produce other things, like vegetables, fruit trees, honey, etc., that also provide food for the home?

- Of all of these activities that you mentioned, what are the three that are most important for your farm? (Ask the following questions for each of the most important activities.)

- What are the advantages of this crop/animal?

- What do you do to make sure you are successful in this activity? Or, what are your main responsibilities in this activity? Why are these practices important? What affects do they have on production?

- Do you have to change your practices during different times of the year? How do you know when it is a good time to apply a practice? For example, how do you know when it is time to plant, fertilize, prune, vaccinate, etc.?

- From where do you get information about good practices for this activity?

- Have you collaborated with other farms or cooperatives in this activity? What might the advantages or disadvantages of this type of collaboration be?

- Have you worked with outside people, like people from MAG, in trying to improve your production or resolve problems in production in the past?

- What are the problems that have to be considered as part of production in this activity? 
- Would you be interested in doing tests or types of experiments on your farm in collaboration with students, scientists, or some other organization that is interested in production? (If the response is yes, ask about the things that they would like to work on. What are the problems, or work areas, that they would be able to get the most advantage from this type of advice?)

\section{COMMUNITY DEVELOPMENT}

What are the biggest obstacles that households in the region face?

(If people keep talking only about agricultural production, ask them specifically about other aspects of community development. For example, In addition to agriculture, what else is involved in community development? Or, you can ask them more direct questions, like questions about the economy, health, education, etc. For example, Overall, how is the school system here? What difficulties do teachers have in the schools? What are the challenges faced by doctors in attending people in this community? Or, what are the biggest obstacles for the economic development of the community?)

Are there people or organizations in the community or in the region that you can rely on in dealing with these challenges? (Remind them of each challenge or problem that they mentioned.)

Are there groups working on community development projects? Have you had the opportunity to work with any of these people or organizations? How was that experience?

What are, or should be, the plans for the development of this community? What aspects of the community do you like the most? What aspects do you like the least?

What is development in the region going to be like twenty years from now? What things would you change if you could?

Is the participation of community members in community development activities important? (For example, is it important that people go to meetings, that they are a part of organizations, etc.?) Why or why not?

Do the majority of people participate? Why or why not? What do you think are the reasons that people participate or don't participate?

What do you think about the La Amistad park? What are its most important characteristics to you and for the community? And, What is your opinion about the relationship between the park and community development?

- What might the advantages that community development contributes to the park? What might be the disadvantages of community development for the park?

- What might the advantages be that the park contributes to the community? What could the disadvantages be? 


\section{THE USE OF RESOURCES AND CONSERVATION}

Could you tell me a little about the history of development and land use in the region? Have there been changes in land use in recent years? How would you consider the current land use? How has land use affected community development? How has land use affected the establishment of the park?

Is it important to have title for your property? What are the benefits? What are the possible reasons for not wanting to have a title for your property? Are there groups working here on this issue, or that have projects related to land use?

Do you think about conserving natural resources when you make decisions about their use? What do you think about the current condition of resource use (water, lumber, etc.) in the region? And, how has community development affected resource use?

Do you think there are parts of the park that are in danger? (If the answer is yes, ask the two following questions. If the answer is no, go to the next set of questions.) What is in danger? And, What should we do about this situation?

(In the following, we will explore the understanding of the geo-physical relationship between park resources and resources on farms by asking about things like: the movements of animals like birds, bees, etc.: services provided by various resources like the purification of water, the provision of habitat, and protection from strong winds; and, the practices that protect resources, habitat, and important natural and agricultural processes.)

- Are there things from the forest or the environment that can be used as indicators of the need to something around the house or farm? (For example, Does the presence of birds, winds, rains, etc., indicate the need to plant, fertilize, prune, vaccinate, etc.?)

- Does agricultural production affect the park? (If the response is no, try to probe with the following series of questions.)

- What might the advantages of agricultural production be for the park? What might the disadvantages be? What could be done to maximize the advantages and minimize the disadvantages?

- Does the park affect agricultural production? (If the response is no, try to probe with the following series of questions.)

- What might the advantages of having the park be for agricultural production? What might the disadvantages be? What could be done to maximize the advantages and minimize the disadvantages?

- Are there production methods that are better or worse for conservation? Are there opportunities to improve land use and other natural resources with good agricultural practices? What are they? What would prevent someone from adopting these practices? 


\section{VITA}

Justin Thomas was born in Washington, Missouri, where he was raised and worked for years in family businesses. After high school, he worked outside of Washington for five years before returning to school and starting college in 1999. He earned an Associate of Arts degree in Business Administration at East Central College in Union, Missouri, before transferring to Truman State University in Kirksville, Missouri. He went on to earn a Bachelors of Arts degree in Business Administration from Truman State University. While studying for his Bachelors degree, he worked for the International Student Office as a tutor, he spent two semesters studying abroad, one in Costa Rica and one in Uruguay, and he worked as the Student Adviser for Casa Hispanica, a Spanishspeaking wing of a campus dorm.

As student at Truman State University, Justin was accepted into the Ronald E. McNair Program Scholars Program and was able to design and implement a study of Latino immigrant workers in the Midwestern United States. While at Truman, he also worked as a counselor and Spanish instructor for two summers with another TRIO Program at Truman State University, Upward Bound.

Justin earned a Master of Arts degree in Sustainable Development from the SIT Graduate Institute in Brattleboro, Vermont. In fulfilling the practicum and research requirements for this degree, he worked as as the manager of an eco-lodge in the Gandoca-Manzanillo Wildlife Refuge in Costa Rica and he studied tourism and development along the southern Caribbean coast of Costa Rica. 
Justin returned to Costa Rica to pursue his dissertation research, which is focused on the process of integrating agriculture and conservation in the development of protected areas.

In addition to his interests sustainable development and studying humanenvironment relationships, Justin is interested in teaching sociology, culture, community development, and research methods. On occasion, he also has the opportunity to serve as a volunteer with environmental protection and restoration projects in and out of the United States and serve as an interpreter and general assistant with medical brigades in Honduras. 